


\section{ELECTROMECHANICAL PROPERTIES OF SUPERCONDUCTORS FOR HIGH-ENERGY PHYSICS APPLICATIONS Part II}

J. W. Ekin

L. F. Goodrich

S. L. Bray

N. F. Bergren

R. B. Goldfarb

National Institute of Standards and Technology U.S. Department of Commerce

Boulder, Colorado 80303-3328

November 1989 



\title{
ELECTROMECHANICAL PROPERTIES OF SUPERCONDUCTORS FOR HIGH-ENERGY PHYSICS APPLICATIONS Part II
}
J. W. Ekin
L. F. Goodrich
S. L. Bray
N. F. Bergren
R. B. Goldfarb

\begin{abstract}
Electromagnetic Technology Division
Center for Electronics and Electrical Engineering

National Engineering Laboratory

National Institute of Standards and Technology

Boulder, Colorado 80303-3328
\end{abstract}

November 1989

Prepared for

Division of High-Energy Physics

U.S. Department of Energy

Washington, DC 20545

(DOE Interagency Agreement \#DE-A105-85ER40240)

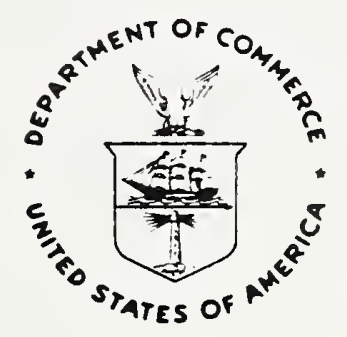

U.S. DEPARTMENT OF COMMERCE, Robert A. Mosbacher, Secretary

National Institute of Standards and Technology, Raymond G. Kammer, Acting Director 

Abstract

Summary

Effect of Room Temperature Stress on the Critical Current of $\mathrm{NbTi}$

S.L. Bray and J.W. Ekin

Electromagnetic Characteristics of NbTi Strands Extracted

From Rutherford Cables

L.F. Goodrich and S.L. Bray

The Effect of Local Area Ratio and Filament Diffusion-Barrier

Material on Critical-Current Bend Degradation of Multifilamentary

$\mathrm{NbTi}$ Wires

J.W. Ekin, S.L. Bray, and N.F. Bergren

Measurement of Saturation Magnetization and Intrinsic

Coercivity of High-Permeability Steel for the SSC

R.B. Goldfarb

Appendix: Publications

Irregularity in $\mathrm{Nb}-\mathrm{Ti}$ Filament Area and Electric

Field Versus Current Characteristics

J.W. Ekin, Cryogenics 27, 603 (1987)

Relationships Between Critical Current and Stress

in $\mathrm{NbTi}$

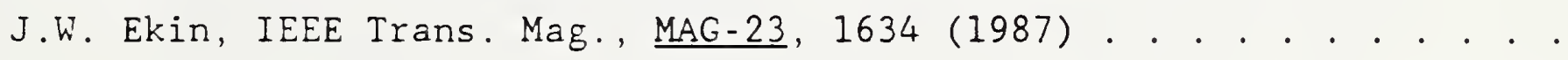

Studies of NbTi Strands Extracted From Coreless

Rutherford Cables

L.F. Goodrich, E.S. Pittman, and J.W. Ekin,

IEEE Trans. Mag., MAG-23, 1642 (1987)

Current Capacity Degradation in Superconducting

Cable Strands

L.F. Goodrich and S.I. Bray, Applied Superconductivity

Conference, ASC, San Francisco, California, Aug. 1988,

IEEE Trans. Mag., MAG-25, 1949 (1989) . . . . . . . . . . . . . . . . 



\section{J.W. Ekin, L.F. Goodrich, S.I. Bray, N.F. Bergren, R.B.Goldfarb Electromagnetic Technology Division \\ National Institute of Standards and Technology Boulder, Colorado 80303-3328}

This report presents data on superconductor performance under mechanical load. The data are needed for setting mechanical design constraints and measuring the electromechanical performance of NbTi superconductors for DOE high-energy physics magnet applications. The effect of axial tensile stress, applied at room temperature, on the critical current of NbTi superconductor strands has been measured. The data show a simple result that the effect on the critical current is independent of the temperature at which the stress is applied; this allows the existing $4 \mathrm{~K}$ data base to be used to determine critical current degradation from room temperature fabrication stress, from cool-down stress introduced by differential contraction, and from $4 \mathrm{~K}$ stress generated by the Lorentz force when the magnet is energized. A study of the criticalcurrent variations along NbTi strands extracted from a Rutherford cable has been made also. The results show that the principal mechanical degradation is extremely localized at the regions where the NbTi strand is bent around the edge of the cable. For example, only $3 \%$ of the total strand length can contribute $92 \%$ of the total strand voltage. A further study has been made of the effects of bending strain on the critical current of NbTi conductors. The degradation of the critical current from bending strain is much greater at low values of electric field than at high, suggesting that irregularity of the filament crosssectional area introduced by bending may be the source of the $I_{c}$ degradation. The bend tolerance of a NbTi conductor can be enhanced by increasing the local copper-to-superconductor area ratio. Measurements of the permeability, saturation magnetization, and intrinsic coercivity of several high-permeability steel alloys were made. The overall differences of saturation magnetization and intrinsic coercivity between cold-rolled steel samples were not significant.

Key words: bending strain; cable; coercivity; critical current; electromechanical; magnetic properties; NbTi; permeability; Rutherford cable; saturation magnetization; SSC; Superconducting Super Collider. 

This report presents data on superconductor performance under mechanical load. The data are needed for setting mechanical design constraints and measuring the electromechanical performance of $\mathrm{NbTi}$ superconductors for DOE high-energy physics magnet applications. The main objective of the program is to develop strategies leading to the most tolerant strain damage limits in these conductors and, therefore, the least overall performance degradation in magnet applications.

In an earlier report from this program (NBS Internal Report \# NBSIR 86 3061), several basic aspects of the electromechanical degradation problem were studied. Highlights of that report include the following:

*The critical current $\left(I_{c}\right)$ degradation in NbTi from transverse compressive stress is comparable to that from axial tension.

*Results on superconductor strands extracted from keystoned Rutherford cables indicate that the principal source of critical-current degradation occurs at the narrow keystone edge, not at strand crossover points along the flat region of the cable.

*An approximate quantitative relationship was established between filament sausaging and the shape of the electric-field vs. current ( $E$ vs. I) characteristic, given by $n$ where $E \alpha I^{n}$ ).

Highlights of this report include the following:

The first measurements of the effect of axial tensile stress, applied at room temperature, on the critical current of $\mathrm{NbTi}$ superconductor strands have been measured. The data show a simple result that the effect on the critical current is independent of the temperature at which the stress is applied; this allows the existing $4 \mathrm{~K}$ data base to be used to determine critical current degradation from room temperature fabrication stress, from cool-down stress introduced by differential contraction, and from $4 \mathrm{~K}$ stress generated by the Lorentz force when the magnet is energized.

A study of the critical-current variations along NbTi strands extracted from a Rutherford cable has been made. The results show that the principal mechanical degradation is extremely localized at the regions where the $\mathrm{NbTi}$ strand is bent around the edge of the cable. For example, only 38 of the total strand length can contribute 928 of the total strand voltage. The degree of variation depends on the orientation of the applied magnetic field. However, the overall voltage is nearly independent of the field angle. All conductors tested showed small resistive voltages associated with current transfer in the regions of deformation.

A systematic study of the effects of bending strain on the critical current of $\mathrm{NbTi}$ conductors has been performed. The $\mathrm{I}_{c}$ degradation decreases with increasing magnetic field, suggesting that the source of degradation is not an intrinsic degradation of $\mathrm{H}_{\mathrm{c} 2}$, as with the elastic axial-strain effect. The degradation of the critical current from bending strain is much greater at low values of electric field than at high, suggesting that irregularity of the 
filament cross-sectional area introduced by bending may be the source of the $I_{c}$ degradation. By testing a series of similarly fabricated NbTi wires, we found that the bend tolerance of a $\mathrm{NbTi}$ conductor can be enhanced by increasing the local copper-to-superconductor area ratio (IAR). Improved bend tolerance also correlates with using a filament diffusion barrier material made of vanadium, instead of $\mathrm{Nb}$ or $\mathrm{Nb} / \mathrm{CuNi}$. The dependence of the bend degradation on LAR represents a mechanical limit to reduction of the LAR when controlling filament-sausaging effects.

Many high-energy-physics accelerators use high-permeability steel for the return flux path of the superconducting magnets. Measurements of the permeability, saturation magnetization, and intrinsic coercivity $\left(\mathrm{H}_{\mathrm{c}}\right)$ of several high-permeability steel alloys were made. Values of $\mathrm{H}_{c}$ at $76 \mathrm{~K}$ ranged from $110 \mathrm{~A} / \mathrm{m}$ ( $1.4 \mathrm{Oe}$ ) for cold-rolled samples to $170 \mathrm{~A} / \mathrm{m}$ ( $2.1 \mathrm{Oe}$ ) for hotrolled samples. The results were independent of whether the field was parallel or perpendicular to the rolling direction. $\mathrm{H}_{c}$ was slightly larger at liquid-nitrogen temperature than at room temperature. At liquid-helium temperature, $H_{c}$ is expected to be slightly higher still. The overall differences of saturation magnetization and intrinsic coercivity between coldrolled steel samples were not significant. 
Effect of room temperature stress on the critical current of NbTi

S. L. Bray and J. W. Ekin

National Institute of Standards and Technology

Electromagnetic Technology Division

Boulder, Colorado 80303

\section{ABSTRACT}

The effect of axial tensile stress, applied at room temperature, on the critical current of NbTi superconducting wire was measured and compared with the effect of tensile stress applied at liquid-helium temperature $(-4 \mathrm{~K})$. The results of these measurements indicate that the effect on the critical current is independent of the temperature at which the stress is applied. Thus, the existing $4 \mathrm{~K}$ data base can be used to determine $I_{C}$ degradation from room temperature fabrication stress, from cool-down stress introduced by differential contraction, and from $4 \mathrm{~K}$ stress generated by the Lorentz force when the magnet is energized. To generalize these results for arbitrary matrix-to-superconductor volume ratios, the data are presented in terms of the stress on the NbTi portion of the composite conductor. Methods for determining the stress on the NbTi from the total composite load are presented. 


\section{INTRODUCTION}

Superconducting composites used in the construction of large-scale magnets may be subjected to several sources of mechanical stress. These stresses occur within three different temperature ranges: room temperature, the transition between room and liquid-helium temperatures, and liquid-helium temperature $(-4 \mathrm{~K})$. At room temperature the sources of stress are associated with the fabrication of the magnet; they are predominantly winding tension and bending stress arising from cabling and conductor-winding operations. In the transition between room temperature and $4 \mathrm{~K}$, stress on the superconductor arises from differential thermal contraction between the superconductor and other materials that compose the magnet. Finally, at $4 \mathrm{~K}$ the source of stress is the Lorentz force that is generated when the magnet is energized.

Until now, critical-current degradation in NbTi from uniaxial stress has been measured only for stresses introduced at liquid-helium temperature. 1-3 This paper presents the results of the first measurements of the effect on critical current of tensile stress applied at room temperature. The results indicate a simple general relationship: the stress effect on the critical current of $\mathrm{NbTi}$ is independent of the temperature at which the stress is applied. The results should be useful in setting limits on the acceptable tensile stress resulting from the combined effects of fabrication, differential thermal contraction, and Lorentz force, particularly in large magnet systems. This result has implications for the fundamental understanding of the source of the stress effect on the upper critical field $\left(\mathrm{Hc}_{2}\right)$ and critical-current density $\left(\mathrm{J}_{\mathrm{C}}\right)$. 


\section{EXPERIMENTAL APPARATUS}

The superconductor used in this experiment is a multifilamentary NbTi sample, containing 648 filaments in a copper matrix. The characteristics of the sample are presented in Table I.

Tensile stress is applied to a $28 \mathrm{~cm}$ long straight sample of the conductor by a servohydraulic feedback load system having the capability of load, stroke, or strain control. The background magnetic field is applied perpendicular to the direction of stress by a $7 \mathrm{~T}$ radial-access solenoidal magnet. Current is supplied to the sample by a $1000 \mathrm{~A}$, controllable battery supply. Details of the apparatus are described in Ref. 2 .

\section{EXPERIMENTAL PROCEDURE}

The experimental procedure consists of two separate tests. The first test ( $4 \mathrm{~K}$ test) is conducted entirely at liquid-helium temperature and serves as a baseline for the room-temperature stress test. The sample is cooled to liquid-helium temperature under no load, and then the critical current is measured as a function of magnetic field and stress applied at liquid-helium temperature. In the second test (room-temperature test) another sample of the same wire from the same spool as the first sample is stressed to a selected level at room temperature and then lowered to liquid-helium temperature while the load is maintained constant by the servohydraulic load system. Once temperature equilibrium is reached at $4 \mathrm{~K}$, the critical current is measured at several applied magnetic fields.

In order to compare the room-temperature stress effect with the $4 \mathrm{~K}$ stress effect in a generic way, the results are presented here in terms of the stress on the NbTi portion of the composite. Comparisons in terms of overall composite stress are specific to only one conductor because of the variations 
in the copper-to-superconductor volume ratio for different conductors. The relative portions of the total load carried by the $\mathrm{Cu}$ matrix and the NbTi depend primarily on their volume ratio and their mechanical properties; however, copper creep and loading history can also somewhat affect the relative loading. For these reasons, the $I_{c}$-degradation data are presented in terms of NbTi stress. The method for applying these results to an arbitrary conductor is discussed in the PRACTICAL APPLICATION section.

\section{RESULTS}

The results of these tests are presented graphically in Fig. 1 where normalized critical current $\left(I_{c} / I_{c m}\right)$ is plotted versus the stress on the NbTi component of the composite (NbTi Stress). The normalized critical current is calculated by dividing the critical current $\left(I_{C}\right)$ measured at a particular load and magnetic field by the maximum critical current $\left(I_{c m}\right)$ measured at no load and at the same magnetic field. The result $\left(I_{c} / I_{c m}\right)$ is expressed as a percent.

$I_{c m}$ is measured after the sample is unloaded from its room-temperature stress point. This procedure is justified by comparisons made between the measured critical currents for the unloaded room-temperature samples and virgin samples of the same wire that have not been loaded. These comparisons show that, within the sample-to-sample variation measured for the virgin wire, the critical-current recovery of the unloaded room-temperature samples is complete.

For comparison, the plot contains data points from a $4 \mathrm{~K}$ test and three room-temperature tests at three magnetic fields and various stress levels. The solid symbols correspond to the room-temperature tests and the open symbols correspond to the $4 \mathrm{~K}$ test. The close agreement between the $4 \mathrm{~K}$ and 
room-temperature data points indicate that the stress effect on NbTi is independent of the temperature at which the stress is applied. The largest disagreement between the $4 \mathrm{~K}$ and the room-temperature data occurs at the maximum room-temperature stress level ( $-1.6 \mathrm{GPa})$ where the NbTi filaments are just starting to yield (at room temperature). Here the room-temperature data points are consistently slightly lower than the $4 \mathrm{~K}$ data points. The maximum discrepancy occurs at $7 \mathrm{~T}$ where the critical current is approximately 78 lower for stress applied at room temperature than for stress applied at $4 \mathrm{~K}$. This difference is less than the uncertainty of the room-temperature measurement. METHOD OF DETERMINING NBTI STRESS

As stated above, the comparisons of $I_{c}$ degradation for stress applied at room temperature versus $4 \mathrm{~K}$ shown in Fig. 1 are based upon the stress state of just the NbTi portion of the conductor. The NbTi stress was used to make the results more generic and not dependent on a specific copper-to-superconductor ratio. Because direct measurement of the stress on the NbTi portion of the composite is not practical, a method of extracting this information from the available composite stress data is required. In the Appendix we discuss the detailed breakdown of each component's load-strain relationship for relating overall composite stress to the stress experienced by just the NbTi filaments. An example of the use of the technique is shown in Fig. 2. The heavy lines in Fig. 2 show the stress-strain curve for the composite upon repeated loading and unloading. The repeated loading portions of the curve between zero load and the upper envelope has been omitted for clarity. [These portions of the curve are equivalent to the A-to-C segment of the composite curve of Fig. 5 in Appendix $A$ and are not required for constructing the NbTi curve.] 
The two other curves shown in Fig. 2, the "Cu" curve and the "NbTi" curve, are derived from the composite curve by using the technique described in the Appendix. This technique, however, is only applicable in the area labeled "Linear Region." The lower nonlinear portion of the "Composite" curve is due to yielding of the $\mathrm{Cu}$, while the upper nonlinearity is due to yielding of the NbTi. Consequently, extrapolation is necessary in order to determine the NbTi load outside this linear region. This extrapolation is possible based on two assumptions: one, that the "NbTi" load curve is linear below its yield point and, two, that the "Cu" load curve is linear above its yield point. Both of these assumptions are supported by independent stress-strain data on these materials. 4

The $\mathrm{Cu}$ load points, indicated by triangular symbols in Fig. 2, are determined by taking the difference between the composite and NbTi load curves. The line defined by these symbols is then extended to the maximum strain of the composite curve, again assuming linearity of the Cu curve above the yield point. Finally, the upper portion of the NbTi curve is constructed by taking the difference between the composite and $\mathrm{Cu}$ load curves. This general technique was used to determine the NbTi stresses for both the room temperature and the $4 \mathrm{~K}$ data that are presented in Fig. 1; (Fig. 2 shows only the $4 \mathrm{~K}$ data).

\section{PRACTICAL APPLICATION}

Figure 3 is a plot of normalized $I_{c}$ versus NbTi stress for a number of magnetic fields at $4 \mathrm{~K}$, and it can be used to estimate the effect of stress at room temperature. However, the stress on the NbTi portion of the conductor must first be determined. Ideally, this should be achieved as described above by measuring the room-temperature composite load-versus-strain characteristic 
of the conductor and then constructing the associated NbTi load-versus-strain curve. Due to the specialized equipment required for making these stress measurements, this technique may, in some cases, be impractical.

Alternatively, a method for estimating the NbTi stress without the aid of these measurements may be used.

Figure 4 is a plot of NbTi stress versus composite stress for several Cuto-NbTi volume ratios. The dashed curve ( $\mathrm{Cu}: \mathrm{NbTi}=1.77: 1)$ is based on the conductor used in these tests. The other curves were derived by using various Cu-to-NbTi volume ratios. These curves are based on a linear model (equation 1 below) of the composite load-versus-strain characteristic and they are sensitive to the material properties used in the model. The material properties of the conductor tested here were used in generating these curves and the values of these parameters are given below, following their definitions. For NbTi superconductors in general, these curves may be used to estimate, at least to first order, the NbTi stress and the resulting $I_{C}$ degradation due to room-temperature loading. If the material properties of a conductor are known, they may be used in the following equation to more accurately estimate the NbTi stress:

$$
\sigma_{\mathrm{NbT} i}=\frac{E_{\mathrm{NbTi}}\left[\mathrm{L} / \mathrm{A}_{\mathrm{c}}-\epsilon_{\mathrm{ym}}(1-\mathrm{f})\left(\mathrm{E}_{\mathrm{Cu}}-\mathrm{M}_{\mathrm{Cu}}\right)\right]}{\mathrm{fE_{ \textrm {NbT } }}+(1-f) \mathrm{M}_{\mathrm{Cu}}}+\sigma_{\mathrm{p}},
$$

where

$\sigma_{\mathrm{NbTi}}=$ the tensile stress on the $\mathrm{NbTi}$

$\mathrm{E}_{\mathrm{NbTi}}=$ the modulus of elasticity for the $\mathrm{NbTi}\left(6 \times 10^{10} \mathrm{~N} / \mathrm{m}^{2}\right)$

$L=$ the composite load

$A_{C}=$ the cross-sectional area of the conductor $\left(0.33 \mathrm{~mm}^{2}\right)$ 
$f=$ the volume of NbTi in the conductor divided by the total conductor volume

$\mathrm{E}_{\mathrm{Cu}}=$ the modulus of elasticity for the $\mathrm{Cu}\left(7 \times 10^{10} \mathrm{~N} / \mathrm{m}^{2}\right)$

$\mathrm{M}_{\mathrm{Cu}}=$ the slope of the stress-versus-strain curve, above its yield point, for the Cu matrix $\left(3 \times 10^{9} \mathrm{~N} / \mathrm{m}^{2}\right)$

$\sigma_{\mathrm{p}}=$ the residual pre-stress on the $\mathrm{NbTi}$ due to the manufacturing process $\left(1 \times 10^{8} \mathrm{~N} / \mathrm{m}^{2}\right)$

$\epsilon_{\mathrm{ym}}=$ the composite strain at matrix yield $(0.002)$

This equation is applicable only beyond the $\mathrm{Cu}$ yield point, which is the region where the effect of stress on the $I_{c}$ becomes large. For strain levels that are below the $\mathrm{Cu}$ yield point the $\mathrm{I}_{\mathrm{C}}$ degradation is negligible.

\section{CONCLUSIONS}

The results of these tests indicate that the effect on critical current of tensile stress applied to NbTi superconductors at room temperature is the same as that of stress applied at $4 \mathrm{~K}$. Thus, we have the simple result that degradation from room-temperature loading can be determined from the existing $4 \mathrm{~K}$ stress-effect data base given in Fig. 3. To generalize the results for arbitrary matrix-to-superconductor volume ratios, the data in Fig. 3 are presented in terms of NbTi stress, which can be determined using the methods outlined in the text. Because room-temperature and $4 \mathrm{~K}$ stress have an equivalent effect on $I_{C}$, we think that Fig. 3 can also be used to estimate the effect of stress at intermediate temperatures generated by differential thermal contraction between the different conductor and magnet materials during cool-down. Presently, the typical level of tensile stress applied to NbTi composites during magnet fabrication ranges from about 40 to $180 \mathrm{MPa}$. At these stresses the resulting $I_{c}$ degradation is negligible. The data presented 
here are useful in defining the acceptable limits of tensile stress in forthcoming magnet designs where increased winding tension may be necessary for restricting conductor motion at high Lorentz forces. For the conductor measured in this study, a 58 degradation in $I_{c}$ occurs at a composite tensile stress of approximately $550 \mathrm{MPa}$ at $5 \mathrm{~T}$ and $390 \mathrm{MPa}$ at $9 \mathrm{~T}$. 
APPENDIX: METHOD TO DETERMINE STRESS ON THE NbTi COMPONENT

Figure 5 is an idealized representation of the load-versus-strain characteristic for a $\mathrm{NbTi}$ and $\mathrm{Cu}$ composite over a single load cycle. Three separate load curves are shown in this figure: one for the NbTi filaments, one for the Cu matrix, and one for the overall composite. The NbTi curve is a straight line with a positive load intercept (point $\alpha$ ) and no hysteresis between loading and unloading (the arrows on the curves indicate the loading sequence). This reflects the assumption of perfect elastic behavior of the NbTi for the strains measured here. The positive load intercept $\alpha$ represents the small residual tensile stress on the NbTi; this stress is a result of the manufacturing process. Similarly, the $\mathrm{Cu}$ curve shows a small negative (compressive) load intercept (point a). The $\mathrm{Cu}$ curve is linear up to point $\mathrm{b}$, where the $\mathrm{Cu}$ begins to yield. There is a transition region between points $b$ and $c$ followed by another linear region between point $c$ and point $d$, the maximum-strain point. This portion of the curve (c-d) is based on the assumption that the yield strength of the $\mathrm{Cu}$ increases linearly with increasing strain. As the load decreases to zero at point è the curve is linear, again indicating elastic behavior. The load becomes compressive after point $\mathrm{e}$ and, again, the $\mathrm{Cu}$ goes through another transition region followed by a linear region. At point $\mathrm{g}$ the load on the $\mathrm{Cu}$ is equal to the load on the NbTi and represents the unloaded state of the overall composite. The composite curve is simply the algebraic summation of the NbTi and Cu curves.

The dashed lines in Fig. 5 are extensions of the linear portions of the load curves and are needed for constructing the NbTi load curve from the composite curve. A fundamental assumption made in drawing the Cu load curve 
is that of symmetry between the compressive and tensile mechanical properties In particular, the curve indicates that the distances from point $d$ to $e$ and from point e to $f$ are equal. This equality shows that the distances from point $D$ to $E$ and from point $E$ to $F$ on the composite curve are also equal. In turn, this allows the determination of the load experienced by the NbTi (point E) simply by bisecting the line between points $D$ and F. Additional points can be similarly determined by loading the conductor to higher levels and unloading. 
References:

1. J. W. Ekin, F. R. Fickett, and A. F. Clark, Proc. Int. Cryog. Mat. Conf. (Aug. 1975), Adv. Cryog. Eng. 22, 449 (1977).

2. J. W. Ekin "Mechanical properties and strain effects in superconductors" Chapt. 7, P. 455 in Superconductor Materials Science, edited by S. Foner and B. B. Schwartz, Plenum Press, New York (1981).

3. J. W. Ekin, IEEE Trans. Mag. 23, 1634 (1987).

4. R. P. Reed, R. P. Mikesell, A. F. Clark, Adv. in Cryog. Eng. 22, 463 (1977) . 
Table I. Multifilamentary NoTi sample characteristics

Strand diameter

Filament diameter

Number of filaments

(single stack construction)

Copper-to-superconductor volume ratio

Twist pitch

Superconductor area

Total area
$0.648 \mathrm{~mm}$

$16 \mu \mathrm{m}$

648

1.77

$1.27 \mathrm{~cm}$

$0.119 \mathrm{~mm}^{2}$

$0.330 \mathrm{~mm}^{2}$ 


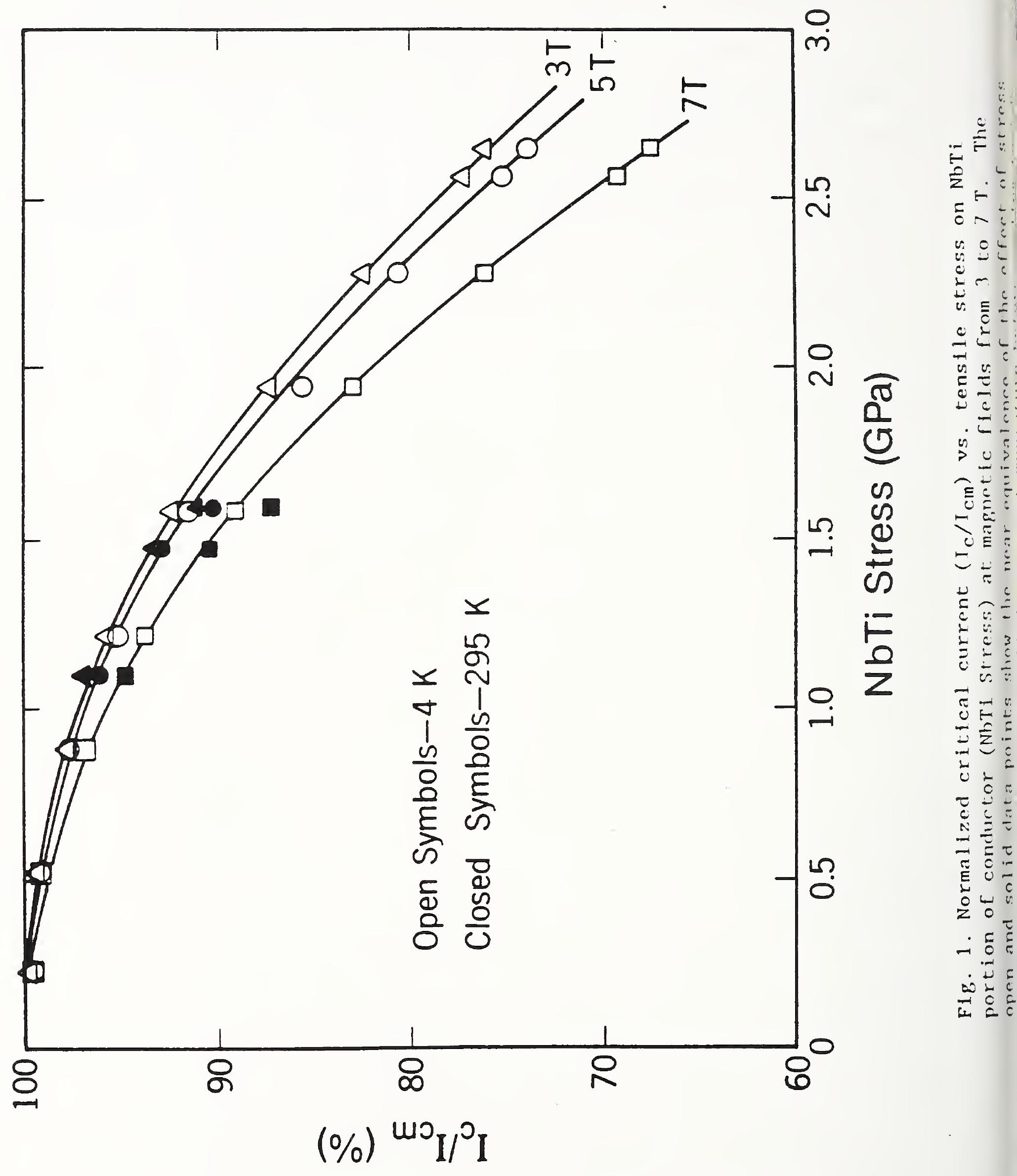




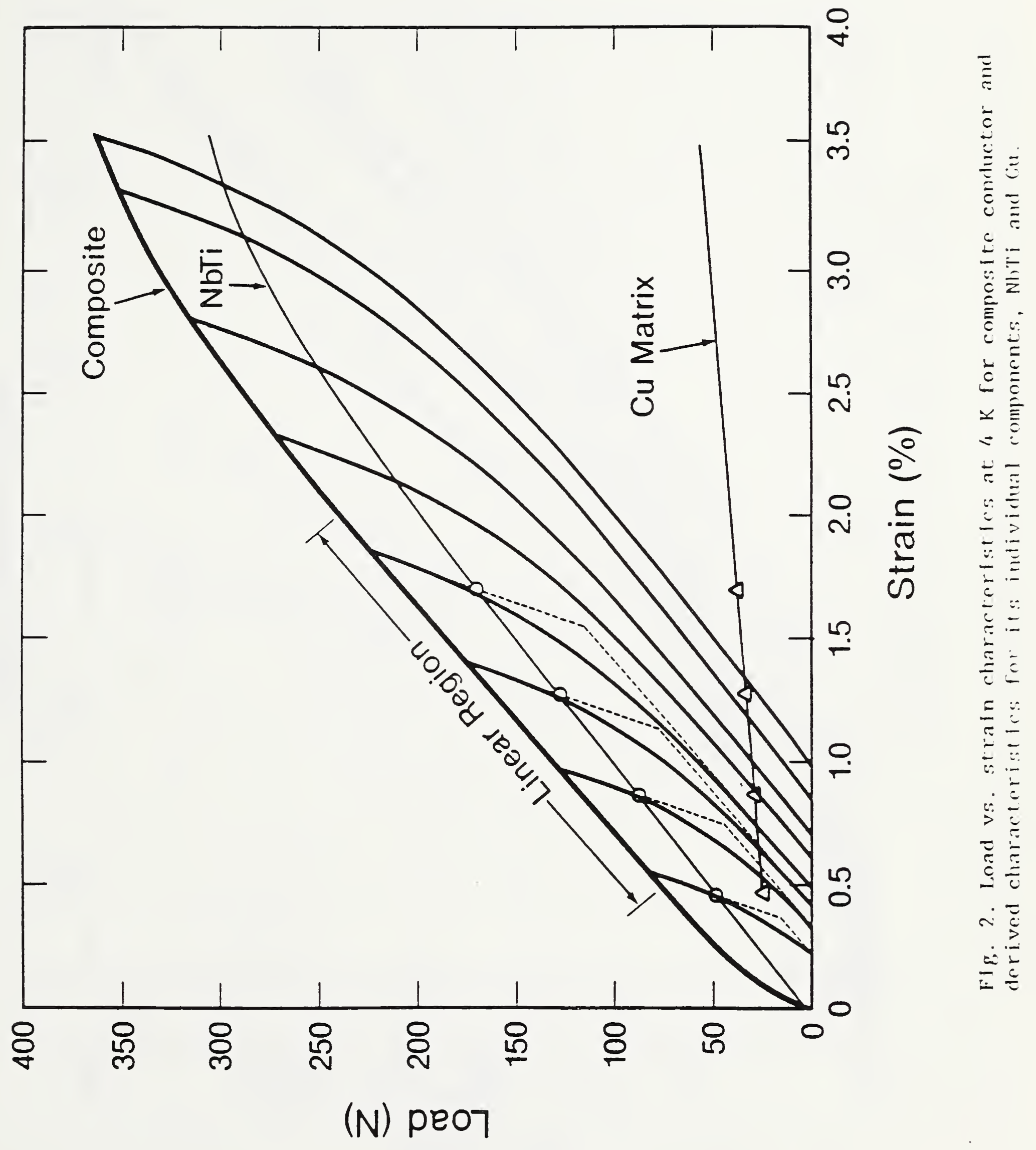




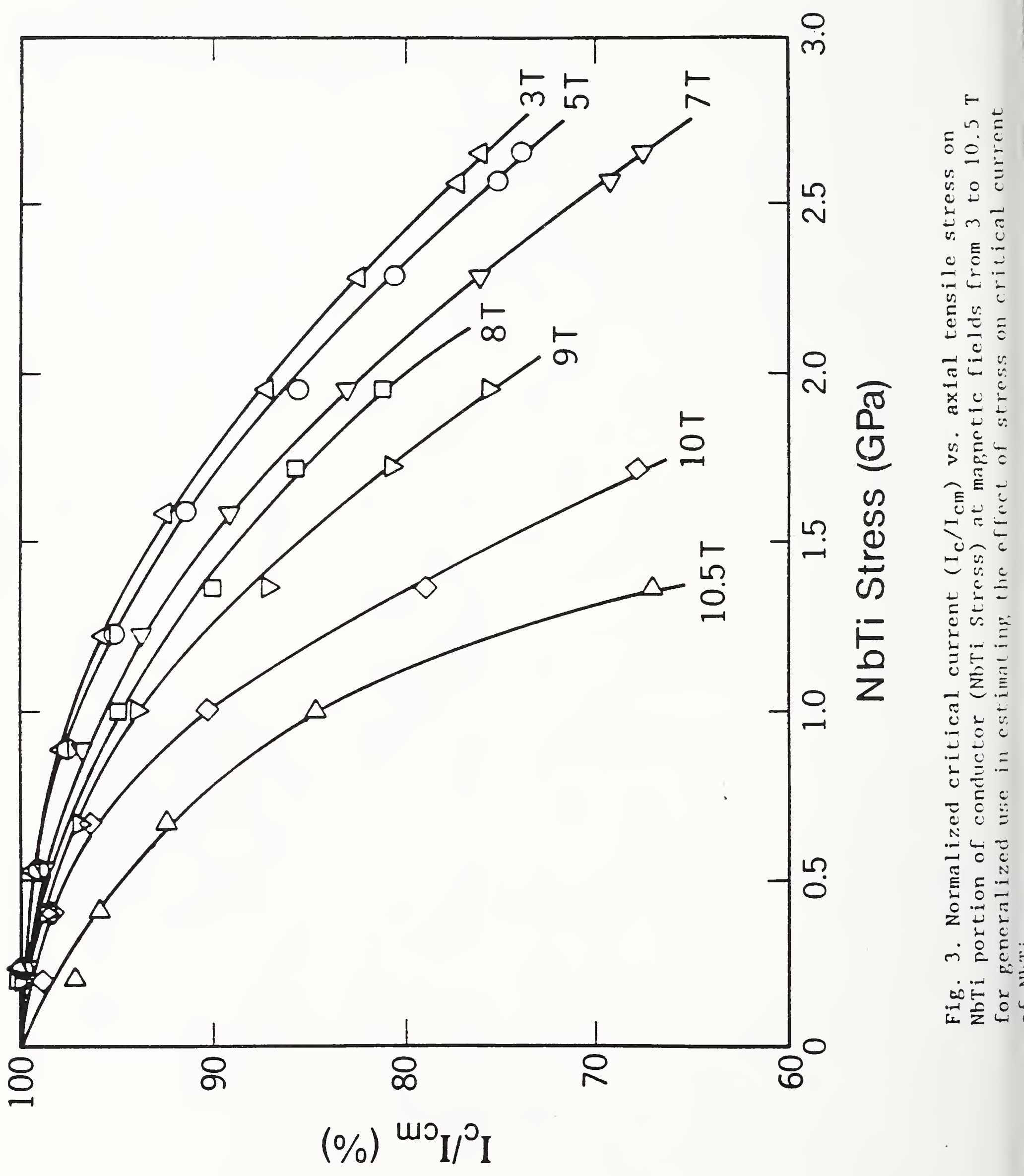




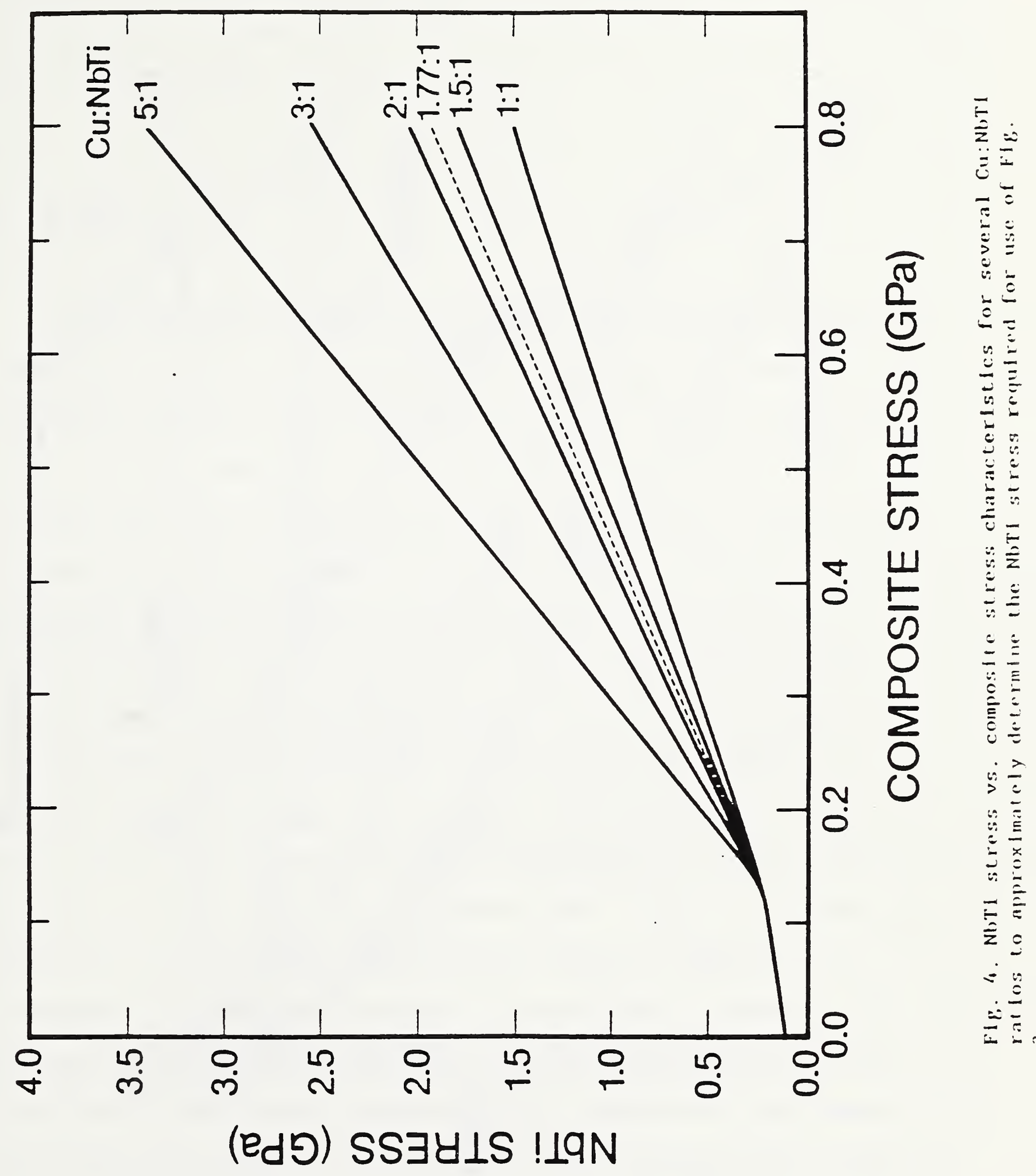




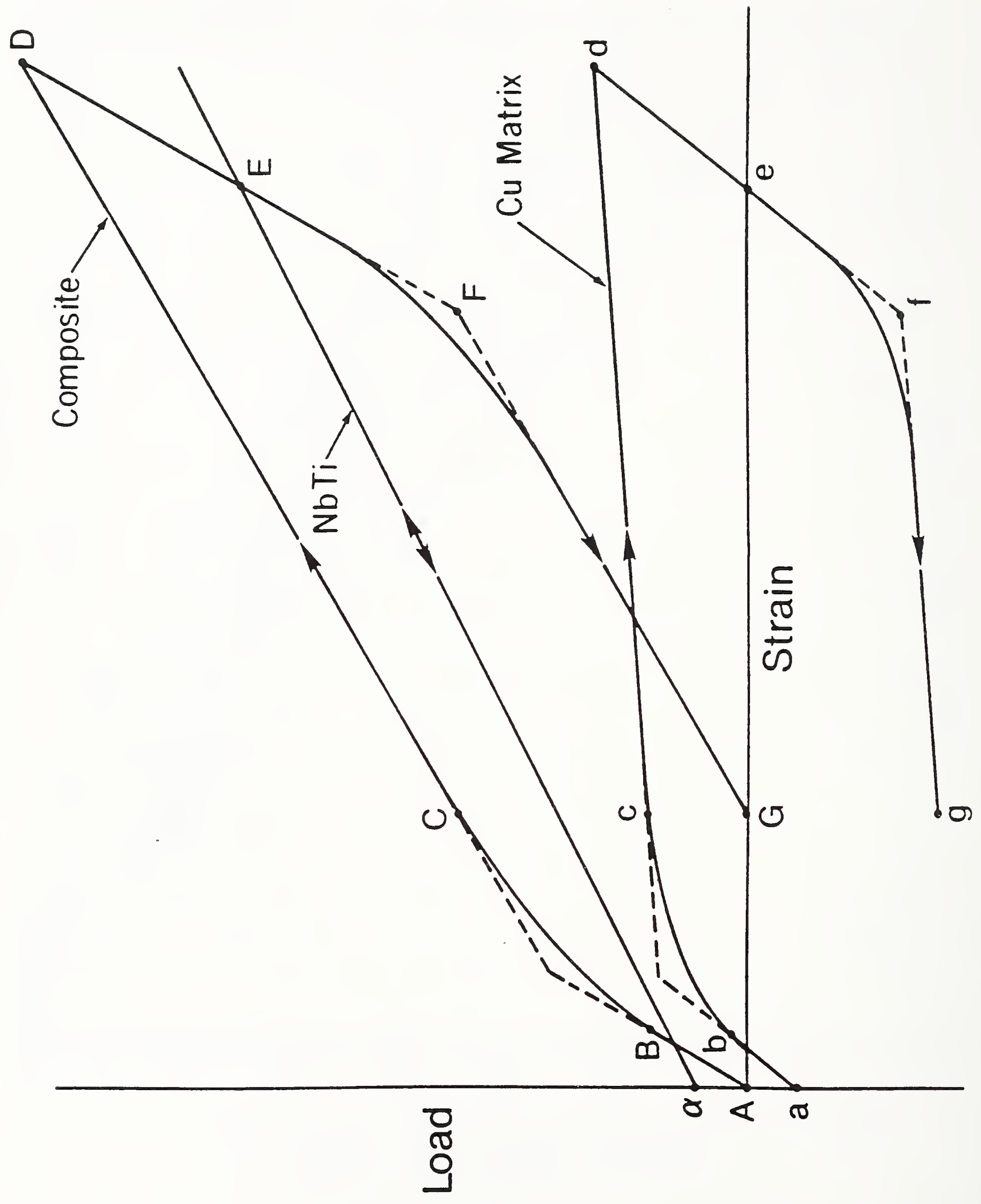


ELECTROMAGNETIC CHARACTERISTICS OF NbTi STRANDS EXTRACTED FROM RUTHERFORD

CABIES

by L. F. Goodrich and S. L. Bray

\section{A. SUMMARY}

The electromagnetic properties of MbTi strands extracted from Rutherford cables were studied to clarify the effect of mechanical deformation, caused by the cabling process, on the current capacity of the strands. The mechanical abuse that these conductors are subjected to present a number of measurement concerns that are not normally encountered in the testing of superconductors. Consequently, a major portion of this study was aimed at determining how the measurement and data-analysis techniques should be adjusted for these conductors to allow a more complete and accurate determination of their current capacities. Four different cables, all of which are prototypes for the Superconducting Super Collider's dipole magnets were studied. The extracted cable strands were instrumented to allow measurement of the voltage across several key regions of mechanical deformation as a function of current and the orientation of the applied magnetic field. The resulting data are presented in several forms besides critical current in order to more thoroughly characterize the conductors' electromagnetic properties. The cable strands show very localized reductions in current capacity that are well correlated with the regions of high mechanical deformation. For example, at a particular field orientation, the voltage across a portion of the strand that is only $3 \%$ of the total strand length contributes 928 of the total strand voltage. Two applied magnetic-field orientations, parallel and perpendicular 
to the cable's width, have pronounced effects on the electrical properties of the strand. Both of these magnetic field orientations will arise in application.

Although there is a pronounced irregularity in the voltage along the pitch length of these conductors and the degree of the irregularity depends on the orientation of the applied magnetic field, the overall voltage of the entire pitch length is comparatively constant. This is the result of a statistical effect where a particular field angle that is detrimental to some of the strand segments is equally beneficial to others. The measured critical currents for these strands are only a weak function of the field angle, and they are well correlated with the quench currents. Since certain field angles result in large reductions in the critical current of individual strand segments, this indicates that the local degradations do not act as weak links in limiting the current capacity of the strand to the reduced level of the most degraded segments. This tolerance for local critical-current degradation depends upon the strand's good longitudinal thermal conductivity, and any reduction in this local cooling capacity might limit the strand's current capacity to that of the weak link.

An important characteristic of all the conductors that were tested in this study is an intrinsic current transfer that is apparently associated with their mechanical deformation. In other words, at high-enough currents and magnetic fields, the deformation of the cable strands results in a periodic redistribution of the current among the superconducting filaments; as a consequence, there are small resistive voltages associated with these 
conductors. This characteristic definitely affects the measurement of these conductors, and it may affect their performance in application.

The conductors tested in this study represent a continuing evolution in design that is aimed at increasing the strand material's precabled current capacity while decreasing its sensitivity to mechanical deformation. The results of these tests indicate that considerable progress is being made toward this goal.

\section{B. INTRODUCTION}

The measurements presented here are a continuation of earlier studies ${ }^{1}$ of MbTi cable strands extracted from Rutherford-type cables (cables provided by the Lawrence Berkeley Laboratory). These are prototype cables for high-energy physics applications. Specifically, they were designed for use in the inner and outer windings of the Superconducting Super Collider's (SSC) dipole magnets. The main emphasis of these studies is the effect of mechanical deformation, during manufacture, on the cable's current capacity. In addition to the bending deformation required to achieve the cable's twist pitch, the cables are compacted into a keystone shape. These mechanical deformations result in a very localized degradation in the electrical properties of the cable strands. The deformation of the cable strands results in a periodic geometry with the various segments of the strands defined by the degree and type of deformation. The desired products of the current studies is information that will lead to methods for reducing the current-capacity degradation associated with the manufacture of superconducting cables, and the 
determination of specific measurement considerations that will result in a more complete and accurate determination of that current capacity.

For all the measurements, the orientation of the applied magnetic field was perpendicular to the cable's longitudinal axis. The angle of the applied field about this axis was varied from $0^{\circ}$ to $360^{\circ}$ with special emphasis given to the $0^{\circ}$ (parallel to the cables width) and $90^{\circ}$ (perpendicular) orientations. The reasons for emphasizing these field directions are twofold. First, there is a pronounced effect on the strands ${ }^{1}$ electrical properties in these orientations and, second, both of these field orientations arise in a dipole magnet.

The mechanical deformation of the cable strands during the cabling process results in localized variations in the conductor's current capacity. The sources of this variation fall into two categories, cross-sectional area differences and angular effects. The cross-sectional variation of the superconducting filaments is due to necking and serrated yielding of the NbTi filaments. Under the second category, angular effects, the orientation of the applied magnetic field with respect to the various segments of the strand (pitch angle effect ${ }^{2}$ ) and their mechanically deformed cross sections (aspect ratio effect ${ }^{3}$ ) varies along the strand.

Several types of data are presented in order to emphasize different characteristics of the cable strands. A number of different cables, manufactured with different virgin wire (source wire for the cable strands) materials and cabling techniques, were studied. These data allow comparisons of the various cables. An overall critical current, defined as the critical 
current $\left(I_{C}\right)$ determined by adding the voltage contributions of each segment of the strand and then dividing this voltage by the sum of the strand segment lengths to arrive at an effective electric field, is presented as a function of the applied field angle. This information is useful in examining the cumulative effect of variations in the spatial orientation and the aspect ratio of different strand segments at different field angles. The concept of an overall $I_{C}$ is also useful for comparing the strand's $I_{C}$ with the $I_{c}$ of the virgin wire from which the cable was manufactured. These comparisons indicate the $I_{c}$ degradation introduced by the cabling process. The variation of the electric field along the strand's longitudinal axis, or the electric-field profile, is presented as a measure of the wire's local current capacity. In order to assess the relative contribution to the total voltage of different strand segments, the voltage distribution at fixed magnetic field angles along the conductor's length is also presented. In addition, plots of $I_{c}$ versus position along the cable strand's length are presented to provide a comparison of the different strand segments in a more conventional form than the electric-field or differential-voltage plots do. Finally, the voltage of the strand segments and of the overall strand, at a fixed current, are presented as a function of the applied magnetic-field angle to exhibit which field orientations are critical for different strand segments and for the overall strand.

\section{SAMPLES}

Four different cables, denoted as $\mathrm{W}, \mathrm{X}, \mathrm{Y}$, and $\mathrm{Z}$, were studied. Detailed specifications for these cables are given in Table 1. Cables $W, X$, and $Y$ are 
all outer-winding SSC conductors, whereas cable $Z$ is an inner-winding conductor. Cable $W$ was re-rolled through a turkshead (for resizing) after it had been cabled. The re-rolled cable is a worst-case situation that was studied to more clearly identify the degradation features. Cable $\mathrm{X}$ is similar to $\mathrm{W}$; however, it was not subjected to as much mechanical deformation and is a more typical example of late-1985 to early-1986 prototype outer cables. Cable $Y(1987)$ is an evolution of cable $X$ where the cabling techniques were refined in an attempt to reduce current-capacity degradation. Finally, cable $Z$ is similar to cable $\mathrm{Y}$ with respect to the cabling technique, but it is an inner, rather than an outer, cable.

Single-strand samples of each cable were obtained by cutting an appropriate length of the cable and then separating the strands. Initially, the strands were difficult to remove from the cable without causing additional mechanical damage. However, after several strands were removed, the cable structure relaxes and additional strands may be removed without damage. These undamaged strands were selected for the measurements. 
Table 1. Parameters for each of the four cables

\begin{tabular}{lllll} 
Parameter & W & X & Y & Z \\
\hline Cable No. & SC297 & SC305 & SC361 & SC362 \\
Billet No. & $5212-3$ & 5914 & $5954-4$ & $5955-2$ \\
Number of strands per cable & 30 & 30 & 30 & 23 \\
Pitch length, mm & 69 & 69 & 69 & 79 \\
Cable width, mm & 9.7 & 9.7 & 9.7 & 9.3 \\
Cable mid-thick, mm & 1.17 & 1.17 & 1.17 & 1.46 \\
Keystone angle, deg & 1.24 & 1.24 & 1.24 & 1.6 \\
Filament twist, cm ${ }^{-1}$ & 0.8 & 0.8 & 0.8 & 0.8 \\
Filament dia., $\mu \mathrm{m}$ & 16 & 5 & 6 & 6 \\
Number of filaments & 648 & 6006 & 4162 & 7249 \\
Virgin wire dia, mm & 0.65 & 0.65 & 0.65 & 0.808 \\
Cu/superconductor ratio & $1.77 / 1$ & $1.64 / 1$ & $1.78 / 1$ & $1.40 / 1$
\end{tabular}




\section{EXPERIMENTAL DETAILS}

Figure 1 is a cross-sectional view of a typical cable showing its key regions. Three regions of the cable were studied: the thin edge, the face (top or bottom), and the thick edge. Each of these regions was divided with voltage taps into three approximately equal-length, adjacent segments. The three segments of each cable edge were denoted as the central flat edge and the two corners. These edge segments had separations of $2 \mathrm{~mm}$ for the outer cable and $2.5 \mathrm{~mm}$ for the inner cable. The voltage taps along the face of the cable had voltage tap separations of about $10 \mathrm{~mm}$ for the outer cable (11 mm for the inner cable) and did not include any of the corner region.

Figure 2 shows the instrumented portion of a cable strand and the location of the voltage taps along the strand's length. The two key orientations of the applied magnetic field relative to the strand's face, $0^{\circ}$ and $90^{\circ}$, are also shown. In this view, the cable's face is in the plane of the figure. Voltage taps on the sample were made using three flat quads (miniature four-conductor flat cable) of four \#32-gauge wires. Within each quad, three adjacent segments could be measured with a minimum of induced voltage. The end leads of adjacent quads were connected to the same tap to allow complete coverage of the sample. An additional voltage-tap pair was connected to the sample so that it spanned an entire cable pitch including all of the other voltage-tap pairs. In order to encompass an entire pitch length, the span of this overall voltage-tap pair extended beyond the thick- and thin-edge taps by about onehalf the face length at each end. Data presented for these extreme strand positions were derived by subtracting the sum of the measured segment voltages from the overall voltage and then assuming that the voltages for the two end 
regions were equal. The quad leads were soldered to twisted-pair leads near the bottom of the sample test fixture. In this position, the soldered joints were immersed in liquid helium during data acquisition. The twisted pairs were continuous from the bottom of the test fixture to the voltmeter's input cables. The junction between the voltage-tap leads and the nanovoltmeter's input leads were maintained isothermal by small bags of lead shot placed under and on top of the junction.

The sample holders are $1 / 2$ in diameter 316 stainless steel rods with a machined longitudinal channel that is slightly wider than the width of the cable. The walls and bed of this channel are insulated with a thin layer of epoxy formed with a TFE (polytetrafluoroethylene) impressioner. The sample is mounted in the holder with a thin layer of epoxy between its lower face and the bed of the sample-holder groove. Small epoxy bridges are then applied across the sample's upper face, leaving the majority of the upper face directly exposed to the helium bath while still providing some mechanical support. The ends of the sample extend past the ends of the stainless-steel rod to allow attachment to the current contacts. The sample holder and longitudinal axis of the sample strand are held perpendicular to the field of a radial access, split-pair magnet. The sample is rotated about its longitudinal axis resulting in various transverse orientations of the applied field, as identified in Figures 1 and 2.

All the measurements were conducted below standard atmospheric pressure (due to the low ambient pressure at the altitude of the test site), resulting in an equilibrium liquid-helium temperature of $-4.02 \mathrm{~K}$. The $I_{c}$ densities for these samples at $4.22 \mathrm{~K}$ would be about $6 \%$ less at $5 \mathrm{~T}$ and 128 less at $8 \mathrm{~T}$ than 
those reported here. The $I_{C}$ densities for these conductors were calculated using the NbTi cross-sectional area, which was determined using the copper-tosuperconductor ratio.

Two four-channel, digital-processing, storage oscilloscopes were simultaneously used for data acquisition. Five channels were used to monitor the sample's voltage taps with analog nanovoltmeters, and a sixth channel was used to monitor the sample current. These signals were measured and averaged at a number of different current levels (point method). The resulting data points were then analyzed to construct the sample's voltage-current characteristic. This procedure is different from the more typical procedure where the current is ramped continuously with time while the voltage and current are recorded. The point method has some advantages over the ramp method. The point method allows for a longer time-averaged voltage to be measured (this is beneficial if voltage noise is a problem) without greatly increasing the time required for taking a complete V-I curve. This is achieved by selecting a distribution of current-bias points that results in a more precise measurement. This requires taking a few widely spaced points in the low-current portion of the curve to establish the base line and then taking a progressively closer-spaced point distribution as the current increases toward $I_{C}$. The point method greatly reduces the effect of inductive voltage and sample motion. The disadvantages are that it takes longer because the voltage has to settle for each data point and the general shape of the voltage-current curve has to be known a priori in order to determine the positions of the data-acquisition points along the V-I curve.

During data analysis, the effects of voltage offsets, changes in thermoelectric voltage, and current-transfer voltage were determined. The 
voltage offsets and changes in thermoelectric voltage were determined using the initial and final zero-current points of the waveforms. The thermoelectric voltage corrections were made assuming a constant drift with time. This correction was generally only a few nanovolts per centimeter. The current-transfer voltages were determined using the low-current portion of the waveforms. These current-transfer voltages may partially be an artifact of the measurement method since only a $64 \mathrm{~mm}$ length of the sample was in full magnetic field; however, the local voltage data indicate that there is also an intrinsic component of the current-transfer voltage. There is a further discussion of current transfer later in this report. Generally, the currenttransfer voltage was quite small because the current contacts were long $(-4$ $\mathrm{cm}$ ) and were located more than $6 \mathrm{~cm}$ from the nearest voltage tap. A currenttransfer correction was made in the determination of the $I_{c}$, but no correction was made on the electric-field or differential-voltage data.

\section{E. RESULTS}

The first three conductors measured in this study, designated as cables $w$, $X$, and $Y$, represent an evolution in the cable fabrication process aimed at reducing cabling's detrimental effect on the critical current density $\left(J_{C}\right)$ of the finished cable as compared to that of the virgin wire. ${ }^{4}$ An evolution has also occurred in the design and processing of the virgin wire. ${ }^{5}$ This evolution can be characterized by a decrease in filament size aimed at reducing ac losses while attempting to maintain $\mathrm{J}_{\mathrm{C}}$. Initially, increased wire drawing that was used to reduce the filament size of wire $\mathrm{X}$ in comparison with wire $W$ resulted in lower $J_{C}$ for the virgin wire. Later, improved 
manufacturing processes that were used for wire $Y$ resulted in a substantial restoration of the $\mathrm{J}_{\mathrm{C}}$. Cable $\mathrm{Z}$ is an inner cable that was manufactured and cabled using techniques similar to those used for cable Y.

\section{Overall Critical Current}

Critical-current measurements were made on the virgin wires from which each cable was manufactured. Three pairs of voltage taps, each pair spanning about $10 \mathrm{~mm}$, were connected to the specimens. This allowed for a check of $I_{C}$ homogeneity with position. Critical-current measurements were also made as a function of the applied magnetic-field angle. This allowed for a test of $I_{C}$ homogeneity with respect to field angle. The average $I_{c}$ of the virgin wire was used to determine the relative degradation of each cable. The typical $I_{c}$ variation among voltage taps was $\pm 0.3 \%$ at $5 \mathrm{~T}$ and \pm 0.58 at $8 \mathrm{~T}$ for cables $\mathrm{W}$, $X$, and $Y$. The $I_{C}$ variation among voltage taps for cable $Z$ was about $\pm 2.2 \frac{z}{z}$ at 5 and $8 \mathrm{~T}$. A reason for this large variation in the case of sample $Z$ is not evident. For cables $X$ and $Y$, the $I_{C}$ variation of a given tap with respect to field angle $\left(0^{\circ}\right.$ to $\left.360^{\circ}\right)$ was measured to be about \pm 0.68 at $5 \mathrm{~T}$.

Figures 3 and 4 show comparisons between the overall $I_{c}$ density of the extracted cable strands and the virgin wires from which they were constructed. The data presented in these plots is tabulated in table 2. Figure 3 shows this comparison for each of the four conductors for applied magnetic-field angles of $0^{\circ}$ and $90^{\circ}$ at $5 \mathrm{~T}$. For cable strands $\mathrm{W}, \mathrm{X}$, and $\mathrm{Y}$, there is a consistent increase in $\mathrm{J}_{C}$ at $0^{\circ}$, although the virgin wire's $\mathrm{J}_{C}$ decreased between wires $W$ and $X$. Recal dangling that cable $W$ is a worst-case situation with respect to the cabling operation. The higher $J_{C}$ for strand $\mathrm{X}$ is due to 
the greatly reduced mechanical deformation of the strand. Cable Y shows a greater mechanical degradation of its $J_{C}$ than cable $W$, but, again, it shows an increased strand $J_{C}$ due to its high virgin-wire $J_{C}$. For cable strand $X$, the mechanical degradation of $\mathrm{J}_{\mathrm{C}}$ was somewhat higher at $90^{\circ}$ than at $0^{\circ}$ and, consequently, its $J_{C}$ was less than strand $W^{\prime} s$. This increased degradation at $90^{\circ}$ was not present in the case of strand $Y$ and it showed a higher $J_{C}$ than its two predecessors. Strand $Z$ was very similar to strand $Y$.

The $8 \mathrm{~T}$ plot, Fig. 4, shows an increase in the strand's $J_{C}$ between $W$ and $Y$ but there is a decrease between $\mathrm{W}$ and $\mathrm{X}$. Comparison between the 5 and $8 \mathrm{~T} \mathrm{~J}_{\mathrm{C}}$ degradation for strands $W, X$, and $Y$ shows a reduced sensitivity to mechanical deformation at the higher magnetic field for all the strands. The virgin wire $\mathrm{W}$, which has larger diameter filaments, had a higher relative $\mathrm{J}_{C}$ at $8 \mathrm{~T}$ than did wires $X$ and $Y$. This lower $J_{C}$ dependency (sensitivity) of wire $W$ to magnetic field results in a higher strand $J_{C}$ for $W$ than for $X$. Comparing the Jc degradation of strand $Z$ at 5 and $8 \mathrm{~T}$ shows a reverse trend of higher sensitivity to mechanical deformation at the higher magnetic field. At $8 \mathrm{~T}$, strand $\mathrm{Z}$ has a considerably higher $\mathrm{J}_{\mathrm{C}}$ degradation than strand $\mathrm{Y}$. 
Table 2. Cable degradation and critical current density $\left(\mathrm{A} / \mathrm{mm}^{2}\right)$ at $0.1 \mu \mathrm{V} / \mathrm{cm}$ $5 \mathrm{~T}$

Cable

Critical current density Cable degradation

\begin{tabular}{|c|c|c|c|c|c|}
\hline & virgin & $0^{\circ}$ & $90^{\circ}$ & $0^{\circ}$ & $90^{\circ}$ \\
\hline $\mathrm{W}$ & 2827 & 2378 & 2469 & -15.98 & -12.78 \\
\hline $\mathrm{x}$ & 2464 & 2442 & 2383 & -0.98 & $-3.3 z$ \\
\hline Y & 3043 & 2835 & 2887 & -6.88 & -5.18 \\
\hline$z$ & 2933 & 2738 & 2713 & -6.68 & -7.58 \\
\hline \multirow{3}{*}{ Cable } & \multirow{2}{*}{\multicolumn{3}{|c|}{ Critical current density }} & \multirow{2}{*}{\multicolumn{2}{|c|}{ Cable degradation }} \\
\hline & & & & & \\
\hline & virgin & $0^{\circ}$ & $90^{\circ}$ & $0^{\circ}$ & $90^{\circ}$ \\
\hline W & 1306 & 1183 & 1194 & -9.48 & -8.68 \\
\hline$x$ & 1036 & 1051 & 1014 & +1.48 & -2.18 \\
\hline$Y$ & 1239 & 1218 & 1210 & -1.78 & -2.38 \\
\hline $\mathrm{z}$ & 1257 & 1121 & 1092 & -10.88 & -13.18 \\
\hline
\end{tabular}




\section{Electric-Field Profile}

Plots of the electric field versus position along the cable strand's length, or the electric field profile, are presented for all four conductors at two magnetic fields ( 5 and $8 \mathrm{~T}$ ) and two orientations $\left(0^{\circ}\right.$ and $90^{\circ}$ ) in figures 5-18. At the top of each plot, located outside the axes, is an outline of the cable strand's geometry positioned to correlate with the horizontal or position axis. The cable outline is labeled to indicate the position of the thin edge, the face, and the thick edge relative to the horizontal axis. The local electric field was calculated by dividing the measured voltage across a strand segment by its length. The discrete data points, therefore, represent the average electric field over the strand segment. The horizontal positions of the data points are at the centers of each strand segment. The lines connecting the data points are intended as a visual aid and not an interpolation between the data points. The actual electric-field profile might have much greater extremes than those indicated by the averaged data points shown in these plots.

There is an electric-field criterion associated with each of these plots. This is an overall electric-field criterion arrived at by dividing the voltage across one cable pitch by the sum of the segment lengths. Consequently, the current associated with different plots or different curves within a plot are not the same. This is necessary to compare different cables within the same plot and to present data taken at different magnetic fields and orientations in a comparable manner. In other words, each curve represents the electricfield profile of a cable strand at a selected $I_{c}$ criterion, and that criterion is consistent for all curves within a particular plot. In examining these 
plots, recognize the inverse relationship between the electric field and $I_{c}$ : a large local electric field indicates a small local $I_{C}$.

Figures 5, 6, 7, and 8 are electric-field profiles for the outer cables $W$, $X$, and $Y$ at $5 \mathrm{~T}$ and $0^{\circ}$. The data in each of these four plots represents a different electric-field criterion. The dominant elements in the structure of these curves are the pronounced peaks located at the centers of the thin and thick edges. In general, the major peak is at the thin edge. The imbalance between the two peaks is greatest for cable $W$, the oldest of the three cables, and progressively less for cables $\mathrm{X}$ and $\mathrm{Y}$. This demonstrates a trend toward a more uniform electric-field profile as these conductors have been refined. The first cable, $W$, has the lowest electric field at the thick edge of the three cables.

The negative electric fields shown in the plots indicate negative measured voltages, not negative resistances. These negative voltages are projection voltages 6,7 associated with current redistribution among the filaments. The strongest evidence of intrinsic (not associated with the location of the current contact) transverse currents within the strand is a region of negative voltage bounded by regions of large positive voltages. The curve for cable Y is the best example of this structure. This type of structure is present in the center of these plots. This location indicates that the current redistribution is caused by the longitudinal variation in the relative current-carrying capacity of the filaments rather than being caused by current injection at the current contact. Thus, voltages associated with this type of redistribution will occur periodically along the entire length of the cable strand. 
Although the negative voltages are the most obvious indication of current redistribution, there are other indicators within the data curves. These indicators have the same general character as the negative voltages with the exception of polarity. The best example of this structure is the center segment (at about $3.5 \mathrm{~cm}$ ) of cable $\mathrm{Y}$. At low currents, the voltage associated with this hump in the electric field profile increases rapidly with increasing current, and indicates an intrinsic $I_{C}$. At higher currents, this voltage becomes a weak function of the current as indicated by the curves of Figs. 6, 7, and 8 . This behavior is evidenced by the relative size of this central hump in the electrical-field profile, for increasing current, in comparison with the dominant edge peaks. This is further evidence of intrinsic current redistribution among the conductor's filaments.

Figures 9, 10, 11, and 12 are the electric-field profiles for cables $W, X$, and $Y$ at a magnetic field of $5 \mathrm{~T}$ and an orientation of $90^{\circ}$. In comparison with the $0^{\circ}$ data, the extremes of the electric field profile are smaller in these plots. This is due to the effects of pitch angle and aspect ratio when the center of the strand edges are in a favorable position relative to the $90^{\circ}$ orientation of the applied magnetic field. This effect is most evident for cables $X$ and $Y$ where the peak in the electric field, observed at the central edges in the $0^{\circ}$ plots, is suppressed in the $90^{\circ}$ case. Comparison of the $0^{\circ}$ and $90^{\circ}$ curves for cable $\mathrm{W}$ also shows a reduction in the peak electric field but to a lesser degree than for the other cables. Although the peak electric field has switched from the center to the corners of the thin edge for cables $X$ and $Y$ in this orientation, the peak still occurs near the region of greatest mechanical deformation, the thin edge. Current redistribution and the resulting current-transfer voltage are lower for this field orientation, as 
evidenced by the reduced negative voltage and more uniform electric field profile.

Figures 13 and 14 are plots of the electric field for cables $W, X$, and $Y$ at an applied magnetic field of $8 \mathrm{~T}$ and orientations of $0^{\circ}$ and $90^{\circ}$. These $8 \mathrm{~T}$ plots are very similar to the $5 \mathrm{~T}$ plots. For the $0^{\circ}$ orientation, the peaks of the electric field profile are again at the edges of the strand, with the larger peak occurring at the thin edge. At $90^{\circ}$, cables $X$ and $Y$ show peaks at the corners of the thin edge and a strong suppression of the electric field at the center of the thin edge. Cable $W$ has a reduced peak at the center of its thin edge at $8 \mathrm{~T}$ as it did at $5 \mathrm{~T}$. The $8 \mathrm{~T}$ data is presented only at the 0.1 $\mu \mathrm{V}$ criterion, but it is typical of the similarities between the 5 and $8 \mathrm{~T}$ data at all criteria.

The electric field profile for cable $Z$, the inner cable, is presented in Figs. 15, 16, 17, and 18. Comparing these curves with those of the other cables indicates a strong similarity to cables $X$ and $Y$. At $0^{\circ}$, and both magnetic fields, the peaks in the electric field profile are comparable, with the thin edge showing a slightly higher electric field. Once again, at $90^{\circ}$ and at both fields, the peaks in the profile switch from the center of the edges to the corners. If a general statement can be made it might be that cable Z's profile is more uniform than that of $\mathrm{X}$ and $\mathrm{Y}$.

\section{Differential Voltage Profile}

Figures 19-26 are similar to the electric-field profiles in that they also exhibit the electrical properties of the cable strand as a function of 
the position along its length. In this case, the differential voltage across the various strand segments is plotted as a function of position. The plateaus, or peak levels, in the curves represent the voltage across the indicated strand segments at the indicated overall $I_{c}$. As was the case for the electric-field plots, the lines connecting these data are only a visual aid. Vertical lines, rather than smooth curves were selected because they more accurately portray the differential nature of these data and more clearly define the positions of the different strand segments.

The plots show that there is a considerable variation in the lengths of the various strand segments. Herein lies the significance of these plots, which show the relative contribution of the separate strand segments to the overall voltage. In other words, because of the variation in segment length, the electric field shows only the relative current capacity of the segments, not each segment's contribution to the total voltage and the resulting overall $I_{c}$. For this reason, a comparison between the electric field and differential voltage profiles shows that the voltage peaks at the strand edges is less than that at the strand faces. This is due to the greater length of the face segments. Moreover, the edges, although highly degraded, are a small portion of the total pitch length of the strand and, therefore, have a limited effect on the overall $I_{c}$.

This comparison between the two types of plots raises a question regarding which of these parameters, local electric field or total voltage, has the greatest practical importance. Several factors, including the sample's longitudinal thermal conductivity, determine which of these parameters are most indicative of the strand's current capacity. For the samples and 
conditions existing in these measurements, the total voltage seems to determine the current capacity of the conductor. This is evidenced by a close agreement between the measured overall $I_{C}$ and the maximum achieved currents (quench currents). For a sample that has poor longitudinal thermal conductivity, the short-edge segments might act as weak links, limiting the current capacity at a total strand voltage below that required to reach the overall $I_{C}$ criterion.

In general, the differential-voltage plots indicate many of the same strand characteristics as do the electric-field plots. For all cables in the $0^{\circ}$ orientation, the majority of the voltage is concentrated at the edges of the cable with the central portions dominant. At $90^{\circ}$, the voltage concentration increases at the corners of the edges in comparison with the centers. The striking difference between these plots and the electric-field plots is the contribution of the face segments at $90^{\circ}$. A comparison between the $90^{\circ}, 8 \mathrm{~T}$, plots for cable Z (Figs. 18 and 26) illustrates this difference. The electric field profile shows peaks at the corners of the strand edges with a relatively small contribution from the faces. On the other hand, the differential voltage profile shows that the majority of the voltage is contributed by the face segments. This trend is evident for all but cable $W$ where the center of the thin edge remains the dominant segment.

\section{Critical Current Profile}

Figures 27-34 are plots of $I_{C}$ versus strand position. The horizontal lines bounded by data symbols represent the average $I_{c}$ of the indicated strand segment over the length of the segment. The vertical lines are, again, 
intended only as a visual aid. Two data symbols are shown for each data point to indicate the region over which each $I_{c}$ data point is averaged. The breaks in the curves indicate missing $I_{c}$ data points for the corresponding strand segments. Missing $I_{c}$ data occur for regions where $I_{c}$ was higher than the quench current of the sample; thus, missing data implies relatively high $I_{c}$ for those regions. Cable $W$ has the most missing points because of its larger range of local critical currents. A low electric-field criterion, $0.05 \mu \mathrm{V} / \mathrm{cm}$, was selected to reduce the number of missing points. A current-transfer voltage correction was made in the determination of $I_{c}$.

The curves of $I_{C}$ versus position for the outer cables, $X$ and $Y$, show a smaller variation at $90^{\circ}$ than at $0^{\circ}$. Because the combination of the pitch angle and aspect ratio is advantageous to the more mechanically deformed edges at $90^{\circ}, I_{c}$ is more balanced. In a previous measurement of a $\mathrm{W}$ strand, ${ }^{8}$ the thin edge was shunted with another superconductor in order to allow the $I_{c}$ of the other segments to be measured. Those measurements showed that the variation in $I_{C}$ was also smaller at $90^{\circ}$ than at $0^{\circ}$. There are some problems with local $I_{C}$ measurements because of the intrinsic current-transfer voltage which was mentioned in the section of this report on electric-field profiles. The voltage-current characteristic of this type of current transfer, where the voltage rises abruptly and then plateaus, is difficult to separate from an intrinsic $I_{c}$ characteristic. This type of current-transfer voltage caused the relatively low measured $I_{c}$ for the center of the cable face in Fig. 29. The reduction in the measured $I_{c}$ of this strand segment is artificial in the sense that it was caused not by the strand segment itself, but rather was caused by the mechanical deformation and resulting current redistribution associated with an adjacent strand segment. 
The $I_{C}$-versus-position data for the inner cable, $Z$, also shows a smaller variation at $90^{\circ}$ than at $0^{\circ}$ with the exception of one point on Fig. 34 . This point was a corner on the thin edge that had a negative transfer voltage at $0^{\circ}$ (missing, high $I_{C}$ ) and apparently an intrinsic, positive transfer voltage at $90^{\circ}$, which may have contributed to the lower measured $I_{c}$.

\section{Differential Voltage Versus Angle}

Plots of the differential voltage versus magnetic-field angle for various positions along the cable strand's length are presented for all four conductors at $5 \mathrm{~T}$ and a given current, Fig. 35-38. At the top of each plot, located outside the axes, is an outline of the cable strand's geometry; in this case it does not correlate with the horizontal axis. The cable outline is labeled to indicate the position of the thin edge, the face, and the thick edge. The data-point symbols are located, horizontally, at the center of each segment on the cable outline. The discrete data points on the plot, therefore, represent the differential voltage over each strand segment at a given angle. The lines connecting the data points are intended as a visual aid and not an interpolation between the data points. This is especially true between the angles -180 and $-105^{\circ}$ because of the widely spaced data points. A plus symbol was used for the total differential (overall) voltage of one cable pitch length. The same data symbols were chosen for equivalent positions along the thick and thin edges, with open symbols for the thin edge and filled symbols for the thick edge. The differential-voltage curves for the end segments of the strand, indicated by the circular data symbols, are equal for the two segments because of the way in which they were derived. Separate data were not available for these two segments; rather, the total voltage of the 
two segments was available and, based on their equivalent positions, their voltages were assumed to be equal.

It is difficult to follow all of the curves, but these plots reveal significant features. In Fig. 35 (cable W) the differential voltage of the center of the thin edge is where most of the total voltage drop occurs for angles around $0^{\circ}$. Two of the positions along the face have a negative differential voltage at all angles. The rest of the positions show little structure with angle and have relatively small differential voltage. The peak in the total differential voltage at 0 and $-180^{\circ}$ indicates the lowest $I_{C}$, the relative minimums at about $\pm 45^{\circ}$ are regions of larger $I_{C}$, and the relative peaks at $\pm 90^{\circ}$ are local minima in $I_{C}$.

Figure 36 (cable $X$ ) has some other features. The lowest $I_{c}$ was at $\pm 90^{\circ}$ rather than $0^{\circ}$. The center of the thin edge still contributes the majority of the total differential voltage around $0^{\circ}$. The corners of the thin edge contribute the most to the total differential voltage near $\pm 90^{\circ}$. The maximum for each of these corners occurs at angles slightly shifted to one side or the other of $90^{\circ}$. This is due to the difference in the average pitch angle of each corner segment. Some positions have a negative differential voltage at some angles and a positive differential voltage at other angles.

A comparison between Fig. 37 (cable Y) and Fig. 35 (cable W) shows a strong similarity between the overall voltage curves. Both curves show a large peak at $0^{\circ}$; however, unlike cable $\mathrm{W}$, where almost all of the voltage is due to the central thin edge, the peak in the overall curve for cable $Y$ is the product of contributions from several strand segments. Most notable, there is 
a significant contribution to the overall voltage at $0^{\circ}$ from the central thick edge.

The overall curve of Fig. 38 (cable Z) is similar to that of Fig. 36 (cable $X$ ) with maximum differential voltages at $\pm 90^{\circ}$, minimums at $\pm 45^{\circ}$, and a local maximum at $0^{\circ}$. In the case of cable $X$, the local maximum at $0^{\circ}$ is primarily due to the central thin edge. On the other hand, in the case of cable $z$, the $0^{\circ}$ local maximum is due to approximately equal contributions from both the thick and thin central edges.

Close examination of the overall voltage curves of Figs. 35-38 shows several instances of $180^{\circ}$ asymmetry. The most prominent example of this asymmetry can be seen by comparing the overall voltages for cable $Z$ at $+90^{\circ}$ and $-90^{\circ}$. The overall voltage at $+90^{\circ}$ is significantly higher than at $-90^{\circ}$. A number of the individual segment curves for cable $Z$ show this same $\pm 90^{\circ}$ asymmetry; therefore this effect is probably a characteristic of the conductor and not a measurement error. Similar asymmetries exist in the individual segment curves for the other three cables $\mathrm{W}, \mathrm{X}$, and $\mathrm{Y}$.

This phenomenon may be due to a transverse asymmetry in the deformation of the cable strand. This condition, in conjunction with the asymmetry of the total magnetic field (the vector summation of the applied field and the strand's self field) over the strand's cross section, might result in applied field angles that are favorably or detrimentally oriented with respect to the local deformation of the filaments. This may explain the asymmetry in the differential-voltage curves. 
The main objective of this work is to determine the current capacity of several different cable strands with the ultimate goal an increased understanding of the sources and degree of current-capacity degradation in these conductors. Typically, $I_{c}$ of a conductor is an accepted practical measure of its current capacity. However, for these conductors, there are some difficulties in relating $I_{c}$ to the actual current capacity of the cable strands. Owing to the electrical inhomogeneity of the strands caused by the cabling operation, there is a large variation in $I_{c}$ along the strand's length. The problem is determining what current level in this fairly broad range of critical currents best reflects the strand's practical current capacity.

One approach is to assume a weak-link condition where the strand segment that has the lowest $I_{C}$ determines the overall current capacity of the strand. A comparison between the actual quenching currents (the maximum observed current prior to thermal runaway) and the weak-link critical currents shows that the current capacity of the strand is significantly higher than the weaklink $I_{C}$. This enhanced current capacity, above the weak-link $I_{C}$, is due to the strand's relatively good stability.

At the other extreme, the current capacity of the strands could be assumed to be equal to the overall $I_{C}$. For the conductors tested here, this would not be a bad assumption, as evidenced by the close agreement between the overall critical currents and the quenching currents. However, there are two problems associated with simply measuring the overall $I_{c}$ and assuming this to be the strand's practical limit. First, the overall $I_{C}$ gives no information about 
the voltage distribution along the strand's length and, consequently, is not useful in understanding the sources of current degradation in the cable. Also, for conductors that are less stable than those tested here, the actual current limit might be close to the weak-link $I_{c}$ and the overall $I_{c}$ level could not be achieved.

Another factor associated with the $I_{c}$ measurements for these cable strands is the presence of intrinsic current-transfer voltages that are caused by periodic current redistribution along the strand's length. This current transfer is apparently caused by the periodic mechanical deformation of the strand and, therefore, it is not isolated to the current contact area. In this sense it is intrinsic to the conductor (not a product of the measurement technique) and it presents a problem in data reduction and analysis. The problem that this intrinsic current-transfer voltage poses is whether or not it is appropriate to separate it from the flux-flow voltage for determining the $I_{C}$, as is the normal practice in the case of nondeformed conductors. In other words, because of its intrinsic nature, these current-transfer voltages play a role in determining the current capacity of the cable, not only in testing but in application as well, and, therefore, their presence should be reflected in the reported $I_{c}$ value. In contradiction to this precept, the critical currents reported here were corrected for current-transfer voltages.

There are two reasons for this apparent inconsistency. First, for these measurements it was impossible to attribute all of the observed current transfer to intrinsic sources. Moreover, the relatively short length (64 mm) of the sample that resided in the full magnetic field may have led to nonintrinsic current transfer. This is why current-transfer corrections were 
made to the overall-I $c$ data. Second, as previously explained, the intrinsic current-transfer voltages do not necessarily appear solely on the strand segments that produced them. This does not present a problem for overall- $I_{C}$ measurements (if the current transfer is purely intrinsic) where only the magnitude of the voltage over one pitch length is important, not the specific sources of the voltage. However, for the localized-I measurements presented here, the comparison of the critical currents of the various strand segments is intended as a measure of the damage caused by mechanical deformation at different segments of the strand. Inclusion of current-transfer voltages, resulting from damage to adjacent strand segments, in the $I_{c}$ criterion would distort the results of this comparison.

Ic data alone are insufficient for characterizing these conductors. For this reason the electric-field and differential-voltage data were presented. The electric-field data are the clearest indicator of the relative current capacity of the different strand segments. However, the limitation of the electric-field data is that they do not indicate the relative contribution of the various strand segments to the total conductor voltage because the segments are of different lengths. Consequently, the differential-voltage data are a necessary supplement to the electric-field data to fully characterize the conductors. Which of these data are the most indicative of the actual current capacity depends on the stability of the particular conductor. In the case of a stable conductor, the total voltage is an important determining factor of the strand's current capacity and, consequently, the voltage distribution along the strand shows which segments are the most detrimental to the current capacity. On the other hand, for a relatively unstable conductor, the local current capacity can be a limiting factor and, in this case, the electric-field data are more relevant. 
Because of the electrical inhomogeneity of these conductors, stability may play a key role in determining their current capacity. This coupling between stability and current capacity increases the importance of the matrix material in the conductor design. For example, the use of CuNi for the cable's matrix material, although beneficial in reducing proximity-effect coupling ${ }^{9}$ and improving the wire's drawing characteristics, might result in a considerable reduction in current capacity because of the relatively low thermal conductivity of the CuNi and resulting reduction in the cable's stability. Also, the increased electrical resistivity of a CuNi matrix would result in larger current-transfer voltages at current-redistribution sites. Another approach to reducing the proximity-effect coupling between filaments without substantially lowering the stability of the wire is a magnetic approach where $\mathrm{Mn}$ is added to the $\mathrm{Cu}$ matrix material. ${ }^{9}, 10$ The Mn reduces the proximityeffect coupling by promoting magnetic scattering of the electron pairs.

To optimize the current capacity of a superconducting cable, three main factors must be considered: the virgin wire's current capacity, its sensitivity to mechanical deformation, and the degree of deformation introduced by the cabling process. A truly optimal design would require the simultaneous determination of the conductor and cabling parameters that, in conjunction with each other, would result in the maximum current capacity of the finished cable. Although ideal, this approach is impractical. Also, the primary concern dictating the cables structural design is mechanical stability, not current capacity. This limits the amount that the cabling parameters can be varied to enhance the current capacity. 
A second approach to this problem would be to simply optimize the virginwire parameters for maximum current capacity, optimize the cabling parameters for minimum strand deformation, and then assume that the wire's sensitivity to deformation will be acceptably low. It can be argued, however, that optimizing the virgin current capacity of the wire is likely to make it sensitive to mechanical deformation. In other words, if the virgin wire is truly optimized, then any change in the wire (mechanical deformation for example) must result in a degradation in its performance. For example, a comparison of cables $X$ and $Y$ in Figs. 3 and 4 shows that the increase in virgin-wire $I_{c}$ density from cable $X$ to cable $Y$ is accompanied by an increase in mechanical degradation, although cabling had been improved for sample $Y$. This apparent increase in sensitivity to deformation may be caused by changes in the virgin-wire construction (matrix-filament configuration) that were necessary to improve its $\mathrm{J}_{\mathrm{C}}$.

A third approach to the problem of cable optimization would be based on an iterative design where a number of different virgin wires, all having relatively high current capacities but different design parameters (filament diameter, matrix-filament configuration, etc.), would be cabled using different parameters (strand diameter, number of strands, strand twist, etc.) and then measured for local degradation. The process would be repeated, with the wire and cabling parameters adjusted according to the results of the

- strand measurements, until an optimal combination of high virgin-wire current capacity and low mechanical degradation was approached. Unlike the first design method, this method might be practical and, unlike the second design method, this method addresses the interrelationship between the virgin wire's current capacity, its sensitivity to mechanical deformation, and the cabling 
parameters. This iterative method might be a practical means of approaching an optimal cable design.

Measuring extracted cable strands rather than an entire cable is partially a matter of convenience; it does not require the high output current supply or the large test fixture that are necessary for cable measurements. In addition, for single-strand measurements, there is less uncertainty in the current measurement because all of the supplied current is carried by the single strand. For a cable measurement, however, the supplied current is distributed among all of the cable strands and not necessarily equally. Also, the lower output-current supplies that can be used for an extracted strand measurement typically are less noisy than the larger supplies required for cable measurements and, therefore, more sensitive voltage measurements can be made at the lower current levels.

A limitation of the extracted-strand measurements is that they do not indicate the effect, on an individual strand's current capacity, of localized magnetic field variations produced by adjacent cable strands (self-field effect). The exact duplication of the magnetic field that the conductors will encounter in application is beyond the scope of these measurements. The intent of these localized measurements is to determine the degree and sources of mechanical degradation of the strand, in general. Although the self-field effect will undoubtedly result in some variations in the local electrical characteristics of the cable, the salient features of the mechanical degradation, such as the locations of weak links and the critical magneticfield orientation, will remain the same. Another electrical characteristic of the cable that is not duplicated by the extracted-strand measurements is 
current transfer between adjacent cable strands. This interstrand current transfer might slightly enhance the stability of the cable as compared to that of an individual strand. 1

All the measurements reported here were made on single specimens of each sample and, as a result, the measurements do not necessarily represent the global characteristics of the cables. Other specimens of samples $W$ and $X$ were measured at an earlier date and the results were reported elsewhere. ${ }^{8} \mathrm{~A}$ second specimen of sample $Y$ was measured during the present tests. The results for these other measurements were generally in good agreement with those reported here. Additionally, the dominant electromagnetic characteristics are consistent among the four samples. For example, the thin edge of the cable strand contributes significantly to the overall strand voltage for a magnetic-field orientation of $0^{\circ}$ for all samples.

As changes are made in the cable design and manufacture, the degree and character of the mechanical degradation might change considerably. For example, these prototype cables were sized using a nonpowered turkshead, but the cables might be sized using a powered turkshead in mass production. A change of this type in the manufacturing process could significantly affect the degradation of the cable. By including periodic measurements of extracted strands as part of the cable development process, the effect of new design and manufacturing parameters on current capacity can be thoroughly evaluated.

An extremely large body of information is contained within the data plots presented here, and only a small portion of that information was specifically addressed. The presentation of this data serves two purposes; it demonstrates 
the intricate and complex nature of these conductors and it documents the evolution and present status of the cable design.

\section{G. CONCLUSIONS}

Based on these measurements, some general conclusions can be stated regarding the electromagnetic character of these cables and its effect on their current capacities. Also, the measurements have implications regarding short sample testing of these cables.

The mechanical deformation of the cable strands associated with cabling can lead to very localized reductions in their current capacity. The widest spread in local current capacity occurs with the applied magnetic field parallel to the cable's width. The deformation geometry of the cable is such that the interaction between the applied magnetic field and a strand segment's aspect ratio or its pitch angle have the same tendency. In other words, a field angle that is either detrimental or beneficial to a strand segment's current capacity due to its aspect ratio is also detrimental or beneficial, respectively, due to its pitch angle. However, strand segments have different critical orientations, so the detrimental and beneficial effects of the field angle on those segments tend to cancel one another over the total length of the strand. Consequently, variations of the overall $I_{c}$ and the quenching current, with the magnetic-field angle, are significantly less than the $I_{C}$ variation for individual segments of the strand. For these conductors, the relevant $I_{c}$ criterion may be a spatial average (the overall $I_{C}$ ) because the degradation in current capacity is concentrated over short regions of the 
cable strand and local temperature rises are limited by strong end cooling. Any compromise in sample stability may lower $I_{c}$ to that of the weak-link segment of the cable strand.

These results have several implications for short-sample $I_{c}$ testing of cables. First, the data indicate that both magnetic-field orientations, parallel to the cable's width and perpendicular to its width, need to be tested in order to determine the limiting case for $I_{c}$. As shown above, the limiting magnetic-field orientation can be parallel or perpendicular to the cable's width and this is not known beforehand. Second, a large difference in. current-capacity degradation can exist between the thick and thin cable edges; therefore, changing the direction of the test current (for each field orientation) can affect the measured $I_{C}$. This is due to a self-field effect where the location of the peak magnetic field depends on the current direction. Consequently, the peak-field location should be part of the data recorded for short-sample measurements of these conductors. These measurements that address the orientation of the applied field and the location of the peak field should be made periodically as part of the cable development. Also, because of their intrinsic nature, the current-transfer voltages that are associated with mechanical damage of the cable strands should be included in their characterization.

The wire from which these cables are made has evolved to the point where the virgin wire has a high current capacity and a relatively high tolerance to mechanical deformation. Considering the amount of mechanical deformation of the strands in the cabling process, the resulting degradation in current 
capacity is surprisingly low. The maximum observed degradation of the overall $I_{c}$ of the latest outer-winding cable, sample $Y$, was only $6.8 \%$.

\section{ACKNOWLEDGMENTS}

The authors extend their thanks to T. C. Stauffer for sample preparation; to A. N. Srivastava for data plotting; and to R. M. Scanlan and J. M. Royet (Lawrence Berkeley Laboratory) for samples and discussions.

\section{REFERENCES}

1. L. F. Goodrich, E. S. Pittman, J. W. Ekin, and R. M. Scanlan, "Studies of NbTi Strands Extracted from Coreless Rutherford Cables," IEEE Trans. on Magnetics, MAG 23, 1642, 1987.

2. A. F. Clark, L. F. Goodrich, F. R. Fickett, and J. V. Minervini, "Development of Standards for Superconductors, Interim Report Oct. 80 to Jan. 82", NBSIR 82-1678, National Bureau of Standards, Boulder, Colorado (July 1982).

3. L. F. Goodrich, W. P. Dube, E. S. Pittman, and A. F. Clark, "The Effect of Aspect Ratio on Critical Current in Multifilamentary Superconductors," Adv. Cryog. Eng. - Materials, Vol. 32, Plenum Press, New York (1986), p. 833-840. 
4. J. Royet and R. M. Scanlan, "Manufacture of Keystoned Flat Superconducting Cables for Use in SSC dipoles," IEEE Trans. on Magnetics, MAG 23, 480, 1987.

5. D. C. Larbalestier, A. W. West, W. Starch, W. Warnes, P. Lee, W. K. McDonald, P. O'Larey, K. Hemachalam, B. Zeitlin, R. Scanlan, and C. Taylor, "High Critical Current Densities in Industrial Scale Composites Made From High Homogeneity Nb 46.5 Ti", IEEE Trans. on Magnetics, MAG 21, 269, 1985.

6. L. F. Goodrich, J. W. Ekin, F. R. Fickett, "Effect of Twist Pitch on Short-Sample V-I Characteristics of Multifilamentary Superconductors," Adv. Cryog. Eng. - Materials, Vol. 28, Plenum Press, New York (1981), p. $571-580$.

7. L. F. Goodrich, "The Effect of Field Orientation on Current Transfer in Multifilamentary Superconductors," IEEE Trans. on Magnetics, MAG 19, 244 , 1983.

8. J. W. Ekin, L. F. Goodrich, J. Moreland, E. S. Pittman, and A. F. Clark, "Electro-Mechanical Properties of Superconductors for High Energy Physics Applications," NBSIR 86-3061, National Bureau of Standards, Boulder, Colorado (December 1986).

9. E. W. Collings, "Stabilizer Design Considerations in Fine-Filament Cu/NbTi Composites," Adv. Cryog. Eng. - Materials, Vol. 34, Plenum Press, New York (1988), p. $867-877$. 
10. T. S. Kreilick, E. Gregory, J. Wong, R. M. Scanlan, A. K. Ghosh, W. B. Sampson, and E. W. Collings, "Reduction of Coupling in Fine Filamentary CuNbTi Composites by the Addition of Manganese to the Matrix," Adv. Cryog. Eng.

- Materials, Vol. 34, Plenum Press, New York (1988), p. 895-900. 

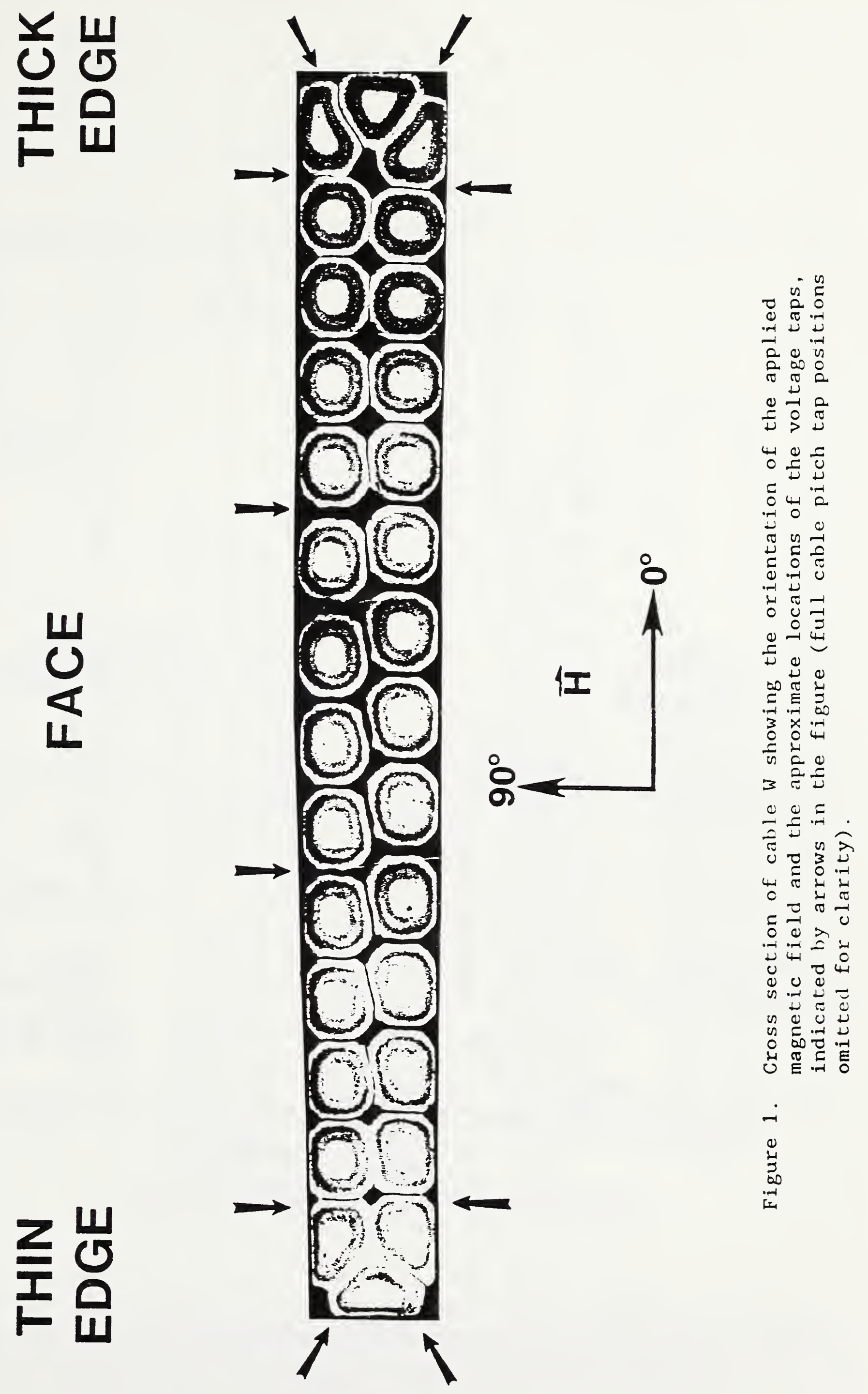


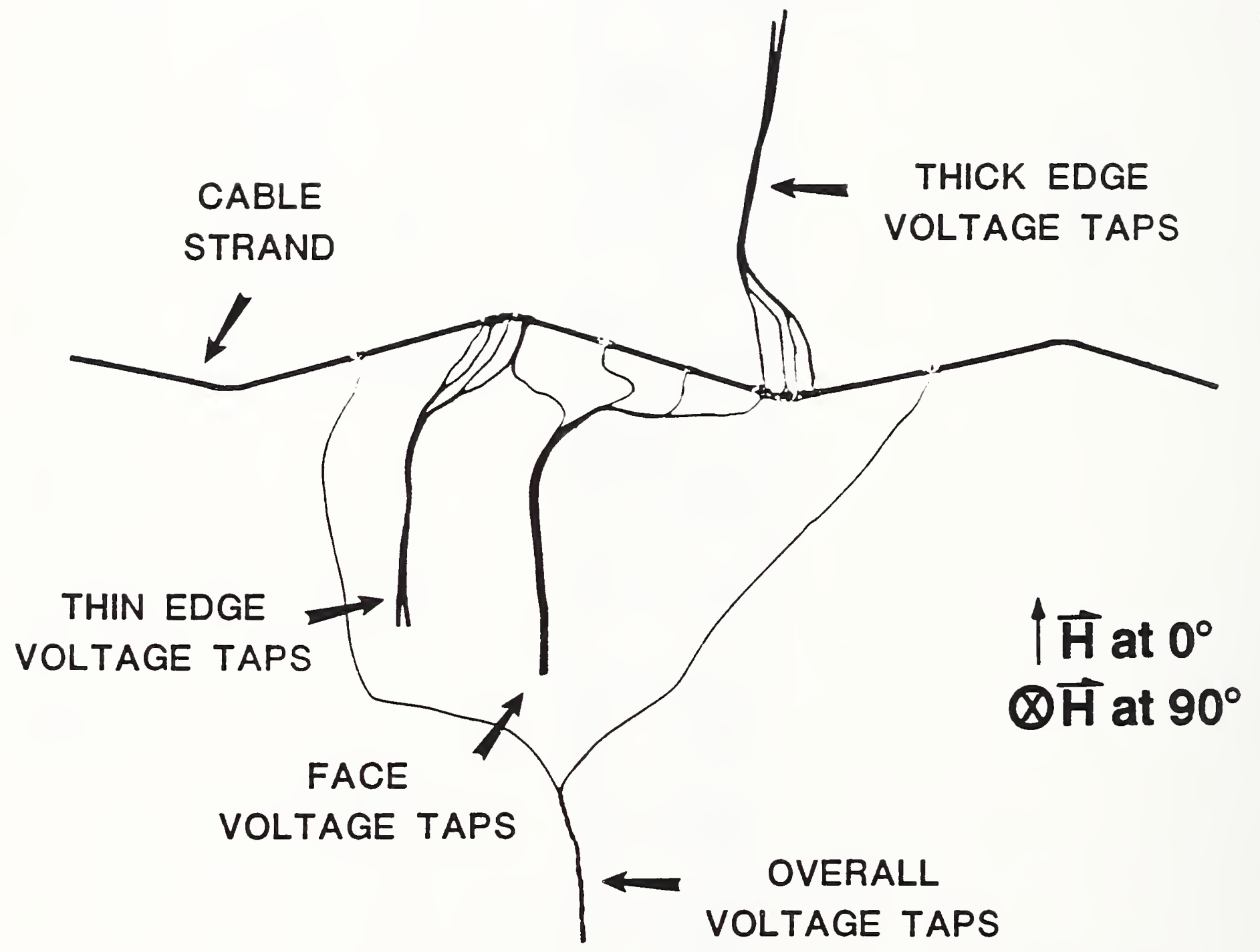

Figure 2. Instrumented portion of an extracted cable strand showing the voltage tap placement and the orientation of the applied magnetic field. 


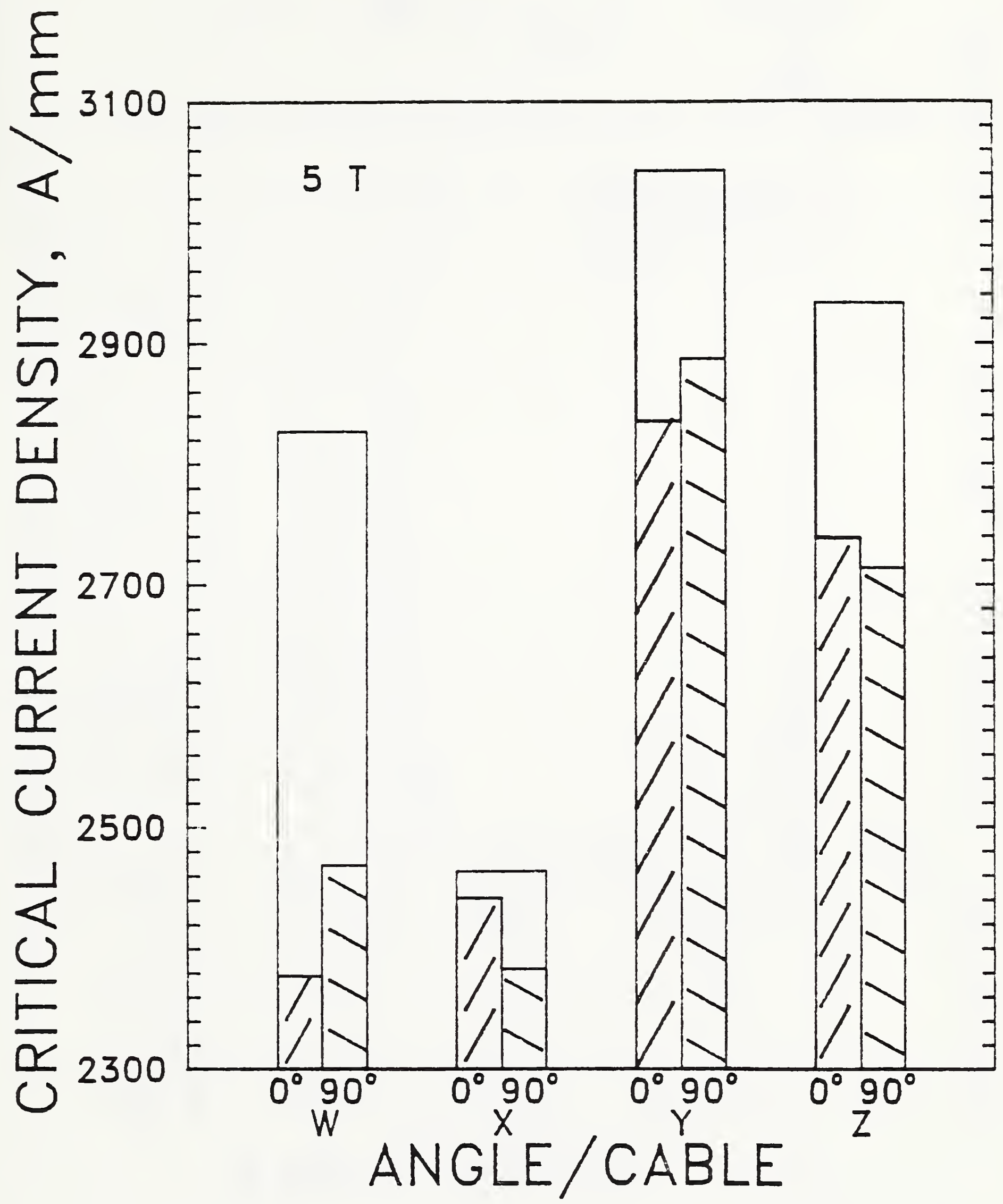

Figure 3. Critical-current density of cable strands and their respective virgin wires for 0 and $90^{\circ}$ at $5 \mathrm{~T}$. The virgin wire $J_{C}$ is represented by the continuous line segment spanning 0 to $90^{\circ}$ for each cable. The strand $J_{c}$ at 0 and $90^{\circ}$ are represented by the shaded bars for each cable. 


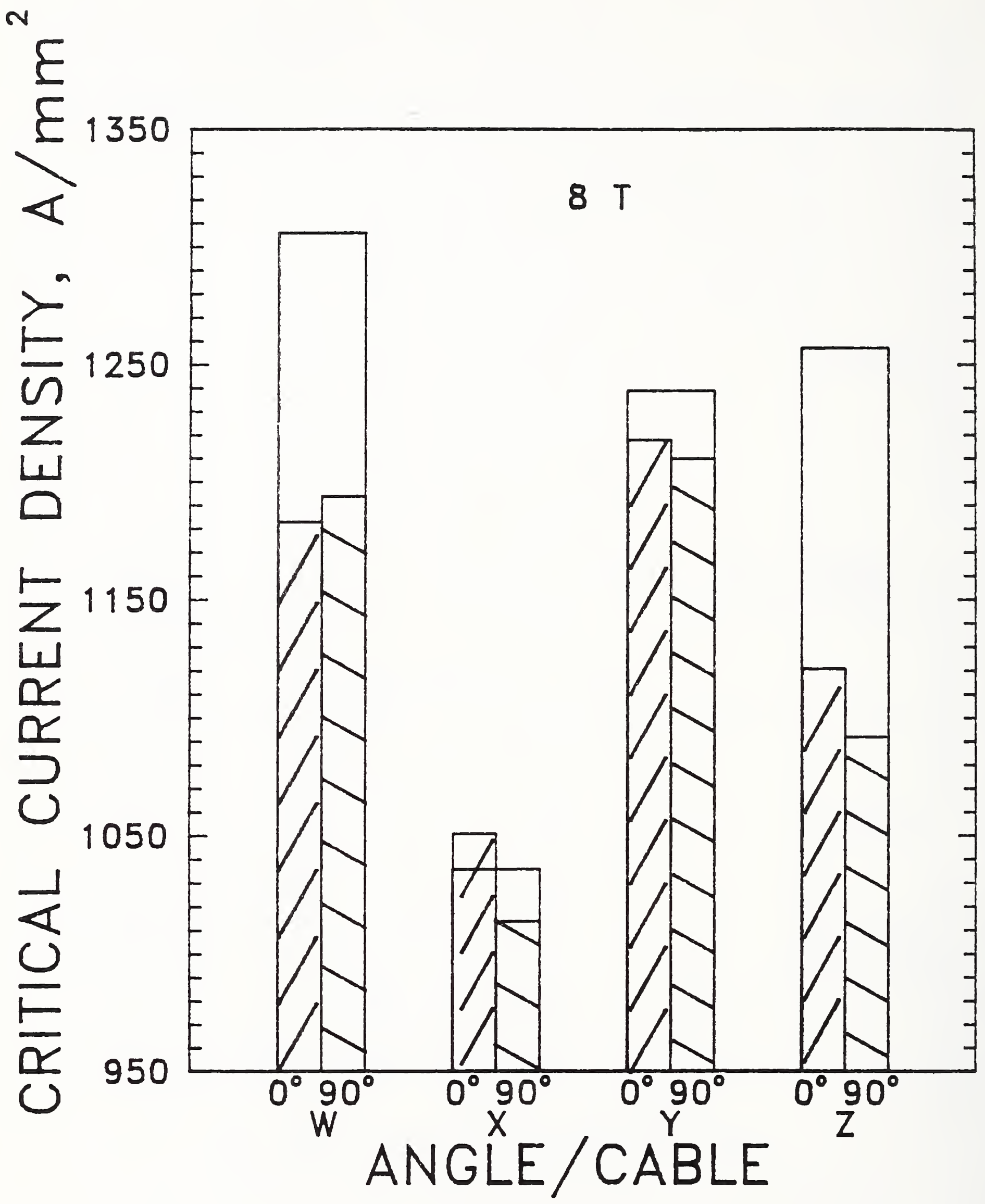

Figure 4. Critical-current density of cable strands and their respective virgin wires for 0 and $90^{\circ}$ at $8 \mathrm{~T}$. The virgin wire $J_{C}$ is represented by the continuous line segment spanning 0 to $90^{\circ}$ for each cable. The strand $J_{c}$ at 0 and $90^{\circ}$ are represented by the shaded bars for each cable. 


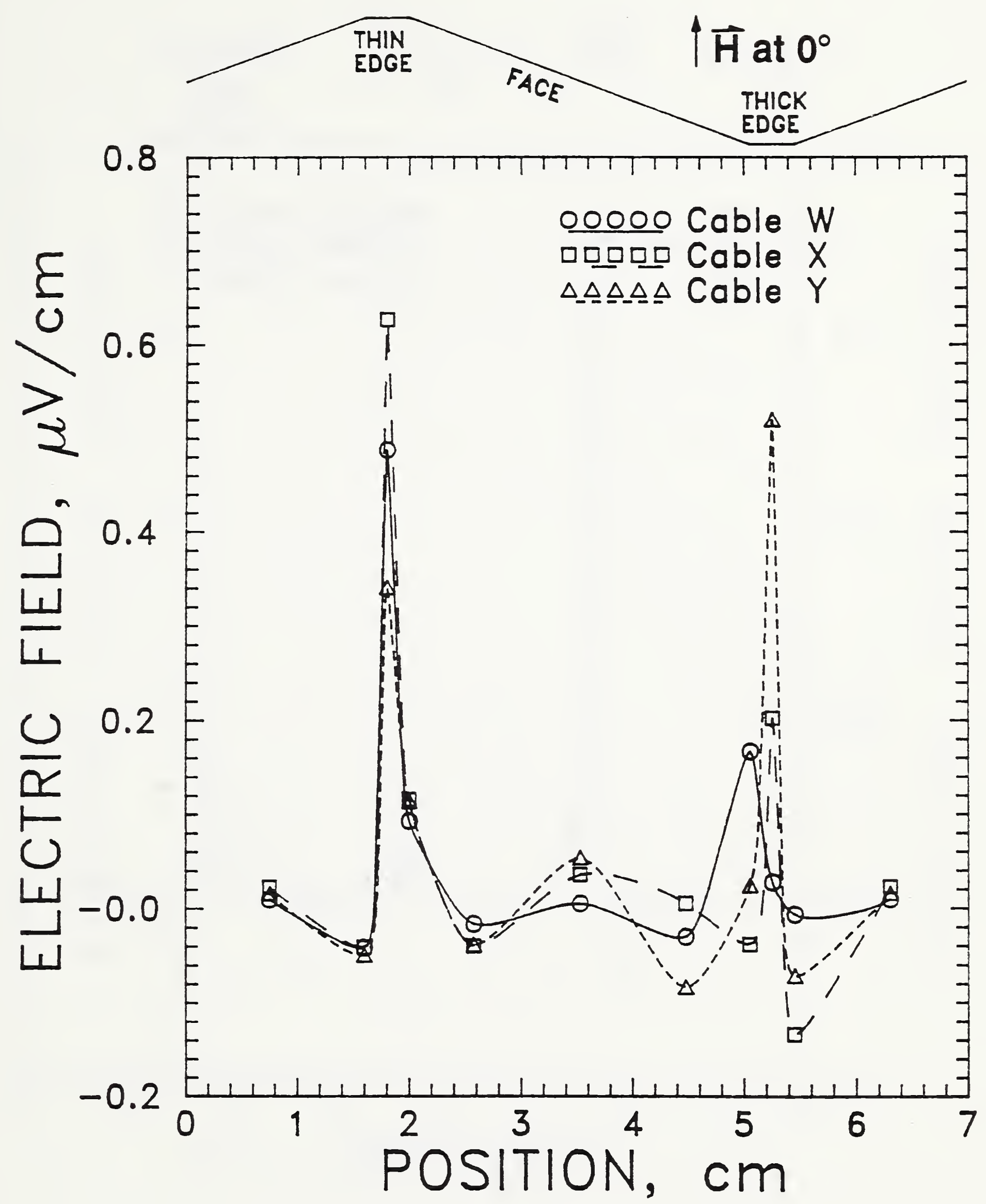

Figure 5. Electric-field profiles at $5 \mathrm{~T}$ and an applied magnetic field angle of $0^{\circ}$ for cables $W, X$, and $Y$ at currents of $267 \mathrm{~A}, 283 \mathrm{~A}$, and $317 \mathrm{~A}$, respectively, which corresponds to an overall electric field of $0.01 \mu \mathrm{V} / \mathrm{cm}$. 


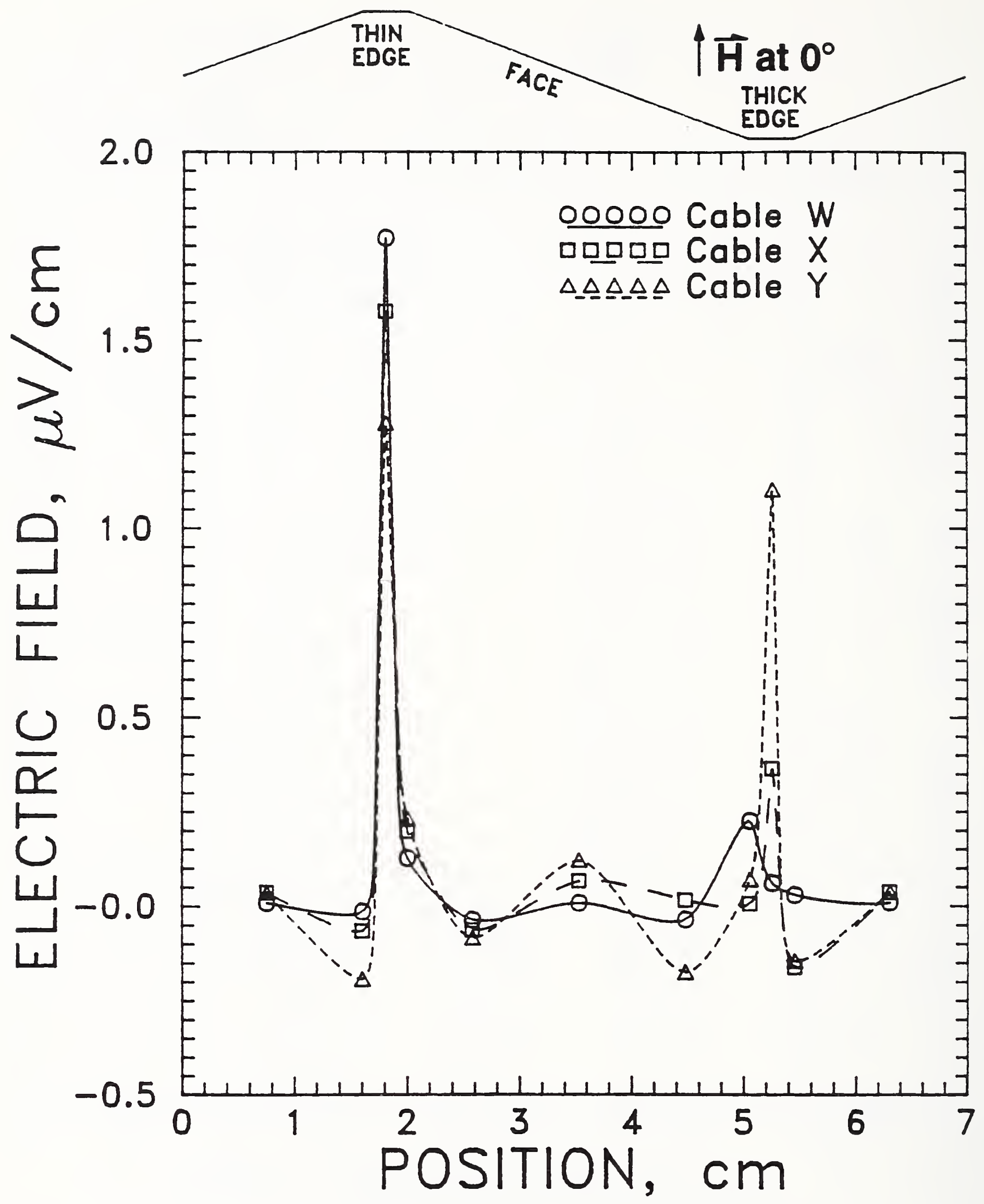

Figure 6. Electric-field profiles at $5 \mathrm{~T}$ and an applied magnetic field angle of $0^{\circ}$ for cables $W, X$, and $Y$ at currents of $279 \mathrm{~A}, 299 \mathrm{~A}$, and $332 \mathrm{~A}$, respectively, which corresponds to an overall electric field $0.05 \mu \mathrm{V} / \mathrm{cm}$. 


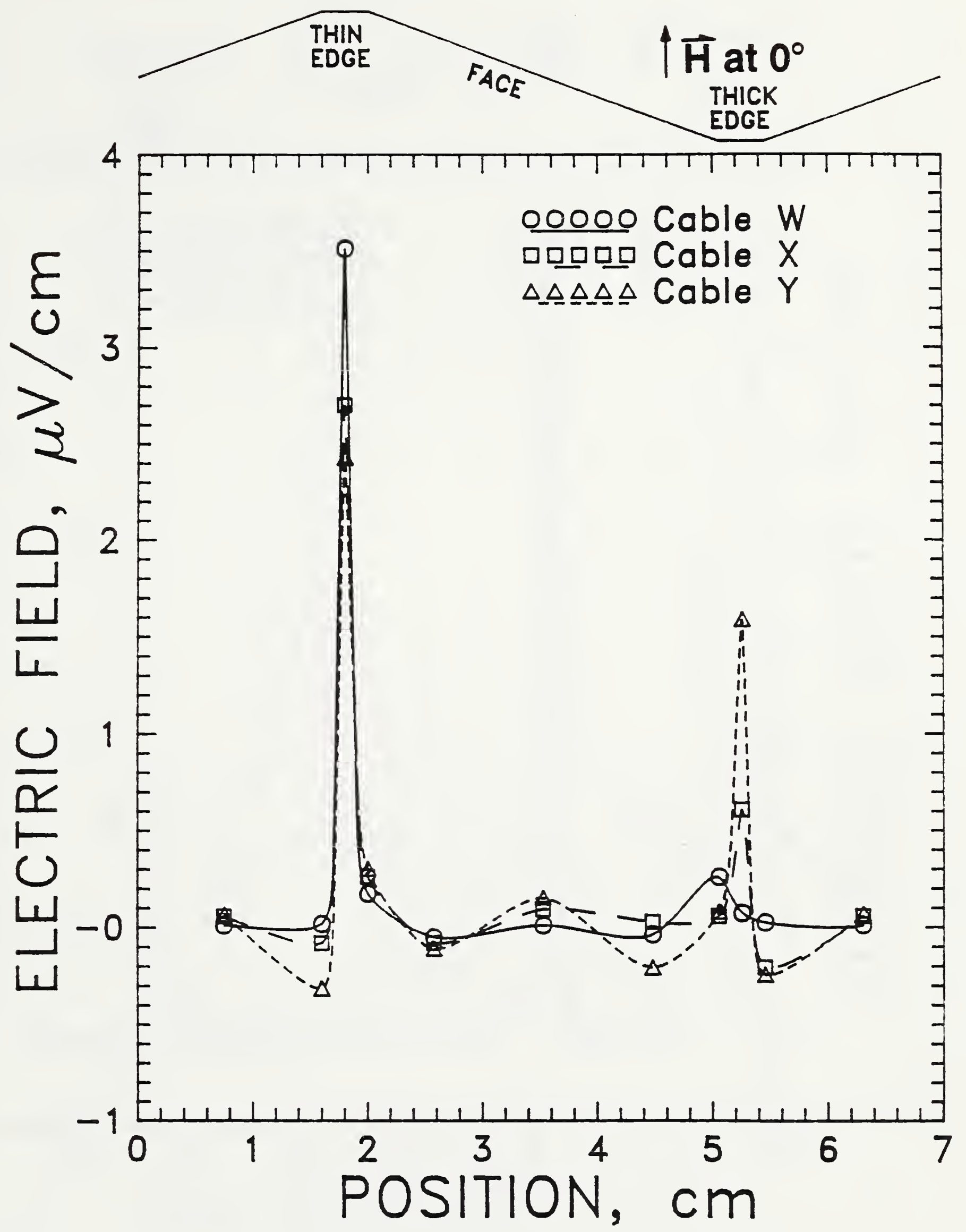

Figure 7. Electric-field profiles at $5 \mathrm{~T}$ and an applied magnetic field angle of $0^{\circ}$ for cables $W, X$, and $Y$ at currents of $285 \mathrm{~A}, 307 \mathrm{~A}$, and $339 \mathrm{~A}$, respectively, which corresponds to an overall electric field of $0.1 \mu \mathrm{V} / \mathrm{cm}$. 


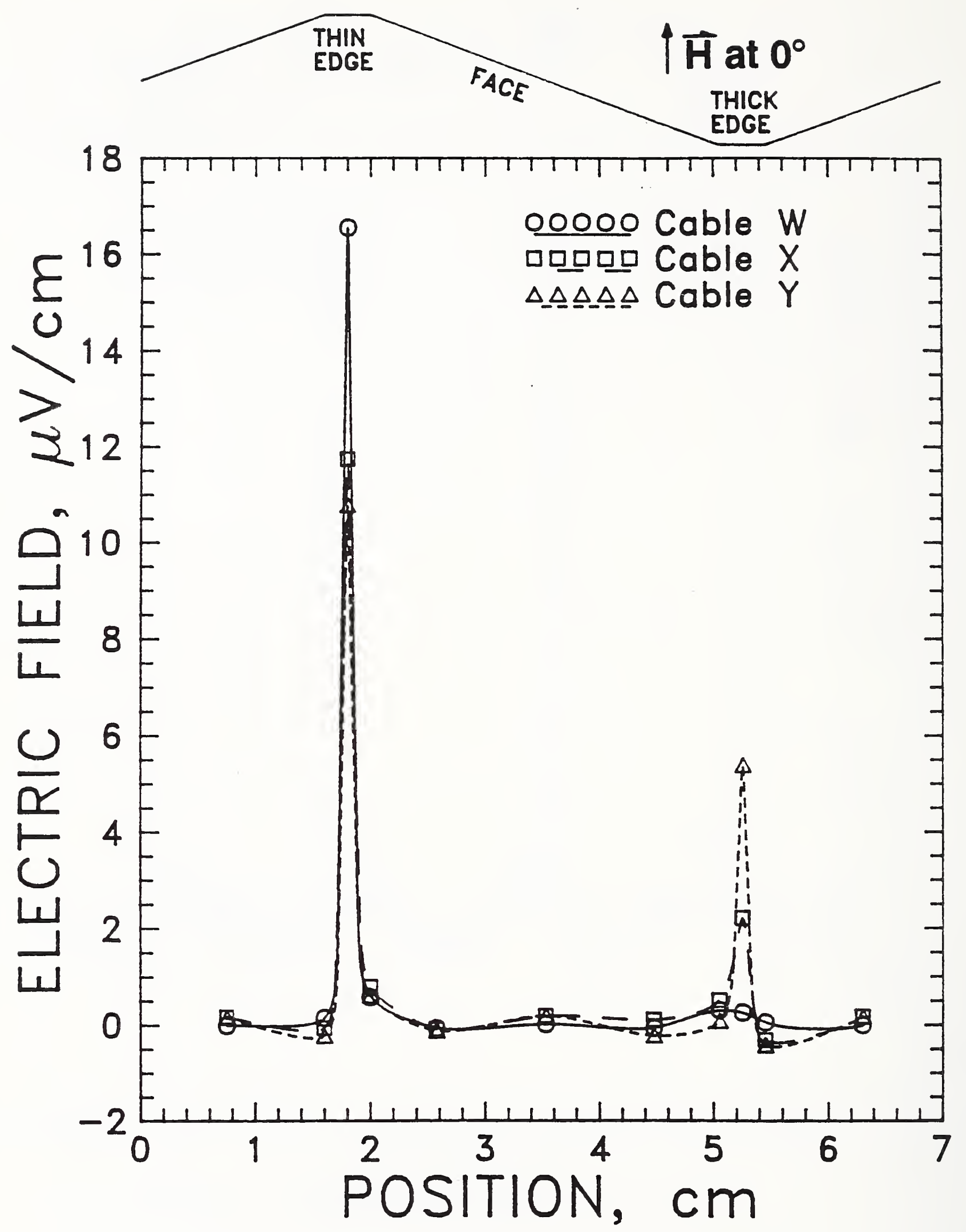

Figure 8. Electric-field profiles at $5 \mathrm{~T}$ and an applied magnetic field angle of $0^{\circ}$ for cables $\mathrm{W}, \mathrm{X}$, and $\mathrm{Y}$ at currents of $300 \mathrm{~A}, 326 \mathrm{~A}$, and $351 \mathrm{~A}$, respectively, which corresponds to an overall electric field of $0.5 \mathrm{\mu V} / \mathrm{cm}$. 


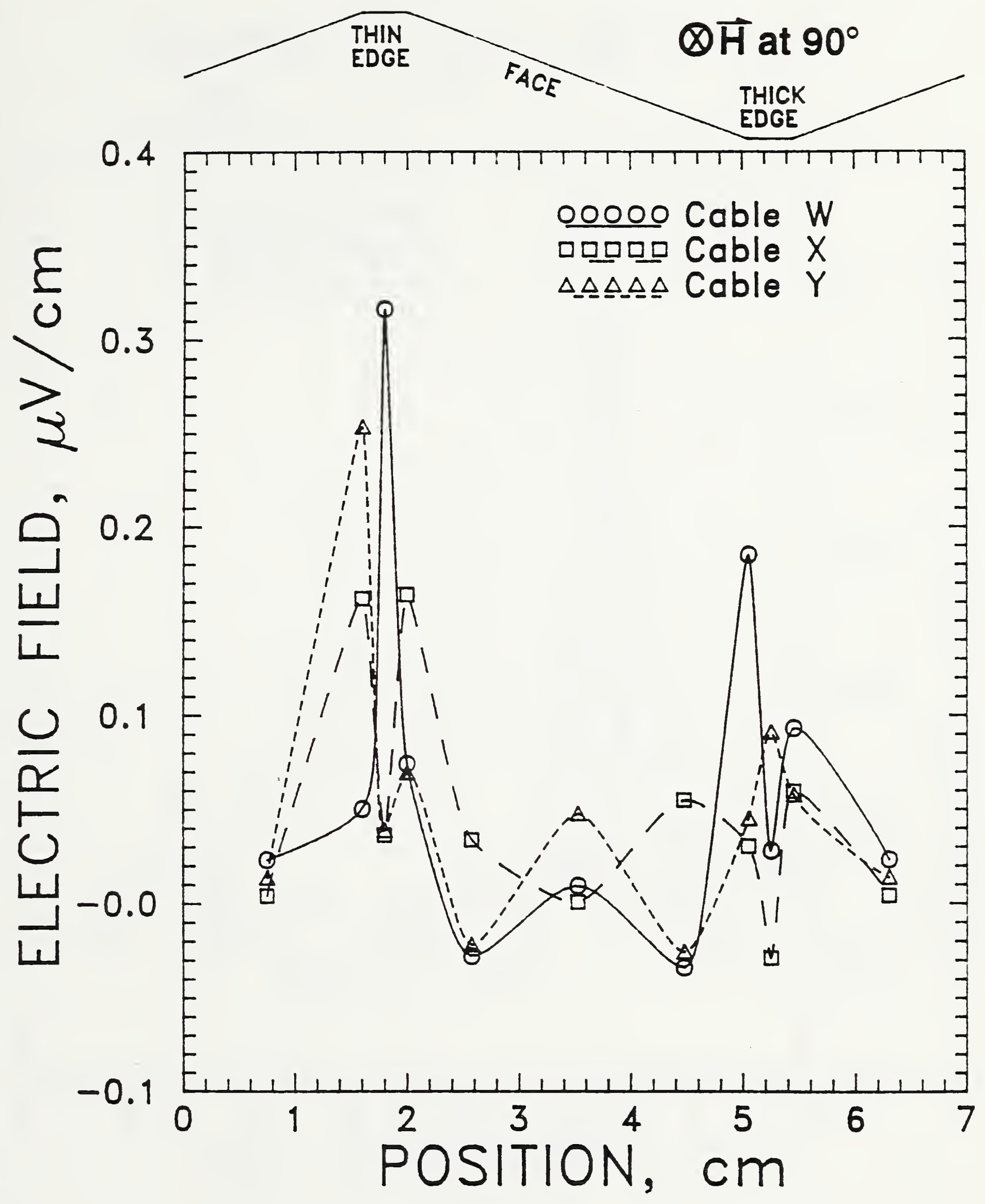

Figure 9. Electric-field profiles at $5 \mathrm{~T}$ and an applied magnetic field angle of $90^{\circ}$ for cables $W, X$, and $Y$ at currents of $275 \mathrm{~A}, 277 \mathrm{~A}$, and $327 \mathrm{~A}$, respectively, which corresponds to an overall electric field of $0.01 \mu \mathrm{V} / \mathrm{cm}$. 


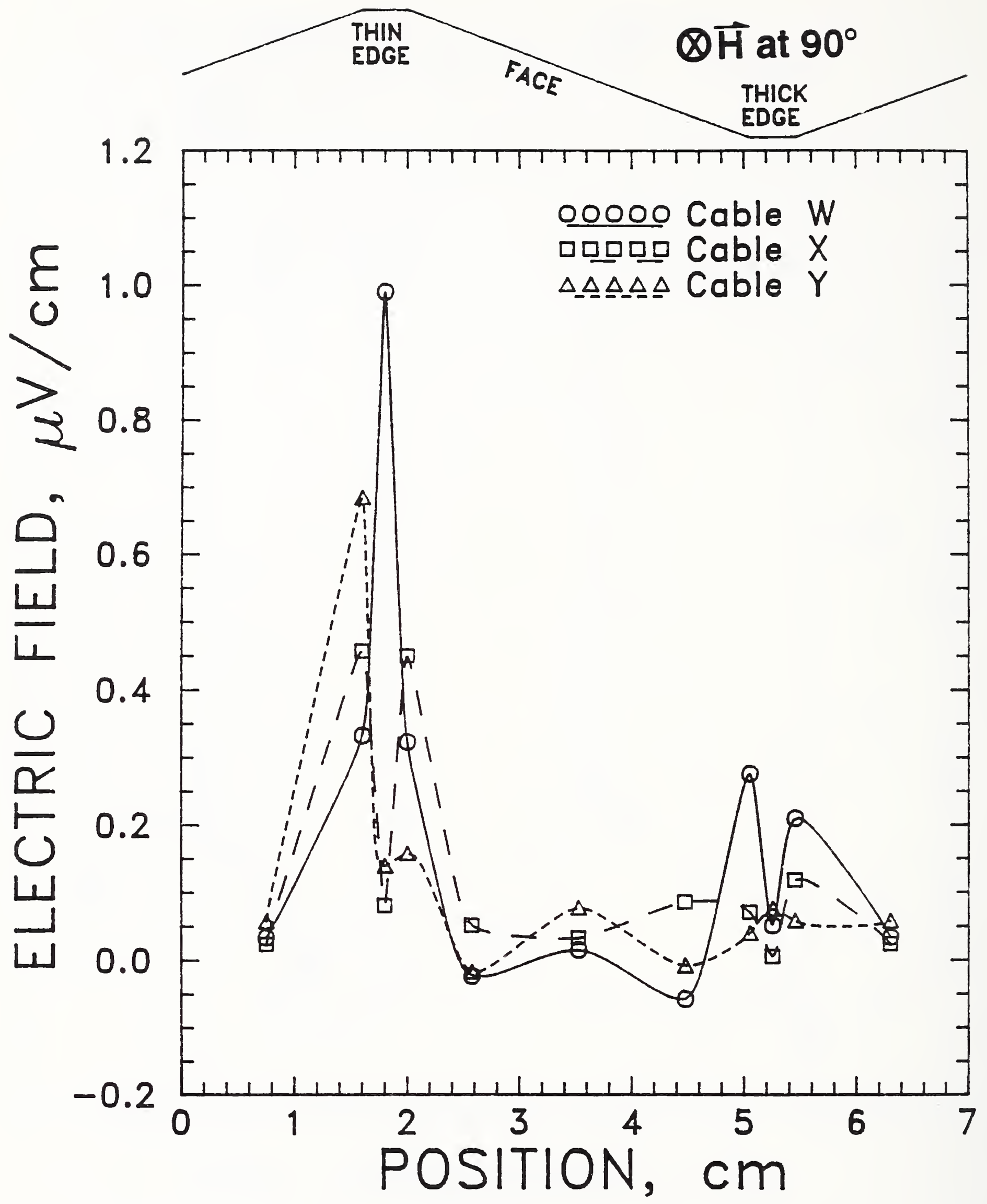

Figure 10. Electric-field profiles at $5 \mathrm{~T}$ and an applied magnetic field angle of $90^{\circ}$ for cables $\mathrm{W}, \mathrm{X}$, and $\mathrm{Y}$ at currents of $289 \mathrm{~A}, 292 \mathrm{~A}$, and $339 \mathrm{~A}$, respectively, which corresponds to an overall electric field of $0.05 \mu \mathrm{V} / \mathrm{cm}$. 


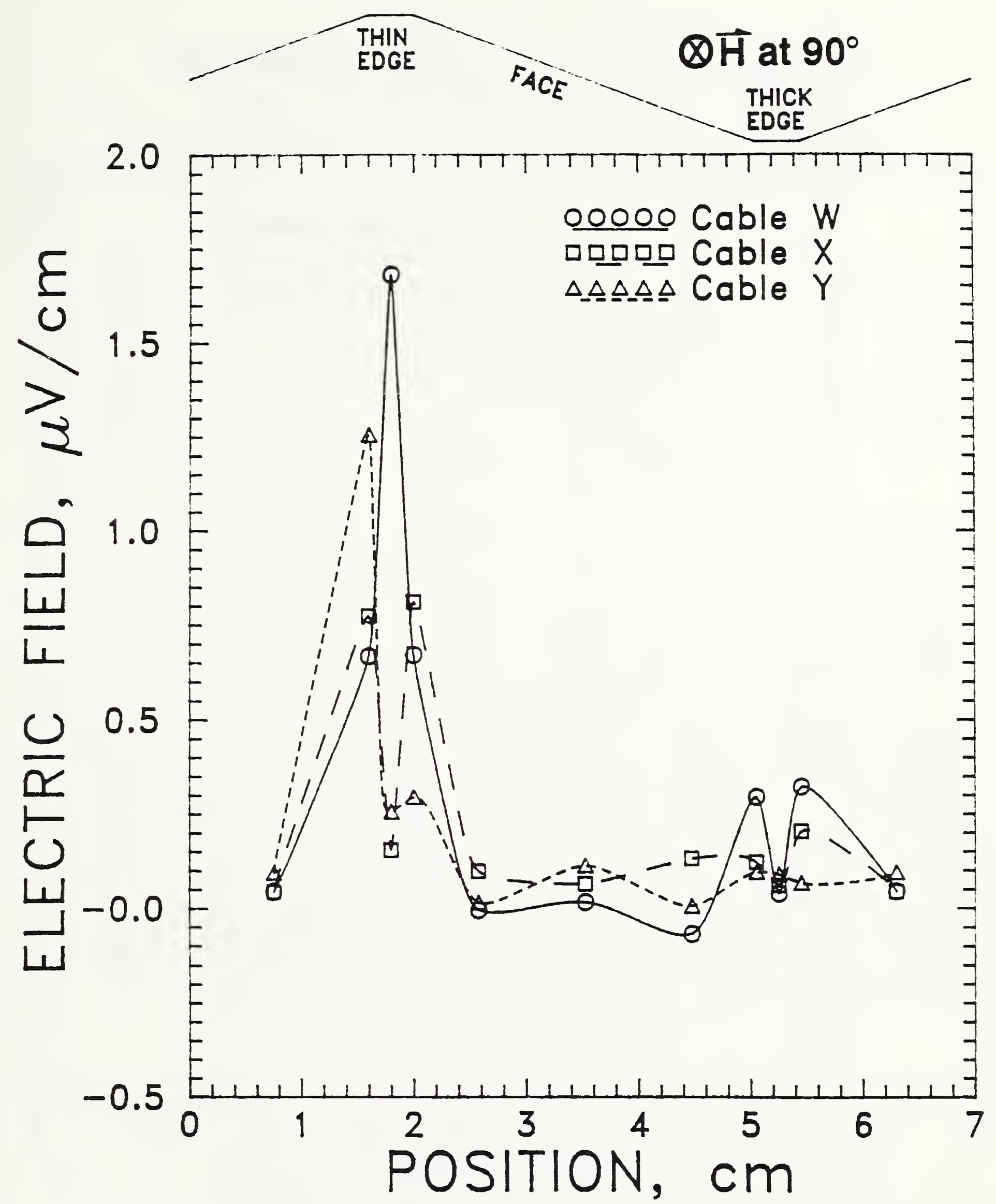

Figure 11. Electric-field profiles at $5 \mathrm{~T}$ and an applied magnetic field angle of $90^{\circ}$ for cables $\mathrm{W}, \mathrm{X}$, and $\mathrm{Y}$ at currents of $296 \mathrm{~A}, 300 \mathrm{~A}$, and $345 \mathrm{~A}$, respectively, which corresponds to an overall electric field of $0.1 \mu \mathrm{V} / \mathrm{cm}$. 


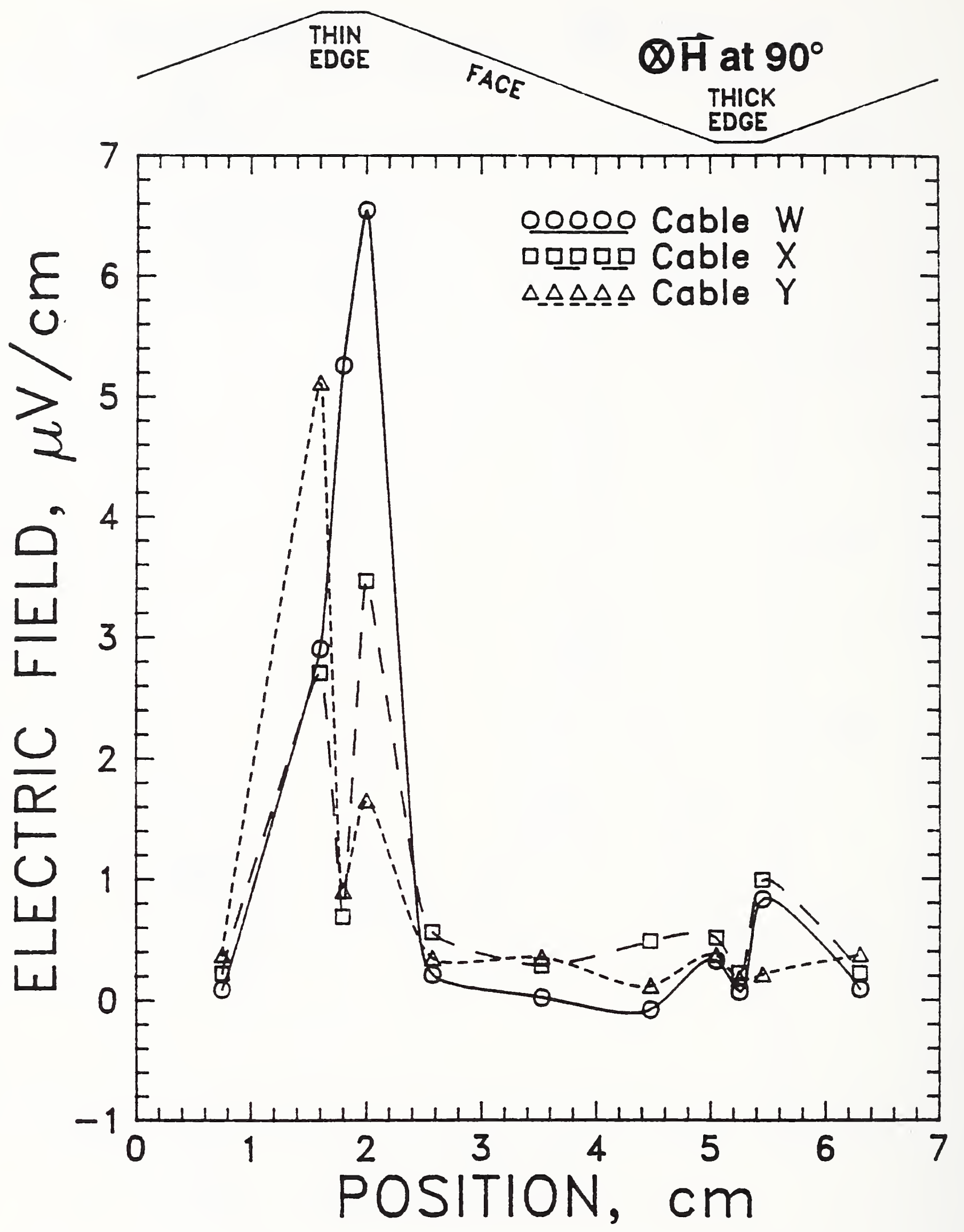

Figure 12. Electric-field profiles at $5 \mathrm{~T}$ and an applied magnetic field angle of $90^{\circ}$ for cables $W, X$, and $Y$ at currents of $307 \mathrm{~A}, 318 \mathrm{~A}$, and $358 \mathrm{~A}$, respectively, which corresponds to an overall electric field of $0.5 \mu \mathrm{V} / \mathrm{cm}$. 


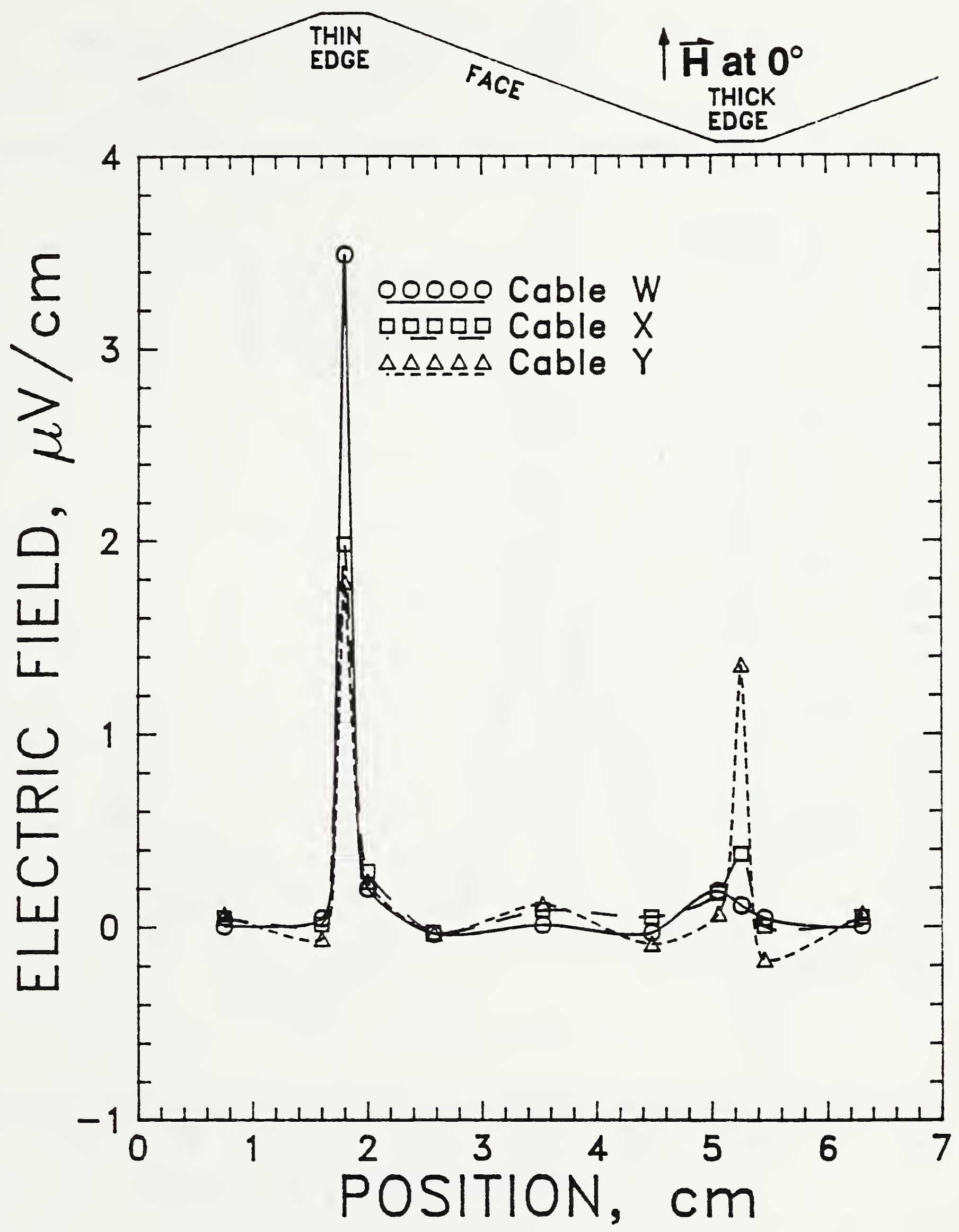

Figure 13. Electric-field profiles at $8 \mathrm{~T}$ and an applied magnetic field angle of $0^{\circ}$ for cables $\mathrm{W}, \mathrm{X}$, and $\mathrm{Y}$ at currents of $142 \mathrm{~A}, 132 \mathrm{~A}$, and $145 \mathrm{~A}$, respectively, which corresponds to an overall electric field of $0.1 \mathrm{\mu V} / \mathrm{cm}$. 


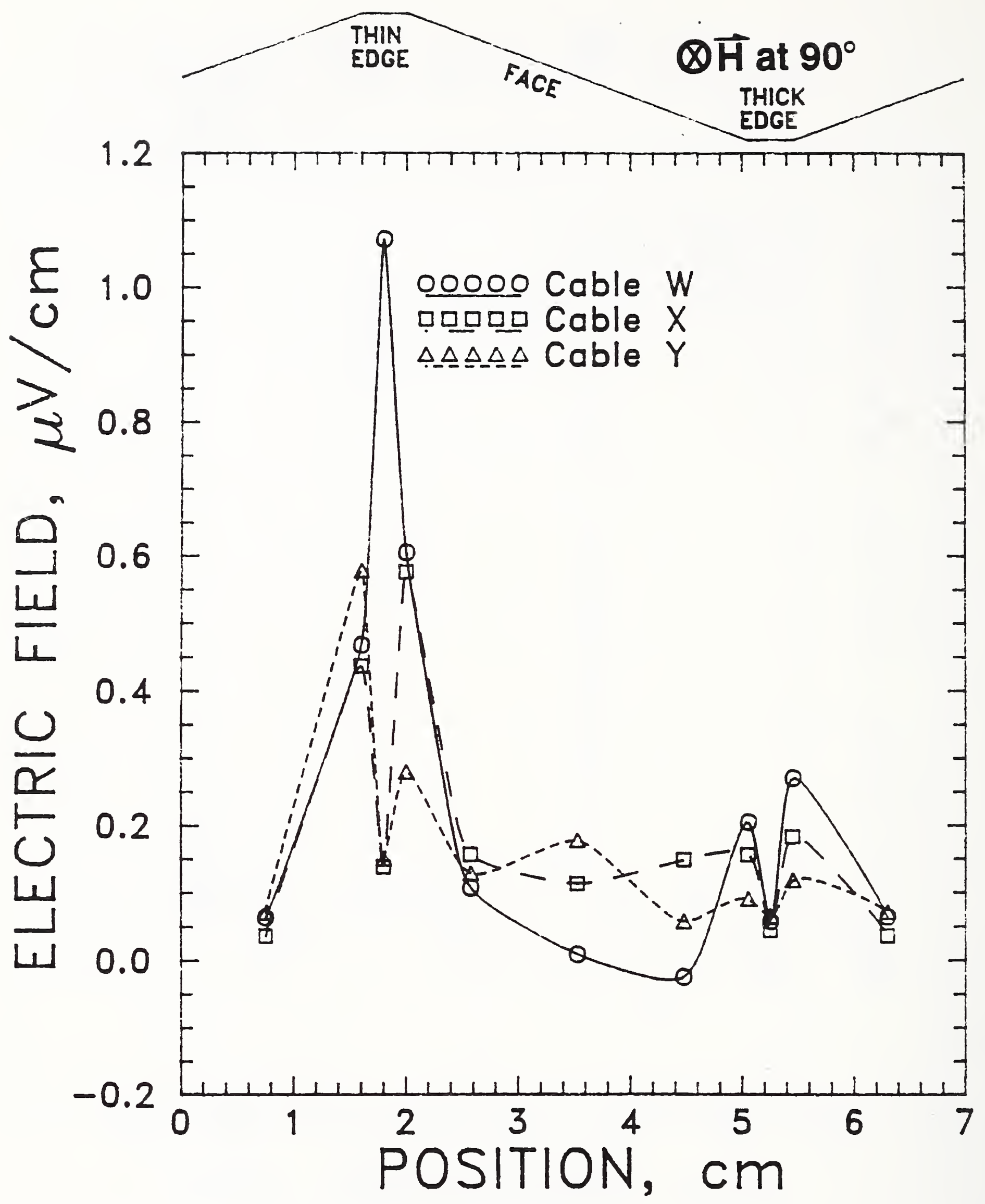

Figure 14. Electric-field profiles at $8 \mathrm{~T}$ and an applied magnetic field angle of $90^{\circ}$ for cables $W, X$, and $Y$ at currents of $143 \mathrm{~A}, 128 \mathrm{~A}$, and $144 \mathrm{~A}$, respectively, which corresponds to an overall electric field of $0.1 \mu \mathrm{V} / \mathrm{cm}$. 


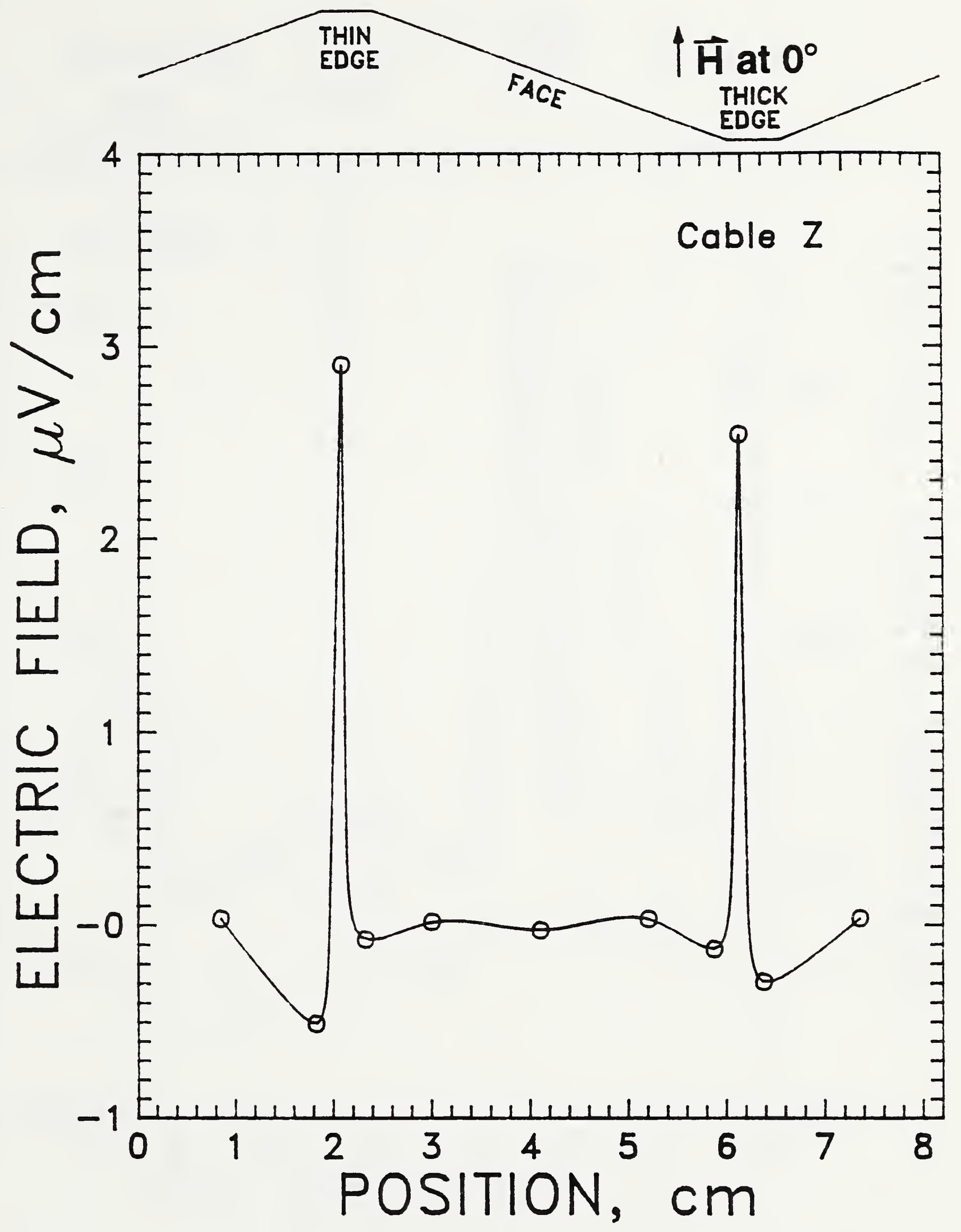

Figure 15. Electric-field profiles at $5 \mathrm{~T}$ and an applied magnetic field angle of $0^{\circ}$ for cable $Z$ at a current of $585 \mathrm{~A}$, which corresponds to an overall electric field of $0.1 \mu \mathrm{V} / \mathrm{cm}$. 


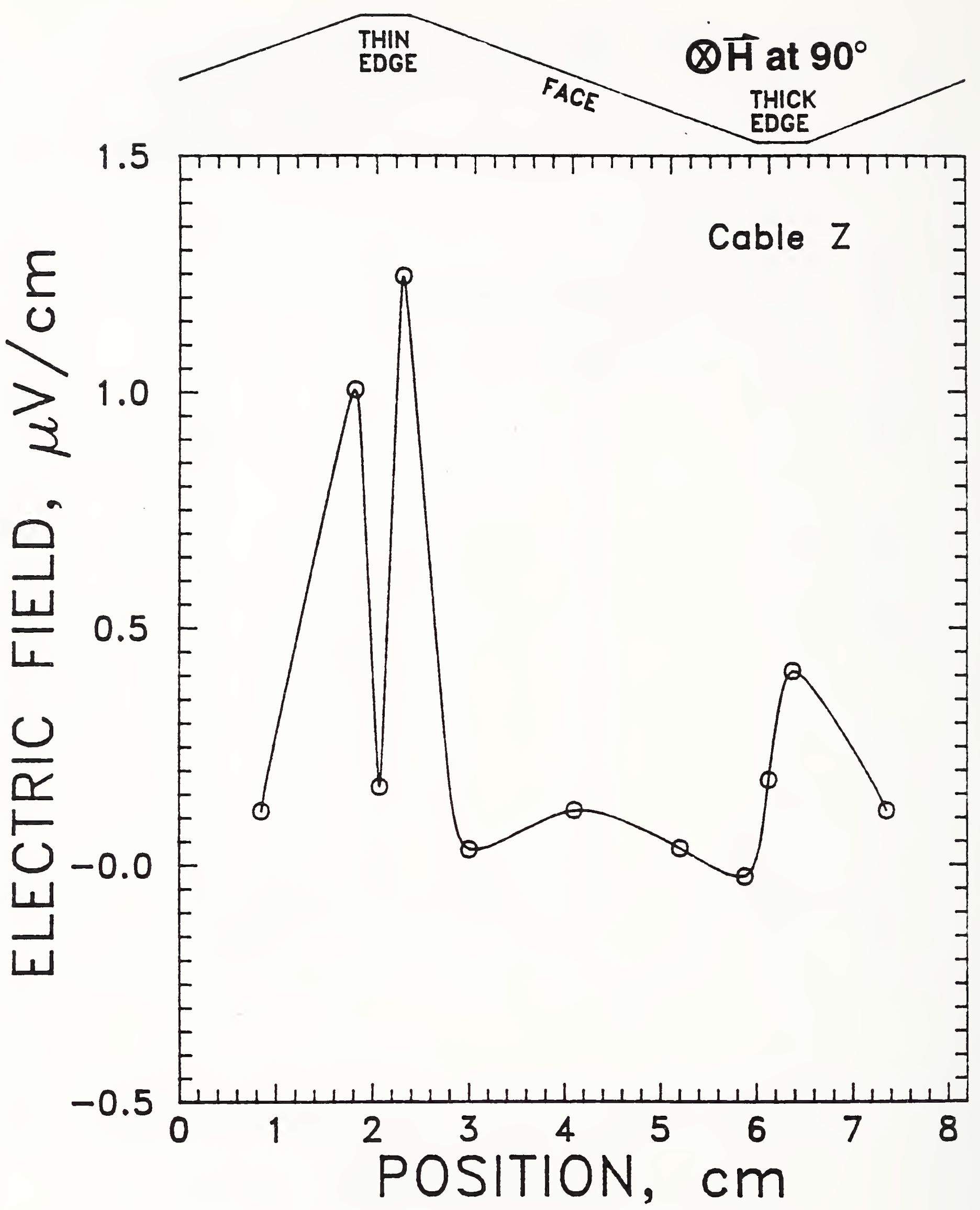

Figure 16. Electric-field profiles at $5 \mathrm{~T}$ and an applied magnetic field angle of $90^{\circ}$ for cable $Z$ at a current of $579 \mathrm{~A}$, which corresponds to an overall electric field of $0.1 \mu \mathrm{V} / \mathrm{cm}$. 


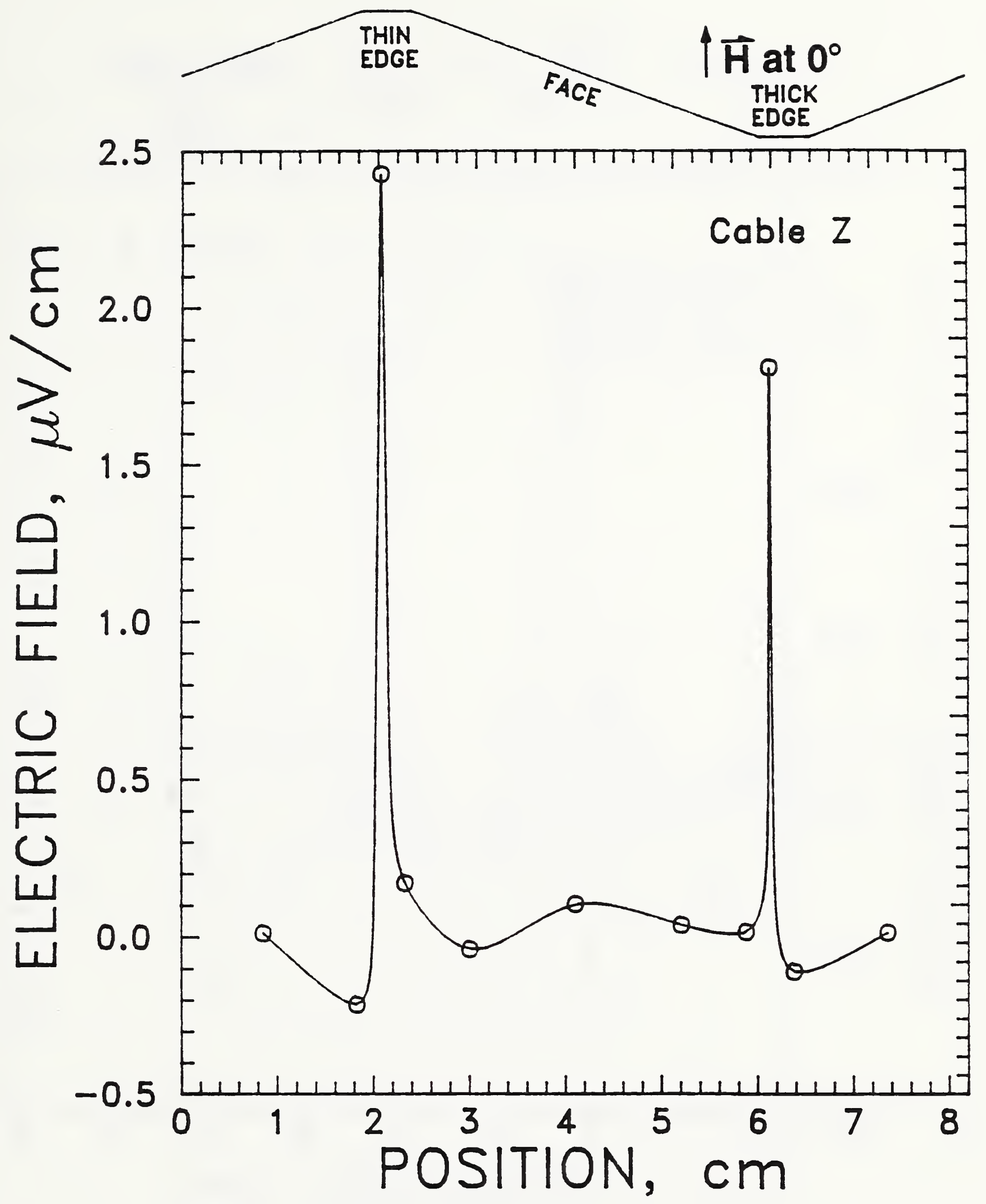

Figure 17. Electric-field profiles at $8 \mathrm{~T}$ and an applied magnetic field angle of $0^{\circ}$ for cable $Z$ at a current of $239 \mathrm{~A}$, which corresponds to an overall electric field of $0.1 \mu \mathrm{V} / \mathrm{cm}$. 


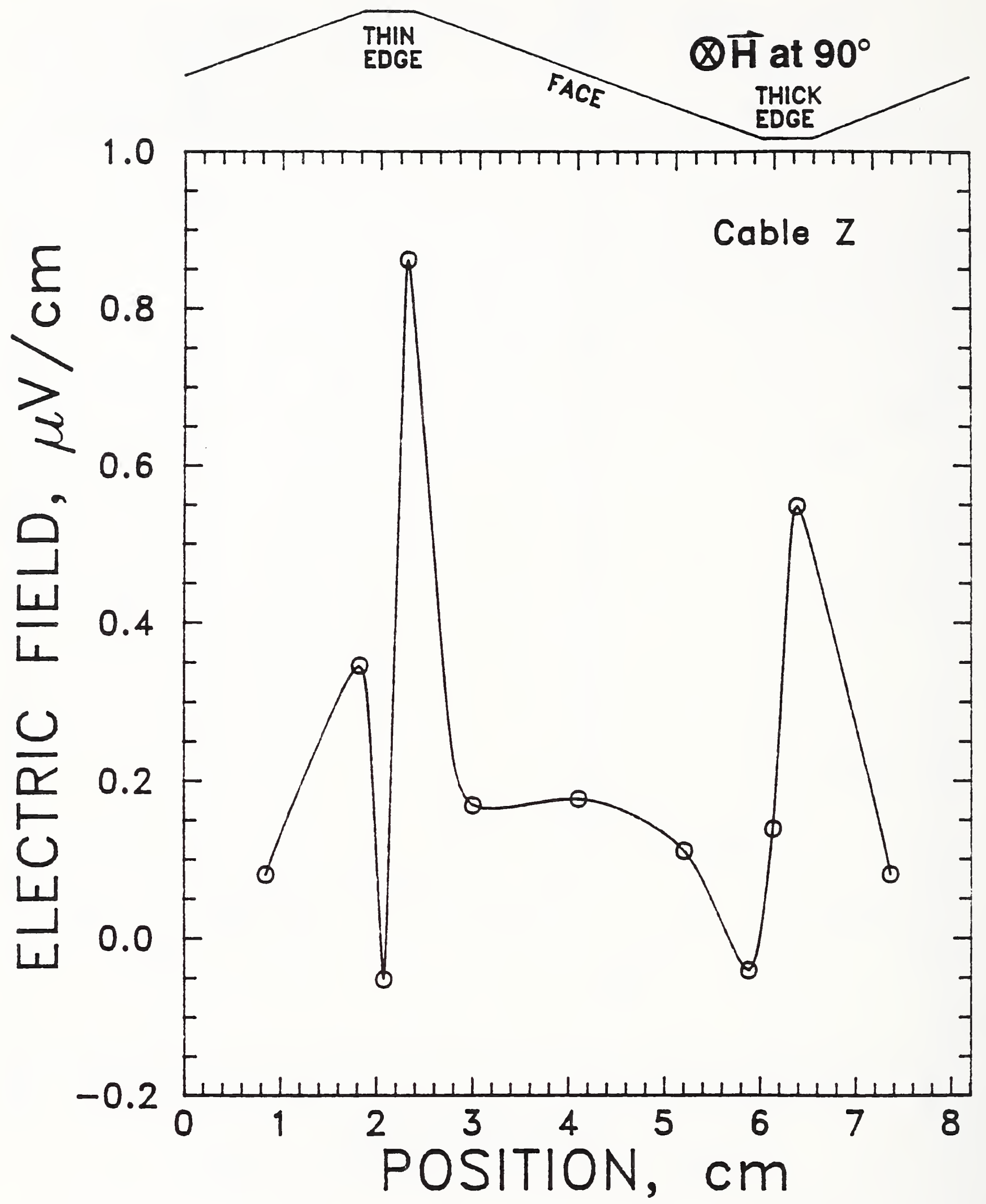

Figure 18. Electric-field profiles at $8 \mathrm{~T}$ and an applied magnetic field angle of $90^{\circ}$ for cable $Z$ at a current of $233 \mathrm{~A}$, which corresponds to an overall electric field of $0.1 \mu \mathrm{V} / \mathrm{cm}$. 


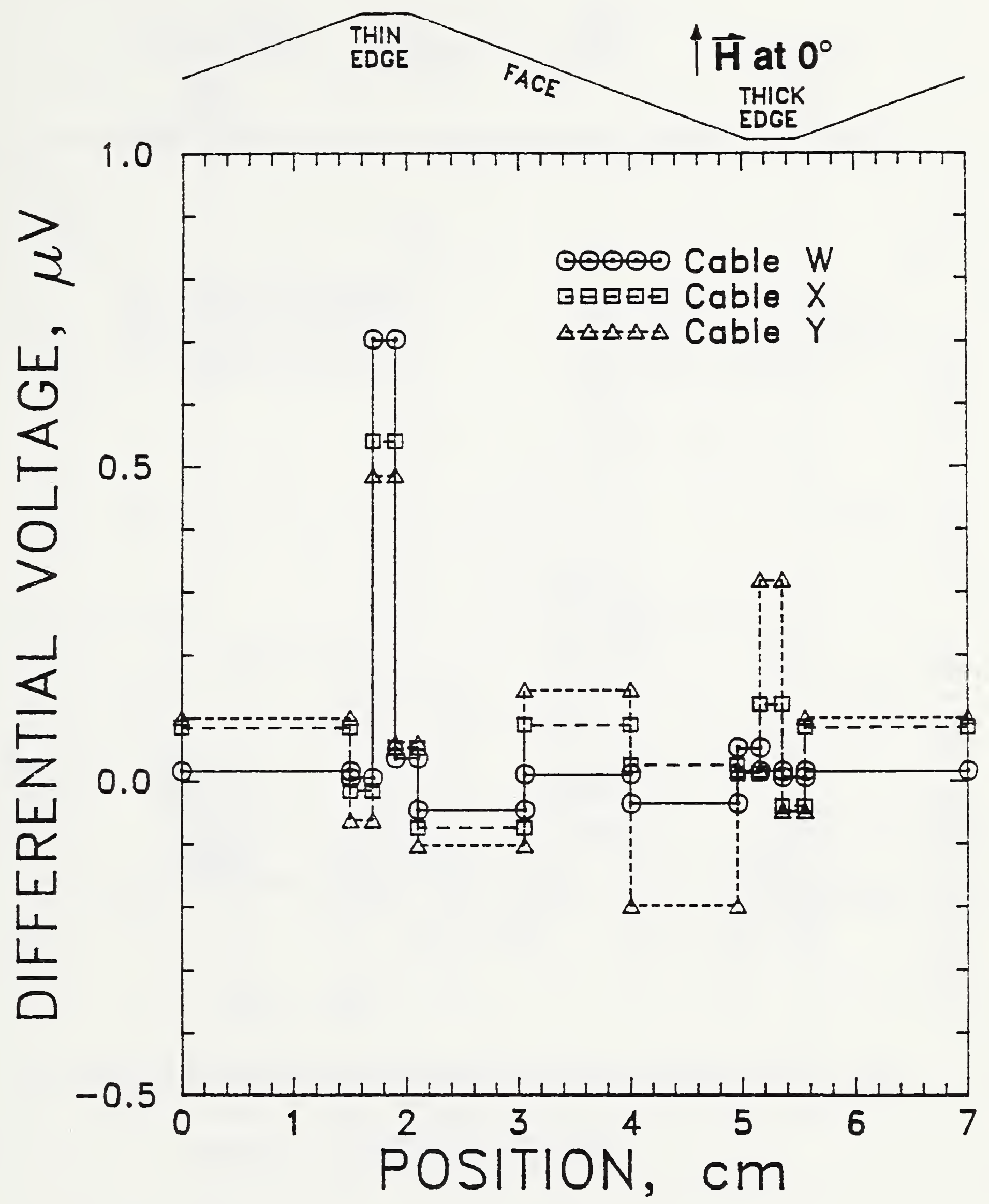

Figure 19. Differential-voltage profiles at $5 \mathrm{~T}$ and an applied magnetic field angle of $0^{\circ}$ for cables $W, X$, and $Y$ at currents of $285 \mathrm{~A}$, $307 \mathrm{~A}$, and $339 \mathrm{~A}$, respectively, which corresponds to an overall electric field of $0.1 \mu \mathrm{V} / \mathrm{cm}$. 


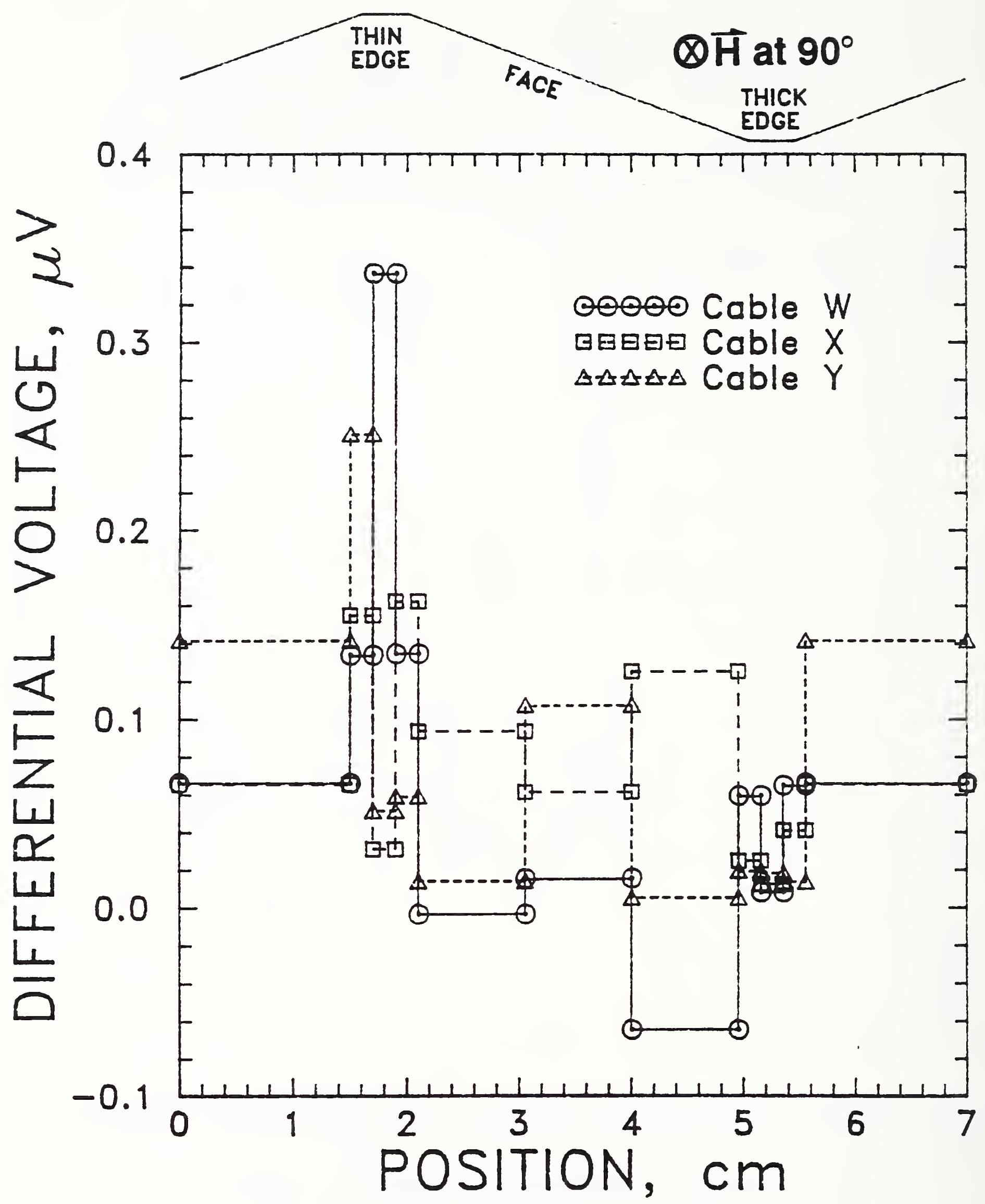

Figure 20. Differential-voltage profiles at $5 \mathrm{~T}$ and an applied magnetic field angle of $90^{\circ}$ for cables $W, X$, and $Y$ at currents of $296 \mathrm{~A}$, $300 \mathrm{~A}$, and $345 \mathrm{~A}$, respectively, which corresponds to an overall electric field of $0.1 \mu \mathrm{V} / \mathrm{cm}$. 


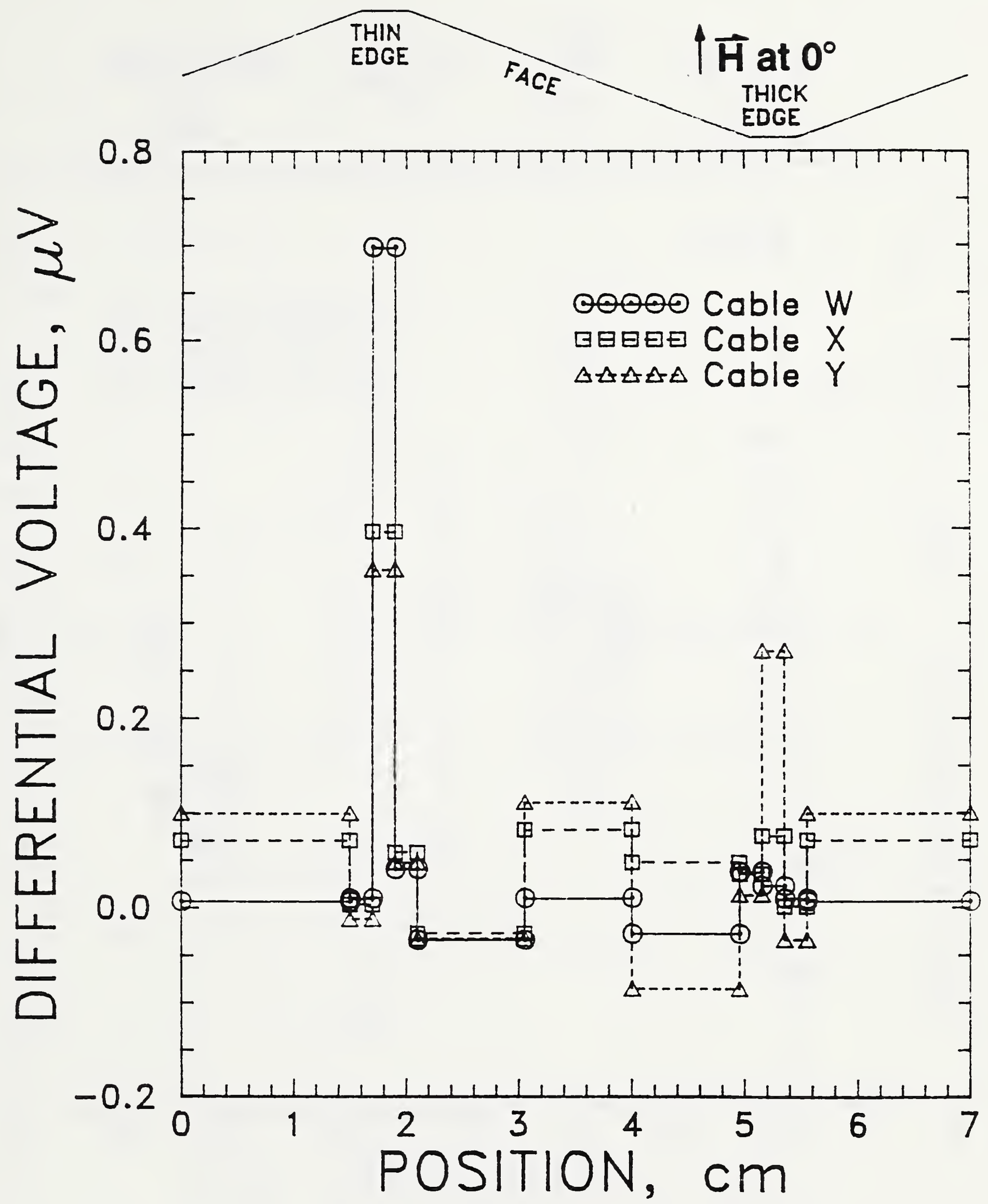

Figure 21. Differential-voltage profiles at $8 \mathrm{~T}$ and an applied magnetic field angle of $0^{\circ}$ for cables $\mathrm{W}, \mathrm{X}$, and $\mathrm{Y}$ at currents of $142 \mathrm{~A}$, $132 \mathrm{~A}$, and $145 \mathrm{~A}$, respectively, which corresponds to an overall electric field of $0.1 \mu \mathrm{V} / \mathrm{cm}$. 


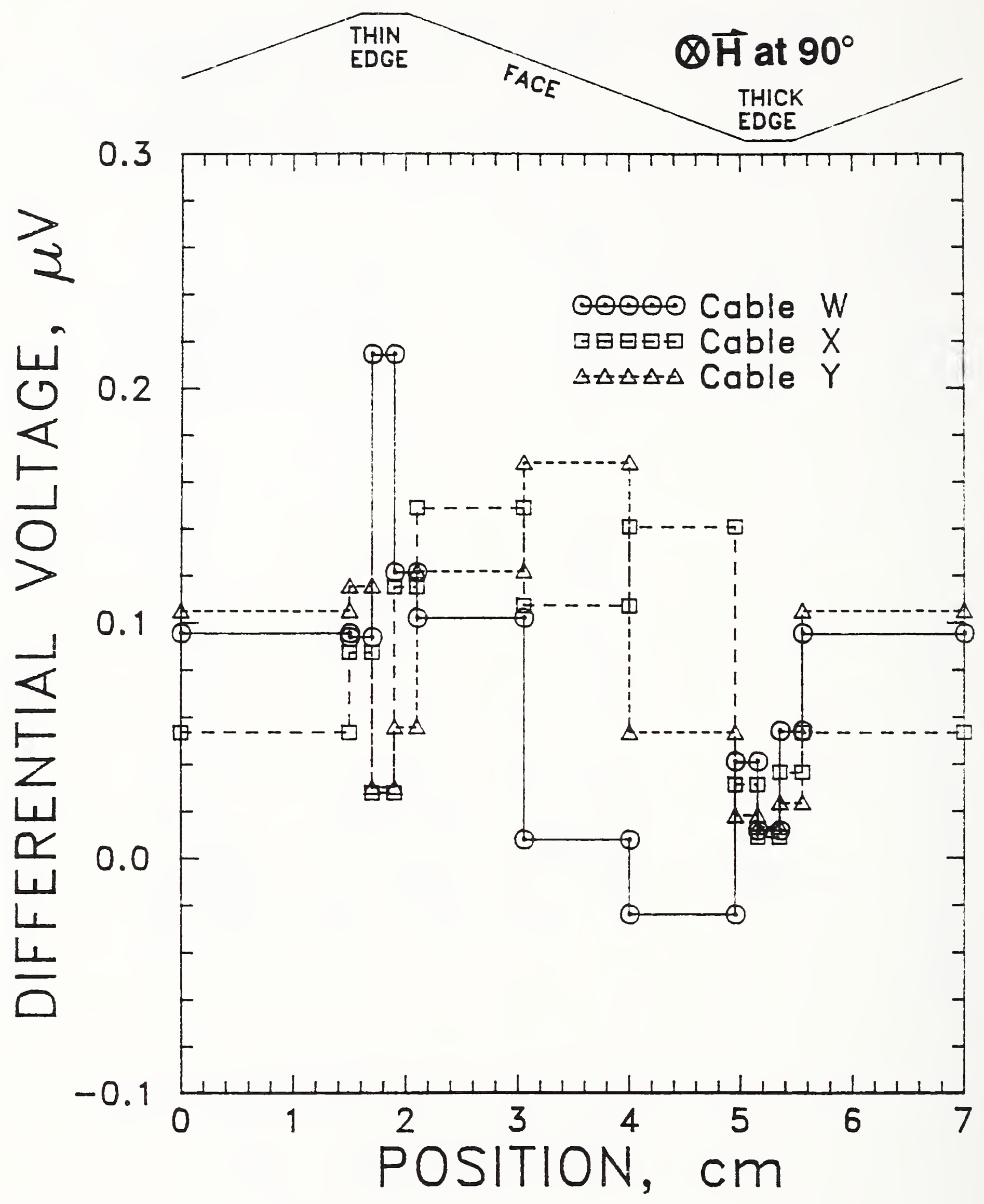

Figure 22. Differential-voltage profiles at $8 \mathrm{~T}$ and an applied magnetic field angle of $90^{\circ}$ for cables $W, X$, and $Y$ at currents of $143 \mathrm{~A}$, $128 \mathrm{~A}$, and $144 \mathrm{~A}$, respectively, which corresponds to an overall electric field of $0.1 \mu \mathrm{V} / \mathrm{cm}$. 


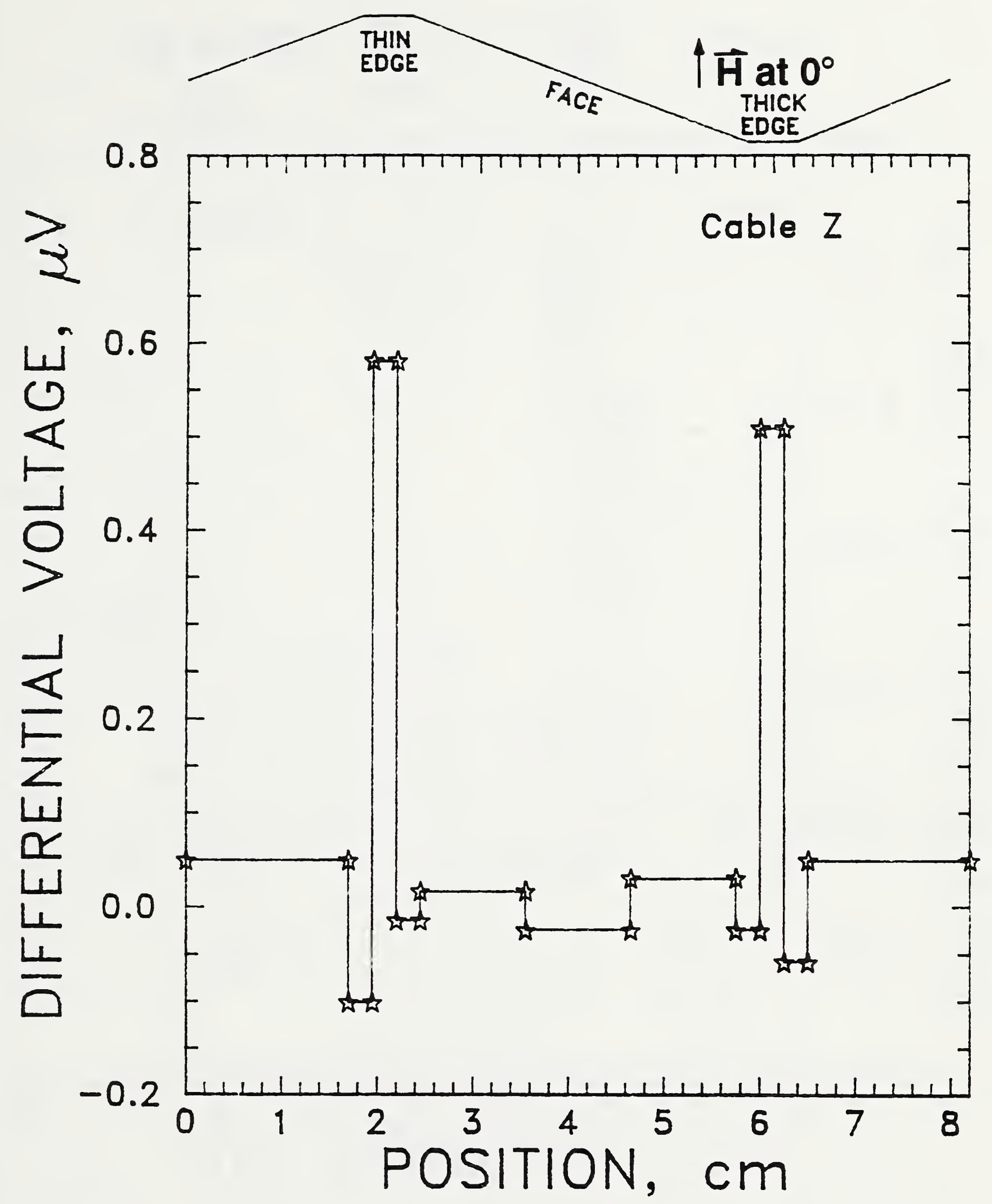

Figure 23. Differential-voltage profiles at $5 \mathrm{~T}$ and an applied magnetic field angle of $0^{\circ}$ for cable $Z$ at a current of $585 \mathrm{~A}$, which corresponds to an electric field of $0.1 \mu \mathrm{V} / \mathrm{cm}$. 


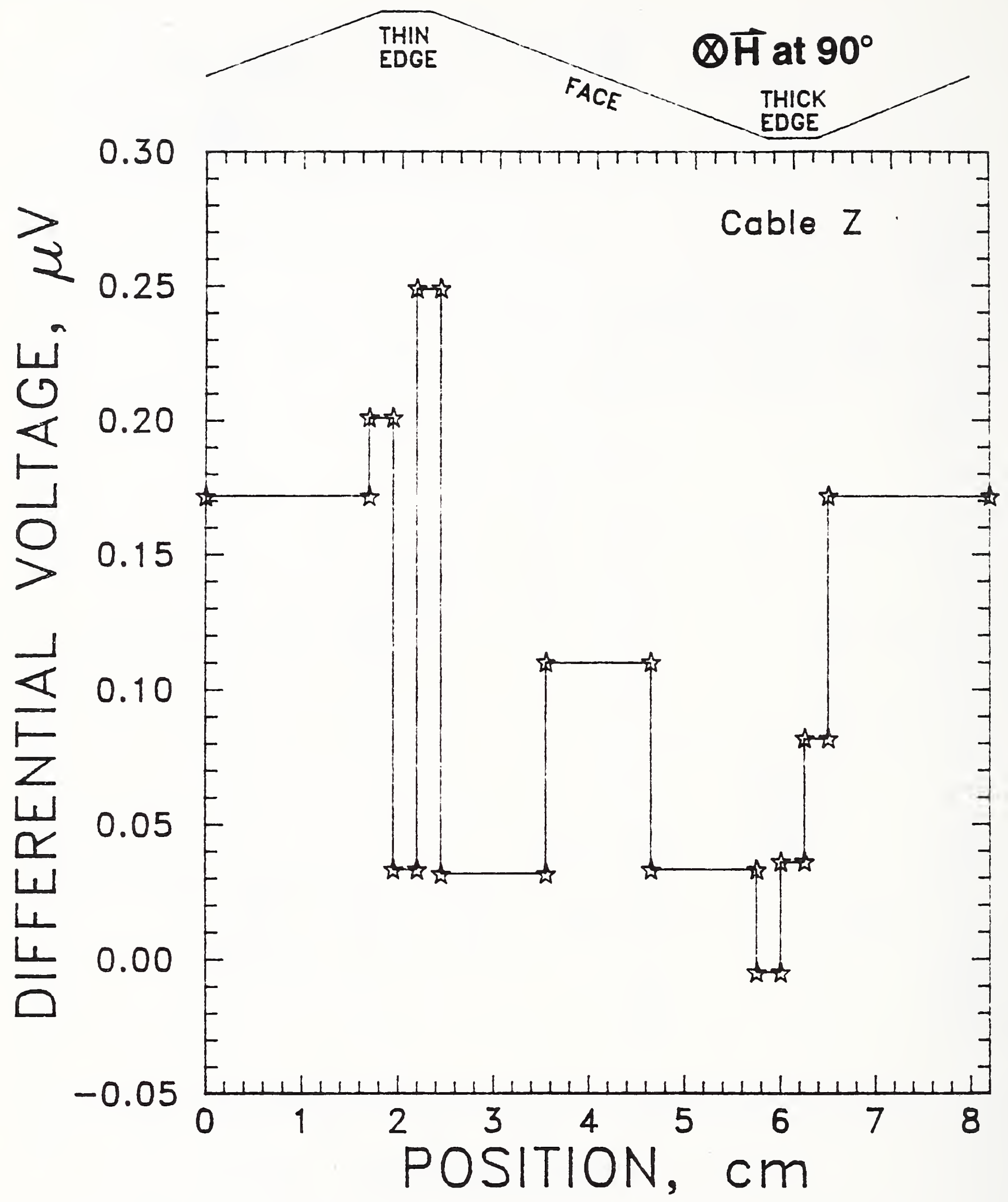

Figure 24. Differential-voltage profiles at $5 \mathrm{~T}$ and an applied magnetic field angle of $90^{\circ}$ for cable $Z$ at a current of $579 \mathrm{~A}$, which corresponds to an electric field of $0.1 \mu \mathrm{V} / \mathrm{cm}$. 


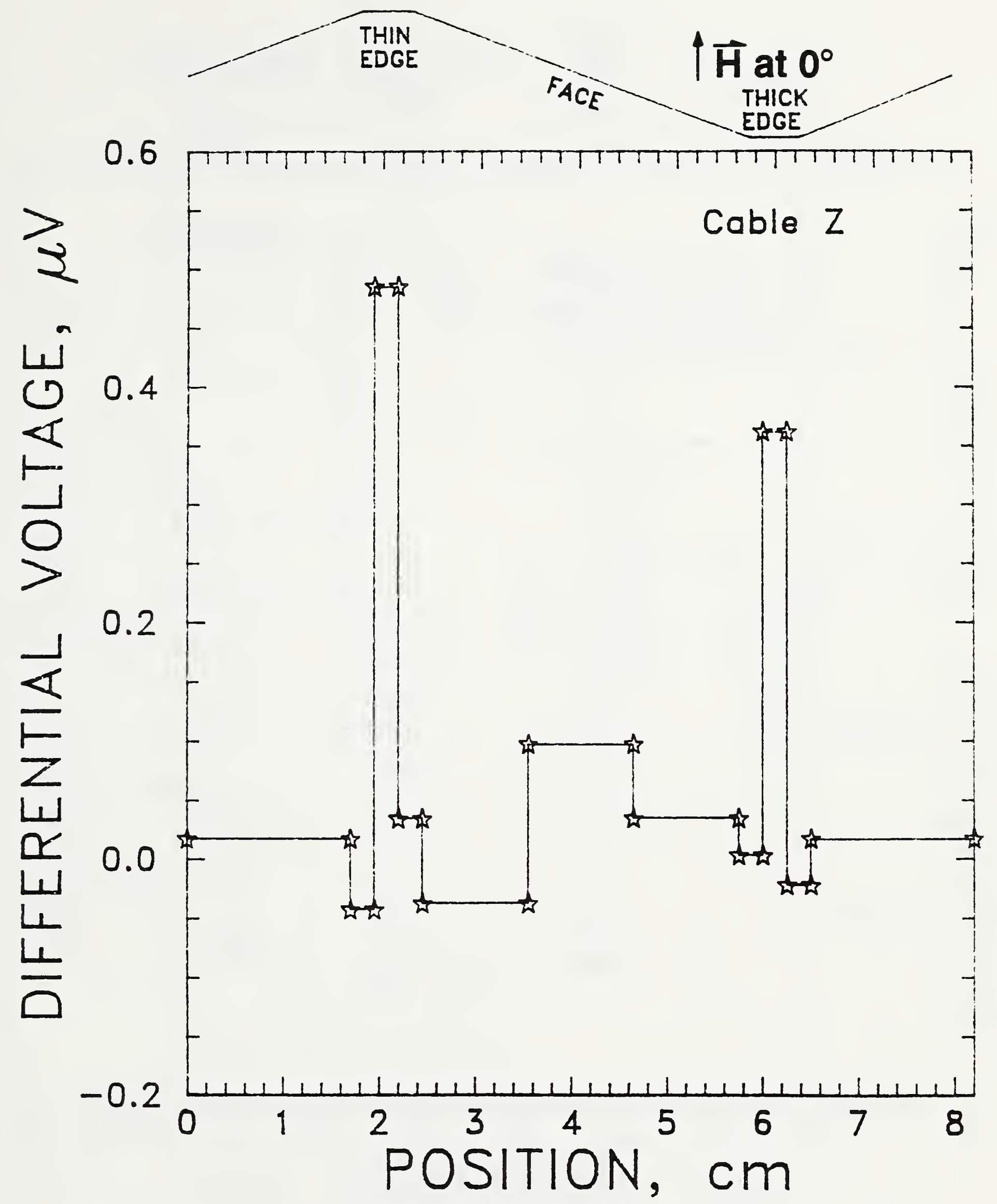

Figure 25. Differential-voltage profiles at $8 \mathrm{~T}$ and an applied magnetic field angle of $0^{\circ}$ for cable $Z$ at a current of $239 \mathrm{~A}$, which which corresponds to an electric field of $0.1 \mu \mathrm{V} / \mathrm{cm}$. 


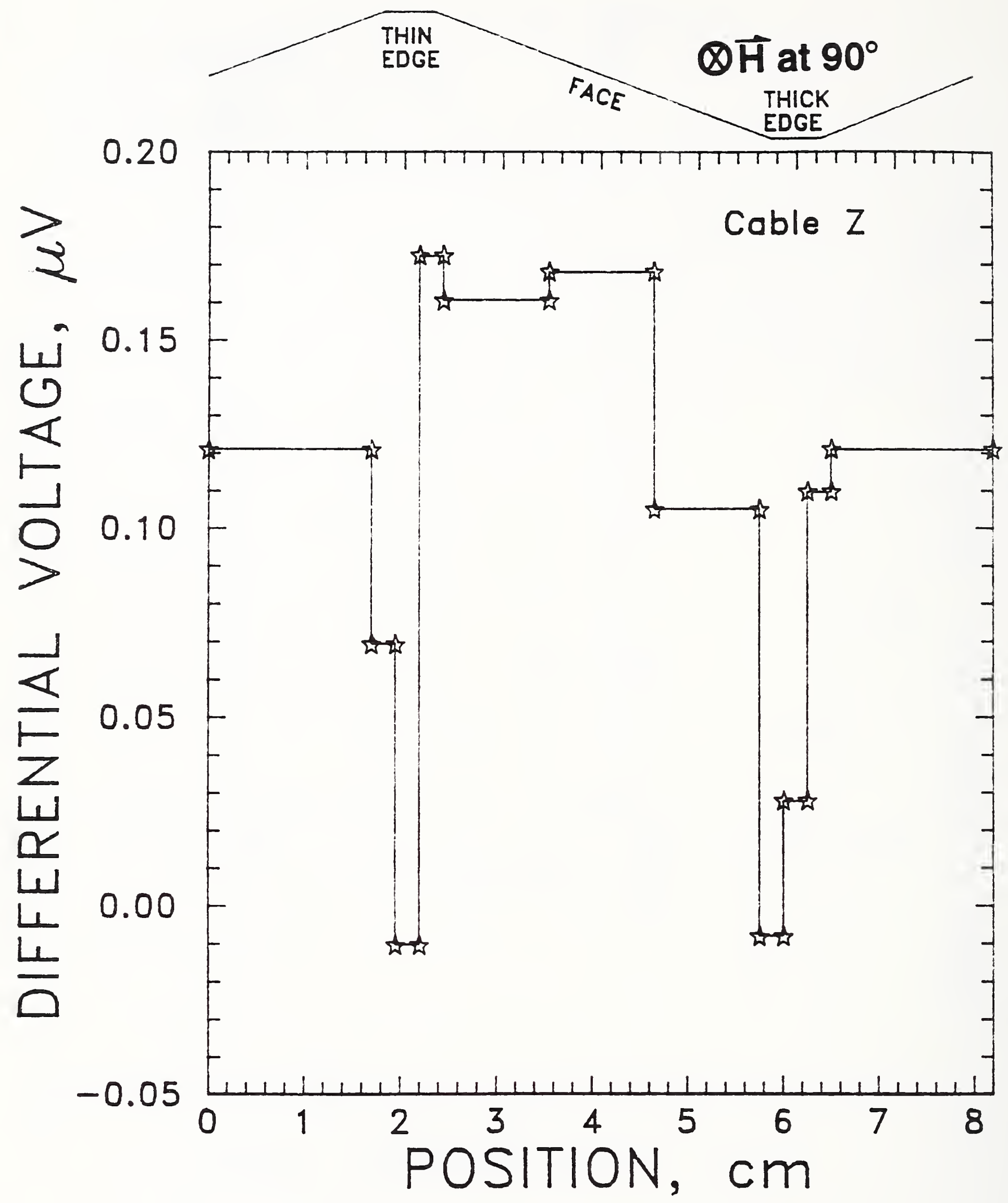

Figure 26. Differential-voltage profiles at $8 \mathrm{~T}$ and an applied magnetic field angle of $90^{\circ}$ for cable $Z$ at a current of $233 \mathrm{~A}$, which which corresponds to an electric field of $0.1 \mu \mathrm{V} / \mathrm{cm}$. 


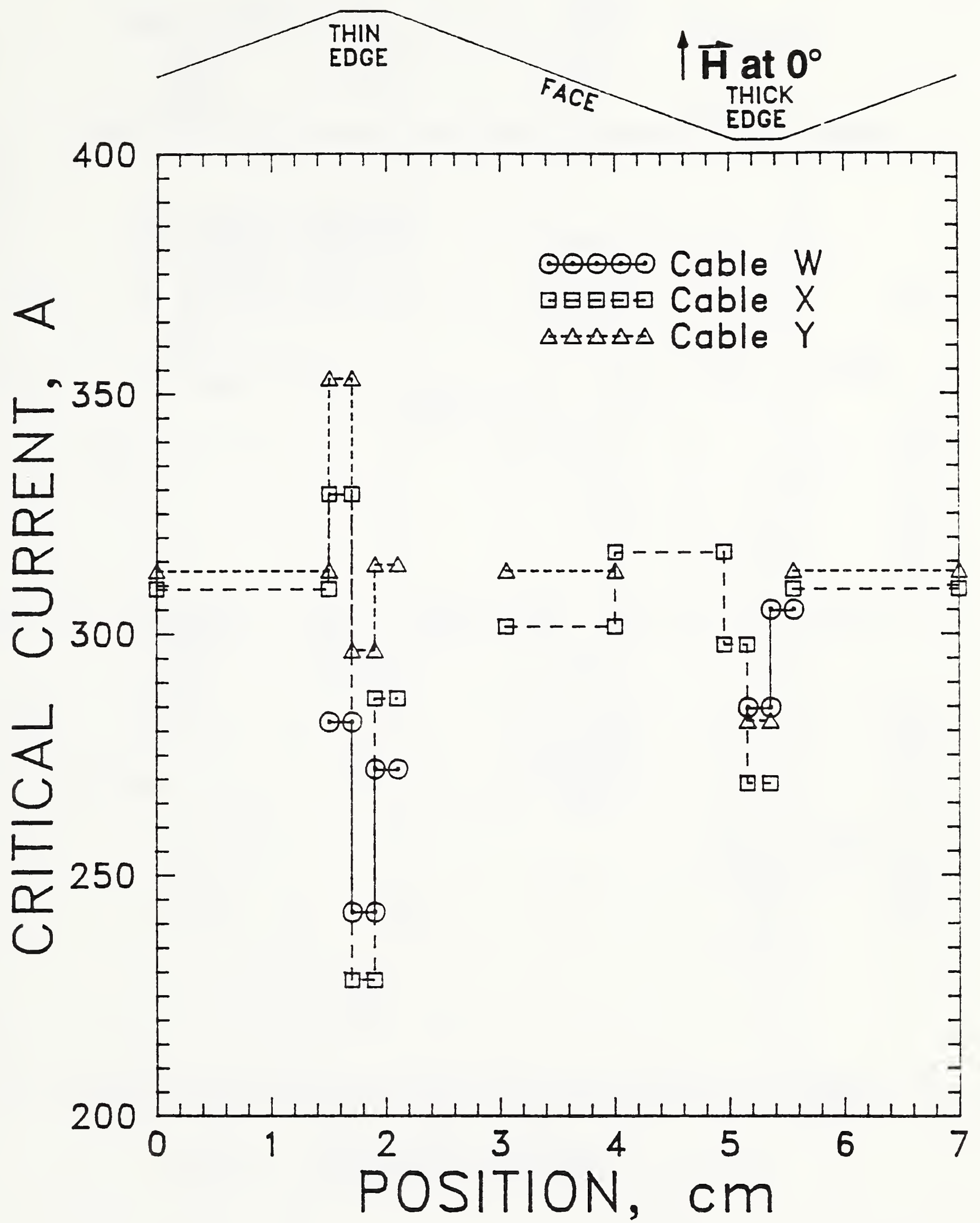

Figure 27. Critical-current profiles at $5 \mathrm{~T}$ and an applied magnetic field angle of $0^{\circ}$ for cables $W, X$, and $Y$ at an electric field of $0.05 \mu \mathrm{V} / \mathrm{cm}$. 


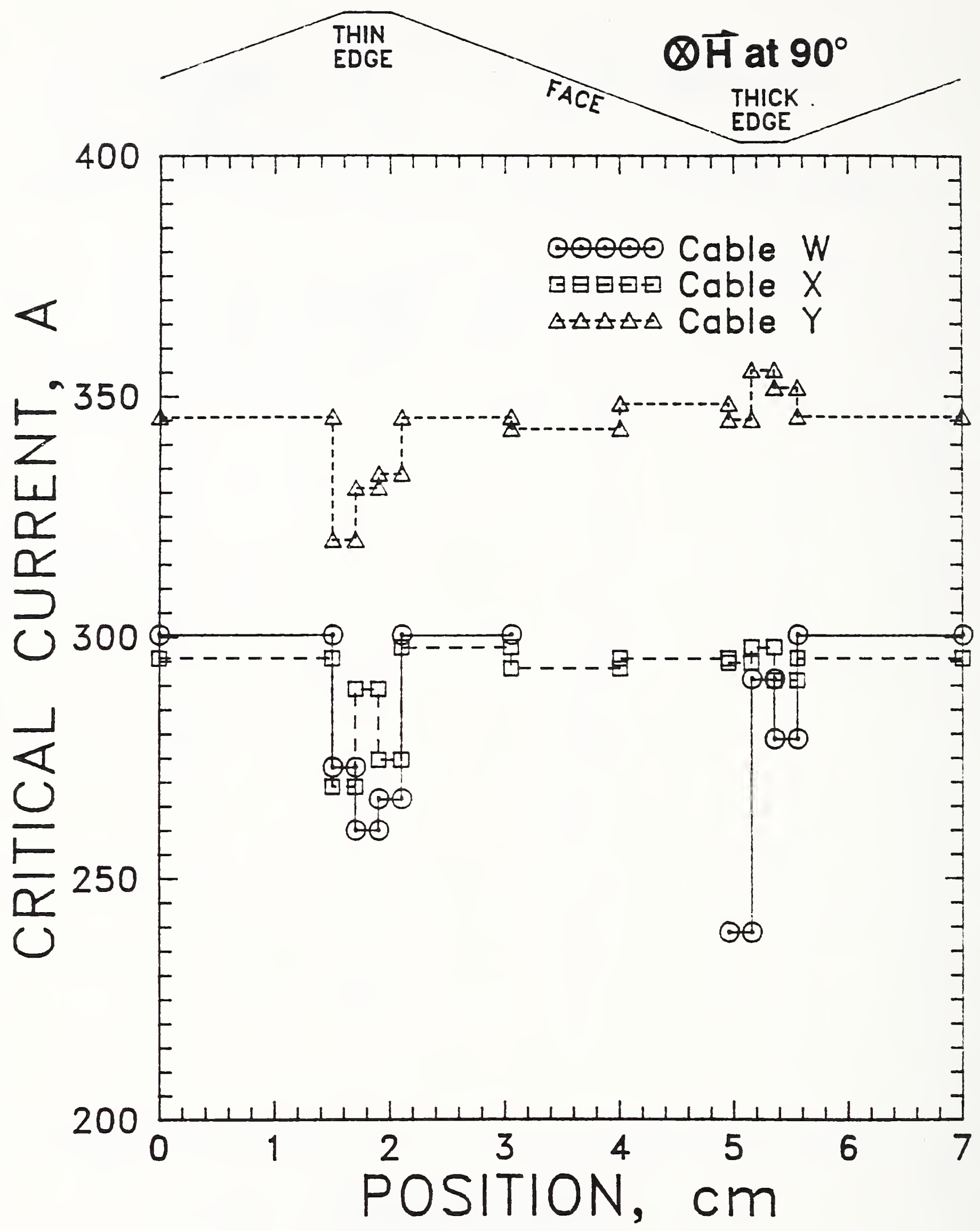

Figure 28. Critical-current profiles at $5 \mathrm{~T}$ and an applied magnetic field angle of $90^{\circ}$ for cables $W, X$, and $Y$ at an electric field of $0.05 \mu \mathrm{V} / \mathrm{cm}$. 


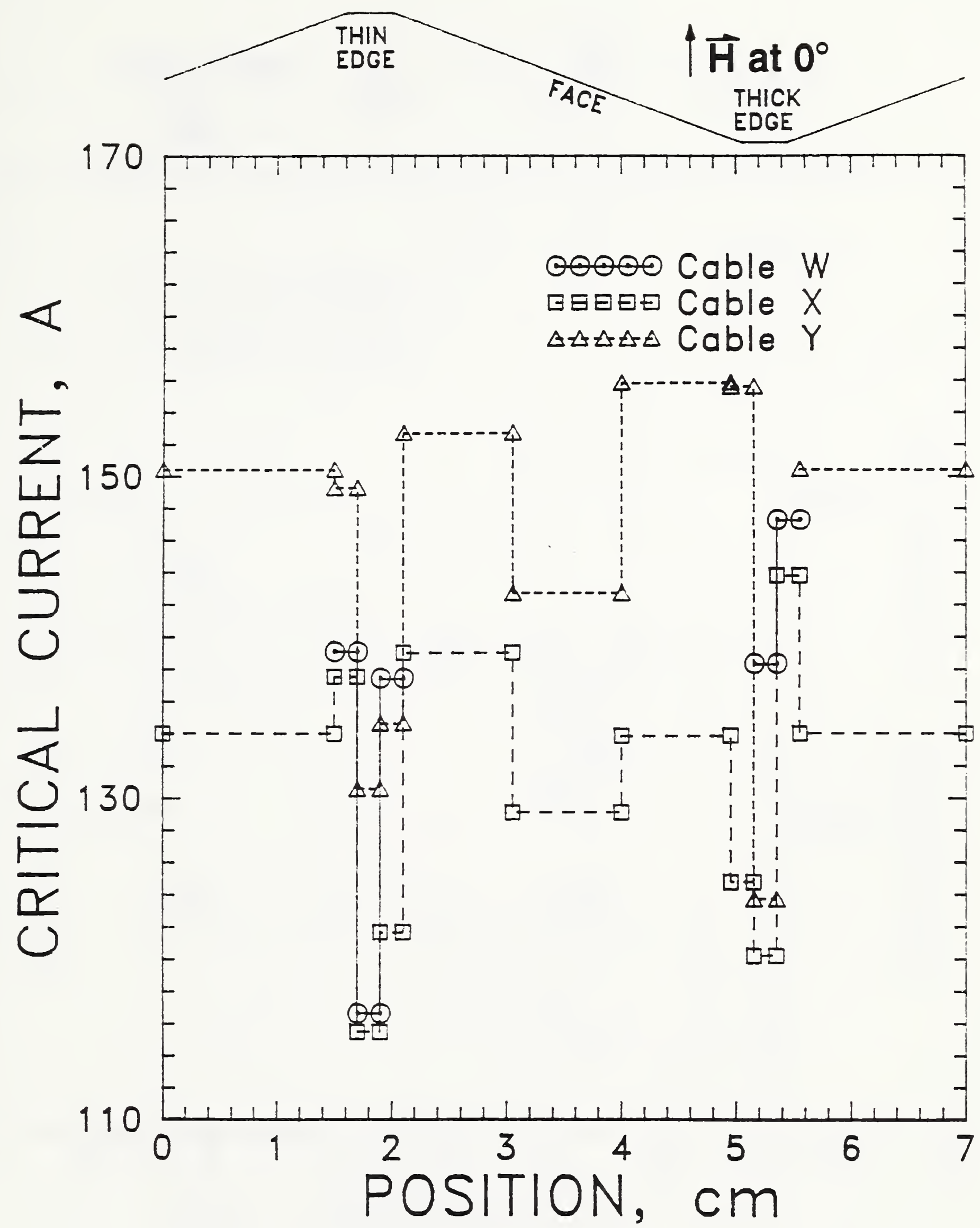

Figure 29. Critical-current profiles at $8 \mathrm{~T}$ and an applied magnetic field angle of $0^{\circ}$ for cables $\mathrm{W}, \mathrm{X}$, and $\mathrm{Y}$ at an electric field of $0.05 \mu \mathrm{V} / \mathrm{cm}$. 


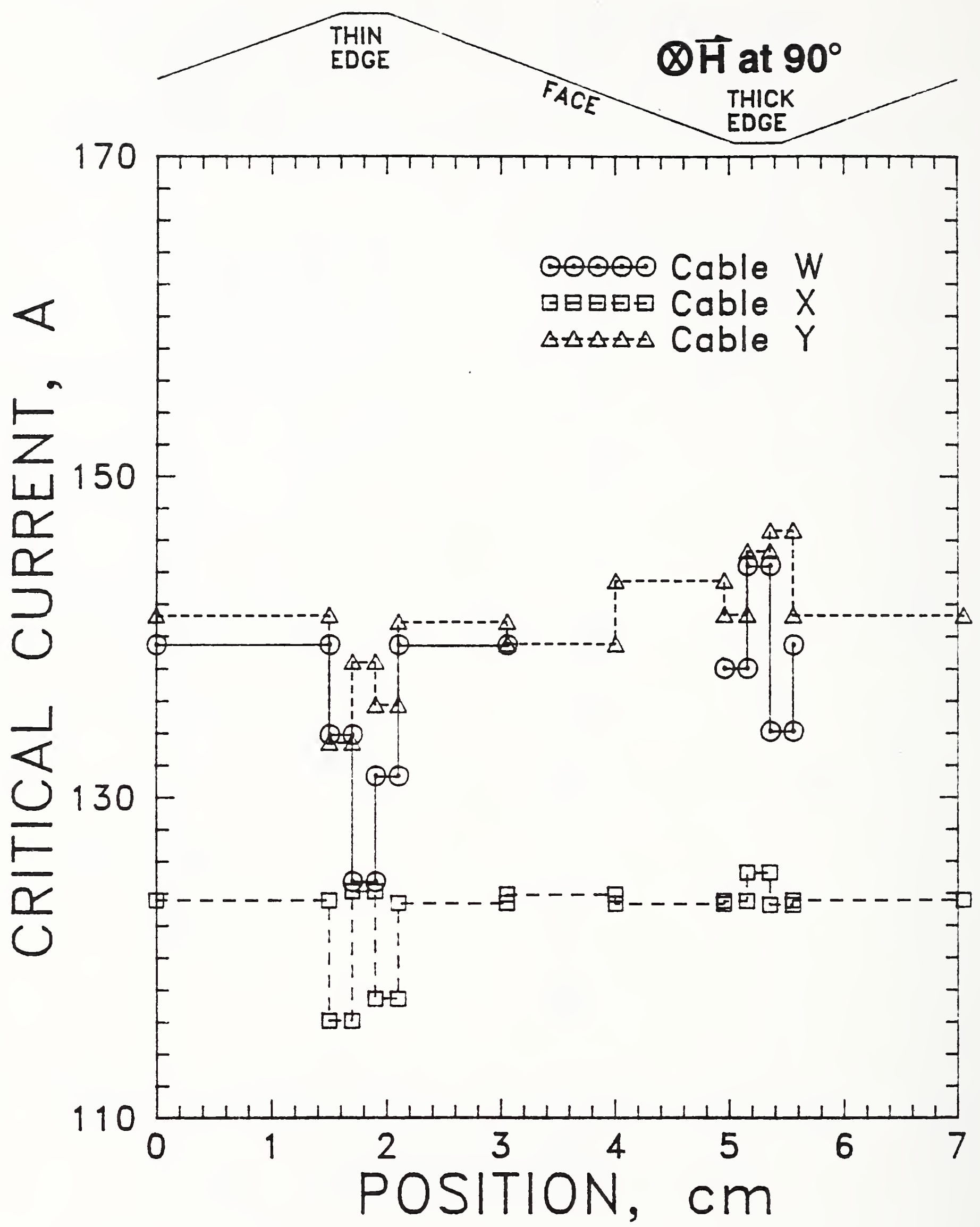

Figure 30. Critical-current profiles at $8 \mathrm{~T}$ and an applied magnetic field angle of $90^{\circ}$ for cables $W, X$, and $Y$ at an electric field of $0.05 \mu \mathrm{V} / \mathrm{cm}$. 


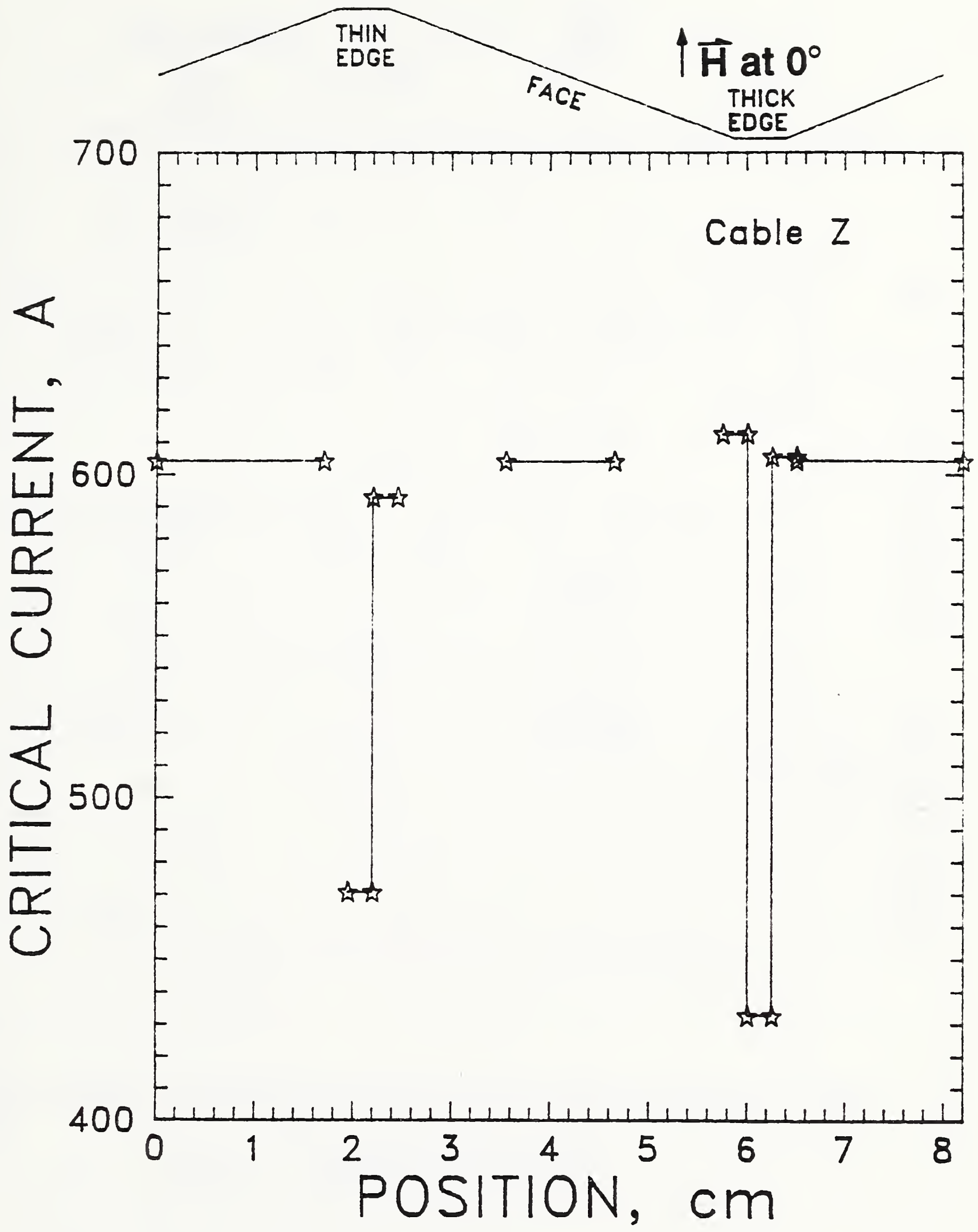

Figure 31. Critical-current profile at $5 \mathrm{~T}$ and an applied magnetic field angle of $0^{\circ}$ for cable $Z$ at an electric field of $0.05 \mu \mathrm{V} / \mathrm{cm}$. 


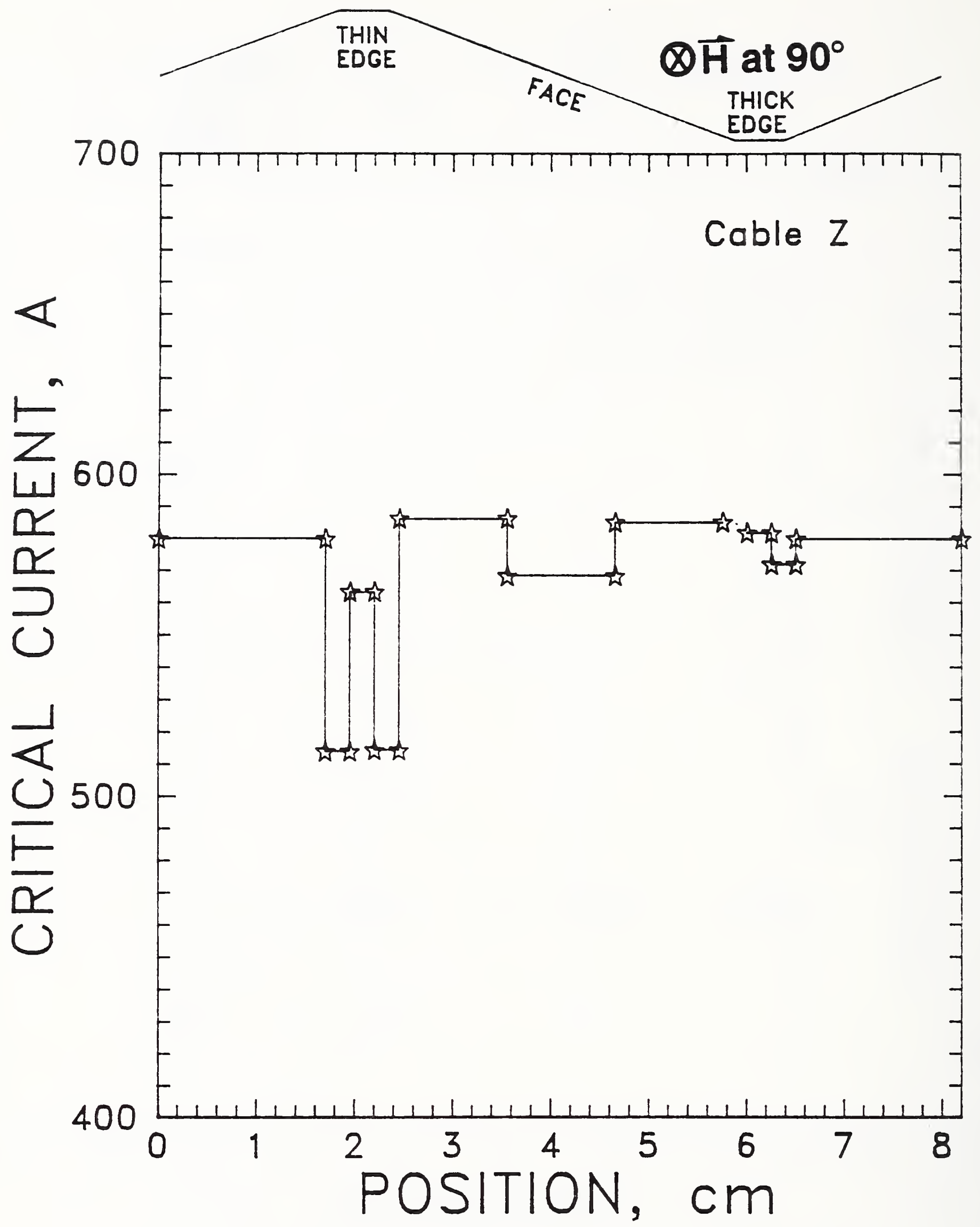

Figure 32. Critical-current profile at $5 \mathrm{~T}$ and an applied magnetic field angle of $90^{\circ}$ for cable $\mathrm{Z}$ at an electric field of $0.05 \mu \mathrm{V} / \mathrm{cm}$. 


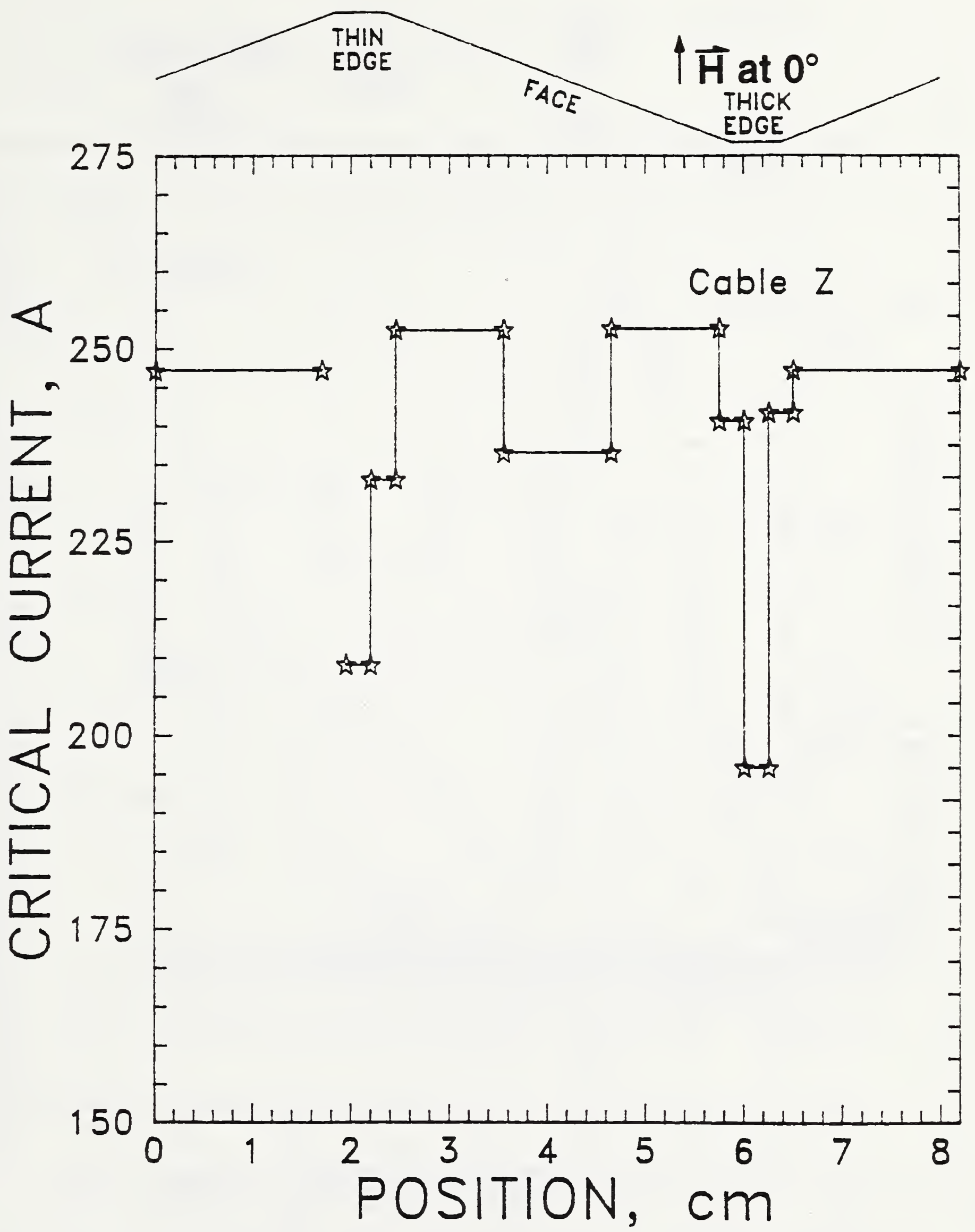

Figure 33. Critical-current profile at $8 \mathrm{~T}$ and an applied magnetic field angle of $0^{\circ}$ for cable $Z$ at an electric field of $0.05 \mu \mathrm{V} / \mathrm{cm}$. 


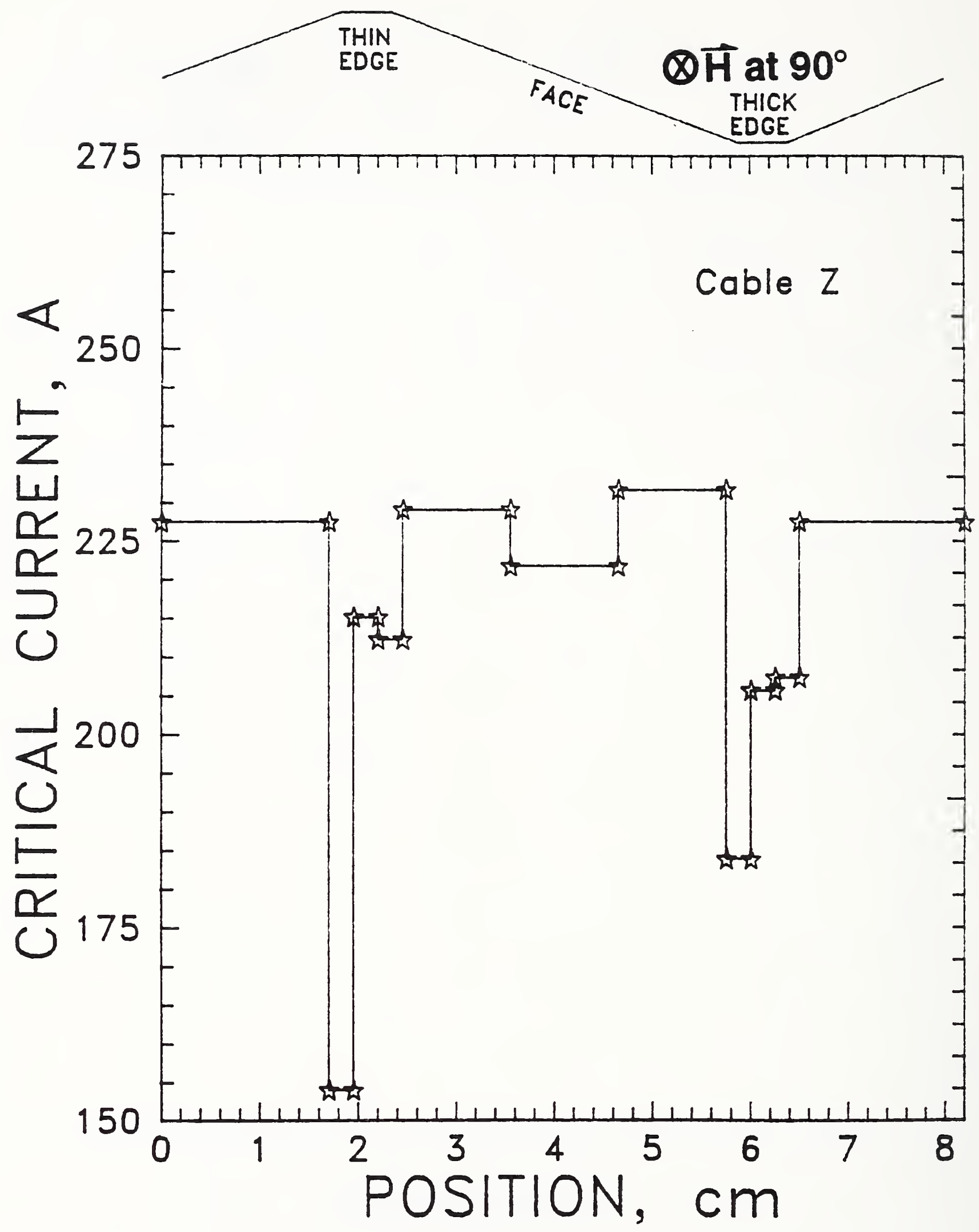

Figure 34. Critical-current profile at $8 \mathrm{~T}$ and an applied magnetic field angle of $90^{\circ}$ for cable $Z$ at an electric field of $0.05 \mu \mathrm{V} / \mathrm{cm}$. 


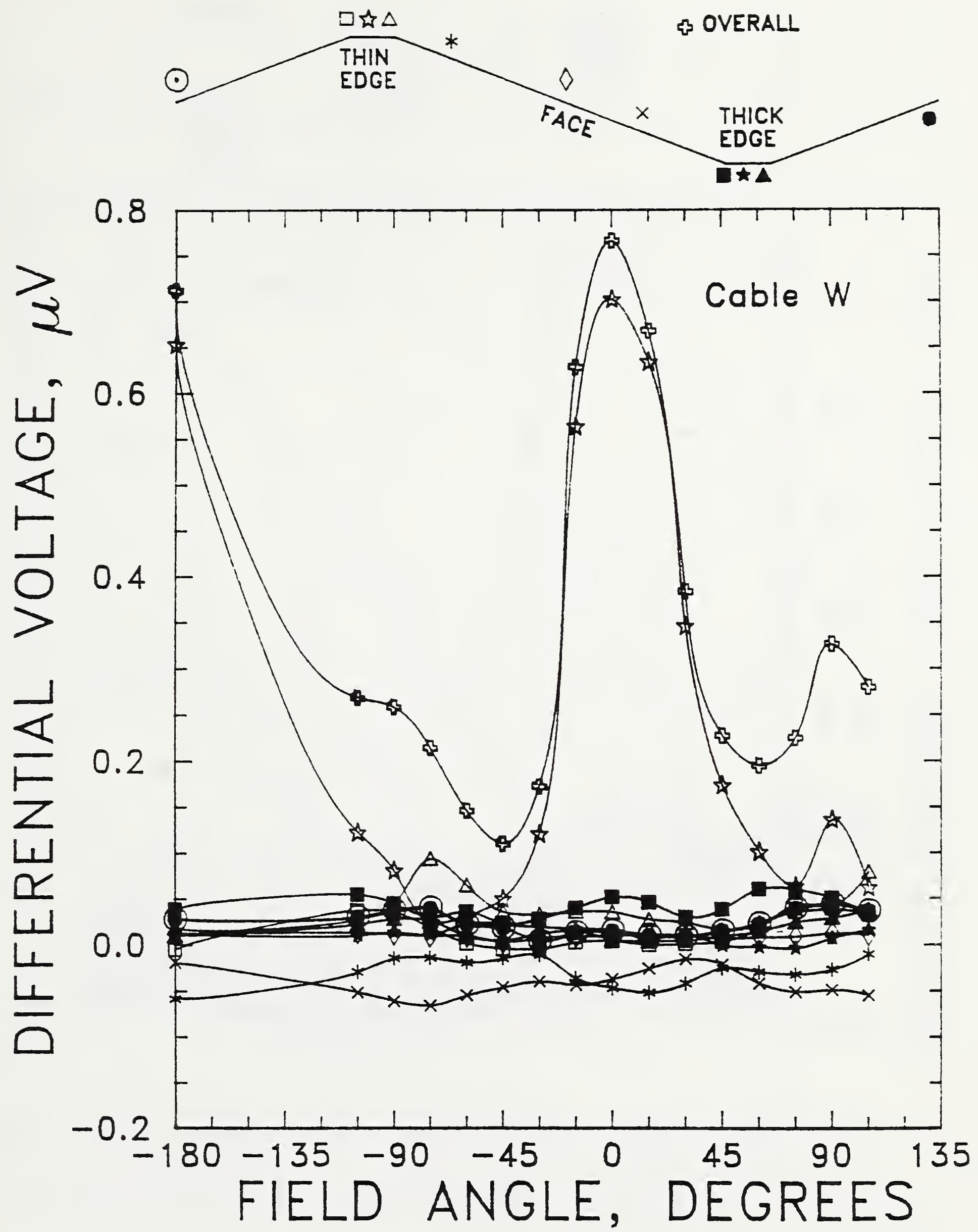

Figure 35. Differential-voltage plotted as a function of the applied field angle for all of cable $W^{\prime} s$ taps at $5 \mathrm{~T}$ and a current of $285 \mathrm{~A}$, which corresponds to an overall electric field of $0.1 \mu \mathrm{V} / \mathrm{cm}$ at $0^{\circ}$. 


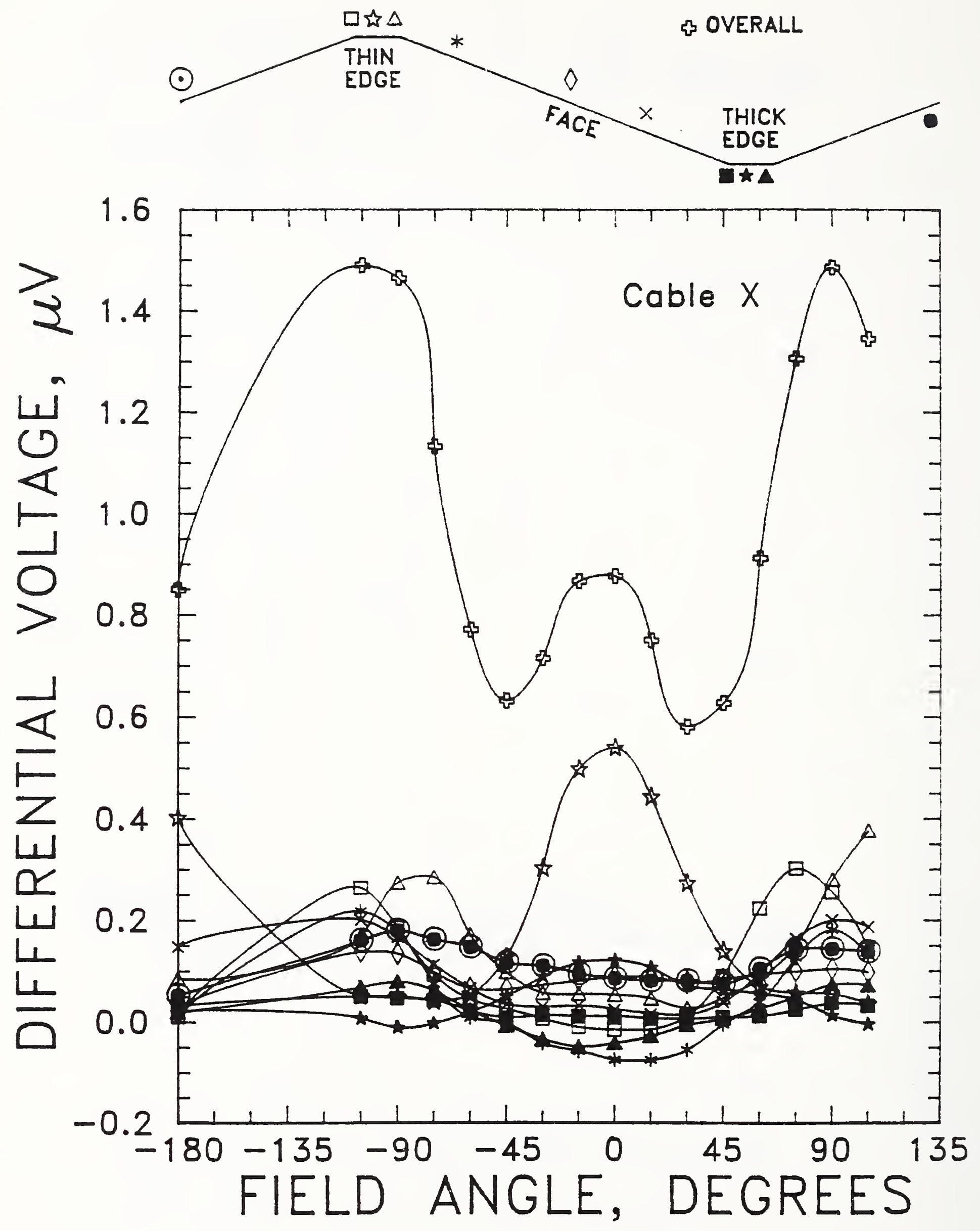

Figure 36. Differential-voltage plotted as a function of the applied field angle for all of cable $\mathrm{X}^{\prime} \mathrm{s}$ taps at $5 \mathrm{~T}$ and a current of $307 \mathrm{~A}$, which corresponds to an overall electric field of $0.1 \mu \mathrm{V} / \mathrm{cm}$ at $0^{\circ}$. 


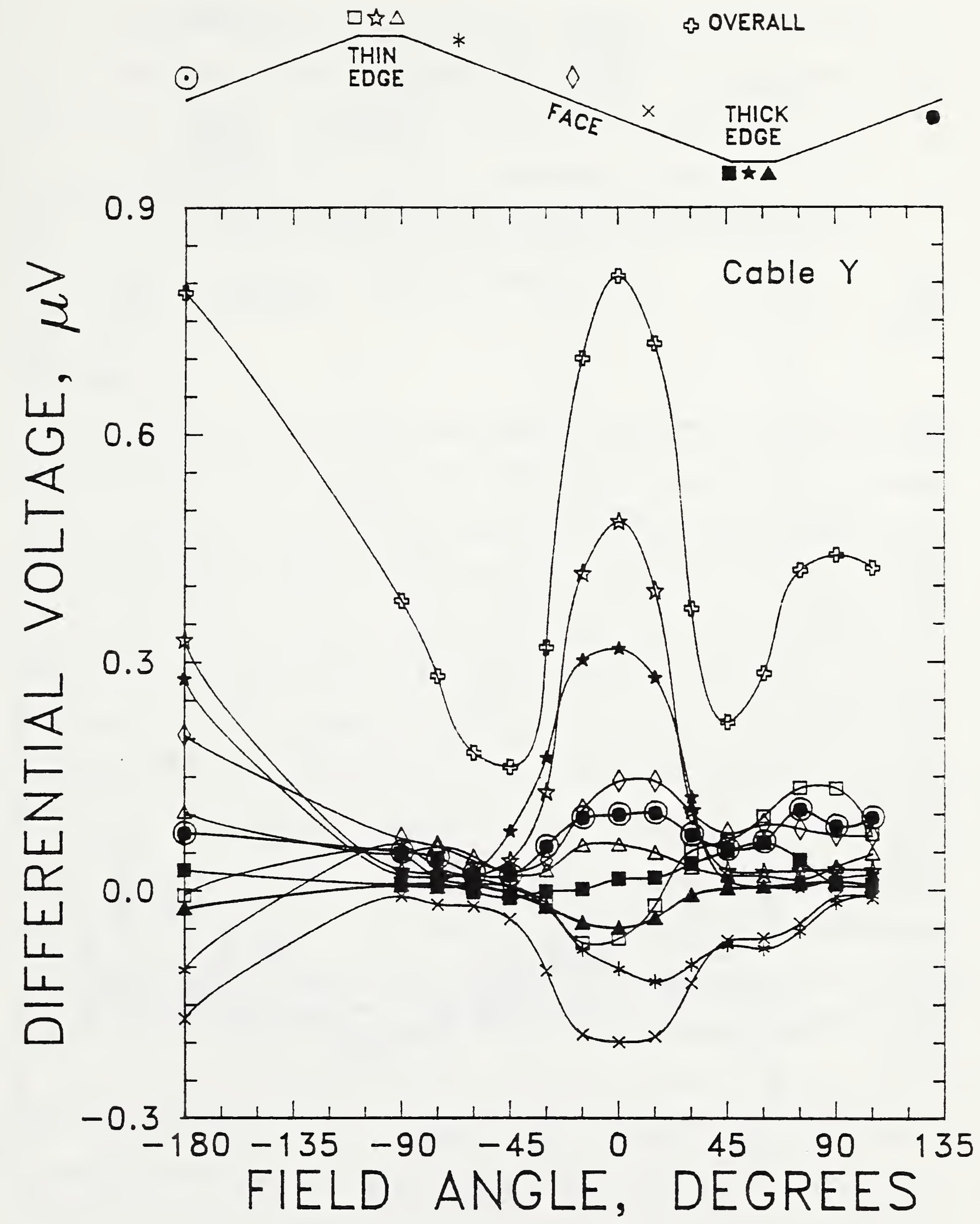

Figure 37. Differential-voltage plotted as a function of the applied field angle for all of cable $Y^{\prime} s$ taps at $5 \mathrm{~T}$ and a current of $339 \mathrm{~A}$, which corresponds to an overall electric field of $0.1 \mu \mathrm{V} / \mathrm{cm}$ at $0^{\circ}$. 


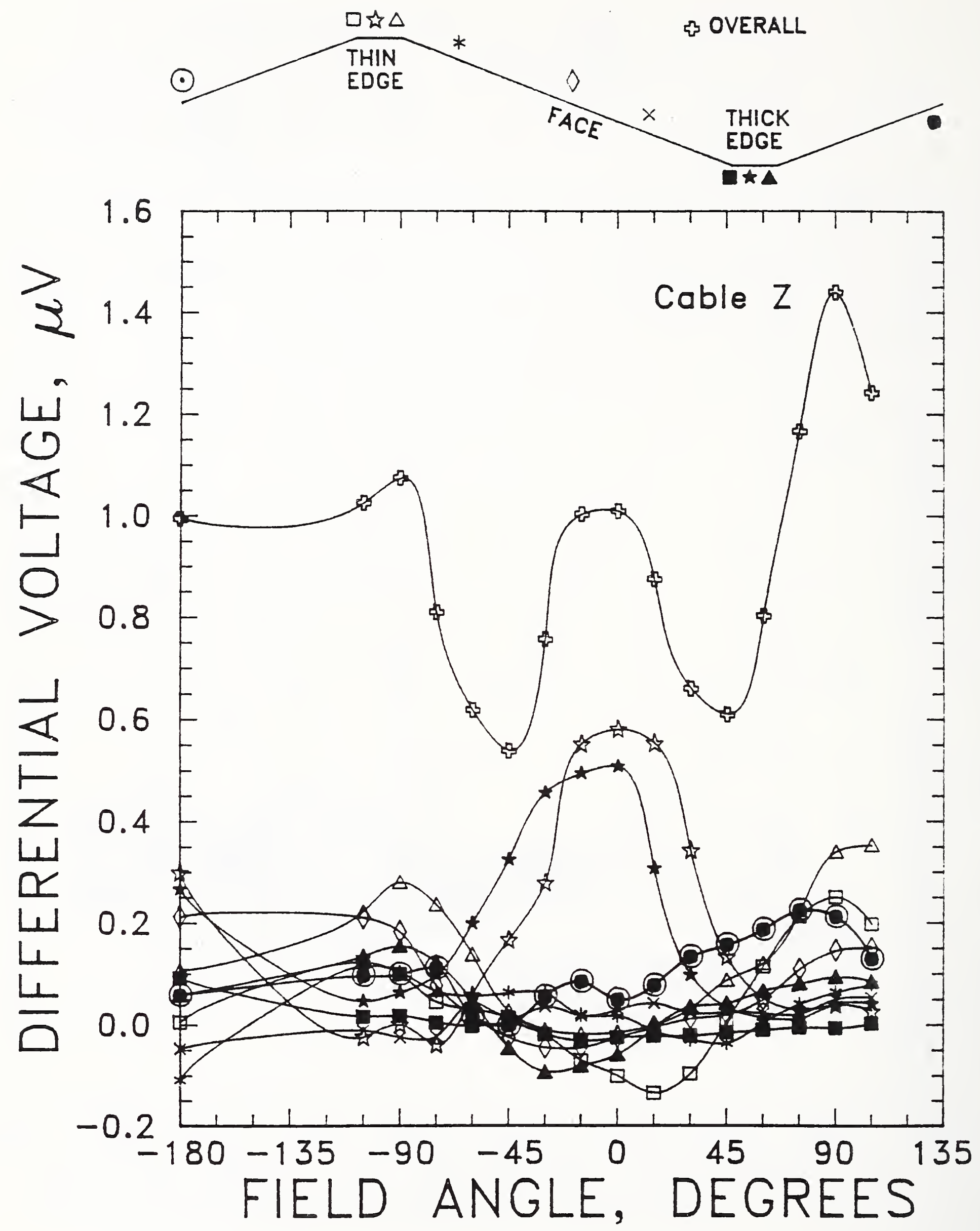

Figure 38. Differential-voltage plotted as a function of the applied field angle for all of cable $Z^{\prime}$ 's taps at $5 \mathrm{~T}$ and a current of $585 \mathrm{~A}$, which corresponds to an overall electric field of $0.1 \mu \mathrm{V} / \mathrm{cm}$ at $0^{\circ}$. 
THE EFFECT OF LOCAL AREA RATIO AND DIFFUSION-BARRIER MATERIAL

ON CRITICAL-CURRENT BEND DEGRADATION OF MULTIFILAMENTARY MBTi WIRES

J. W. Ekin, S. L. Bray, and N. F. Bergren

Electromagnetic Technology Division

National Institute of Standards and Technology

Boulder, Colorado 80303

\section{Abstract}

A systematic study of the effects of bending strain on the critical current of NbTi conductors has been performed. The critical-current $\left(I_{C}\right)$ degradation caused by bending decreases with increasing magnetic field, suggesting that the source of degradation is not an intrinsic degradation of $\mathrm{H}_{\mathrm{c} 2}$, as with the elastic axial-strain effect. The degradation of the $I_{c}$ from bending strain is much greater at low electric field criteria $E_{c}$ than at high (for example, $12 \%$ degradation at $E_{c}=1 \mu \mathrm{V} / \mathrm{cm}$ versus over 22 at $E_{c}=0.1 \mu \mathrm{V} / \mathrm{cm}$ for a conductor-core-to-bend-diameter ratio of 0.43 ). The effect of bending on the critical current may be characterized simply by a decrease in the value of $n$ toward the same low value for all conductors, typically 10 to 15 . Here $\mathrm{n}$ represents the sharpness of the electric field-vs.-current relationship for the $\mathrm{NbTi}$ wire $\left(\mathrm{E} \alpha \mathrm{I}^{\mathrm{n}}\right)$. The degradation of $\mathrm{n}$ suggests that irregularity of the filament's cross-sectional area, introduced by bending, may be the source of the $I_{c}$ degradation. By testing a controlled series of similarly fabricated NbTi wires in which the local copper-to-superconductor area ratio (LAR) was systematically varied, we found that as the LAR increased from 0.4 to 0.7 , the $I_{c}$ bend degradation decreased by about $1 / 7$. The increasing susceptibility of a superconductor to bend degradation with decreasing LAR thus places a 
mechanical limit on the reduction of the LAR for controlling filamentsausaging effects. In another controlled series of $\mathrm{NbTi}$ wires in which the diffusion barrier material that surrounds each NbTi filament was systematically changed, the $I_{c}$ bend degradation was less by about $1 / 4$ to $1 / 5$ for diffusion barriers made of vanadium, than for diffusion barriers made of niobium or niobium with a copper-nickel matrix.

\section{Introduction}

In the manufacture of superconducting cables for many magnet applications, compaction of the cable is necessary to achieve high filling factors and, consequently, high overall critical-current densities. However, compaction can also introduce strain concentrations in the cable strands; these may act as weak links in limiting the cable's critical current ( $\left.I_{C}\right)$. In both rope cables and braided cables these strain concentrations occur periodically at the points where the cable strands cross one another. In flattened hollow cables (sometimes referred to as Rutherford cables) the strain is concentrated at the cable edges where each strand is subjected to severe bend strain $\left(\epsilon_{\mathrm{b}}\right)$ and flattening.

Rutherford cables were developed for use in high-energy physics applications, the Fermilab Tevatron accelerator and the Superconducting Super Collider (SSC), for example. The Rutherford design allows for higher compaction then rope or braided cables with minimal strain concentration and strand deformation. Rutherford cables are typically rectangular in cross section, or trapezoidal in the case of a keystone cable, and each strand follows a path of full transposition about the cable's cross section. In 
traversing from one cable face to the other, the strands must periodically bend around the cable edges. The severity of the bend depends primarily on the strand diameter, the cross-sectional dimensions of the cable, and its pitch length. This paper presents measurements on a controlled series of NbTi conductors to determine strand-design parameters that could be changed to minimize the effect of bending on the critical current.

Localized $I_{c}$ measurements of NbTi strands that were extracted from prototype SSC cables indicate that significant $I_{C}$ degradation can occur at the edges of a Rutherford cable (See Ref 1-4). Microscopy studies of these specimens have shown that the severity of filament damage and the resulting $I_{C}$ degradation varies among strands that are extracted from different cables. In an extreme case, the damage is characterized by serrated yielding and breakage of the NbTi filaments, which is accompanied by a reduction of more than 30 in the measured $I_{C}$. This level of degradation is not typical of most cables, nor is it typical of the specimens that were studied here. A reduction of less than 208 in the $I_{C}$ and virtually no visible filament damage is typical for these specimens. The results presented here are a systematic study of the effect of severe bending on the $I_{c}$ of $\mathrm{NbTi}$ wires that are candidate strands for SSC cables. The filament damage for the specimens tested in this study is similar to what is commonly found in cable strands.

The measurements were conducted in two stages. First, the effect of bending on $I_{C}$ was measured in a number of different deformation geometries in order to determine a standard test method that would yield a significant and reproducible test of the $\epsilon_{\mathrm{b}}$ effect. Once this test method was determined, it 
was then used to evaluate a number of different conductors to obtain a relative measure of the effect of local area ratio diffusion-barrier material on critical-current bend degradation.

Rather than attempt to reproduce or even mimic the complex strand deformation found in Rutherford cables, a much simpler bend geometry was selected for the standard test method. There are several reasons for this approach. To begin, the cost and time required to manufacture Rutherford cables from the broad range of strand materials that were tested would be prohibitive. Furthermore, this approach would also introduce a great number of variables that would diminish the level of experimental control. Finally, the results of measurements using the simple bend geometry are more general and, therefore, they begin to address the issue of understanding the basic mechanism underlying bend degradation of $I_{c}$ in $\mathrm{NbTi}$ superconductors.

\section{Experimental Details}

The detailed specifications of the superconducting samples are given in Table I. The conductors are similar in the sense that they are all prototype materials for SSC cables. These are round NbTi wires with a $0.648 \mathrm{~mm}$ diameter. The samples have different local copper-to-superconductor area ratios (LAR, the local area ratio of the cross-sectional area of the filament to that of the copper surrounding each filament going into the billet), different diffusion barrier materials locally surrounding each filament, and, in some cases, different filament configurations. 
For this study, the background magnetic field is provided by a $9 \mathrm{~T}, 3.8$ $\mathrm{cm}$ bore superconducting solenoid. A voltage-controlled $1000 \mathrm{~A}$ battery-powered constant-current supply is used as the sample-current source.

The basic testing geometry is that of a coil, shown in Fig. 1, where the diameter of the coil determines the severity of the bending strain, $\epsilon_{b}$. The tested bend diameters range from a maximum of $31.7 \mathrm{~mm}$ (minimum $\epsilon_{\mathrm{b}}$ ) to a minimum of $0.38 \mathrm{~mm}$ (maximum $\epsilon_{\mathrm{b}}$ ). The $I_{c}$ degradation for the $31.7 \mathrm{~mm}$ coil measurements is negligible, as substantiated by measuring the $I_{c}$ of a straight sample. Consequently, the $31.7 \mathrm{~mm}$ coil measurements serve as a baseline for determining the bend degradation of the small diameter coil samples. The sample coils are wound on cylindrical measurement mandrels that are made from either nonmagnetic stainless steel (\#316) or, in the cases of the $31.7 \mathrm{~mm}$ and the $3.18 \mathrm{~mm}$ mandrels, fiberglass-epoxy composite (G-10) tubes. A $1.28 \mathrm{~mm}$ stainless-steel mandrel (approximately twice the wire diameter) is the standard selected for the second stage of testing where various samples were tested at a common level of $\epsilon_{\mathrm{b}}$ to determine whether there were conductor parameters that could be changed to maximize the bending strain tolerance. This standard bend diameter yields significant and repeatable degradations in the $I_{c}$ of a given wire sample.

A significantly different coil geometry was also tried in an attempt to simulate the current-transfer effects that might occur in actual cable strands. In these tests the sample coil was wound around a thin rectangular plate with rounded edges. This resulted in a series of hairpin bends at the edges of the plate, separated by straight nondeformed sections of the wire 
across the faces of the plate to simulate the deformation found in actual Rutherford cable strands. This plate geometry was abandoned in favor of the cylindrical geometry because it was difficult to control and it yielded inconsistent bending at the plate edges.

To address the effect of the magnetic field generated by the sample coil on the measured $I_{c}$, the $I_{c}$ measurements were made with two different orientations between the background field and the solenoidal sample field, parallel and antiparallel. The reported $I_{c}$ is the average of these two $I_{c}$ measurements. The difference between the two measurements was, in all cases, less than $10 \%$ of their average value. The sample coils were bonded to the mandrels with a light coating of varnish. The varnish coating is necessary for containing the outward Lorentz force acting on the sample in the parallel magnetic-field case.

With the exception of the $31.7 \mathrm{~mm}$ diameter mandrels, the sample mandrels are held in the test fixture by the current contacts; see Fig. 1. Round copper rod of $12.7 \mathrm{~mm}$ diameter is used for the current contacts. The ends of the contacts that hold the mandrel in place are tapered to allow a gradual transition from the smaller diameter of the sample mandrel to the larger diameter of the current contact.

A pair of voltage-tap leads are soldered to the sample with a separation of about 12 coil-turns. One of the voltage leads is counter-wound around the sample coil to minimize induced voltage noise from variations in the magnetic field. To measure the length of the sample that is spanned by the voltage 
taps, first a known length of the sample wire is weighed using an analytic balance and then the actual sample coil is cut at its voltage taps and the resulting coil segment is weighed. The length of the instrumented portion of the sample coil is calculated from these weight values.

An automated, computer controlled, data acquisition and analysis system that was developed at NIST was used in this study. This system measures the voltage-current ( $\mathrm{V}-\mathrm{I}$ ) relationship at discrete points along the $\mathrm{V}$-I curve by holding the current constant, at preselected levels, and monitoring the resulting voltage. This technique allows averaging of the voltage data at each current level and, therefore, reduces the uncertainty associated with the voltage signal noise. Furthermore, the system uses an optimization process that automatically adjusts the locations of the discrete data points along the nonlinear V-I curve using voltage feedback. This process was designed to enhance the precision and accuracy of the $I_{c}$ measurement while minimizing the data-acquisition time. The overall accuracy of the $I_{c}$ measurement is within $\pm 3 z$, the precision within \pm 0.58 .

\section{$\underline{\text { Results }}$}

The effect of severe bending on the electrical characteristics of NbTi wires is shown in Figures 2 and 3 where the logarithm of the current (IOG I) is plotted against the logarithm of the electric field (LOG E) for several different bend diameters. The data presented in Fig. 2 is for sample $A$ of Table 1 and the data in Fig. 3 is for sample B. 
In Fig. 2 each curve is labeled with the sample coil's mandrel bend diameter with the exception of the curve that is labeled "STRAIGHT." A straight specimen of sample A was measured to determine what degradation, if any, is present in the $31.7 \mathrm{~mm}$ coil samples that serve as a baseline for comparison of the small-diameter-coil measurements. The close agreement between the "straight" curve and the "31.7 mm" curve, in their overlap region, indicates that the $31.7 \mathrm{~mm}$ coil data adequately represent the nondegraded state of the conductor.

Several effects of bending are evident in both of these plots. First, bend degradation is much more severe at low electric-field criteria ( $E_{c}$ ) than at high $E_{c}$. In other words, the slope of the $\log E-\log I$ curves vary with $\epsilon_{b}$. For these logarithmic plots, the slope of the E-I curve is equal to the characteristic value $\mathrm{n}$, where $\mathrm{n}$ is given by the approximate relationship between the electric field and the current $E \propto I^{n}$. Thus, the effect of bending is characterized by a decrease in the value of $n$.

Figures 2 and 3 show that the overall magnitude of the bend effect is nontrivial; it amounts, for example, to over 298 at $E_{c}=1 \mu \mathrm{V} / \mathrm{cm}$ for Sample $\mathrm{A}$ at the most severe $\epsilon_{\mathrm{b}}$ (bend diameter $=0.38 \mathrm{~mm}$ ) and increasing to 358 at $\mathrm{E}_{\mathrm{c}}=$ $0.1 \mu \mathrm{V} / \mathrm{cm}$.

In Figures 4 and 5, the normalized critical currents of various specimens of samples $A$ and $B$ are plotted against the reciprocal of the normalized bend diameters of the specimens. The data shown in Fig. 4 were taken at $5 \mathrm{~T}$ while the data in Fig. 5 were taken at $7 \mathrm{~T}$. The critical currents are normalized 
with respect to the $I_{c}$ of a $31.7 \mathrm{~mm}$ coil specimen of each of the sample wires, $A$ and $B$. The samples have a core region formed by the NbTi filaments. The bend diameter of each specimen is normalized with respect to the diameter of this NbTi core region. This method of bend-diameter normalization is motivated by the fact that the level of axial strain applied to the NbTi filaments, as a result of bending the conductor, depends on the distance between the filaments and the wire's center, or its neutral axis. Consequently, the reciprocal of the normalized bend diameter is a measure of the maximum axial strain in the outermost NbTi filaments of a specimen. Both of these plots show a substantial degradation in the measured $I_{C}$ with decreasing bend diameter. The degradation for sample A is significantly greater than for sample $\mathrm{B}$ at both $5 \mathrm{~T}$ and $7 \mathrm{~T}$, and the degradation for both samples decreases as the magnetic field is increased.

In Fig. $6, \mathrm{n}$ is plotted as a function of the normalized reciprocal of the bend diameter for Samples $A$ and $B$ at three magnetic fields. At the largest bend diameters, $\mathrm{n}$ is considerably higher for sample $\mathrm{A}$; however, at the smallest bend diameters, $\mathrm{n}$ is reduced to a comparable level for both samples. The conspicuous feature of this plot is that both samples show a degradation in $\mathrm{n}$ that seems to approach a comparable limiting value. The degradation of $\mathrm{n}$ suggests that irregularity in the filament cross-sectional area introduced by bending may be the source of the $I_{c}$ degradation. 7

As part of the second stage of testing, the results of a systematic comparison of three samples (C, D, and E) are presented in Fig. 7. As indicated by the specifications of Table 1 , these three conductors are 
comparable to one another with one exception, their local area ratios. The local area ratios are $0.70: 1,0.55: 1$, and $0.40: 1$, respectively, for samples $C$, $D$, and $E$. The normalized $I_{C}$ at the standard bend diameter $(1.28 \mathrm{~mm})$ is plotted as a function of the applied magnetic field for each of the three conductors. The data indicate a correlation between the LAR of the sample and the level of $I_{c}$ degradation that results from bending. As the LAR of these conductors increases, their sensitivity to bending decreases. All of these samples show a decreasing level of $I_{c}$ degradation with increasing magnetic field. This indicates that the source of the degradation is not an intrinsic degradation of $\mathrm{H}_{\mathrm{c} 2}$, as with the elastic strain effect. 5

Figure 8 is a similar plot for three samples that have the same local area ratios $(0.55: 1)$, but different diffusion barrier materials locally surrounding each filament (samples F, G, and D). These data indicate that the diffusion barrier material may be at least as important as the LAR in determining the sensitivity of a conductor to $\epsilon_{\mathrm{b}}$. The vanadium diffusionbarrier material correlated with the least $I_{c}$ degradation from bending. Differences in the shear strength of the filament-matrix-filament interface for these different diffusion barrier materials may account for this dependence.

Figure 9 is a plot of the normalized $I_{c}$ at the standard bend diameter as a function of the LAR at several magnetic fields. The difference between the $I_{c}$ degradation for the maximum and minimum local area ratios is about $1 / 7$ the total $I_{c}$ degradation. Once again, the tendency for the degradation to increase with decreasing LAR is evident. 


\section{Discussion}

Two possible sources of the degradation in $I_{C}$ are residual elastic strain in the NbTi filaments $3,5,6$ and local reductions in their cross-sectional areas.7-9 The data presented in Figs. 7, 8, and 9, where the $I_{c}$ degradation decreases with increasing magnetic field, refute the former explanation of the Ic degradation. The elastic-strain effect results in an intrinsic degradation of $\mathrm{H}_{\mathrm{c} 2}$, which, in turn, results in greatly increasing $\mathrm{I}_{c}$ degradation at fields approaching $\mathrm{H}_{\mathrm{c} 2}$. This is just the opposite of what is observed. The data presented in Fig. 6, where the $\mathrm{n}$ value is shown to decrease with increasing $\epsilon_{\mathrm{b}}$, supports the latter explanation, that $I_{c}$ and $n$ degrade from an increase of the filaments' cross-sectional irregularity with bending.

The correlation between the $L A R$ and $I_{c}$ degradation that is shown in Fig. 9 indicates that in order to increase a conductor's tolerance to bending its LAR should be large. However, if the LAR is made to large, the increase in the wires' tolerance to bending may be negated by a decrease in its tolerance to drawing. A large LAR is conducive to the development of filament irregularities, or sausaging, during drawing, which, in turn, results in degradation of $I_{c}$ and $n$. Consequently, the optimum LAR may be a compromise between the wire's tolerance to bending and its tolerance to drawing.

A large LAR apparently reduces the strain that is transmitted to the filaments as a result of bending. A speculative explanation for this behavior is that the low yield stress and resulting compliance of the copper matrix material, between the filaments, in a large LAR conductor facilitates independent motion of the filaments. Furthermore, different diffusion-barrier 
materials may affect the filament-to-filament shear strength of the composite. This increased independence of motion may allow the filament bundle to flatten during bending, with the outer filaments moving toward the wire's neutral axis, thereby reducing the axial strain of individual filaments introduced by bending.

\section{Conclusions}

Severe bending strain can cause a large reduction in the $I_{c}$ of multifilamentary NbTi wires. This degradation is not associated with an intrinsic $\mathrm{H}_{\mathrm{c} 2}$ effect, as evidenced by a reduction in degradation with increasing magnetic field. Bending strain results, however, in a significant degradation in the $\mathrm{n}$ values of these conductors. This suggests that the degradation is associated with filament cross-sectional area irregularity introduced by bending.

By using a series of samples where the local area ratio (LAR) of copper to superconductor is systematically varied, it is shown that the wire's tolerance to bending can be increased by increasing its LAR. However, conductors that have a large LAR are more susceptible to the development of filament irregularities, or sausaging, during drawing. A compromise between these two conflicting effects (sausaging and bending degradation) is required in order to optimize the $I_{c}$ of these conductors.

For the conductors tested in this study, bending degradation of $I_{c}$ is also correlated with the diffusion-barrier material locally surrounding each filament. The effect is at least as great as that of the LAR. Of the 
diffusion-barrier materials that were tested, the vanadium barrier material resulted in less sensitivity to bending strain than niobium barriers or niobium barriers with a copper-nickel matrix.

This systematic study of bending degradation in NbTi superconductors has thus shown that the critical-current degradation from bending can be reduced through an appropriate choice of conductor-design factors, including local area ratio and diffusion-barrier material. The overriding factor in the cables' $I_{c}$ degradation is nevertheless the care used in cabling; no amount of bending tolerance engineered into the conductor design can compensate for the damage that can be introduced during cabling.

\section{Acknowledgements}

We gratefully acknowledge the assistance of R. Scanlan, who supplied the NbTi samples for this study, and Intermagnetic General Corp. for fabricating them as part of a Department of Energy SBIR program. We also extend our appreciation to $C$. Thompson for designing, machining, and performing the initial testing of the bend test fixtures; R. Scanlan, H. Kanithi, L. F. Goodrich, I. M. Larson, G. Reinacker, and W. Bahn for useful discussions; L. F. Goodrich for his help in constructing the current supply; and $\mathrm{J}$. Brauch and T. M. Larson for their assistance in writing the program for the critical current automatic data acquisition system. This research was supported by the U.S. Dept. of Energy, Div. of High Energy Physics under Interagency Agreement No. DE-AI05-85ER40240. 


\section{References}

1. J. W. Ekin, L. F. Goodrich, J. Moreland, E. S. Pittman, and A. F. Clark, "Electromechanical Properties of Superconductors for High Energy Physics Applications," National Bureau of Standards Internal Report No. NBSIR 863061, December 1986.

2. L. F. Goodrich, E. S. Pittman, J. W. Ekin, and R. M. Scanlan, "Studies of NbTi Strands Extracted from Coreless Rutherford Cables," IEEE Trans. Magn., MAG-23, 1642 (1987).

3. J. W. Ekin, "Relationships Between Critical Current and Stress in NbTi," IEEE Trans. Magn. MAG-23, 1634 (1987).

4. L. F. Goodrich and S. L. Bray, "Current Capacity Degradation in Superconducting Cable Strands," IEEE Trans. Magn. (1989), to be published.

5. J. W. Ekin, F. R. Fickett, and A. F. Clark, "Effect of Stress on the Critical Current of NbTi Multifilamentary Composite Wire," Proc. Int'l. Cryog. Mat. Conf. (August 1975), Adv. Cryo. Eng. 22, 449 (1977).

6. S. L. Bray and J. W. Ekin, "Effect of Room Temperature Stress on the Critical Current of NbTi," to be published in Jour. Appl. Phys. (1989).

7. J.W. Ekin, Quarterly Progress Report No. SR-724-13-82, National Bureau of Standards (1982) and Quarterly Progress Report No. SR-724-26-82, National Bureau of Standards (1982). J. W. Ekin, "Irregularity in Nb-Ti Filament Area and Electric Field versus Current Characteristics," Cryogenics 27, 603 (1987).

8. M. Garber, M. Suenaga, W. B. Sampson, and R. L. Sabatini, Adv. Cryog. Eng. 32, 707 (1986). 
9. W. H. Warner and D. C. Larbalestier, Proc. Int'1. Symp. on Flux Pinning and Electromagnetic Properties in Superconductors (Ed. T. Matsushita, K. Yamafuji, and F. Irie) p. 156, Matsukuma Press, Japan (1986). 


\begin{tabular}{|c|c|c|c|c|c|c|c|c|c|c|}
\hline 0 & \begin{tabular}{l}
$\infty$ \\
\multirow{j}{0}{} \\
0 \\
0
\end{tabular} & 0 & $\begin{array}{l}8 \\
8 \\
\text { O }\end{array}$ & 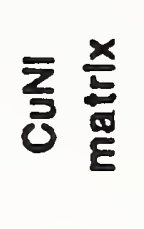 & $\begin{array}{l}\text { 先 } \\
\text { ?ִ? }\end{array}$ & 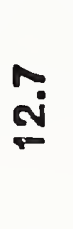 & 1 & $\stackrel{0}{z}$ & $\sum_{3}$ & 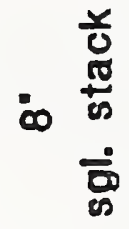 \\
\hline u & $\begin{array}{l}\infty \\
\stackrel{0}{*} \\
0\end{array}$ & 0 & $\begin{array}{l}8 \\
8 \\
8\end{array}$ & $\begin{array}{l}\text { Oִ } \\
\mathscr{6}\end{array}$ & $\begin{array}{l}\text { Lึ } \\
\text { เి } \\
0\end{array}$ & $\stackrel{\widetilde{N}}{\widetilde{\sim}}$ & $\frac{\text { L2 }}{\stackrel{0}{0}}$ & $>$ & $\begin{array}{l}\text { 응 } \\
\text { 응 } \\
\text { 응 }\end{array}$ & 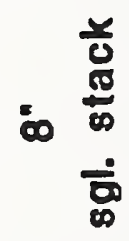 \\
\hline Ш & $\begin{array}{l}\infty \\
⿱ 亠 凶 \\
0\end{array}$ & 6 & $\begin{array}{l}8 \\
8 \\
\end{array}$ & $\underset{\mathscr{\infty}}{\mathscr{0}}$ & 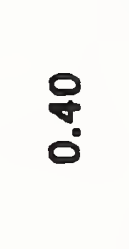 & $\hat{\stackrel{\alpha}{\sigma}}$ & $\frac{\stackrel{5}{0}}{0}$ & $\frac{0}{z}$ & $\begin{array}{l}\text { 능 } \\
\text { 응 } \\
0 \\
0\end{array}$ & 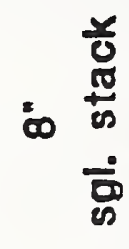 \\
\hline 0 & \begin{tabular}{l}
$\infty$ \\
\multirow{+}{*}{} \\
0 \\
0
\end{tabular} & 0 & $\begin{array}{l}8 \\
8 \\
0 \\
\end{array}$ & $\stackrel{0}{\dddot{r}}$ & 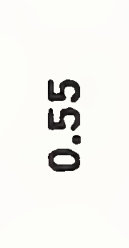 & $\stackrel{\vec{\sim}}{\stackrel{\sim}{\sigma}}$ & 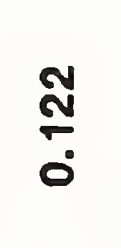 & $\frac{0}{z}$ & $\begin{array}{l}\text { o } \\
0 \\
0 \\
0\end{array}$ & 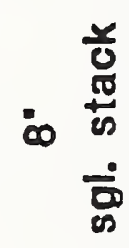 \\
\hline 0 & 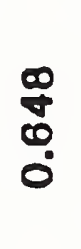 & 0 & $\begin{array}{l}8 \\
8 \\
\text { ㅇ }\end{array}$ & $\stackrel{0}{\circ}$ & $\begin{array}{l}\stackrel{R}{R} \\
0\end{array}$ & $\hat{\mathfrak{N}}$ & $\frac{⿱}{2}$ & $\frac{0}{z}$ & $\begin{array}{l}\frac{1}{0} \\
0 \\
0\end{array}$ & 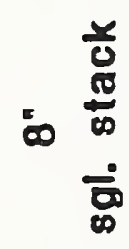 \\
\hline$\infty$ & \begin{tabular}{l}
$\infty$ \\
\multirow{d}{0}{} \\
0
\end{tabular} & L & $\begin{array}{l}0 \\
8 \\
0\end{array}$ & 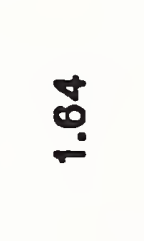 & $\begin{array}{l}18 \\
0 \\
0\end{array}$ & $\stackrel{\sim}{\sim}$ & $\frac{\stackrel{1}{~}}{\circ}$ & $\frac{0}{z}$ & $\begin{array}{l}\frac{1}{0} \\
0 \\
0 \\
0\end{array}$ & $\stackrel{\frac{\pi}{0}}{\frac{\pi}{0}}$ \\
\hline$<$ & \begin{tabular}{l}
$\infty$ \\
\multirow{0}{0}{} \\
0 \\
0
\end{tabular} & $\stackrel{0}{ }$ & $\underset{\mathbb{\infty}}{\infty}$ & $\stackrel{\sim}{r}$ & $\begin{array}{l}\text { Nै } \\
\text { เั? } \\
0\end{array}$ & 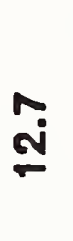 & $\frac{9}{\sigma}$ & 응 & $\begin{array}{l}\text { o } \\
0 \\
0 \\
0\end{array}$ & $=\frac{\substack{0 \\
0}}{\stackrel{0}{0}}$ \\
\hline $\begin{array}{l}\hat{\imath} \\
\frac{\infty}{0} \\
\frac{0}{E} \\
\tilde{E}\end{array}$ & 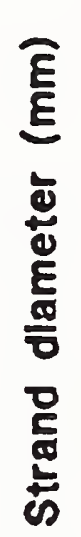 & 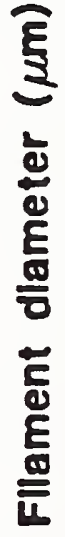 & 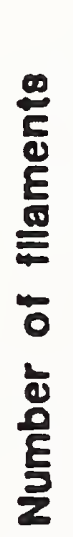 & 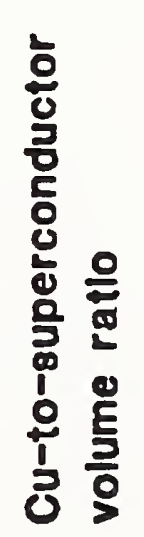 & 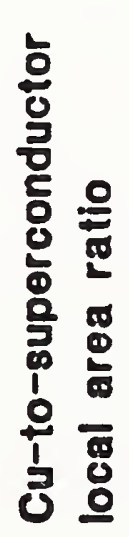 & 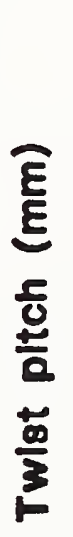 & 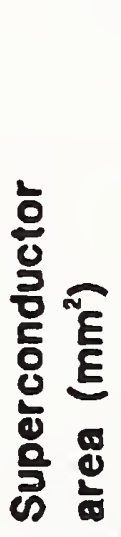 & 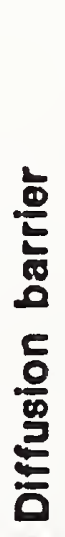 & 竞 & 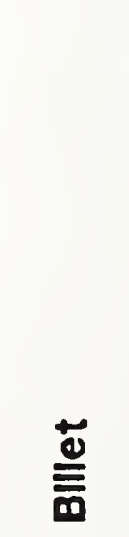 \\
\hline
\end{tabular}




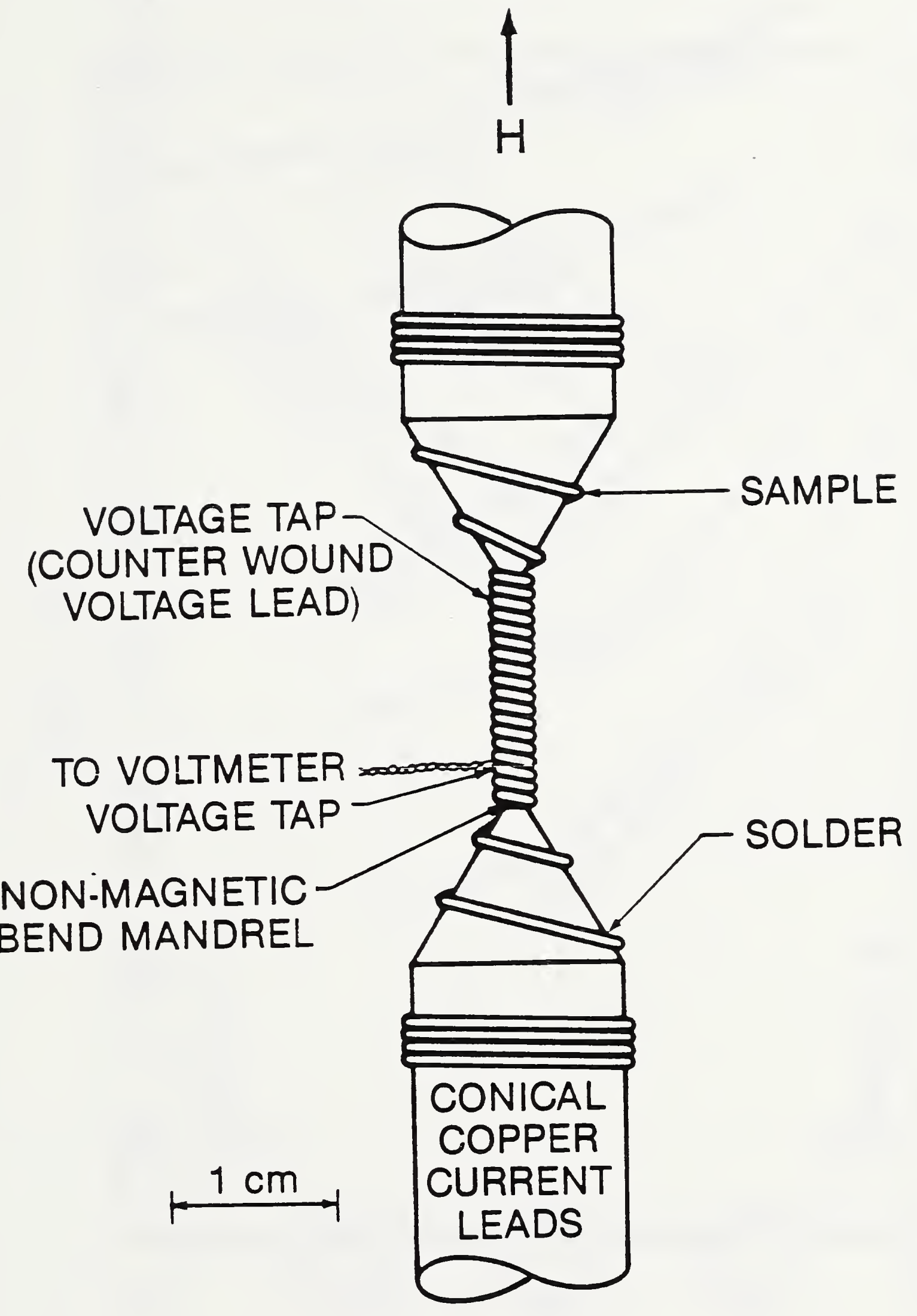

Fig. 1. Long bend test coil configuration. 


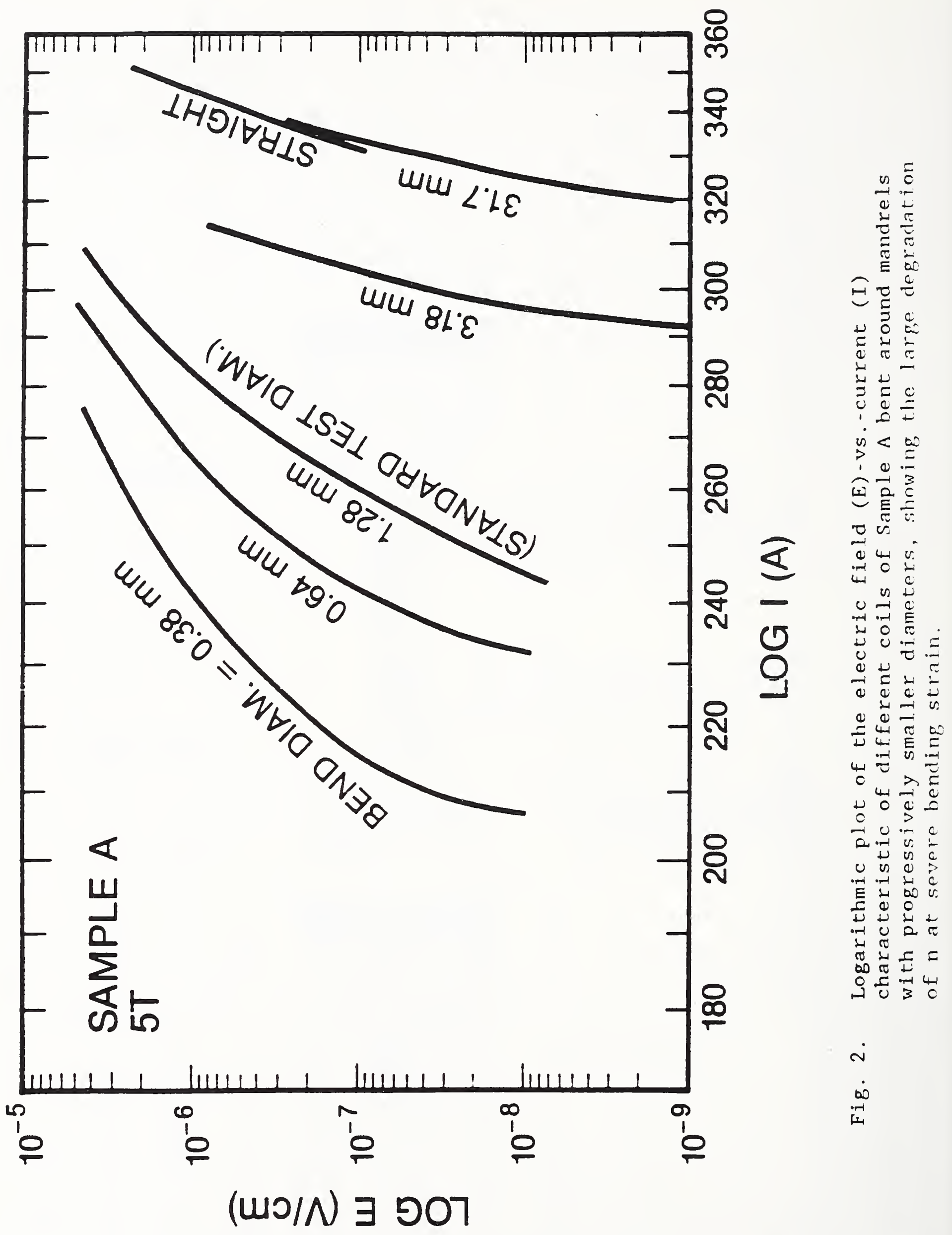




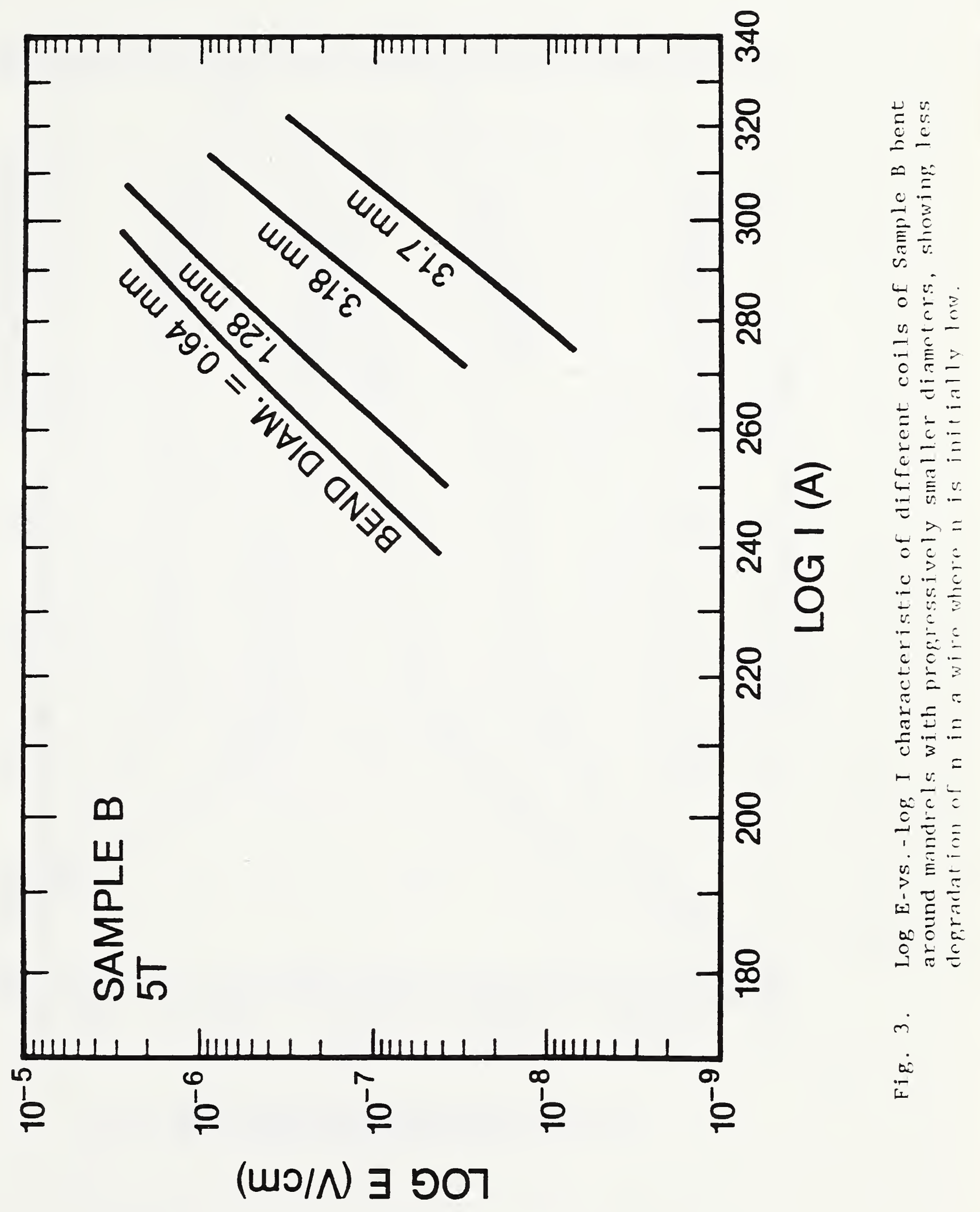




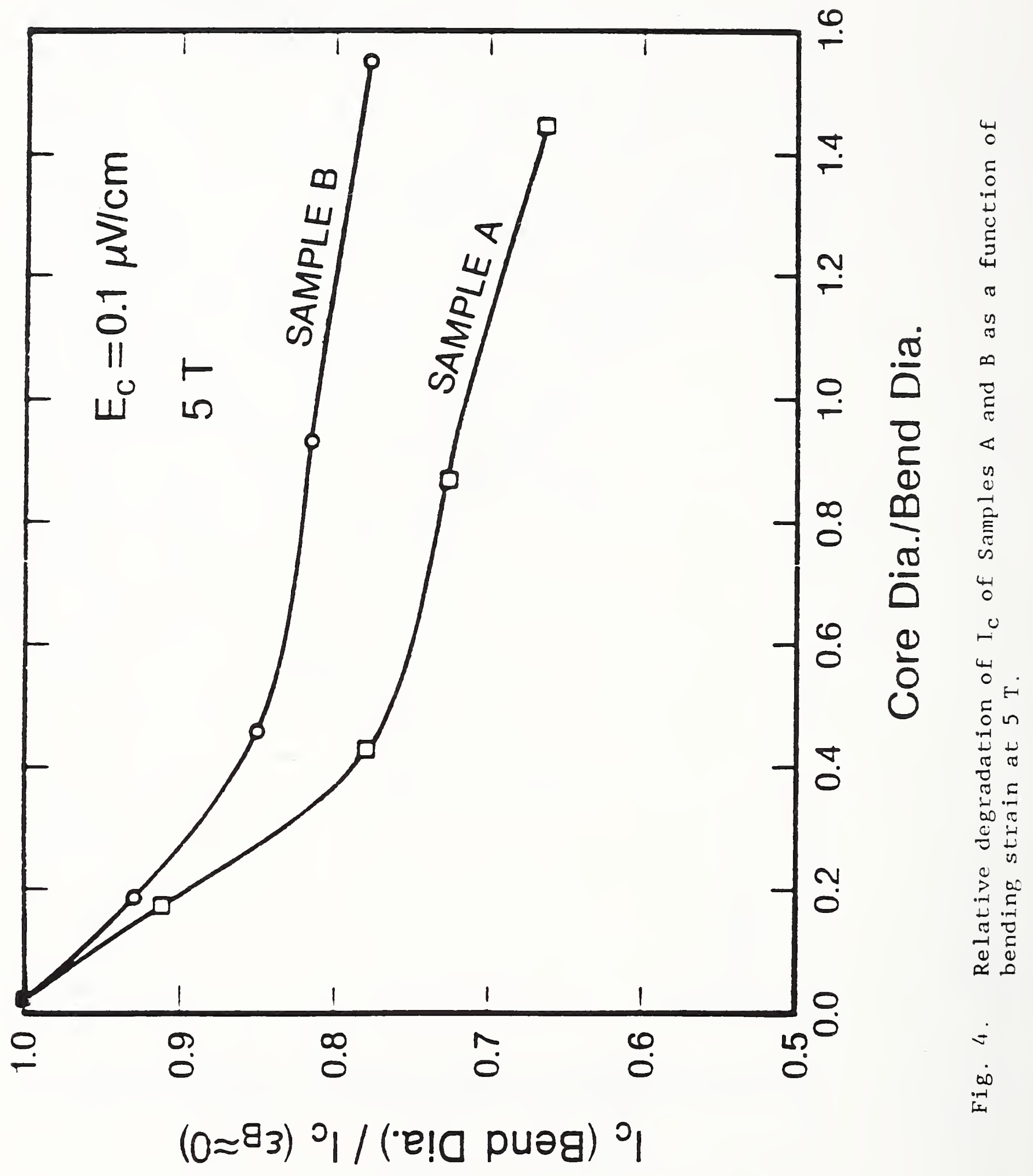




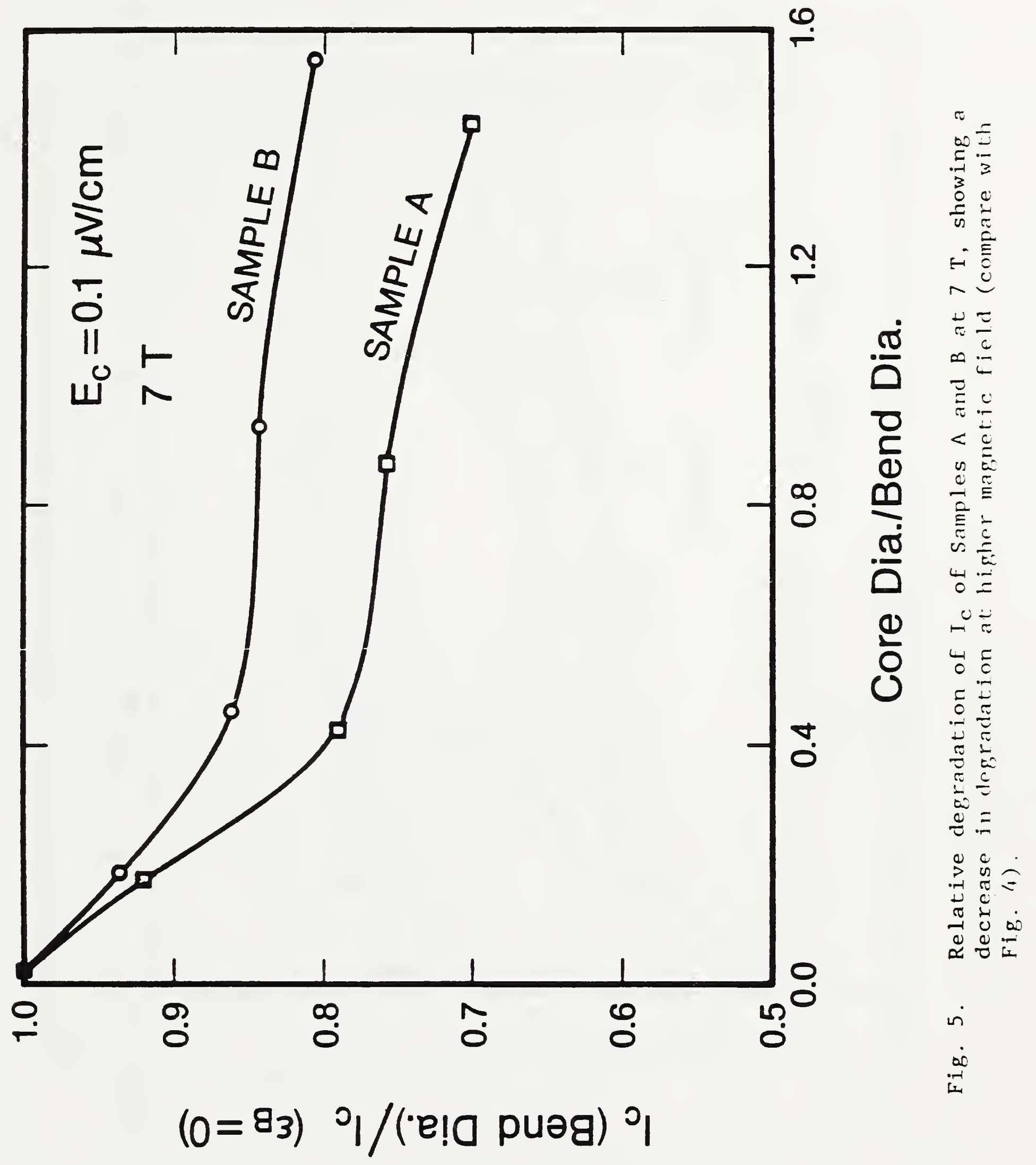




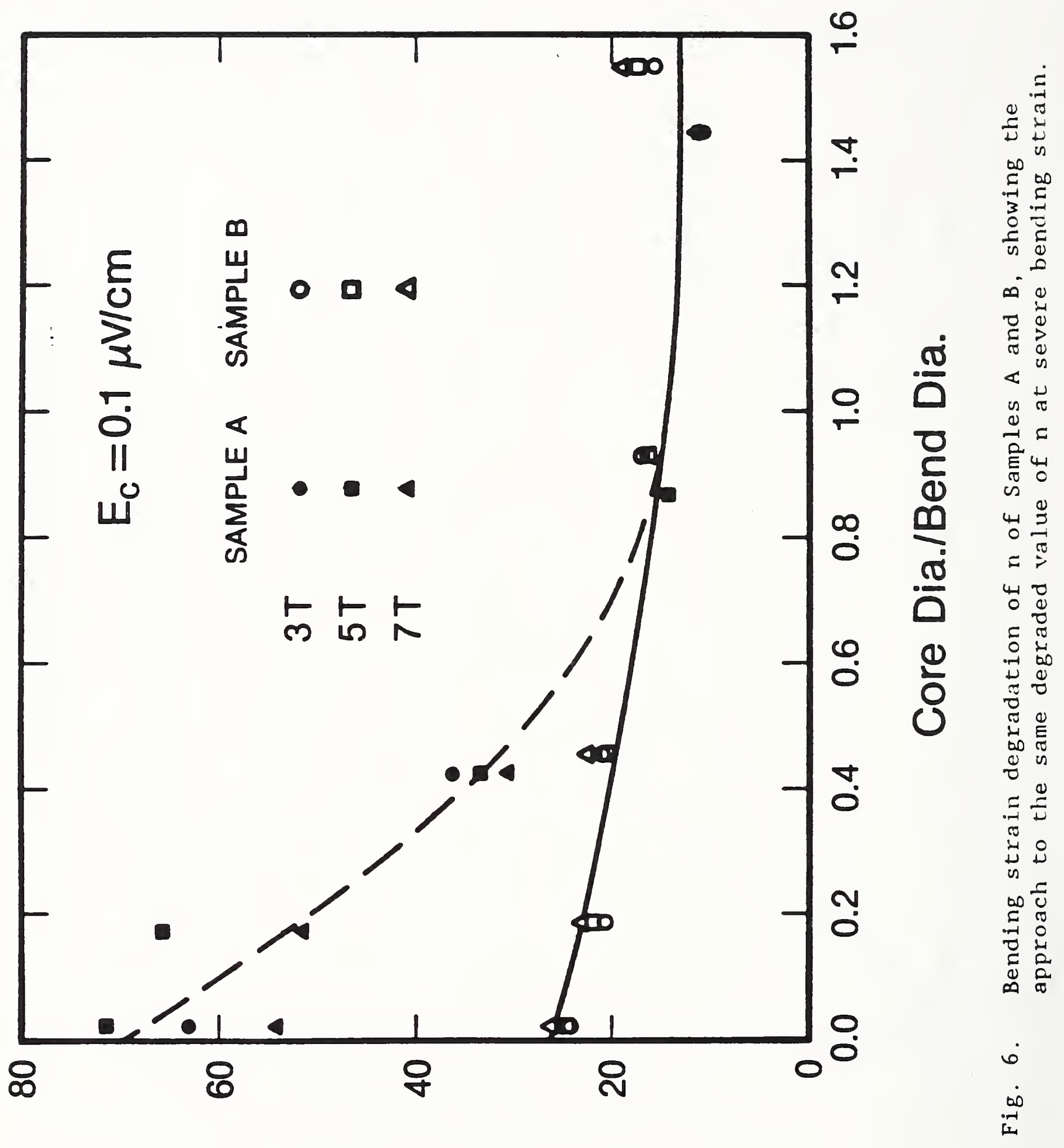

әnjen u 


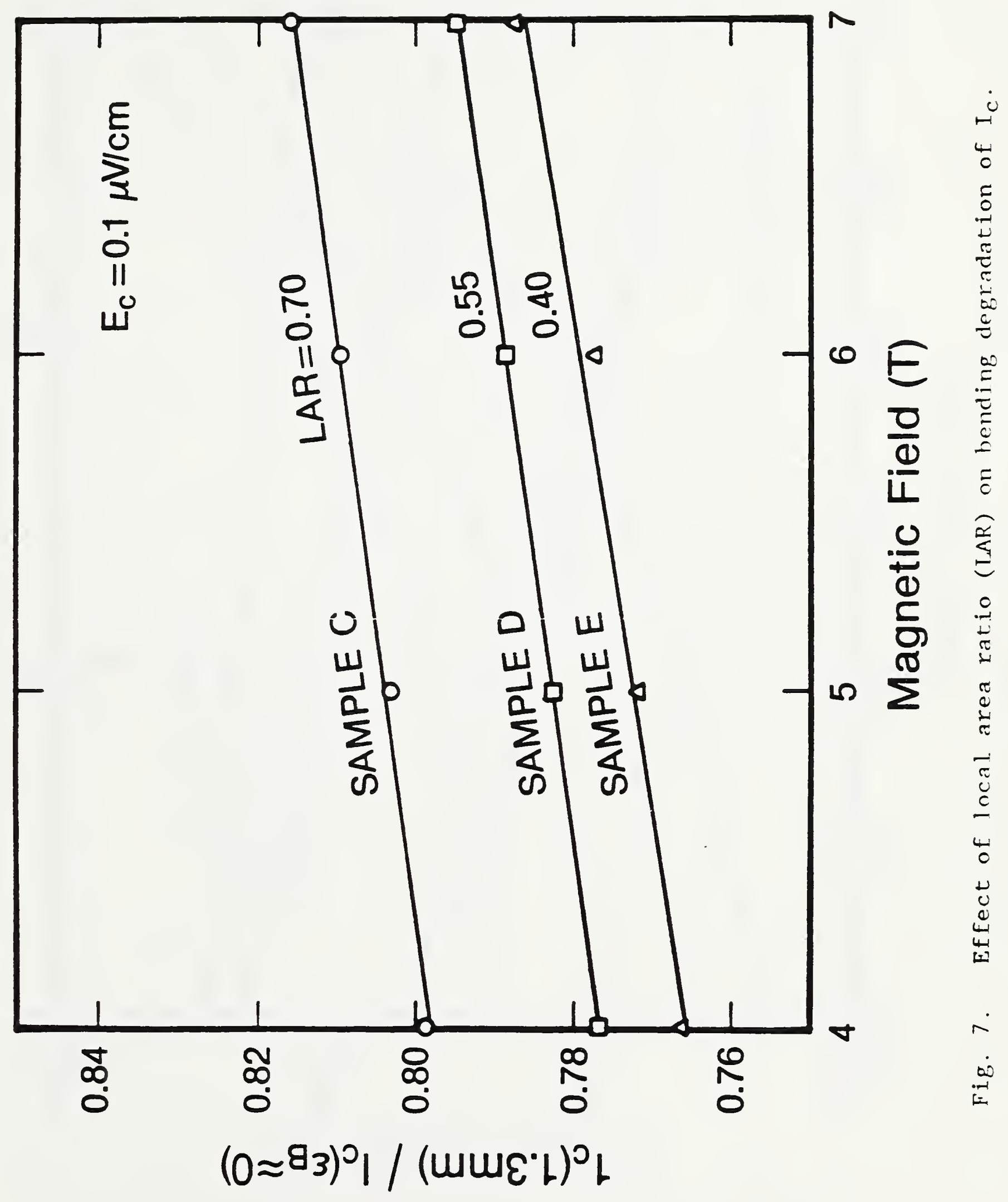




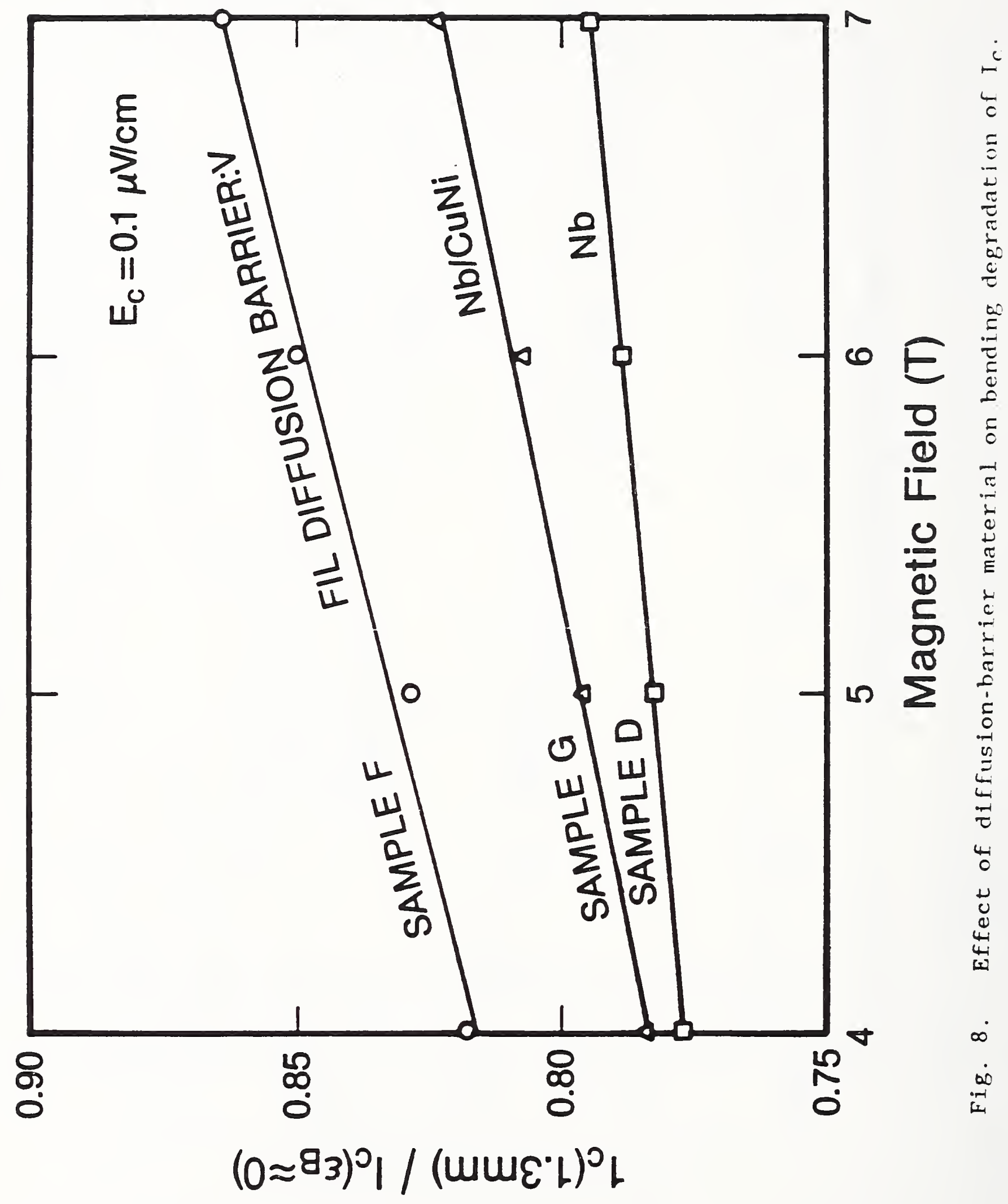




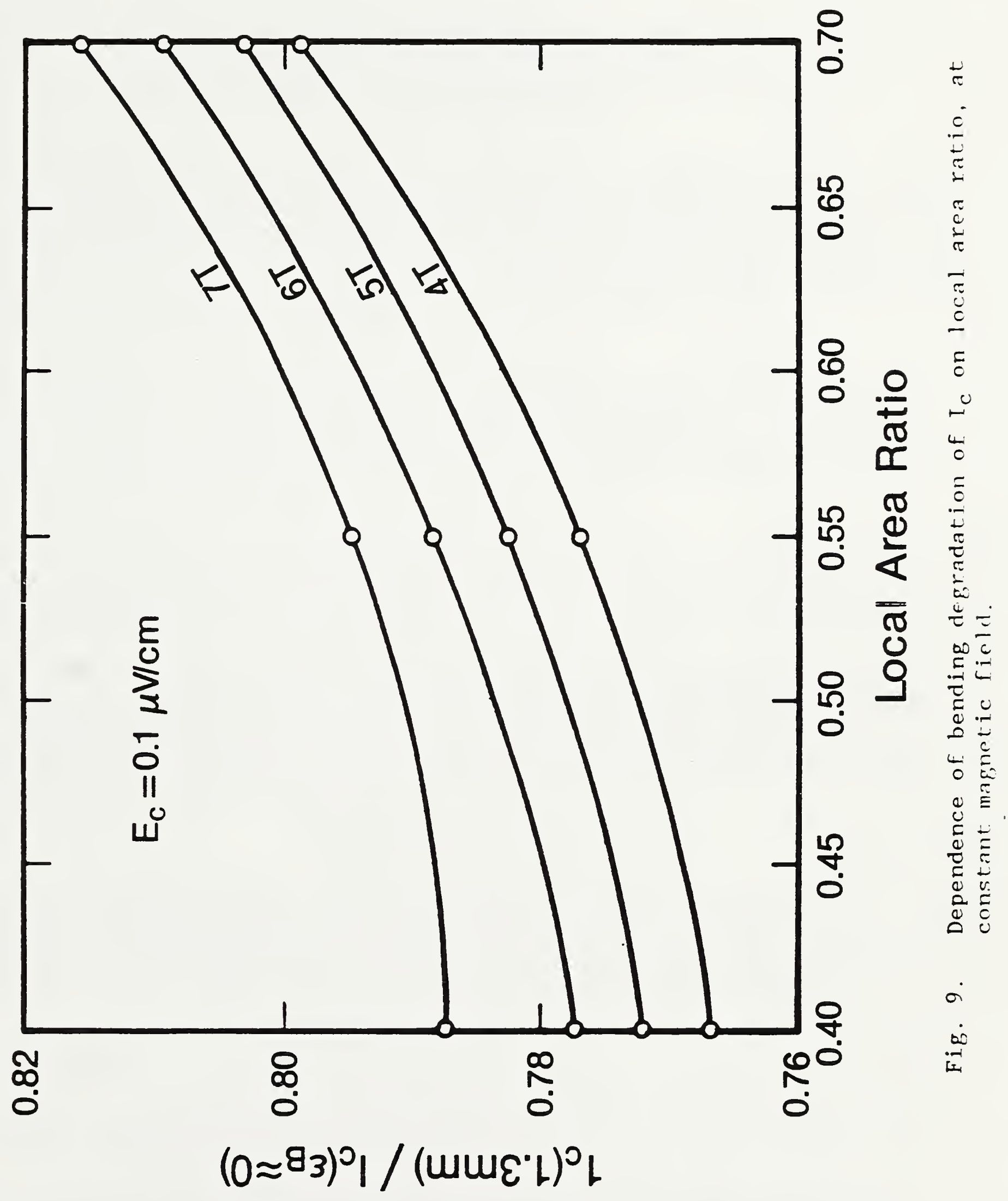





\title{
Measurement of Saturation Magnetization and Intrinsic Coercivity of High-Permeability Steel for the SSC
}

\author{
R. B. Goldfarb \\ Electromagnetic Technology Division \\ National Institute of Standards and Technology \\ Boulder, Colorado 80303
}

Accelerators such as the proposed Superconducting Super Collider (SSC) and the Tevatron at Fermilab use high-permeability steel for the return flux path of their superconducting magnets. It is the same type of steel that is commonly used for electrical transformers. In addition to high permeability $(\mu)$, desirable magnetic properties include large saturation magnetization $\left(M_{S}\right)$ and small intrinsic coercivity $\left(H_{C}\right)$.

It is useful to define $M_{S}$ and $H_{c}$ with reference to an idealized curve of magnetization ( $M$ ) vs. magnetic field strength $(H)$. Figure 1 represents a hysteresis loop for a sample with zero demagnetization factor, such as a long, thin needle. The parameters are indicated. If required, magnetic flux density (B) may be derived as

$$
B=\mu_{0}(H+M)
$$

(SI units, where $\mu_{0}$ is the permeability of free space) and plotted as a function of $\mathrm{H}[1,2]$.

In actual measurements with instruments such as a vibrating-sample magnetometer, a sample geometry with finite demagnetization factor is used $[3,4]$. Magnetic field $(\mathrm{H})$ in the above equations and plot refers to the internal field ( $H_{i n t}$ ), equal to the applied field ( $H_{\text {ext }}$ ) corrected for the proper geometric demagnetization factor (D) [5],

$$
\mathrm{H}_{\text {int }}=\mathrm{H}_{\text {ext }}-\mathrm{DM} \text {. }
$$

As a result of a sample's demagnetization factor, its plot of $M$ vs. Hext is "sheared" along the H-axis [6]. Generally, to deduce parameters characteristic of the material of which the sample is made, the data have to

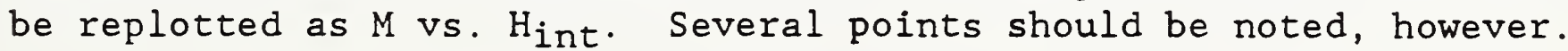

1. $\mathrm{H}_{\mathrm{c}}$ is independent of demagnetization factor; when $\mathrm{M}$ is zero, $\mathrm{H}_{\mathrm{int}}$ is identical to $\mathrm{H}_{\text {ext. }}$

2. $M_{S}$ is independent of demagnetization factor. At high fields, DM is only a small correction to $\mathrm{H}_{\text {ext }}$ in Eq. 2 .

3. It is difficult to extract the exact value of $\mu$ from magnetometer data when $\mu$ is large. The most successful methods use samples with exactly known demagnetization factors, such as spheres, or with zero demagnetization factors, such as toroids with azimuthal fields [7]. 
In this brief note, I report on the measurement of $\mathrm{M}_{s}$ and $\mathrm{H}_{c}$ for several steels suitable for accelerator applications. We used a conventional vibrating-sample magnetometer [8]. A high-field superconducting solenoid was used for the $M_{s}$ determination and a low-field copper-coil Helmholtz transverse pair was used for the $\mathrm{H}_{\mathrm{C}}$ measurements.

The samples consisted of rectangular prisms, about $1.5 \mathrm{~mm}$ thick, $6 \mathrm{~mm}$ wide, and $12 \mathrm{~mm}$ long. All magnetic measurements were made with the field in the longest axis. This minimized the demagnetization factor. Brief sample descriptions are given in Table $I$.

Magnetization was measured in liquid helium ( $4 \mathrm{~K}$ ) for maximum applied fields of $\pm 5.6 \mathrm{MA} / \mathrm{m}$ ( $\pm 70 \mathrm{kOe}$, or $\pm 7 \mathrm{~T}$ in free space). There were no significant differences between the samples; they all saturated at $M_{S} \simeq 1.75$ $\mathrm{MA} / \mathrm{m}\left(1750 \mathrm{emu} / \mathrm{cm}^{3}\right.$, or $\left.4 \pi \mathrm{M}_{\mathrm{s}} \simeq 22 \mathrm{kG}\right)$. A typical hysteresis loop is shown in Fig. 2. The field was cycled from zero to $+7 \mathrm{~T}$ to $-7 \mathrm{~T}$ to $+7 \mathrm{~T}$. There was no measurable hysteresis on this coarse scale.

Intrinsic coercivity was determined from the field required for zero magnetization. Measurements were made at room temperature $(296 \mathrm{~K})$ and in liquid nitrogen $(76 \mathrm{~K})$. Maximum applied fields were $\pm 800 \mathrm{kA} / \mathrm{m}$ ( \pm 10 Oe, or \pm 1 $\mathrm{mT}$ in free space). The samples were initially demagnetized [9].

The field was increased to $1 \mathrm{mT}$ while magnetization was recorded. At 1 $\mathrm{mT}$, the samples were briefly exposed to field of $0.1 \mathrm{~T}$ in an attempt to approach saturation. (A larger field would have been preferable, but was not available. Generally, $\mathrm{H}_{\mathrm{c}}$ is a weak function of the maximum applied field.) Thereupon data were recorded as the field was reduced to $-1 \mathrm{mT}$. At - $1 \mathrm{mT}$, the sample was exposed to a field of $-0.1 \mathrm{~T}$. The cycle continued to $1 \mathrm{mT}$. A typical trace is shown in Fig. 3. Note that the loop is sheared in the sense discussed above.

Table II summarizes the results for the five samples. Values of $\mathrm{H}_{c}$ ranged from $110 \mathrm{~A} / \mathrm{m}(1.4 \mathrm{Oe})$ for cold-rolled samples to $170 \mathrm{~A} / \mathrm{m}(2.1 \mathrm{Oe})$ for hot-rolled samples. The results were independent of whether the field was parallel or perpendicular to the rolling direction. Liquid-nitrogen $\mathrm{H}_{c}$ was slightly larger than room-temperature $\mathrm{H}_{\mathrm{c}}$. At liquid-helium temperature, $\mathrm{H}_{\mathrm{c}}$ is expected to be slightly higher still.

In summary, there appear to be no significant differences in these steel samples with regard to saturation magnetization and intrinsic coercivity.

\section{ACKNOWLEDGMENTS}

R. L. Spomer assisted with the measurements. The steel samples were provided by M. V. Bala, Inland Steel Company. The work was supported by the Department of Energy, Division of High Energy Physics.

Certain commercial materials are identified to adequately specify the experimental study. Recommendations or endorsements by NBS are not implied. 


\section{REFERENCES}

[1] "Intrinsic coercivity" is the $\mathrm{H}$ at which $\mathrm{M}$ goes to zero. The terms "coercive force" and "coercivity" refer to the value of $\mathrm{H}$ at which $B$ goes to zero. The symbol $\mathrm{H}_{\mathrm{c}}$ is commonly used for both meanings.

[2] Permeability $\mu$ is defined as $d B / d \mathrm{H}$. $\chi$, is $d \mathrm{M} / d \mathrm{H}$. In SI units, $\mu=1+\chi$.

[3] R. M. Bozorth and D. M. Chapin, J. Appl. Phys. 13, 320 (1942).

[4] T. L. Templeton and A. S. Arrott, IEEE Trans. Magn. MAG-23, 2650 (1987).

[5] R. B. Goldfarb, Cryogenics 27, 621 (1986).

[6] If a sample has a large $M$ but unknown $D$, the value of $D$ can be estimated as that required to "unshear" the hysteresis loop, using Eq. 2. For example, see: J. C. Mallinson, The Foundations of Magnetic Recording, (Academic Press, San Diego, 1987) P.23.

[7] R. B. Goldfarb and H. E. Bussey, Rev. Sci. Instrum. 58, 624 (1987).

[8] S. Foner, Rev. Sci. Instrum. 30, 548 (1959).

[9] The ac demagnetization process consists of exposing the sample to an alternating field that is decreasing in amplitude. In practice, a simple wire-wound solenoid is energized with a variable transformer ("Variac") at line frequency. The purpose is to remove any remanent magnetization in the sample. 
Table I. Samples for $\mathrm{M}_{\mathrm{S}}$ and $\mathrm{H}_{\mathrm{C}}$ measurement.

\begin{tabular}{ll}
\hline Sample & Description \\
\hline A & Inland, plate steel, hot rolled, ultra-low carbon \\
$B$ & Inland, cold rolled, H parallel to rolling direction \\
C & Inland, cold rolled, H perpendicular to rolling direction \\
D & Armco, cold rolled, $\mathrm{nP}$ coating, H parallel to rolling direction \\
$\mathrm{E}$ & Armco, cold rolled, $\mathrm{nP}$ coating, H perpendicular to rolling direction \\
\hline \hline
\end{tabular}

Table II. Intrinsic coercivity at 296 and $76 \mathrm{~K}$.

\begin{tabular}{cccccc}
\hline \hline & \multicolumn{2}{c}{$296 \mathrm{~K}$} & & \multicolumn{2}{c}{$76 \mathrm{~K}$} \\
\cline { 2 - 3 } \cline { 5 - 6 } Sample & $\mathrm{H}_{\mathrm{C}}(\mathrm{A} / \mathrm{m})$ & $\mathrm{H}_{\mathrm{C}}(\mathrm{Oe})$ & & $\mathrm{H}_{\mathrm{c}}(\mathrm{A} / \mathrm{m})$ & $\mathrm{H}_{\mathrm{c}}(\mathrm{Oe})$ \\
\hline $\mathrm{A}$ & 160 & 2.0 & 170 & 2.1 \\
$\mathrm{~B}$ & 110 & 1.4 & & 130 & 1.6 \\
$\mathrm{C}$ & 100 & 1.3 & 110 & 1.4 \\
$\mathrm{D}$ & 100 & 1.3 & 110 & 1.4 \\
$\mathrm{E}$ & 100 & 1.3 & 110 & 1.4 \\
\hline \hline
\end{tabular}

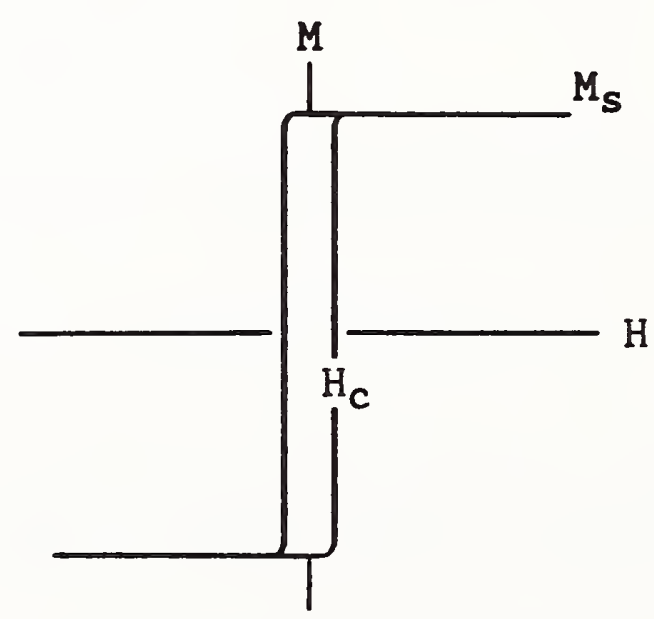

Figure 1. Idealized hysteresis loop of magnetization (M) vs. magnetic field $(H)$, showing saturation magnetization $\left(M_{S}\right)$ and intrinsic coercivity $\left(H_{C}\right)$. 


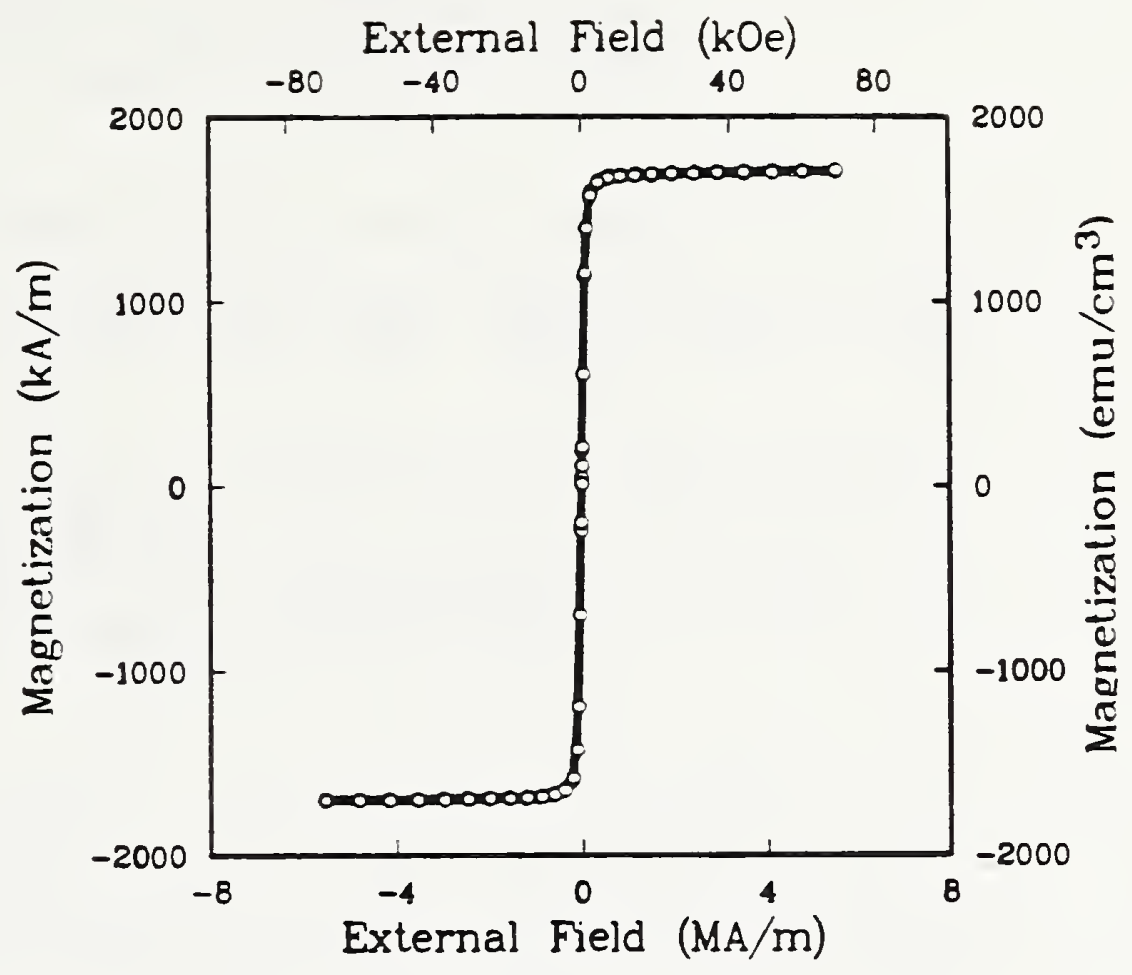

Figure 2. Hysteresis loop of magnetization vs. applied field at liquid-helium temperature for sample $E$. Curves for the other samples are similar.

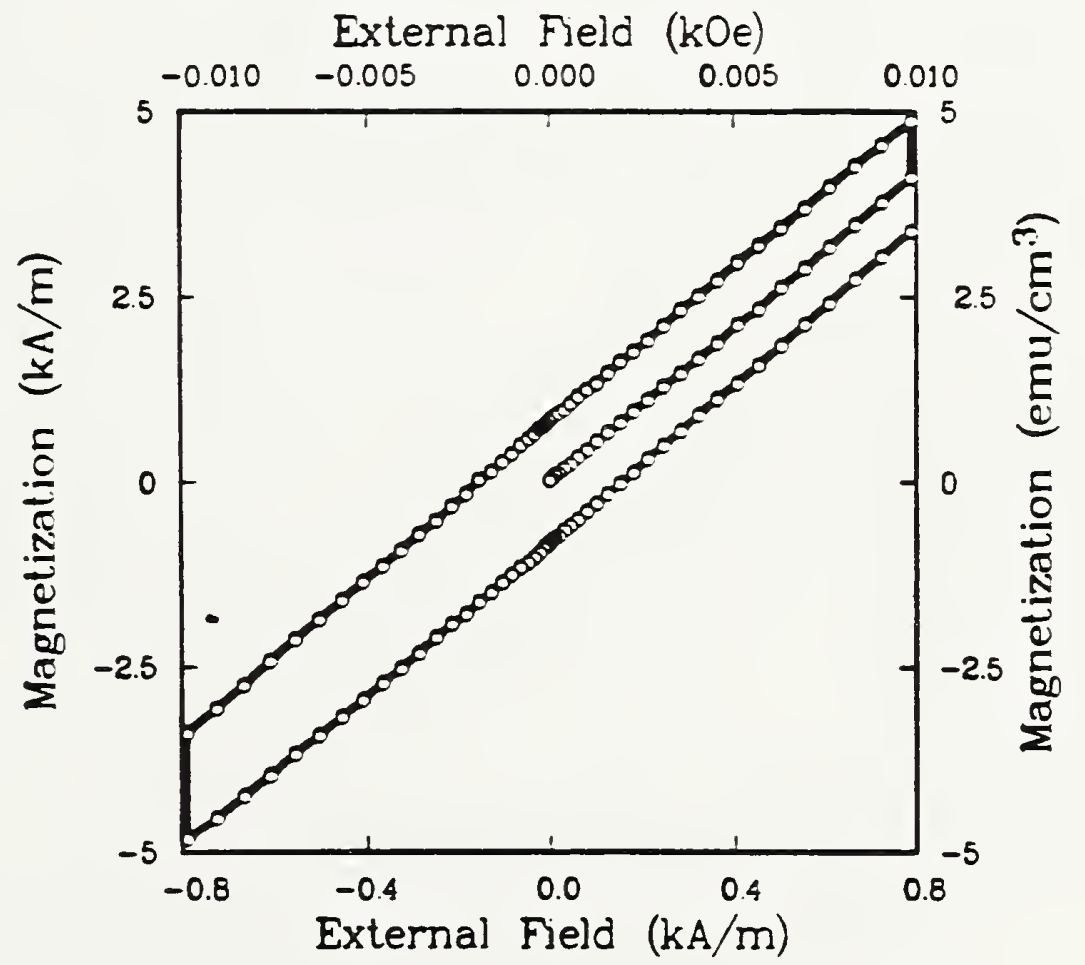

Figure 3. Plot of magnetization vs. applied field ( $\pm 1 \mathrm{mT}$ maximum field) at room temperature for sample A. Curves for the other samples at room temperature and liquid-nitrogen temperature are similar. Upon reaching $\pm 1 \mathrm{mT}$, the sample was exposed to a field of $\pm 0.1 \mathrm{~T}$. 

Appendix: Publications

Irregularity in $\mathrm{Nb}-\mathrm{Ti}$ Filament Area and Electric Field Versus Current Characteristics

J.W. Ekin, Cryogenics 27, 603 (1987)

Relationships Between Critical Current and Stress in $\mathrm{NbTi}$

J.W. Ekin, IEEE Trans. Mag., MAG-23, 1634 (1987)

Studies of NbTi Strands Extracted From Coreless Rutherford Cables

L.F. Goodrich, E.S. Pittman, and J.W. Ekin, IEEE Trans. Mag., MAG-23, 1642 (1987)

Current Capacity Degradation in Superconducting Cable Strands

L.F. Goodrich and S.L. Bray, Applied Superconductivity Conference, ASC, San Francisco, California, Aug. 1988, IEEE Trans. Mag., MAG-25, 1949 (1989) 
$-$ 


\title{
Irregularity in $\mathrm{Nb}$ - $\mathrm{Ti}$ filament area and electric field versus current characteristics
}

\author{
J.W. Ekin \\ Electromagnetic Technology Division, Center for Electronics and Electrical Engineering, \\ National Bureau of Standards, Boulder, CO 80303, USA
}

Received 23 December 1986

There is a correlation between irregularity in filament area ('sausaging') and the shape of a superconductor's electric field $(E)$ versus current $(I)$ relationship. The shape of the $E-I$ characteristic is quantified in terms of the resistive transition parameter, $n$, defined by $E x I^{n}$. Low values of $n$ less than about 20 correlate with a wide filament diameter distribution, while $n$ values over 50 correspond to a distribution more than 2.5 times smaller. It is proposed that the low-field (constant) value of $n$ be used as an index of filament quality in evaluating different superconductors for practical applications. A model is also suggested to explain this effect in terms of a locally depressed filament critical current, which forces current to transfer across the normal matrix material into neighbouring filaments. The relationship between $n$ and the statistical distribution of filament diameters may be useful as an easy method of estimating the extent of sausaging in practical multifilamentary $\mathrm{Nb}-\mathrm{Ti}$ superconductors from measurements of $n$.

Keywords: superconductors; $\mathrm{Nb}-\mathrm{Ti}$; sausaging; multifilamentary superconductors

In a multifilamentary superconductor a correlation exists between irregularity in filament cross-sectional area (sometimes called 'necking' or 'sausaging') and the shape of a superconductor's electric field versus current characteristic ${ }^{1}$. Measurements show that the greater the extent of irregularity in filament cross-sectional area, the more gradual is the rise in the electric field versus current $(E-I)$ characteristic. The shape of the $E$-I curve is quantified in terms of the resistive transition parameter, $n$, defined by $E \propto I^{m}$. Low values of $n$ indicate significant filament irregularity. The first part of this article proposes that the parameter $n$ be used as an index of filament quality in evaluating different superconductors for practical applications.

A model is also suggested to explain this effect : filament necking depresses the critical current, $I_{c}$, of a filament locally; this forces current to transfer across the normal matrix material into (unnecked) neighbouring filaments. The current transfer is intrinsic to the wire and occurs continuously along its length wherever the filaments are necked down to a smaller cross-sectional area. These currents crossing the matrix generate significant voltage at transport current levels well below the critical current, which causes the reduction in the value of $n$. (According to this model, filaments that are uniform along their length but with different cross-sectional areas do not cause intrinsic current transfer. It is only when filaments neck that significant current transfer occurs and the value of $n$ is degraded.)

The second part of this article presents a quantitative relationship between $n$ and the statistical distribution of filament diameters ${ }^{2}$ measured for the $\mathrm{Nb} \mathrm{Ti}$ superconductors studied in the first part. The relationshıp may be useful as a quick method for estimating the extent of sausaging in practical multifilamentary $\mathrm{Nb}-\mathrm{Ti}$ superconductors from measurements of $n$.

This article is based on two internal reports of the Electromagnetic Technology Division of the National Bureau of Standards ${ }^{1.2}$. The two main features of these reports - the correlation of $n$ with filament sausaging and the flament-necking model - have been confirmed by subsequent research at several laboratories ${ }^{3-9}$. The sausaging model and data should aid in present efforts to produce high critical current density multifilamentary conductors and to develop a theory treating $I_{c}$ inhomogeneity. They also help explain and quantify some observations of a preliminary nature, which noted a concurrence of filament sausaging and a lowering of $I_{c}^{10-12}$

The transition parameter, $n$, was introduced some time ago by Voelker ${ }^{13}$ in another connection relating to filament breakage rather than sausaging. The $n$ value ( $n$ $\approx 3$ ) he measured was significantly lower than the $n$ values reported here; in a sense, his work represents an extension of filament sausaging to the extreme case of filament breakage. We suspect that filament necking may have also contributed to the relatively low $n$ values $(7 \leqq n \leqq 12)$ in some of the 'good' multifilamentary samples he measured, since n-values are typically much greater than 30 in multiflamentary superconductors with little filament necking.

The model of Jones et al. ${ }^{14}$, which has formed the basis 
for much $I_{c}$ inhomogeneity analysis ${ }^{8.14-17}$, does not inclide the effects of current transfer between sausaged filanients. as described in the model ${ }^{1}$. The data and model presented here show that filament sausaging. rather than chemical or intrinsic material inhomogeneity, is the dominant source of $I_{c}$ inhomogeneity that needs to be considered at low and medium fields in many practical multifilamentary $\mathrm{Nb}-\mathrm{Ti}$ superconductors. The effective sausaging length is several filament diameters, which makes filament-to-filament current transfer an important consideration in $I_{c}$ inhomogeneity theory. Recently, Evetts and Plummer ${ }^{8}$ have incorporated current transfer effects into a unified analysis of sausaging effects in multifilamentary conductors. A preliminary comparison indicates that these data are in reasonable agreement with their model.

The following two sections are based, respectively, on References 1 and 2; the third section contains an addendum that summarizes the statistical data in convenient form. The identities of the superconductors have been relabelled, but otherwise the internal reports appear in their original form.

\section{Effect of superconductor filament irregularity}

During critical current testing of several Nb-Ti conductors, it was noticed that the electric field iersus current $(E-I)$ characteristic for one conductor did not show the sharp take-off behaviour normally observed in other $\mathrm{Nb}$ Ti: copper superconductors we have tested. Instead. the rise in voltage in this conductor started well below the critical current, $I_{c}$, showing a gradual rise as $I$ approached $I_{c}$ rather than a sharp rise right at $I_{c}$ (see sample $A$ in Figure /1. This limits the usefulness of the conductor in magnet applications. since a significant electric field in the conductor below $I_{c}$ leads to heating and decreased stability. Several tests were consequently undertaken to determine the source of this electric field.

The effect may be quantified by describing the superconductor $E-I$ characteristic in terms of the equation

$\frac{E}{E_{\mathrm{c}}}=\left(\frac{I}{I_{\mathrm{c}}}\right)^{n}$

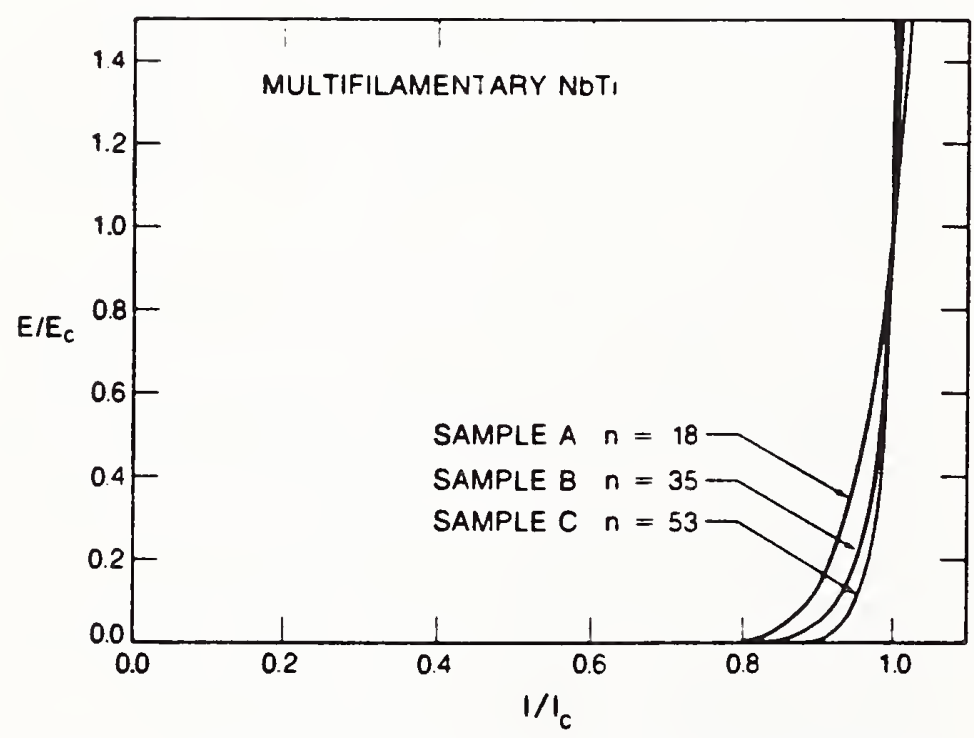

Figure 1 Normalized electric field versus current plots for three multifilamentary $\mathrm{Nb}-\mathrm{Ti}$ superconductors, showing the more gradual resistive transition in sample $A$ compared with samples $B$ and $C$

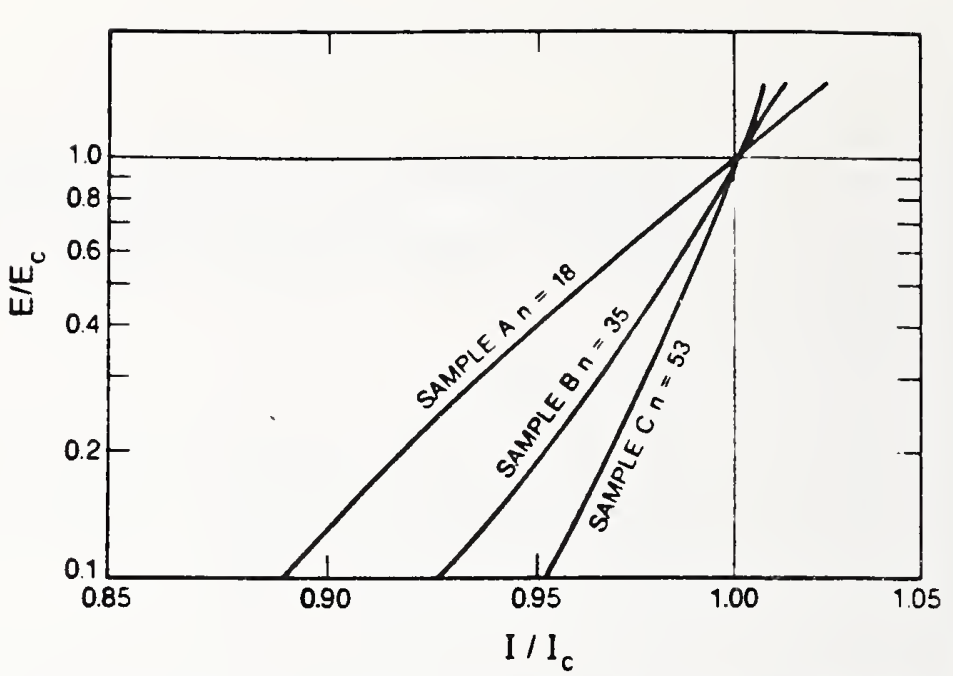

Figure 2 Logarithmic plot of electric field versus current for the curves in Figure 1, showing the low value of $n$ in sample A compared with samples $B$ and $C$ ( $n$ is defined by the relationship $V x r^{n}$ )

where: $I_{\mathrm{c}}=$ critical current; and $E_{\mathrm{c}}=$ electric field criterion at which $I_{c}$ is determined. The larger the exponent $n$, the sharper the $E-I$ take-off at $I_{c}$. Thus, large $n$ is desirable for magnet applications.

In Figure $2, \log E / E_{\mathrm{c}}$ is plotted versus $/ / I_{\mathrm{c}}$ for sample $\mathrm{A}$ as well as another previously tested conductor, sample B. to determine comparative values of $n$. As seen from the curves in Figure 2, sample B has an $n$-value of $\approx 35$, whereas sample $A$ has an $n$-value of only $\approx 18$.

One possible source of the low $n$ in sample $A$ is filament irregularity. If there is sausaging in the filaments, current will transfer out of a filament where it necks down. into a neighbouring filament which can carry the extra current. When the current in the neighbouring filament encounters a necked region. it too will be forced out of that filament through the matrix material and into another filament (perhaps back into the original filament if its diameter is back to average size or greater). In this manner, filament irregularity forces current transfer through the resistive matrix material continuously. causing significant electric fields along the conductor well below $I_{c}$. resulting in a low value of $n$.

To test this hypothesis a series of scanning electron micrographs were made of the filaments in each conductor. The copper matrix of each conductor was chemically removed and the filaments photographed longitudinally. The results are shown in Figures $3 a$ and $4 a$. Significantly greater filament irregularities were found in sample $\dot{A}$ than in sample B. As shown in Table $I$, the average diameter fluctuations, $\Delta D$, for sample $A$ amounted to $\approx 9 \mu \mathrm{m}$, or $\approx 33 \%$ of its average filament diameter $\langle D\rangle$. In sample $\mathrm{A}$, in contrast. $\Delta D$ was less than $7 \mu \mathrm{m}$, or $\approx 20 \%$ of its average filament diameter. The relative amount of filament irregularity, $\Delta D /\langle D\rangle$, in these conductors thus correlates well with degradation in the value of $n$ characterizing their $E-I$ curves.

To see if this large filament irregularity is a characteristic of conductors containing a large volume fraction of copper, a third conductor, sample $\mathrm{C}$, was also tested. The conductor contained a large amount of copper similar to sample A but had a somewhat larger filament diameter. As shown in Figure $S$ and Table $1, \triangle D$ for this conductor was only $\approx 6 \%$ of its $\langle D\rangle$. The $E-I$ characteristic of this conductor was correspondingly sharper, with a measured $n$ value of 46 , which is more than twice that of sample $A$. Thus, large values of $\Delta D$ need not be an inherent 

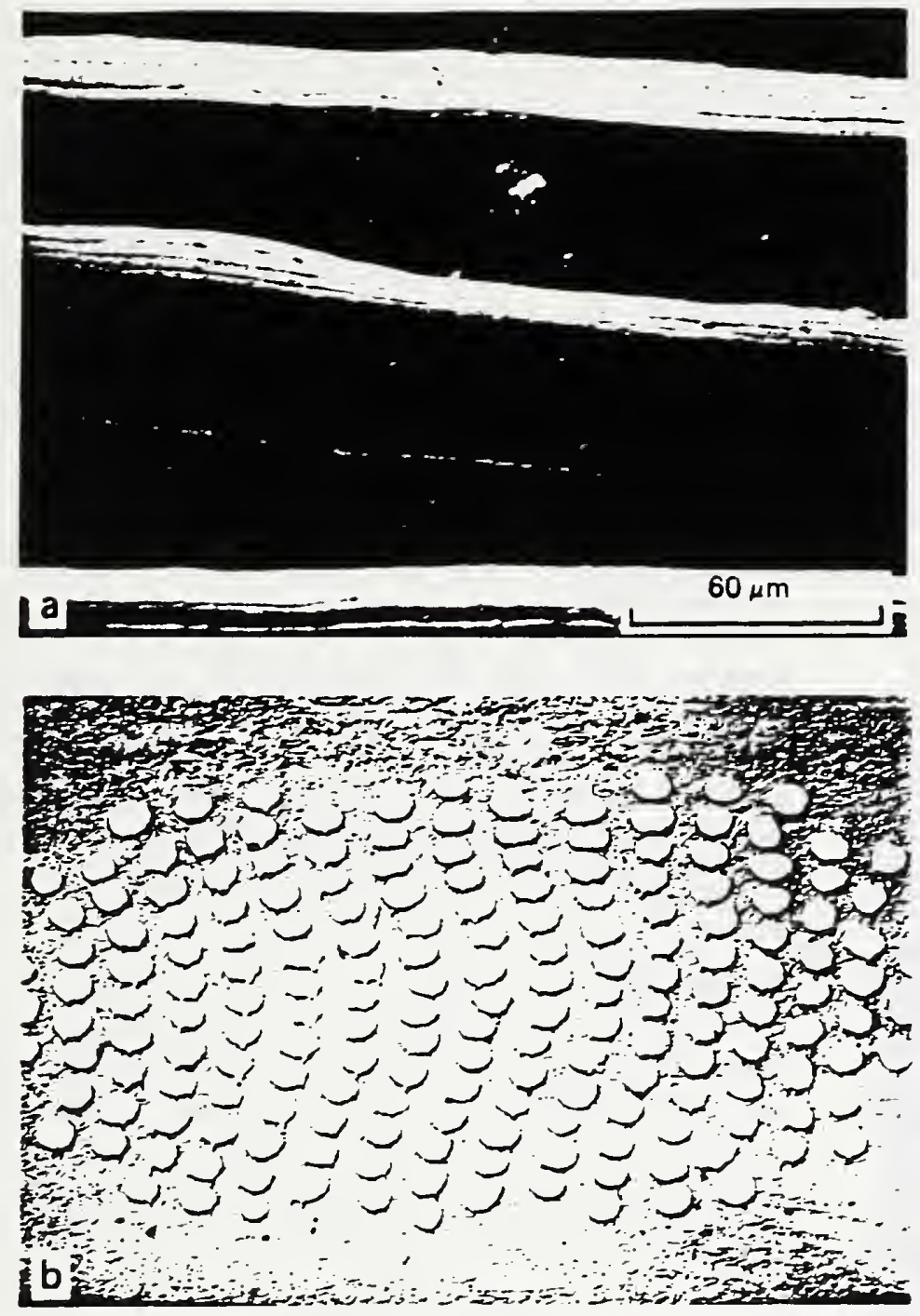

Figure 3 Longitudinal (a) and cross-sectional (b) views of the filaments in sample $A$

characteristic of conductors containing high percentages of copper stabilizer.

In summary, these results show that the degradation in the value of $n$ for these multifilamentary $\mathrm{Nb}$ - Ti conductors correlates well with the relative amount of filament irregularity observed in each and that such irregularities need not be a characteristic of conductors containing a large fraction of copper. The value of $n$ measured for sample $A$ is significantly lower than that measured for other $\mathrm{Nb}-\mathrm{Ti}$ conductors and these data would suggest it could be substantially improved by reducing the large filament diameter irregularities observed in this conductor. Furthermore. it would seem that the parameter $n$ could be used as a valuable index of filament quality in evaluating different superconductors. Certainly, $n$ should be an extremely useful parameter in characterizing the quality of a superconductor's $E-I$ characteristics, complementing the $I_{\mathrm{c}}$ value usually supplied with commercial conductors.

\section{Relationship between $n$ and the statistical distribution of filament sizes}

In the preceding section, it was reported that the electric field versus current characteristics for sample A did not show the sharp take-off normally found in other $\mathrm{Nb}-\mathrm{Ti}$ :copper conductors we have tested. The effect was quantified in terms of a parameter, $n$, which for sample $A$ was only $\approx 18$, compared with values of $n=35$ for sample $\mathrm{B}$ and $n=53$ for sample $C$ (another high copper to $\mathrm{Nb}$-Ti ratio superconductor). The low value of $n$ was ascribed to irregularities (sausaging) in the filament diameter of sample A as observed in SEM longitudinal micrographs of isolated filaments.

To quantify these preliminary observations, a series of SEM micrographs of the complete cross-section of the conductor has been obtained (shown in Figures $3 b-5 b$ ).
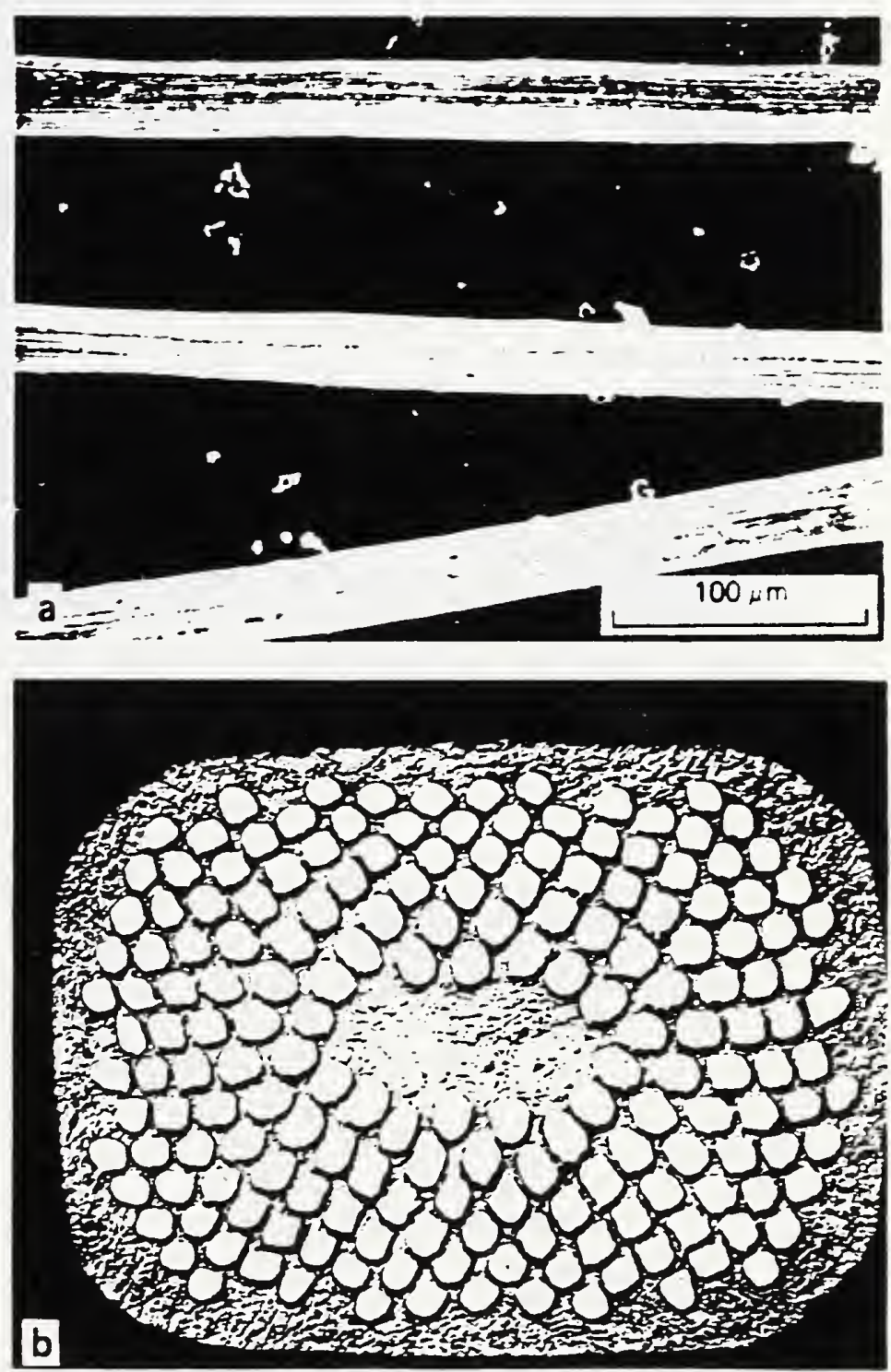

Figure 4 Longitudinal (a) and cross-sectional (b) views of the filaments in sample $B$

Table 1 Filament diameter variations for three Nb-Ti conductors

\begin{tabular}{|c|c|c|c|c|c|c|c|c|c|}
\hline Conductor & $\begin{array}{l}\text { Size } \\
(\mathrm{mm})\end{array}$ & $\begin{array}{l}\text { Number of } \\
\text { filaments }\end{array}$ & $\begin{array}{l}\text { Twist } \\
\text { pitch } \\
\text { (cm) }\end{array}$ & $\mathrm{Cu}: \mathrm{Nb}-\mathrm{Ti}$ & $\begin{array}{l}\text { Average } \\
\text { filament } \\
\text { diameter, } \\
\langle D\rangle(\mu \mathrm{m})\end{array}$ & $\frac{D_{\max }}{D_{\min }}$ & $\begin{array}{l}\Delta D \\
(\mu \mathrm{m})\end{array}$ & $\begin{array}{l}\text { Deformation } \\
\text { length } \\
(\langle D\rangle)^{\circ}\end{array}$ & $n$ \\
\hline $\begin{array}{l}\text { Sample A } \\
\text { Sample B } \\
\text { Sample C }\end{array}$ & $\begin{array}{l}0.51 \times 1.02 \\
0.56 \times 0.71 \\
1.00 \text { diameter }\end{array}$ & $\begin{array}{l}187 \\
180 \\
114\end{array}$ & $\begin{array}{l}1.8 \\
1.3 \\
2.5\end{array}$ & $\begin{array}{l}4.77 \\
1.8 \\
5.5\end{array}$ & $\begin{array}{l}27 \\
33 \\
37\end{array}$ & $\begin{array}{l}1.33 \\
1.20 \\
1.06\end{array}$ & $\begin{array}{l}8.9 \\
6.5 \\
2.2\end{array}$ & $\begin{array}{l}4 \\
8 \\
6\end{array}$ & $\begin{array}{l}18 \\
35 \\
53\end{array}$ \\
\hline
\end{tabular}



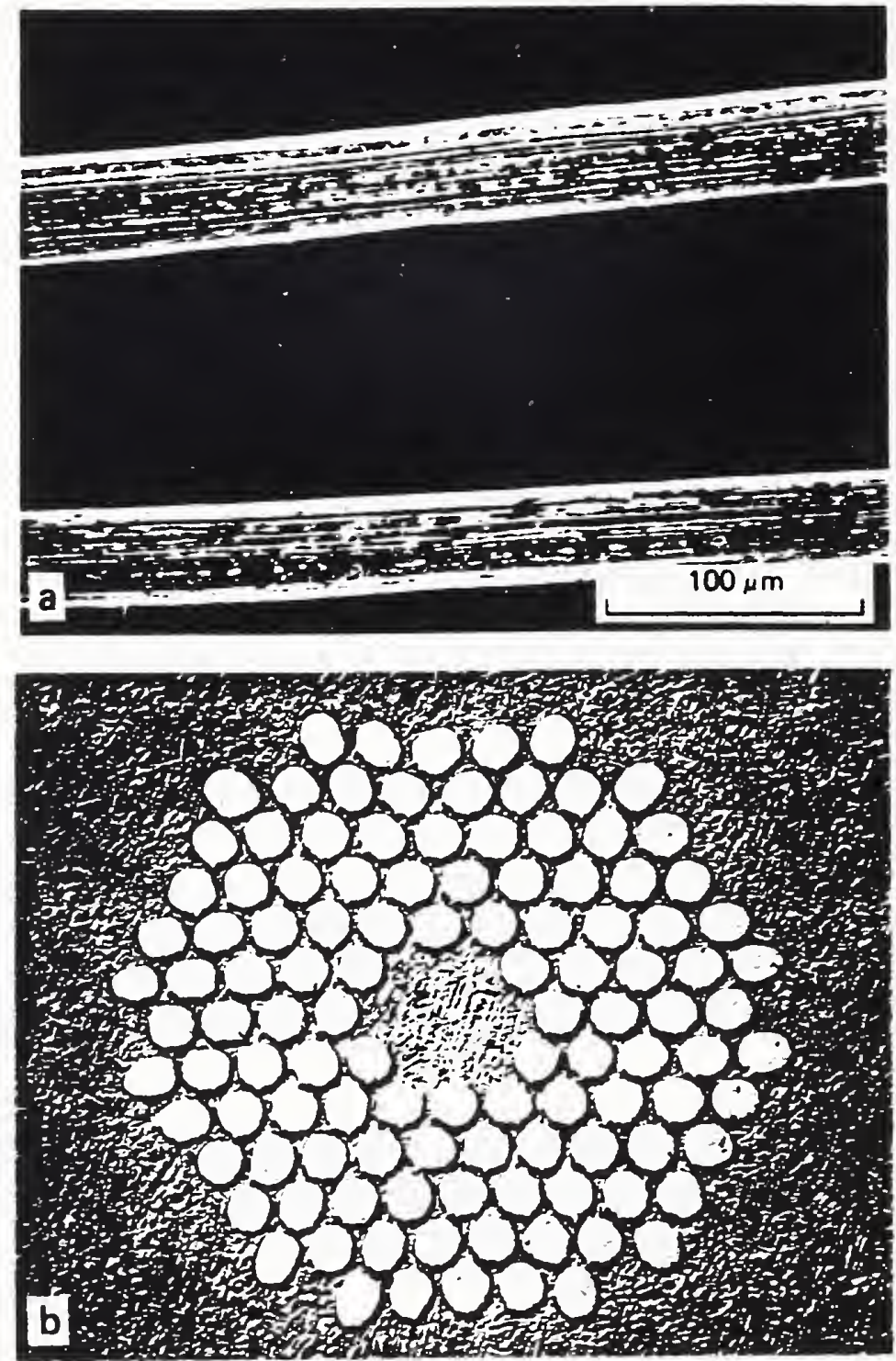

Figure 5 Longitudinal (a) and cross-sectional (b) views of the filaments in sample $\mathrm{C}$

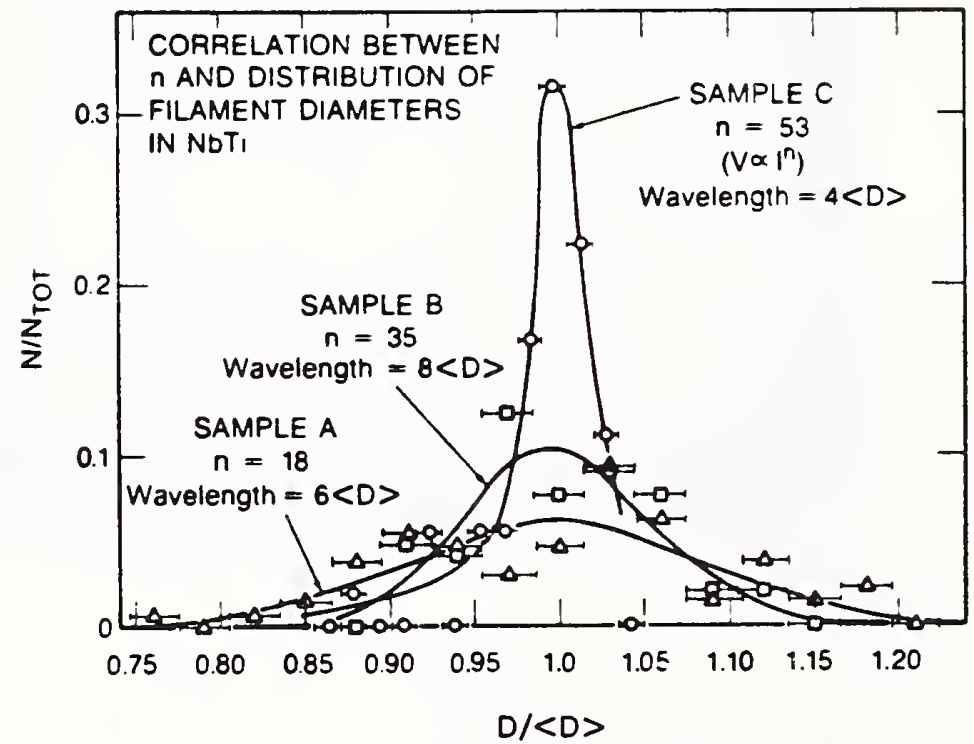

Figure 6 Distribution of filament diameters in samples A, B and C Horizontal bars indioete the sampling interval for each histogram. Irregularities in the cross-sectional area of each filament mainly determine $n$, rather than variations in the average filament diameter from filament to filament. In these samples, the average filament diameter varied with radial position in the composite. The radial effect was eliminated from the plotted distribution by determining the variation in diameter of each filament relative to the average diameter of other filaments at the same radial position
From many measurements of the individual filament diameter in these micrographs, a statistical distribution of the filament diameters in each conductor has been obtained. Figure 6 shows the distribution of filament diameters, $D$, about the average filament diameter of each ring of filaments, $\langle D\rangle$. The spread in the distribution for sample $A$ is much broader than for samples $B$ or $C$, confirming the earlier qualitative treatment given the filament irregularities. The half-width of the filament diameter distribution correlates very nicely with the variations in the parameter $n$. This evidence is consistent with the current transfer hypothesis advanced in the previous report as the explanation for the relatively large electric field appearing in sample $A$ at currents below the critical current.

In the SEM micrographs in Figures $3 b-5 b$ note the presence of the large centre island of copper in conductor samples B and C, compared with the lack of this feature in sample A. It is believed this centre copper island is a significant factor in minimizing the filament irregularity problem (particularly in conductors having a high copper to superconductor volume ratio).

\section{Addendum}

The $n$ values reported above were nearly independent of magnetic field from 3 to $7 \mathrm{~T}$. Over this field range they varied by less than $\approx 5 \%$. A graph of the standard deviation of the filament diameter distributions shown in Figure 6 is plotted as a function of $n$ in Figure 7. The

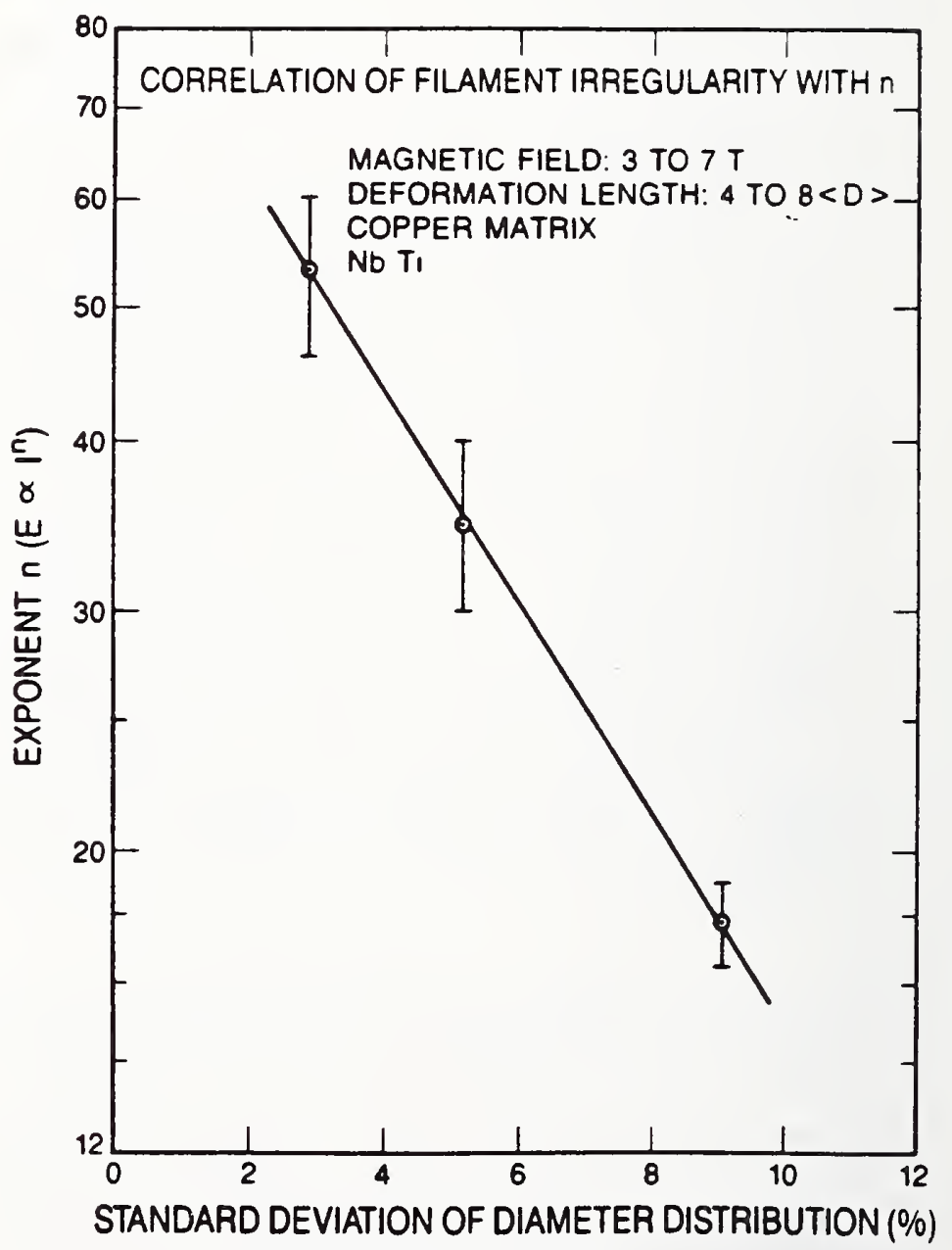

Figure 7 Approximate relationship between $n$ and the standard deviation of the filament diameter distribution for several multifilamentary $\mathrm{Nb}-\mathrm{Ti}$ superconductors (from Figure 6 ) 
approximate relationship shown in Figure 7 may be useful for quickly estimating the extent of filament irregularity in practical multifilamentary $\mathrm{Nb}$ - Ti superconductors from measurements of $n$.

\section{Acknowledgements}

The author extends his appreciation to E. S. Pittman and D. Rule for their assistance in reducing the filament diameter distribution data. and to L. F. Goodrich for several helpful discussions. This work was sponsored by the Naval Ship Research and Development Center and by the US Department of Energy. Division of High Energy Physics under Interagency Agreement No. DEA 105-85ER 40240.

\section{References}

1 Ekin. J.W. Superconducting Coil Characterization Quarterly Progress Report No. SR-724-13-82. Div. 724.05, National Bureau of Standards. Boulder. Colorado. USA (March 1982) unpublished. Distributed at the First Workshop on $\mathrm{Nb}-\mathrm{Ti}$ Superconductors, University of Wisconsin. Madison. Wisconsin. USA (July 1983)

2 Ekin. J.W. Superconducting Coil Characterization Quarterly Progress Report No. SR-724-26-82, Dir. 724.05, National Bureau of Standards. Boulder, Colorado. USA (June 1982) unpublished.
Distributed at the First Workshop on $\mathrm{Nb}-\mathrm{Ti}$ Supercon Juctors, University of W'isconsin. Madison. Wisconsin. USA (July 1983)

3 Garber, M. McInturf, A. and Larbalestier, D. presentations made at the Second Workshop on Nb-Ti Superconductors, University of Wisconsin, Madison, Wisconsin, USA (Jul! 1984)

4 Gregory, E., Hemachalam, K.. Hong, M., Garber, M.. Sampson. W.. Suenaga, M., McInturff. A. Warnes, W.H., Larbalestier, D. and Scanlon, R. presentations made at the Third Workshop on $\mathrm{Nb}-\mathrm{Ti}$ Superconductors, Lawrence Berkeley Laboratory, Berkeley. California, USA (January 1985)

5 Garber, M., Suenaga, M., Sampson, W.B. and Sabatini, R.L. Ad Criog Eng Plenum Press. New York. USA (1986) 32707

6 Lirbalestier, D.C. and West, A.W. Acta Mer (1984) 321871

7 Harnes, W.H. and Larbalestier, D.C. Proc Int Symp Flux Pinning and Electromagnetic Properties in Superconductors (Ed Matsushita. T., Yamafuji. K. and Irie, F.) Matsukuma Press, Japan (1986) 156

8 Evetts, J.E aod Plummer, C.J.G. Proc Int Symp Flux Pinning and Electromagnetic Properties in Superconductors (Ed Matsushita. T.. Yamafuji. K. and Irie. F.) Matsukuma Press, Japan (1986) 146

9 Plummer, CJ.G. and Evetts, J.E. IEEE Trans Magn (1987) MAG231179

10 Smathers, D.B., Marken, K.R., Larbalestier, D.C. and Scanlan. R.M. IEEE Trans Magn (1983) MAG-19 1417

11 West, A.W, Warnes, W.H Mofat, D.L and Larbalestier, D.C. IEEE Trans Magn (1983) MAG-19 749

12 Evetts, J.E IEEE Trans Magn (1983) MAG-19 1109

13 Voelker, F. Paricle Acceleraiors (1970) 1205

14 Jones, R.G., Rhoderick, E.H. and Rose-Innes, A.C. Phys Lell (1967) 24A 318

15 W arnes, W.H. and Larbalestier, D.C. Appl Phy:s Letr (1986) 481403

16 Warnes, W.H. and Larbalestier, D.C. Cryogenics (1986) 26643

17 Warnes, W.H. and Larbalestier, D.C. IEEE Trans Magn (1987) MAG-23 1183 


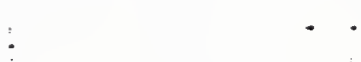


J. W. Ekin

Electromagnetic Technology Division

National Bureau of Standards

Boulder, Colorado 80303

\section{ABSTRACT}

The effects of varlous types of stress on the crltica: current of a multifilamentary NoT1 superconductor a.e reported. Degradation of critical current due to axlal tension applled at $4 \mathrm{~K}$, transverse compression applied at $4 \mathrm{~K}$, and halrpln bending strain applied at room temperature has been measured. The degradation from axlal tension is wuch greater tian from transverse compression in many practical cases because the soft copper matrix limits the bulldup of transverse compression. The degradation from typical levels of transverse compression is only about 45 at $8 \mathrm{~T}$, for example. For axial tension, on the other hand, hlgher stresses can occur that w111 degrade the critlcal current by $24 \%$, for example, at $7 \mathrm{~T}$ and $2.7 \%$ siraln. Both the axlal-tenslle and the transverse-compressive stress effects are about 98\% reversible; thus the degradation will be seen only when the conductor is under operational stress. The results indlcate that a primary or 1 in of the critical curreat degradation in NoT1 is a stress-induced reversible decrease in the upper critical fleld.

\section{INTRODUCTION}

In the inltial phase of tinis study, reported here, severa: types of mechanlcal tests were made on the same concuctor materlal to evaluate the critlcal- current dezradation from different types of stress. Once identified, the most important siress tests w111 be perforsed on many different conductors in a later phase of testing to obtain a data base useful for minimizing critical-current degradation in magnet design.

In this paper, measurements of the effect of $4-k$ transverse compressive stress on the critical current of NOI 1 are reported. These results are compared with the effects of axial tenslon applied at $4 \mathrm{~K}$ and severe hatrpin bending strain applied at $295 \mathrm{~K}$, all measured on samples of the same NoTI conductor. The conductor chosen for tnese first tests was the strand materlal used to make many of the 30-strand Rutherford cables in the Lawrence Berkeley Laboratory (LBL) cabledevelopment program.

\section{TRANSVERSE COMPRESSION TESTS}

The effect of axial tension on the critical current of practical multifllamentary NoI1 superconductors was first studied about ten years ago. ${ }^{1}$ Little electromechanlcal research has been made on NOT1 superconductors since then, and this has been mostly axial stress studies.? Less is known about the effects of stress components other than the axial component. 3 In pract lcal superconducting magnets, however, the superconductor is subjected to threedimensional stress. Typically the transverse component of stress is compressive. For example, in solenoldal magnets the transverse component arlses irod hoop stress which compresses the magnet winding radially. In dipole magnets $1 t$ arises from Lorentz rorce compression of the magnet windings at the midplane.

Manuscript recelved September 30, 1986. Contribution of NBS, not subject to copyright.
To obtain data on the effects of this component of stress on the crltical current of practical superconductors, a transverse-stress apparatus was designet and bullt. It simultaneously applies mutually perpendicular components of current, high magnetlc fleid, and transverse compressive stress to a single strand superconductor in a $4-K$ liquid hellum bath.

The sample is prepared in the shape of a flat sided halrpin. Compressive load is applled by sandwiching the central plat section of the hairpin between two stainless-steel anvil heads. Magnetic fleld is applied mutually perpendlcular to both the directions of the force and the sample current with a radial access magnet. The fleld is also perpendicular to the hairpin legs of the sample to minimize curreattransfer effects. (Otherwlse, if the hairpin legs were paralle! to the applied magnetic fleld, a large difference in critical current would ar ise between the legs and the central section.) Further detalls and plctures of the apparatus are given in Re?. 4.

The plrst test results were obtalned on an unused segment of NoT1 strand materlal simllar to that used to make many of the 30-strand Rutherford cables in the LBL cable development programs. The NoT1 strand characteristics are given in Table 1. The sample was manufactured using a single stack technlque without a diffusion barrier around the fllaments.

Figure 1 shows the degradation of critica!current by transverse stress applied to the sample at $4 \mathrm{~K}$. The ordinate in Fig. i is the measurec critical current normalized by 1 ts starting (zero-stress) value. The absissa is transverse force per unit sample length, F/L (top scale). A second abscissa scale is also shown (bottom scale) which is an effective overall transverse stress obtained by dividing the applied load by the projected area of the sample in the direction of the applied load. Inis projected area is simply taken as the length over which compressive load is applied $(9.5 \mathrm{~mm}$ ) multiplled by the starting sample dlameter ( $0.648 \mathrm{~mm}$ ).

\section{TRANSVERSE FORCE PER UNIT LENGTH, FILRNUm)}

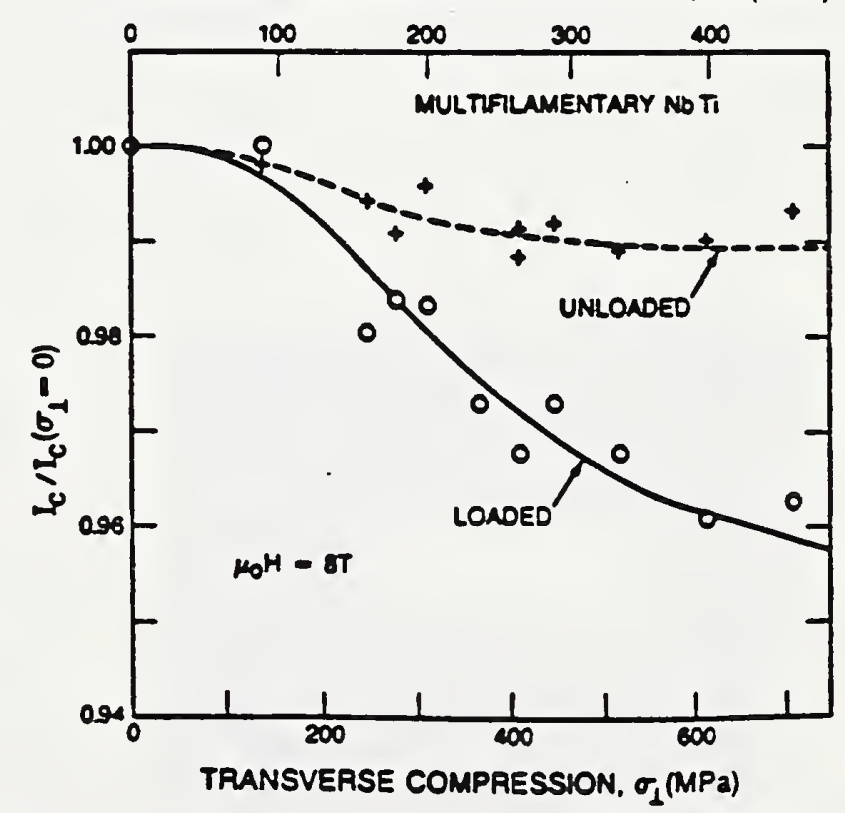

Figure 1. Effect of transverse compressive force on the eritical current a NoT! conductor at $8 \mathrm{~T}$. 


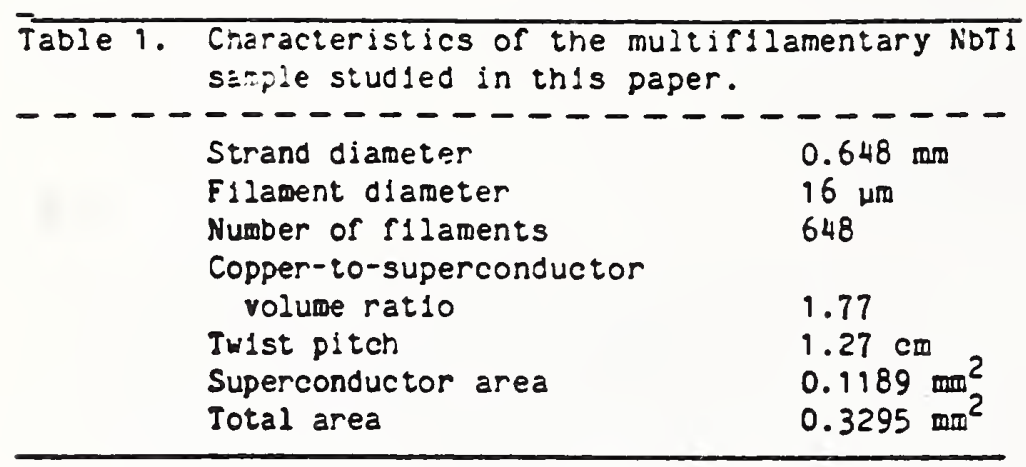

Inis effective stress is given for comparative purposes only. In the experiment, the anv1l heads were flat and the sample round, so this simple method of determining stress does not take into account the small initlal contact area, nor the increase in contact area between the anvil heads and the sample as the sample is progressively deformed. However, it represents reasonably well the approximate average stress experlenced by the NOI 1 fllaments within the composite.

The overall sample strain was quite great because of deformation of the soft copper matrix. It amounted to about $24 \%$ at the maximum value of forceper-sample-length $(E / \mathrm{L})$ of $458 \mathrm{kN} / \mathrm{m}$. In1s overall sample strain, however, is typically much greater than the actual NbTI fllament strain because the copper matr 1x material yielos at a relatively low stress. A plcture of the deformed sample after the maximum loading $(F / L=458 \mathrm{kN} / \mathrm{m})$ at $4 \mathrm{~K}$ is shown in Fig. 2.

The separation of the voltage taps was relatively small, $8.7 \mathrm{~mm}$. Consequently a relatively high critical-current voltage criterion was used, corresponding to an electric fleld of $5 \mathrm{\mu V} / \mathrm{cm}$. The critical-current values at more sensitive crlterla are easily calculated, however, using the measured values of the exponent $n$ given in Fig. $3\left[I_{c 1} / I_{c 2}=\right.$

$\left(E_{c 1} / E_{c 2}\right)^{1 / n_{j}}$. Note that for this sample, which was fabricated using a single stack technique with relatively large fllaments $(9 \mathrm{\mu m})$, I reached values of about 80 at low magnetic rields. Th1s is relatively high for multiflamentary NbT1 superconductors.

As seen from the results at $8 \mathrm{I}$ in Fig. 1 , 11ttle degradation ( $50.5 \%$ ) was observed for this particular sample up to a $F / L$ value or about $100 \mathrm{kN} / \mathrm{m}$ (corresponding to an approximate transverse compressive stress, ol. of about $150 \mathrm{MPa}$ ). The degradation effect then increased monotonlcally to about $4 \$$ as $\mathrm{F} / \mathrm{L}$ was increased to $460 \mathrm{kN} / \mathrm{m}(0 \mathrm{l}=700 \mathrm{MPa})$. Because the yleld stress of the copper matrix is so low, it is difficult to generate much higher stress without severe sample deformation; see F1gure 2. Thus, the maximum critical-current degradation from transverse stress is about 48 at $7 \mathrm{I}$.

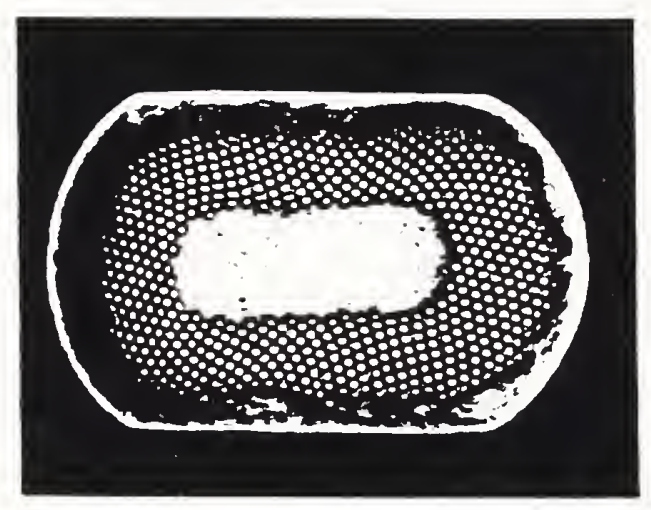

F1gure 2. Cross section view of the NDT1 conductor after application of $458 \mathrm{kN} / \mathrm{m}$ transverse load at $4 \mathrm{~K}$.
The effect was almost completely reversibje. Upon unloading from $: / \mathrm{L}=460 \mathrm{kN} / \mathrm{m}$, the critical current recovered to within 0.58 of 1 ts or 1 ginal value. This recovery took place even though the sample was permanently deformed by about $25 \%$.

The transverse stress degradation was largest at high magnetlc fleld. At lower flelds ( $5 \mathrm{I}$ and $3 \mathrm{I})$ the effect was less than 0.5 at a $F / L$ value of $460 \mathrm{kN} / \mathrm{m}$.

\section{AXIAL TENSION TESTS}

Iests at Magnet1c Flelds Up to 7 I

To compare the relative magnitudes of the effects of transverse compression with axial tension, another sample of the same starting material (see Table 1) was tested in an axial tensile mode. The experiments were carried out using an apparatus described in Rei. 6.

Results corresponding to a $5 \mathrm{uV} / \mathrm{cm}$ criterion (the same as that used for the transverse compression tests) are given in Fig. 4 as a inction of stress and strain. Stress was calculated using the overall conductor cross sectional area. The results of $F 18$. 4 compared with F18. I show that the effect of axial tensile stress applled at $4 \mathrm{~K}$ is signiflcantly greater than the effect of transverse compression at $4 \mathrm{~K}$, in terms of the overall stress on the conductor. For example, the degradation of the critlcal current at 7 $I$ is about 248 at an average tensile siress of $700 \mathrm{MPa}$ (tensile strain of 2.78). Inis compares with an $8 \mathrm{I}$ degradation of about $4 \$$ at $700 \mathrm{MPa}$ transverse stress, about one sixth.

However, because the copper matrix has a relatively low yleld stress (about $130 \mathrm{MPa}$ ), the axial stress in the NOT1 Pllaments 1 actually higher (about 2.1 times higher) than the overall stress on the conductor. Accounting for this, the degradation from axlal tension at $700 \mathrm{MPa}$ in the NDII filaments corresponds to about $340 \mathrm{MPa}$ overall conductor stress, or a degradation of only about 77 at $8 \mathrm{I}$. Thus, the two effects (axlal and transverse) are nearly comparable in terms of actual NDI1 fllasent stress. The slight difference in critlcal-current degradation between the two components of stress may arlse from texturing of the fllaments introduced during fabrication.

Much more stress can be developed in the NbT1 fllaments from axial tersion than from transverse

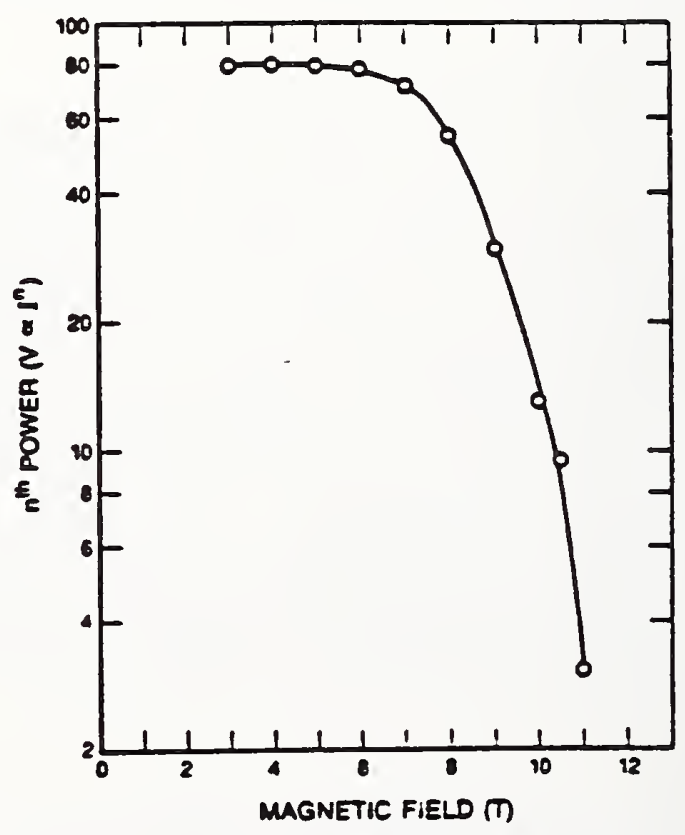

Figure 3. Magnetic rleld depencerse of tr:e Exporiert n. 
compression because the sort copper matrix linits the buildup of transverse compression. Thus, in many practical cases, axlal tenslle stress is the more important source of critical-current degradation.

In other respects the two types of stress effects (axial and transverse) are similar. Both stress effects increase with increasing magnetic field. For example, the degradation at an axlal stress of $700 \mathrm{MPa}$ (2.7\% strain) was 198 at $3 \mathrm{~T}$, and increased to 268 at $7 \mathrm{~T}$. For transverse stress, the degradation was negligible ( $50.5 \%$ ) below $5 \mathrm{~T}$, and increased to 48 at $8 \mathrm{~T}$.

Both types of stress efrects are also highly reversible. For example, upon unloading from an applied axial stress of about $700 \mathrm{MPa}$ (strain of 2.7\%), the critical current at 5 I recovered to within is of its original value. This extreme reversiblitty persisted up to the fracture point of the sample, which occurred at a strain of 4.06\%. Just before the sample fractured, the critlcal current still recovered to within $1.5 \%$ of its original value upon unloading.

A significant serrated yleld event (load drop of $10 \%$ ) took place at a tensile strain of $3.0 \%$. Figure 4 shows that this did not signiflcantly affect the smooth monotonic decrease of the critical current with stress and strain.

However, a thermal runaway event, a "quench" took place while the sample was under high stress, 842 MPa ( $3.5 \%$ strain), which did significantly affect the critical current degradation. As shown in F18. 4, the critical current rose significantly after the transient heating that accompanied the thermal runaway and current-supply shutdown. During this quench the strain in the sample was maintained constant, but the stress decreased about is: due to annealing. Thus, the event indicates that critical-current degradation in NDI1 is predominantly stress controlzed rather than strain controlled, since strain was constant whlle both the stress and critical current recovered. The event suggests that strain and deformation alone are not the prime causes of degradation in NOT1, but rather the stress that accompanies deformation is the major cause, at least at $4 \mathrm{~K}$. Thus, stress annealing the conductor wight be a method for improving the critical current.

\section{Tests at Magnetic Fields Above $7 \mathrm{~T}$}

To measure the effect at magnetic fields approaching the upper critlcal fleld, another serles of tests was made at fields above $7 \mathrm{~T}$ using an apparatus described in Ref. 7. The results are given in Fis. 4 along with the low-field results.

These data show that the relative magnituse of the stress effect becomes much larger as the wasnetic field approaches the upper critical fieid. he 2.14\% strain, for example, the critical-current cestedation is 198 at $8 \mathrm{~T}, 248$ at $9 \mathrm{~T}, 428$ at $10 \mathrm{~T}$, ant $r$ ises to 608 at $10.5 \mathrm{~T}$.

\section{HAIRPIN BEND TEST AT $295 \mathrm{~K}$}

To compare these $4 \mathrm{~K}$ stress efrects with room-temperature bending-strain effects, the same superconductor strand material was subjected to a severe bending strain test. The conductor was bent into a halrpin shape at $295 \mathrm{~K}$ and placed transversely to the bore of a 9 I solenoidal magnet. This fleld orientetion was chosen to reduce current-trans:er effecis.

The sample was subjected to bending sirain, starting at about 158 and increasing to a littie ove? 100\%. This was done progressively in the same sampie by bending it at room temperature, cooling the sampie to $4 \mathrm{~K}$, measuring $I_{c}$, warming the sample to roor terperture, bending the sample into a tighter radius, e:s repeating the whole process. The critical current wiss measured at each radius until the radius was reduced to nearly zero.

The I results corresponding to a $5 \mathrm{uV} / \mathrm{cr}$ criterion are shown in Fig. 5. In this rigure, the relative critical-current degradation is plotted as a function of bending strain in the outer rilaments, $\varepsilon_{B}$. Critlcal current was measured for current flowing
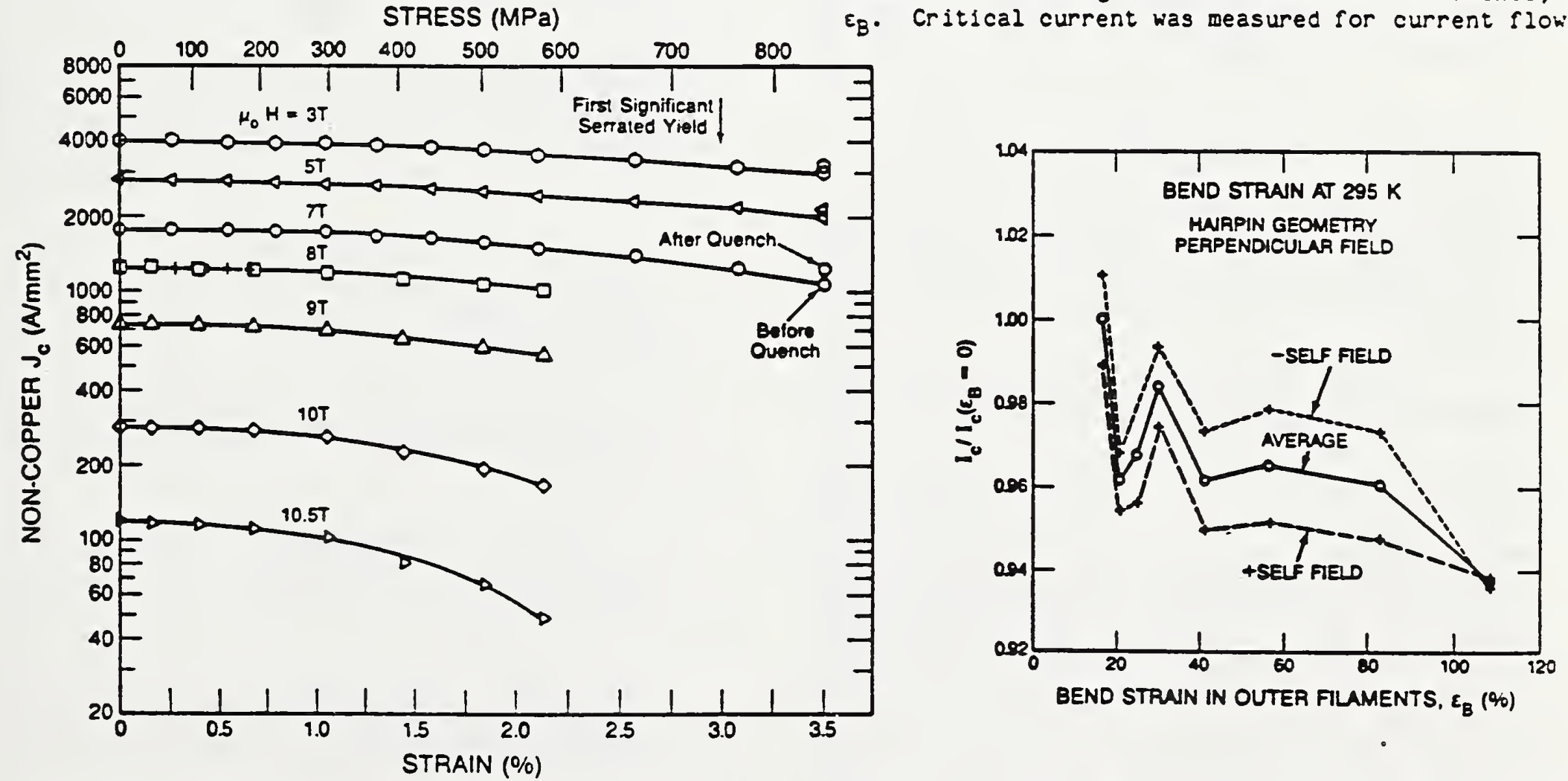

Flgure 4. Effect of axial tensile strain and stress on the critlcal current of a NoTI conductor at magnetic slelds frow $3 \mathrm{~T}$ to $10.5 \mathrm{~T}$. A much coarser scale was used here than in Figs. $I$ and 5 .
Figure 5. Effect of room-temperature bend strain on the critical current of a NDTi conductor at $8 \mathrm{I}$. The abscissa is the calculated bending strain in the outermost rllaments. 
in two directions in the hairpin sample, one direction where the self rield of the sample added to the background field (marked +) and the other where the self field subtracted from the background fleld (marked -). The average of the two critical-current values is plotted with open circles in Fig. 5 .

The magnitude of the degradation at the high bending strains shown in Fig. 5 is small. The erfect of room temperature bending strain on the critical current is less than $4 \%$ at bending strains of over 100\%. All bending was done at room temperature, and there was no stress applied to the sample when it was cooled for the critical-current measurement. Further bend tests need to be made to better simulate cabling conditions. Note that the conductor strand was not under tension when 1 t was bent, nor was it bent around a mandrel or severely pressed. The critical current under bending strain also needs to be measured at lower electric sields.

\section{CONCLUSION}

The main results of these measurements are summarized below:

1. The magnitude of critical-current degradation in NOTI from transverse compression applied at $4 \mathrm{~K}$ is much less than from axial tension in terms of overail conductor stress, but the two are comparable in terms of stress in the NDI1 filaments.

2. Much more stress can be developed in NoTl filaments from axial tension than from transverse compression, because the soft copper matrix 11mits the bulldup of transverse compression to low levels. At such levels the I degradation is only about is at 8 $T$, for example. Thus, in tany practical cases, axial tensile stress (from tension or bending strain) is the more important source of critical-current degradation. For example, the $I_{c}$ degradation is $24 \%$ at $7 \mathrm{~T}$ when the NoI1 lilaments are axially strained $2.7 \%$.

3. The I degradation from both types of stress is about $98 \%^{\circ}$ reversible, indicating that the effects of stress in NDIi will be seen only when the conductor is under stress.

4. The data indicate that a primary origin of the critical-current degradation in NDTi is a stress induced reversible decrease in the upper critical field. This is true for degradation due to both transverse-compression and axial-tension degradation. It is shown by the large relative increase in the critical-current degradation from both types of stress as the magnetic field approaches the upper critical sield.

There are several practical consequences of these prelioinary findings for cable fabrication:

1. In Rutherford cables, not wuch transverse stress is generated in the NDTi fllaments along the cable faces because of ylelding of the soft copper matrix material surrounding the fllaments. Huch more stress can be developed in the NbTI Illaments from axial tension at the cable edges where they are bent around the cable. Inis may explain the relatively small degradation measured along conductor strands extracted from the face of Rutherford cables compared to the edge region. 8

2. The potentially large effect of axlal tension indicates that tension on the cable strands should be set at the minimum level needed for cable integrity.
3. Stress annealing the conductor nay improve the critical current under some circtmstances.

Additional measurements will be needed to determine whether the effect is predominastly a very low temperature (4-K) stress phenomenon or also arises from stress applied at higher temperatures. The consistency of the effects among different NDI 1 superconductors needs to be tested and further bend testing is needed to relate this to the axial tension results.

\section{ACKNOWLEDGEMENTS}

J. C. Brauch, C. A. Thompson, and D. L. Ruze helped with apparatus design and construction as well as data acquisition and reduction. R. M. Scanian, J. M. Royet, C. Taylor, L. F. Goodrich, A. F. Clark, and members of the NBS Superconductor and Magnetic Measurements Group contributed a number of helpful discussions to this research. Thanks are also extended to E. S. Pittian for preparing the photomicrograph in Eig. 2, R. A. Shenko for typing the manuscript and $R$. B. Goldfarb for a detalled reading of the text. This research was supported by the U.S. Department of Energy, Div. of High Energy Physics under Interagency Agreement No. DE-AI05-E5 $\equiv R 40240$. The high magnetic flelds needed for part of this study were obtained using the magnet facilities of the Francls Bltter Natlonal Magnet Laboratory.

\section{REFERENCES}

1. J. W. Ekin, F. R. Flckett, and A. F. Clark, "Effect of Stress on the Critical Current of Noti Multifilamentary Composite Wire," Proc. Int'1. Cryog. Mat. Conf. (Aug. 1975), hdv. Cryo. Eng. 22 449 (1977).

2. For a review, see J. W. Ekin, "Mechanical Properties and Strain Effects in Superconcuctors," in Superconducting Materials Science: Metallungy, Fabrication, and hpplications, edited ty S. Foner and B. B. Schwartz, Plenum Press, New York, $p$. 455-510 (1981).

3. The effect of critical-current anisotropy introduced by room-temperature rlattening has been studled by Garber, unpublished, and by L. F. Goodrich, W. P. Dube, E. S. Pittwan, and A. F. Clark, Adv. Cryog. Eng. 32, 833 (1986).

4. J. W. Ekin, L. F. Goodrich, J. Morelant, E. S. Plttman, and A. F. Clark, "Electrorechanical Properties of Superconductors for High Energy Physics Applications," NBS Iniernal fieport, NeSiR (86-306i (1986), in press.

5. J. Royet and R. M. Scanlan, "Manufacture of Keystoned Flat Superconducting Cables for Use in SEC Dipoles," Paper LB-1 of these cor:ierence proceedings.

6. J. W. Ekin, "Superconductors," Chapt. 13 in Materials at Low Temperatures, edited by R. P. Reed and A. F. Clark, American Soc. Sor Metais, $p$ 465-513 (1983.)

7. J. W. Ekin, "Strain Scaling Law for Fiux Pinning in Practical Superconductors, Part I: Basic Relationship and Application to $\mathrm{ND}_{3} \mathrm{Sn}$ Conductors," Cryogenics $20,611-624(1980)$.

8. L. F. Goodrich, E. S. Pittman, J. W. Ekin, and R. M. Scanlan, "Electromechanical Proper: :ES of NoTi Strands Extracted Frod Cabies," Fapte wit-s of these conference proceedines. 


\title{
STUDIES OF NUTI STRANDS EXTRACTED FROM CORELESS RUTHERFORD CABLES
}

\author{
L. F. Goodricn, E. S. Pittman, and J. W. Ekin \\ National Bureau of Stanoards \\ Boulder, Colorado 80303
}

and

R. M. Scanlan

Lawrence Berkeley Laboratory

Berkeley, Callpornia 94720

\section{Aostract}

The electromechanical propertles of NoTl strands extracted Prow coreless Rutherford cables were studied to clarify the relative effects of strand location and field angle on current degradation that occurs in cables that have been compacted into a keystone snape. Detailed critical-current measurements were made on two samples wnich were fabricated under controlled conditions. These are prototype cables for high energy pnysics applications. Speciflc Pdctors that are addressed are the nature, location, and amount of degradation. This information is intended to lead to wetnods for reducing the amount of critical-current degradation in saole manufacture.

\section{Introduction}

The measurements reported here were made on two samples, denoted as Sample A (billet 5914, cable SC 305 ) and Sample $B$ (Dillet 52:2, cable SC 297). Sample A was a strand from a cable that was comonly used for cable studies late in 1985 and early 1986. Sample $B$ was a strano frow a cable that was re-rolled througn the turksnead (to re-size it) after it had been cabled. Inis re-rolling may have been done in the direction opposite the original cabling and roll direction. The re-rolled cable Sample $B$ was a worstcase situation that was studied to more clearly identify the degracation features. The comparison of the results of measurements on these two cables indicated significant similarities and differences. The critical current, $I_{c}$, of strands extracted from cables was

measured as a function of position along the cable and magnetic field or ientation. A more complete report on this work can be pound in Ref. 1. Information on the saole fabrication and current density with nign nomogeneous NDTL alloy can be found in Refs. 2,3 and 4 .

\section{Experimental Detalls}

The samples were from 30-strand caoles and started as 0.65-m-diameter round wires with a right hand fllament twist of about $0.8 \mathrm{twist} / \mathrm{cm}$. The cable had a left hand lay with a 69-mm pitch and a cable width of $9.7 \mathrm{~mm}$, wid-thickness of $1.17 \mathrm{~mm}$, and a keystone angle of about $1.24^{\circ}$. Sample $A$ had a No diffusion barrier on each of the 6006, 5-um-diameter filaments. Sample $B$ had 648, 16-um-dlameter Pllaments and did not have a diffusion barrier. The Sample A billet das double stacked; Sample B was single stack. The starting-wire critical currents (before the cabling process) were determined at $5 \mathrm{I}$ and $4.02 \mathrm{~K}$ using $\mathrm{a} 0.1$ WV/cm criterion (Sample A, 320 A; Sample B, 347 A). The critical-current density was calculated using the NOTI cross-sectional area (Sample A, $2500 \mathrm{~A} / \mathrm{mm}^{2}$; Sample B, $2900 \mathrm{~A} / \mathrm{mm}^{2}$ ), which was determined using the copper-to-superconductor volume rat10 (Sample $A, 1.64$;
Sample B, 1.77). The critical-current density at 4.22 $K$ would be about 68 less than the values $1: s t e d$ at $4.02 \mathrm{~K}$.

A number of voltage taps were placed along the length of the strand to determine its local electrical propertles after it had been deformed oy the cabling process. Three reglons of the caole were studied: the thin edge, the face (top or bottom), and the thick edge. Each of these reglons was divided with voltage taps into three approximately equal-length, adjacent segments. The three segments of each cable eage were denoted as the central flat edge ano the two corners (bent portion). These edge voltage taps nad separations of 2 to $2.5 \mathrm{~mm}$ (thin eage) and 2.5 to $3 \mathrm{~mm}$ (thick edge). The voltage taps along the face of the cable had separations of about $9 \mathrm{~mm}$ and tney did not include any of the cable corner regions. The precision and accuracy of the critlcal current measurements were limited by the low voltage for these closely spaced voltage taps and the fact that the sample would quench before very much voliage drop could be developed between some voltage taps. The precision was about \pm 18 and the accuracy was about $\pm 2 \%$.

The effective critlcal current was defined as the critical surrent determined by adding the voltage contributions of each strand segment, taking into account that the positions along the pace need to be counted twice for one pitch length. Inls total voltage was then converted to an effective electric field by dividing by one pitch length. This was useful because it related more directly to measurements made on the whole cable where several pitch lengths were included between the voltage taps.

\section{Results}

The data presented here are preliminary in that they may not represent averages of a number of specimens. There is no reason to belleve, however, that these two specimens were not typical. Independent measurements on the cables 5 Indicated that Sample $A$ was degraded by about 98 and had a fleld anisotropy of about 118 and Sample $B$ was degraded by 228 and had an anisotropy of -118 . Anisotropy refers to 1 minus the ratio of perpendicular $I_{c}\left(90^{\circ}\right)$ to parellel $I_{c}\left(0^{\circ}\right)$

and degradation refers to 1 minus the ratio of perpendicular I to starting,wire $I_{c}$ (see Ref. 6). These results are consistent with those presented here. These additional data presented here on the nature, location, and amount of degradation are intended to lead to methods for reducing the degradation.

In the pirst run of Sample B, the thin edge had the lowest critlcal curent, and this region was 1101 ing the current. For the second run, a short section of the thin edge was shunted with a $0.7-\mathrm{cm}$ length of 
another cabil strand. This allowed the current to get slightly higner and enabled testing of the otner regions of the strand before the sample quenched. The data presented for Sample $B$ are a comoination of these two runs, not shunted and shunted.

The critical current as a function of position along the strand at $0^{\circ}$ and $90^{\circ}$ field angle is given in Figs. 1 and 2 for Sample $A$. The critical current was defineo as the current at which the electric pleld strengtn was $0.1 \mathrm{HV} / \mathrm{cm}$. The zero angle was depined as the orientation with the magnetic fleld parallel to the wide face of the cable. The critical current values varied by as much as $27 \%$ from the maximum at $0^{\circ}$ and 118 at $90^{\circ}$. At $0^{\circ}$ the central flat portion of the thin edge had the lowest $I_{c}$. The central flat portion of the thick edge was less degraded. The corners of Doth edges had a higner $I_{C}$ and had some asymetry in

the same cable lay direction. Inls may be due to mass flow away from the cable eage during the cable fabrication. The difference between 0 and $90^{\circ}$ is due to the effect of the conductor aspect ratio ${ }^{7}$ and the fact that the applied magnetic fleld is not exactly perpendicular to the current for all portions of the strand at all angles. The cable pitch is about $17^{\circ}$, which would increase $I_{C}$ at $0^{\circ}$ by about $8 \%$ for the portions across the cable face. ${ }^{8}$ At $90^{\circ}$ the applied magnetic field is perpendicular to the cable face, but it is not perpendicular to portions of the cable edges. The major deformation direction for the cable edge is $90^{\circ}$ from that for the cable face. The eages have their lowest $I_{c}$ at $0^{\circ}$. The central region of the cable face does not have very much change in $I_{c}$ between 0 and $90^{\circ}$ because the strand is almost round there.

The critical current as a function of position at $0^{\circ}$ and $90^{\circ}$ for the Sample $B$ is given in Figs. 3 and 4 . The critical current values varied by as mucn as $35 \%$ from the maximum at $0^{\circ}$ anc $33 \%$ at $90^{\circ}$. At $0^{\circ}$ the

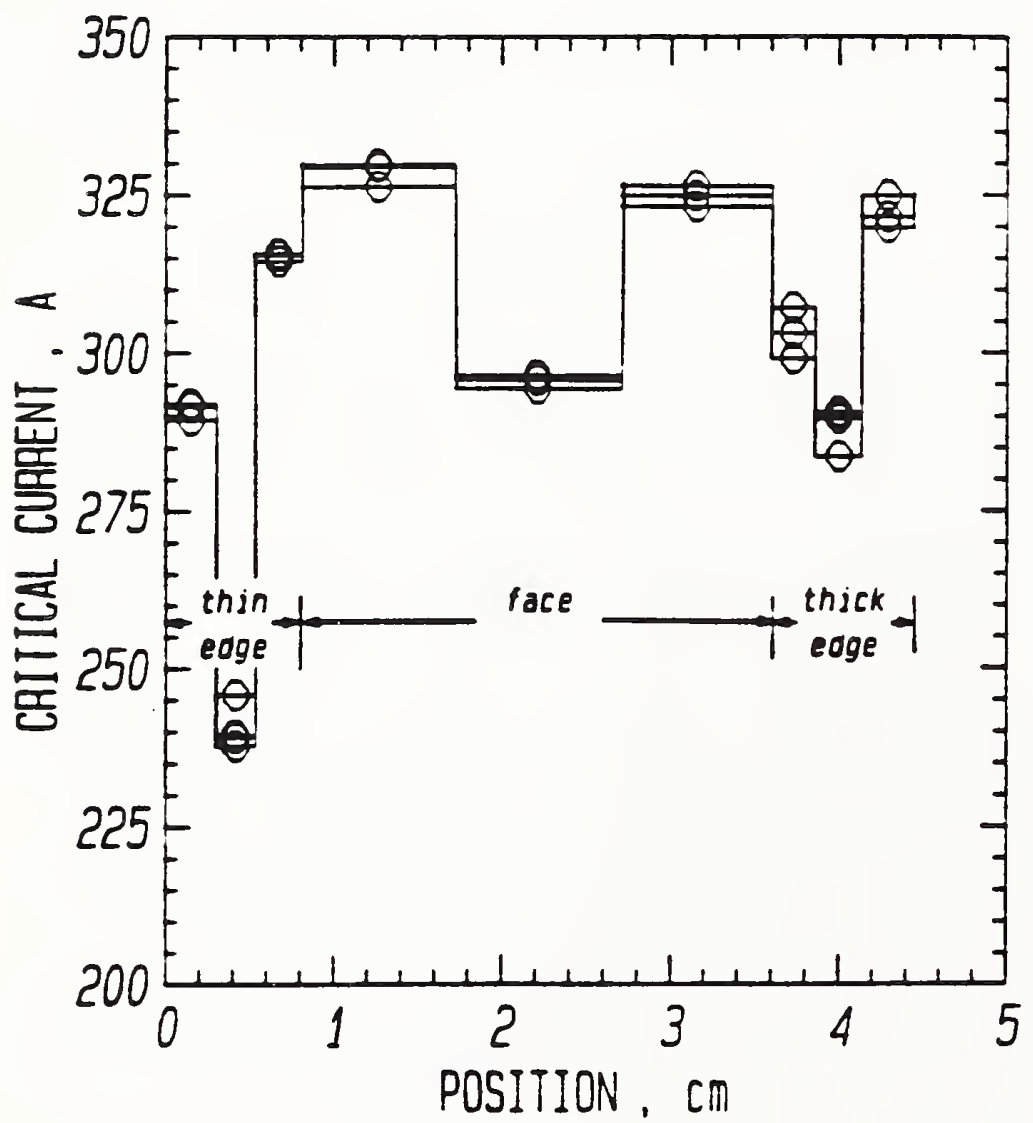

Figure 1. Sample $A, I_{c}$ vs, position at $0^{\circ}$. central flat of the thin edge had the lowest: ${ }_{Q}$, and unlike Sample $A$, it did not increase very mucn a. $90^{\circ}$. For both samples the difference between the this and thick edges were similar, as were the corner values. The central flat region of the thin edge is the weak link and would appear to have a degraded ic rather than a large aspect ratlo effect. 6

A relevant question at this point is: what is the effective critical current of these siranas as a function of orientation? One possibility is the current at whicn the average electric fiela strength is equal to some value (see experimental section). The effective critical current and quencn current $f=$ ? Sample $A$ are plotted as a function of angle in Fig. $三$. The effective critical current at various electric rleld criteria had an angular dependence very simi:iar to the quench current. This was not expected considering that the quench current should be strongiy dominated by the degraded section (or weak link) c? the strand and consequently lower at $0^{\circ}$. This suggests that the average $E$ does give a relevant critical current. The end cooling around the weak link must have been sufficient such that the local heating did not nave an adverse effect on $I_{c}$. The

weak link at $0^{\circ}$ contributed about $55 \%$ of the total voltage even though it oniy represented $5 \%$ of the total lengtn. For the effective critical current, tre weak link region is at a high electric field where tre effect of a single bend is not as large (See Ref.? for effect of benaing).

The effective critical currents and quench current for Sample $B$ are plotted as a function of angie in Fig. 6. There are two curves without symbols. The upper was the quench current after a shunt was placec on the thin edge. The lower was the quench current Defore the shunt was placed on the thin edge. The lowest curve is the effective $I_{c}$ at $0.1 \mathrm{iV} / \mathrm{cm}$. The

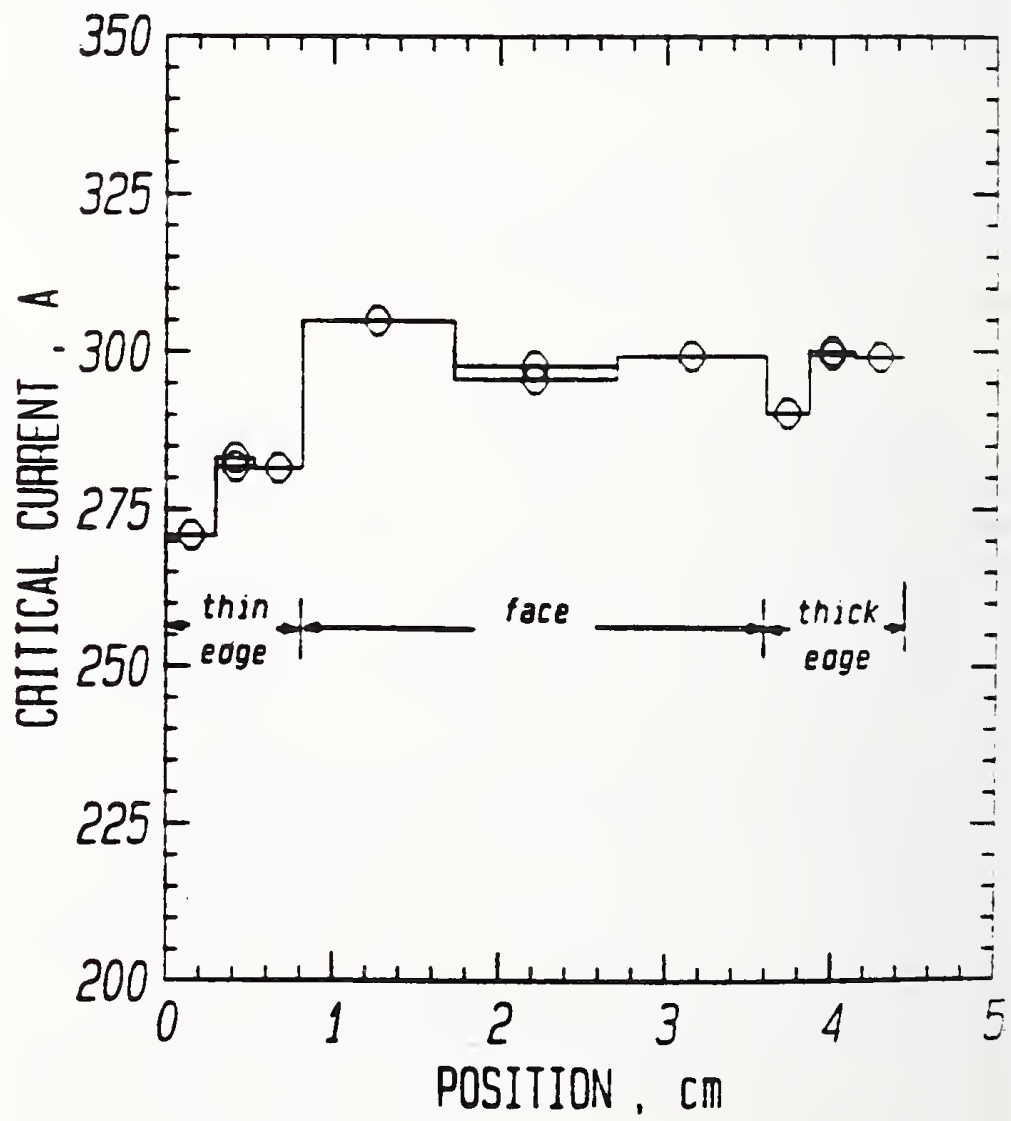

Figure 2. Sample $A, I_{c}$ vs. position at $90^{\circ}$. 


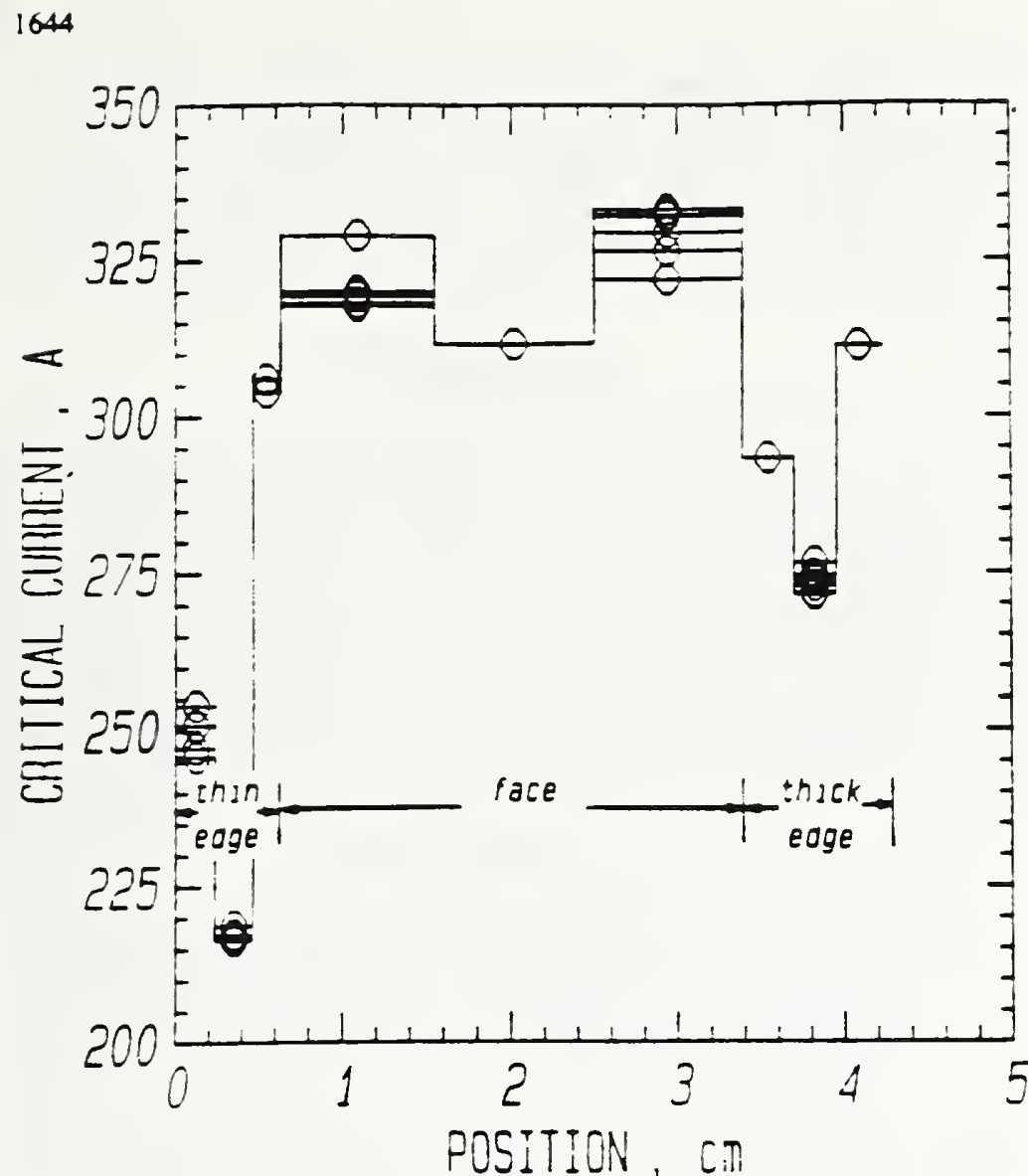

E:sure 3. Sample B, I vs. position at $0^{\circ}$.

reak link at $0^{\circ}$ contributed adout $95 \%$ of the cotal voltage even thougn it represented only $5 \%$ of the total lengtn.

Table 1 snows the percent differences of the ic's from the starting wire (before cabling) values. The starting wire Ic's are approximate because they

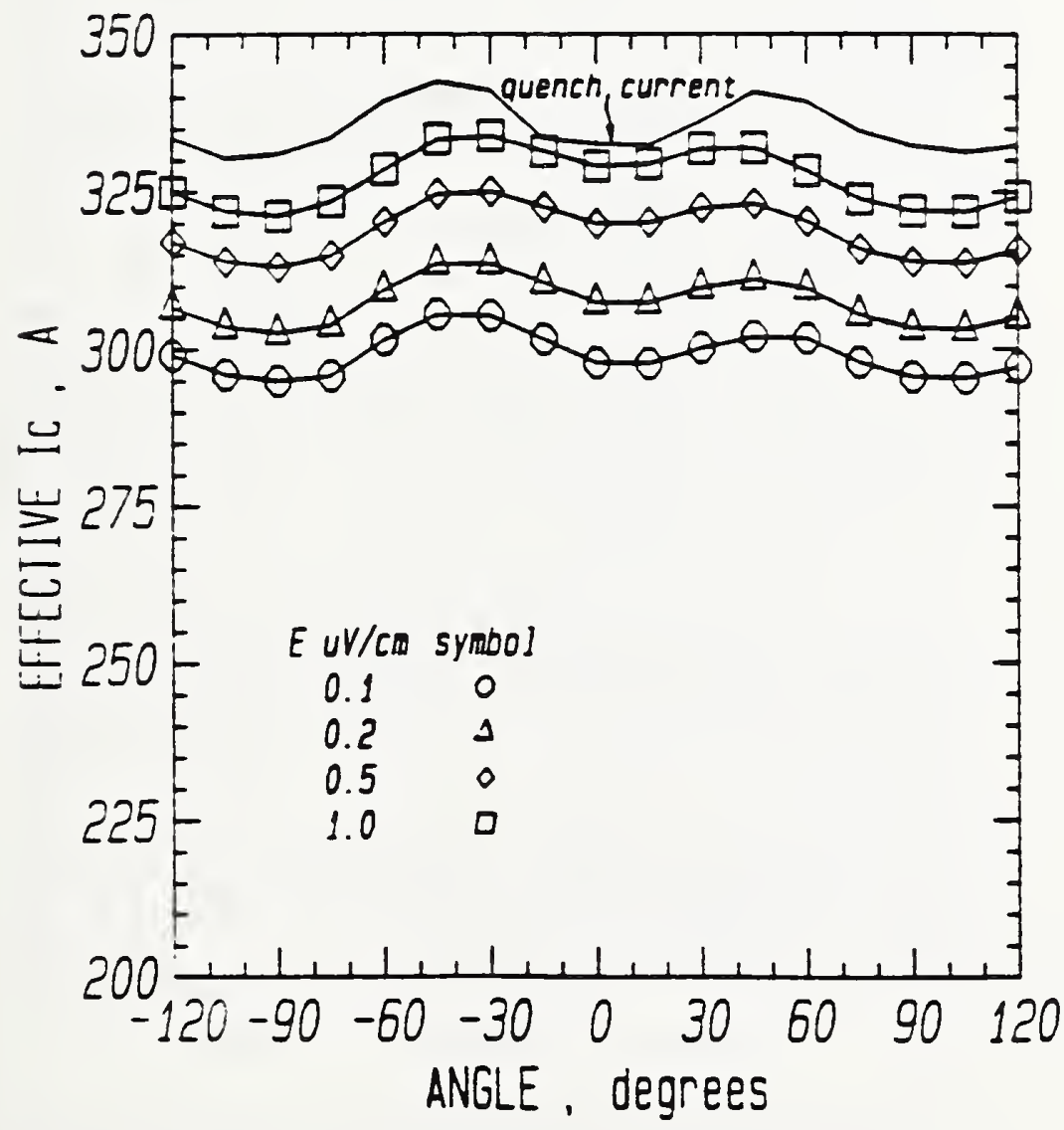

Figure 5. Sample $A$, effective $I_{C}$ and quench I vs. angle.

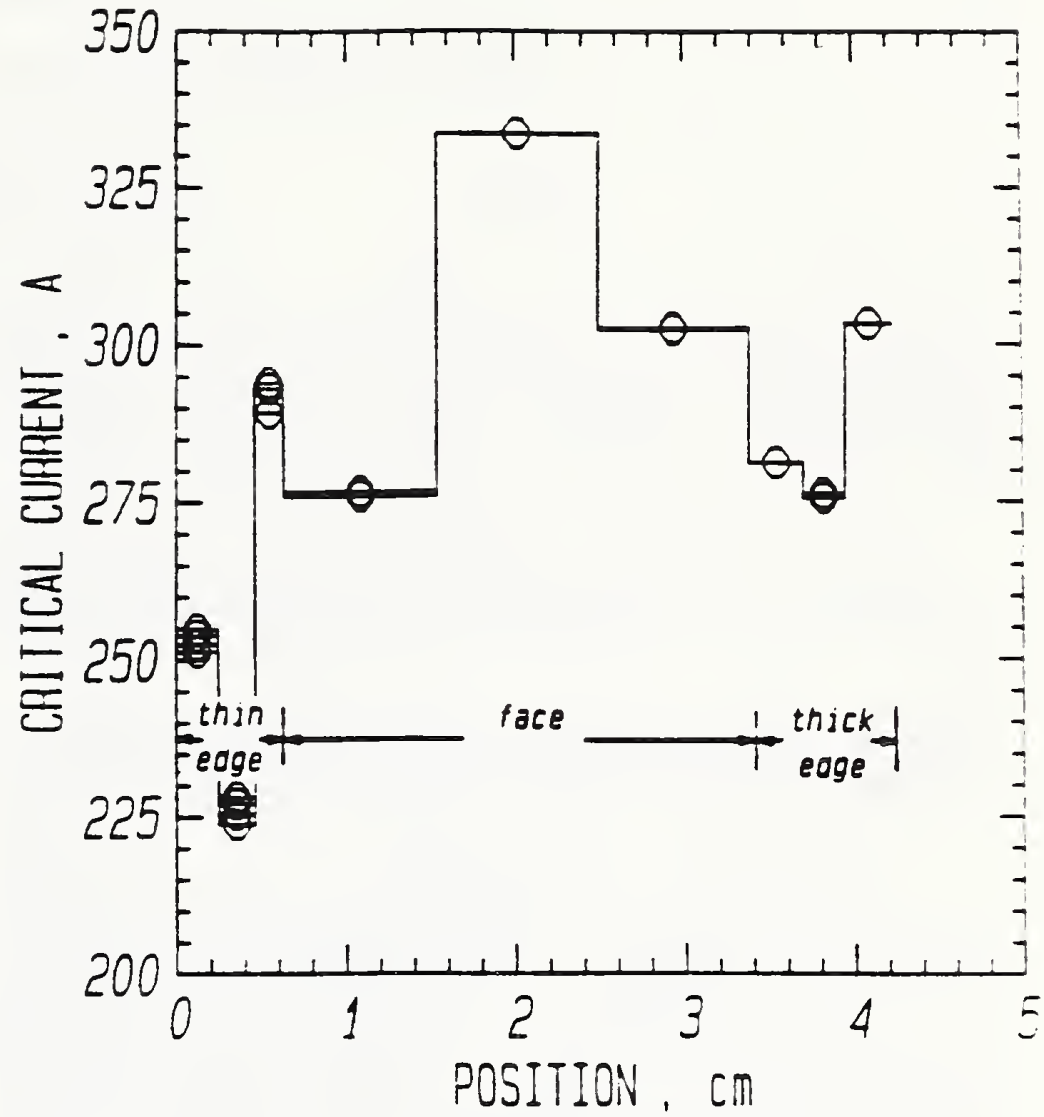

Flgure 4. Sample B, I vs. position at $90^{\circ}$.

were measured as another part of this program in another magnet. 9 The additional lowering of the weaklink I for Sample $B$ resulted in a much lower effective $I_{C}$. In fact, the difference in effective $I_{c}$ 's was greater than the difference in weak link Ic's at $0.1 \mathrm{\mu V} / \mathrm{cm}$. At $0^{\circ}, I_{c}$ of Sample $B$ was an additional

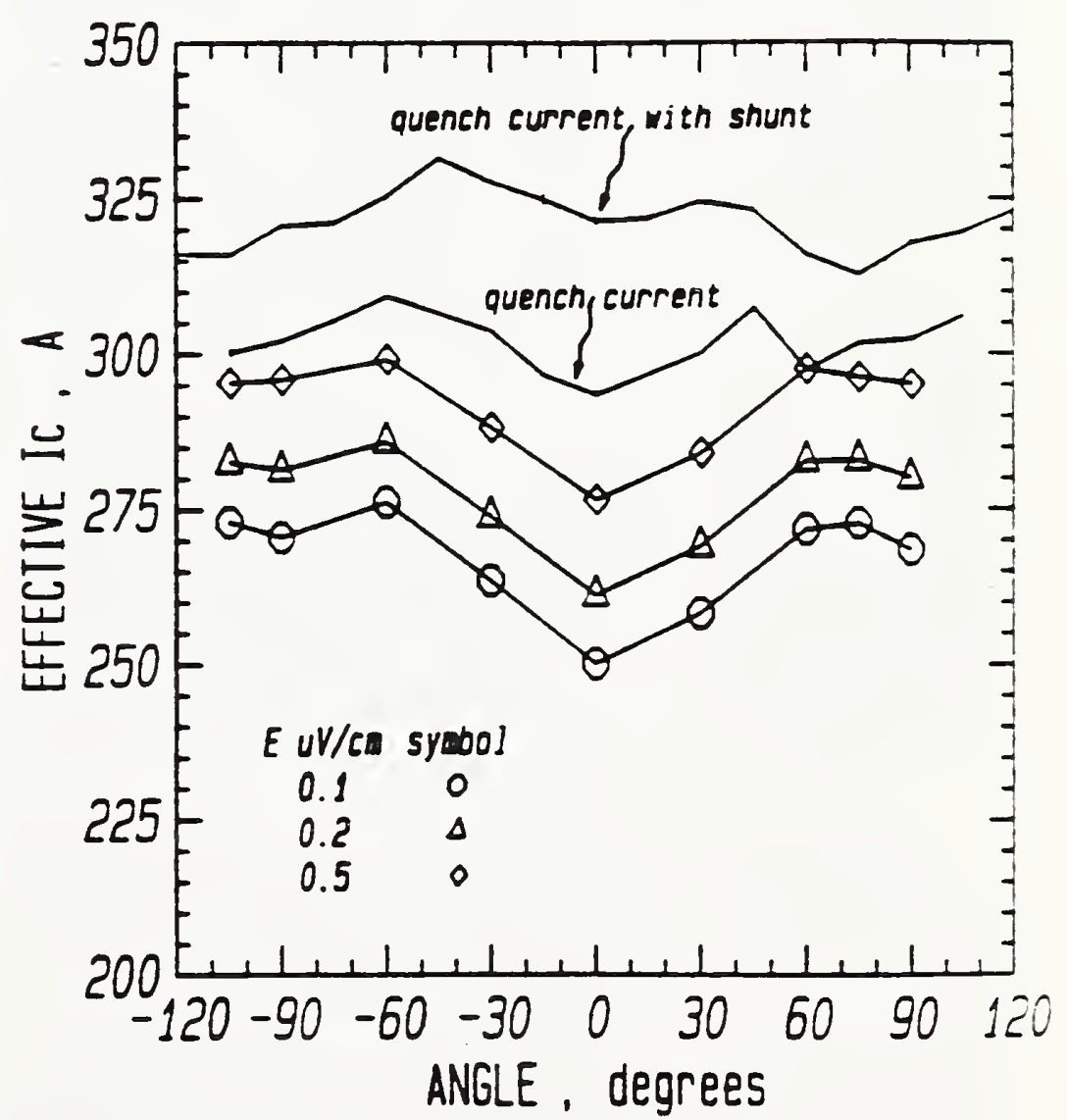

F1gure 6. Sample B, effect Ive $I_{c}$ and quench I vs. angle. 
Table 1. Fercent differences in $I_{c}$ from starting wire I 's at $5 \mathrm{~T}, 4.0 \mathrm{~K}$, and $0.1 \mathrm{HV} / \mathrm{cm}$

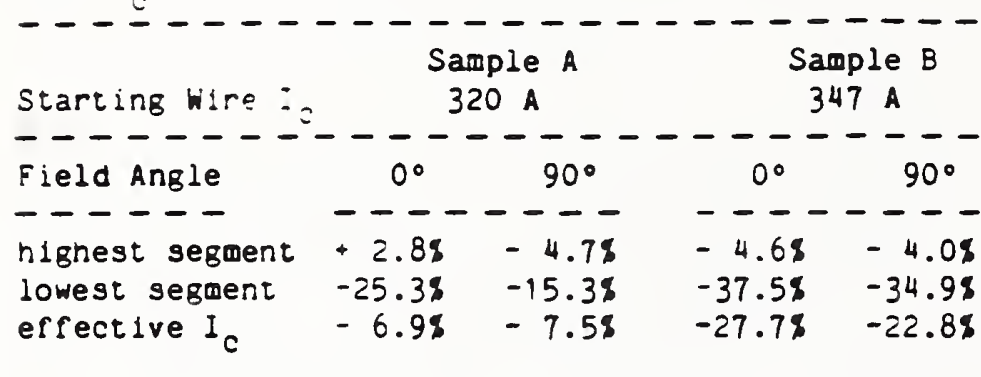

128 lower than that of Sample $A$ but the effective $I_{c}$ was 20 lower. The difference in I c's at higher

electric flelds, however, was more than 12\%. Inis increased effect y show that the local heating had an adverse effect on $I_{c}$ for Sample $B$.

\section{Discussion}

Understanding the relationship between the mechanical deformation in the cabling process and the electrical performance may lead to improvements in the critical current of a cable. Comparisons of these two samples should be tempered by the fact that the starting wires were not the same but were similar enough to support the conclusions drawn from each sample. Add1tionai current sharing that can take place in the cable will help reduce the effects of local changes in critlcal current. However, the experiment of shunting Sample $B$ by soldering another strand to it (with no transport current of 1 ts own) may indicate that the best case would only be a 78 improvement. On the other hand, any compromise in end cooling could have a significant effect.

These results have two implications for shortsample critical-current testing of cables. First, the data Indicate that both magnetic-field orientations need to be tested in order to determine the limiting case for the critical current. As snown above, for wore degraded cables, the parallel-field case may limit. In the less degraded cables, the perpendicular case limits. The amount of degradation is not known beforehano, so both orientations need to be measured.

Second, the difference between thick and thin edge degradation shown in these data indicates tnat changing the direction of the test current (for each fleld orientation) will affect the critlcal current. This is because the location of the peak magnetic Pield changes with current direction (see F1B. 3 in Ref. 6). Thus, the peak fleld location relative to the thin edge should be recorded. The conservative approach in short-sample cable tests would be to make the measurement for both directions of the test current and use the critical current for the worst case. The additional measurements w1ll help increase the understanding of cable degradation.

\section{Conclusions}

Cabling can lead to very localized reduction in critlcal current within a single strand. The lowest critlcal current was observed for the central flat part of the thin edge and this segment contributes most of the overall voltage drop. The widest spread in local critlcal current values along the cable strands occurs with the magnetic pleld perpendicular to the cable edge. Unfortunately in the dipole magnet application, this orientation is near the critical orlentation. The relevant critlcal-current criteria
Por local measurements may be based on a spatial average. This is because of the extreme localization. of damage, linited extent of the voltage, and strong end cooling effect which all limit the local temperature rise. Any compromise in sample stability may lower the critical current to that of the weak link.

\section{Acknowledgements}

The authors extend their thanks to S. L. Bray ar.a W. E. Look for sample holder construction, cata aria ysis, and plotting; J. M. Royet for samples and discussions; and $R$. A. Shenko for typlng this paper. Research at NBS was supported by the U.S. Department of Energy, Division of High Energy Pnysics under Interagency Agreement NO. DE-AI05-85ER40240 and research at LBL was supported by the U.S. Department of Energy, Office of Energy Sclences, Office of Energ: Research under Contract No. DE-ACO3-765F00098

\section{References}

1. J. W. Ekin, L. F. Goodrich, J. Moreland, E. S. Pittman, and A. F. Clark, "Electro-Mechanical Propertles of Superconductors for Hign Energy Physics Applications," NBSIR 86-3061, National Bureau of Standards, Boulder, Colorado.

2. J. Royet and R. M. Scanlan, Manufacture of Keystoned Flat Superconduct ing Cables for Use in SSC Dipoles," these proceedings, paper LB-1.

3. R. Scanlan, J. Royet, and C. E. Taylor, "Superconducting Materlals for the SSC," Adv. Cryog. Ens. Materials, Vol. 32, 697. Plenux Press, New York (1986).

4. D. C. Larbalestier, A. W. West, W. Starch, W. Warnes, P. Lee, W. K. McDonald, P. O'Larey, K. Hemacnalam, B. Zeitlin, R. Scanlan, and C. Taylor, "Hign Critical Current Densities in Industria: Scale Composites Made From Hign Homogeneity No 46.5 Ti," IEEE Irans. On Magnet1cs, MAG 21, 269. 1985.

5. W. B. Sampson, Brookhaven National Laboratory., Upton, New York, private communications (1986).

6. M. Garber and W. B. Sampson, "Critlcal Current Anlsotropy in NoTl cables," IEEE Trans. On Magnet1c9, MAG 21, 336, 1985.

7. L. F. Goodrich, W. P. Dube, E. S. Pittman, and A. F. Clark, "The Effect of Aspect Ratio on Critica: Current in Multifilamentary Superconductors," Adv. Cryog. Eng. - Materials, Vol. 32, 833, Plenum Press, New York (1986).

8. A. F. Clark, L. F. Goodrlch, F. R. Fickett, and J. $\checkmark$. Minervini, "Development of Standards for Superconductors, Interim Report Oct. 1980 to Jan. 1982," NBSIR 82-1678, National Bureau of Standards, Boulder, Colorado (July 1982), pp 1736.

9. J.H. EkIn, "CrItlcal Current vs. Stress Relationshlps in NoT1 Superconductors," these proceedings, paper MH-6. 


\author{
L. E. Goodrich and S. ¿. Bray \\ National Bureau of Standards \\ Bouider. Colorado 80303
}

\section{AbstE:=}

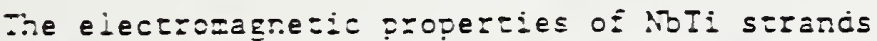
extzacted fzor kutherford cables were sudied to ciarif $\because$ the ežct of mechanical deformation, caused by ihe cajiing frocess. on the current capacity of the strands. Theee different cables were studied, a:l of winich are protorvpes for the Superconducting Super Collider's dipole magnets. The extracted cable strands were instrumented to allow measurement of the voltage across severai key regions of mechanical deformarion as a funciion of current and the orientarion of the applied magneric field. The resulting data are presenced in terms of the strand's volicage profile as weli as its crizical current in order so more thorougily characterize the conductor's

electromagnetic properties. The cable strands show yery localized reductions in current capacity that are well correlated with the regions of high mechanicai deformation. Eor examole, ar a particular fielo orientazion. tie voliage across a portion of the strand that is only i of the toral strand lengrin contributes Ij of tie torai strand voltage. Iwo applied magnerzc Eelc oriencajions. parallel and perpendicular ro the caple's widti. have pronounced effects on the ejectrical properties of the strand. Both of these magnetic Eieid orientations will arise in applications.

\section{Introduction}

The measurements presented here are a continuation of earlier studiest of NoIi cable strands extracted from Rurherford cables (cables provided by the Lawrence Berkeley Laborarory). These are prororype cables for high energy pinysics applications. Specifically, they were designed for use in the outer windings of the Superconducring Super Collider's (SSC) dipole magners The main emphasis of these studies is the effect of mechanical deformation, during manufacture, on the cabie's current capacity. In addicion to the bending deformation required to achieve the cable's twist pirch. Ite cabies are compacted into a keyscone shape. These mechanical deformations resuit in a very iocalized degradarion in the eiectrical properties of the cable strands. The deformacion of the cable strands results in a periodic geometry with the various segments of the strands defined by the degree and type of deformation. The desired product of this work is information that will lead to merhods for reducing the current-capacity degradation associated with the manufacture of superconducting cables.

For all the messurements, the orientation of the applied magneric field was perpendicular to the cable's longitudinal axis. The angle of the applied field about this axis was set at either the $0^{\circ}$ (parallel to the cable widch) or $90^{\circ}$ (perpendicular) orientation. The reasons for emphasizing these field directions are twofold. First, there is a pronounced effect on the strand's electrical properties in these oriencations and, second, both of these field orientacions arise in a dipole magner. The experimencal details of this work wil be reported in a furure publication. 2

The mechanical deformation of the cable strands during the cabling process results in localized variations in the conductor's current capacity. sources of this variation fali into two categories cross-secrional area differences and angular effecss The cross-sectionai variation of the superconauckire Eilaments is due to necking and serrared vielding o: the NoTi fijaments. Linder the secono caregory, anguia: effects, the orientation of the applied magneric with respect to the conductor's longitudinal axis (pitch angie effect) and its mechanically deformec cross section (aspect ratio effect') vary along the strand.

Three different cables, manufactured with differen: virgin wire (source wire for the cable strands) anc cabling rechniques, were studied. These data allo: comparisons among the cables. The scrand critical current (strand $I_{c}$ ) is defined as the current at winic: the sum of the volitages from each of the strand segments divided by the sum of the segment lengths is equal to a selected electric field criterion. The srrand $I_{c}$ is presenced for borh magneric field orientations. $0^{\circ}$ and $90^{\circ}$. This irformation is useful in examining the cumulative effect of variations in sparial oriencarion anc aspect zarlo of differen: strand segmencs at different field angles. The concef= of a strano Is is also useful for comparing the strand's $I_{c}$ with the $I_{c}$ of the virgin wire from winich the cable was manufactured. These comparisons indicate the amount of $I_{c}$ degradation introduced by the cabling process. In order to assess the relative contribution: to the rotal voltage of different strand segments, tice voltage distribution along the conductor's lengri, at both magnetic field angles, is aiso presented.

Three different cables, denoted as $W, X$, and $Y$, were studied. Cable $W$ was re-rolled througi a turksheac (for resizing) after it had been cabled. The re-rolied cable is a worst-case situation that was scudied to more clearly identify the degradation fearures. Cabie $X$ is similar to $W$; however, it was not subjected to as much mechanical deformation and is a more rvpical example of late 1985 to early 1986 procorype ourer cables. Cable $Y(1987)$ is an evolution of cable $X$ where the cabiing teciniques were refined in an arterpt to reduce current-capacity degradarion.

\section{Resules}

The conducrors measured in this srudy represent an evolution in the cable fabrication process aimed at reducing its detrimental effect on the critical. current density $\left(J_{C}\right)$ of the finished cable in comparison to that of the virgin wire. 4 An evolution has also occurred in the design and processing of the virgin wire. 5 Thls evolution can be characterized by a decrease in filanent size ained at reducing ac losses while artempting to maintain the $J_{c}$. Initially, the increased wire drawing that was used to reduce the Ellament size of wire $x$ in comparison with wire $W$ resulted in a lower $J_{C}$. Later, improved mamufacturing processes that were used for wire $Y$ resulted in a substantial restoration of the $J_{c}$ of the virgin wire.

\section{Serand Crifical current}

Ic measurements were made on the virgin wires from which each respective cable vas nanufactured. Three pairs of voltage raps, with each pair spanning about $10 \mathrm{~mm}$, were connected to the specimens. This allowed 
For a check of Ic homogeneicy with posicion. is measurements were aiso mace as a function of the appiied sar-.eile fieid angle. Tis allowed for a test of Ic homozeneity with respect =o field angie. The average $I_{c}$ of the virgin wire was used to determine the relative degradation of each cable. The typical is variation azong voliage taps was $=0.3 \%$ at $\equiv$ I and $=0.5 \bar{z}$ at 8 I for ail of the virgin wire samples. For samples $\because$ anc $\because$. the $i=$ ariation of a Eiven tap with respect zo field angie $\left(0^{\circ}=0360^{\circ}\right)$ was measured to be about \pm 0.6 at $5 \mathrm{I}$.

Figures $:$ and 2 show comparisons between the $J_{c}$ of the extracted cable strands (strand $j_{c}$ ) and the virgin wires from wint they were constructed. Figure 1 shows this comparison for each of the three conductors for applied magnetic field angles of $0^{\circ}$ and $90^{\circ}$ at $5 \mathrm{I}$. There is a consistent increase in the $\mathrm{J}_{c}$ at $0^{\circ}$ from caile $W$ to cable $Y$ aithough the virgin wire's $J_{C}$ decreased between wires $w$ and $X$. Since cable $W$ is $a$ worst-case sizuation with respect to the cabling operation, sne higher $j_{c}$ for strand $x$ is due to the reduced mechanical deformation of the strand. Cable $Y$ shows a greater mecranicai degradation of its $J_{c}$ than cable $X$. but. again. $\vdots$ = shows an increased serand $J_{c}$ due to its high virgin wire $J_{C}$. For cable serand $X$. the mecrianical degracation of the $J_{c}$ was somewnat higher at $90^{\circ}$ than at $0^{\circ}$ and. consequentiv, there was a cecrease in the $j_{c}$ of stranc $x$ as compared with the $j_{c}$ $0 z$ strand $i$. This increased degradation at $90^{\circ}$ was not present in strand $Y$ and $s$ trand $Y$ showed an

increased $j_{c}$ in comparison with its two predecessors.

The $8 \mathrm{I}$ plot, $5 \mathrm{ig} .2$, shows an increase in the strand's $J_{c}$ between $w$ and $Y$ but there is a decrease between $W$ and $X$. Comparison between the 5 and $8 \mathrm{I} \mathrm{J} c$ degradation for all of the strands shows a reduced sensitivity to mecranical deformation at the higher magneric field for all the strands. The virgin wire $W$ which has larger diameter filaments, had a higher relacive $J_{c}$ at 8 I than do wires $X$ and $Y$. This lower sensicivity of wire to magnetic field results in a higher serand $J_{C}$ for $w$ than for $X$.

\section{Differential Voltage Profile}

Figures 3 and 4 show the electrical properties of the cadle strand as a function of the position along its length. At the top of each plot. located outsice the axes, is an outine of the cable strand's geometry positioned so as to correlate with the horizontal or position axis. The cable outline is labeled to indicate the position of the thin edge, the face, and the thick edge reiative to the horizontal axis. The differential voltage across the various strand segments is plotted as a function of position. The plateaus, or peak levels, in the curves represent the voltage across the indicated strand segments at the indicated strand $I_{c}$. The lines connecting the data are only a visual aid and they are not incended as an interpolation between the data points. The current levels for each of the different samples is not the same in these plots (current levels for each of the strands is given in the figure captions); however, the overall voltage level is the same for each of the samples. In other words, the data in these plots represents the same strand $I_{c}$ criterion $(0.1 \mu \mathrm{V} / \mathrm{cm})$ for each of the samples.

The plots show that there is a considerable variation in the lengths of the various strand segments. Herein lies the significance of these plots, which show the relative contribution of the separate strand segments to the overall voltage.

For the samples and conditions existing in these measurements, the cotal voltage seems to determine the

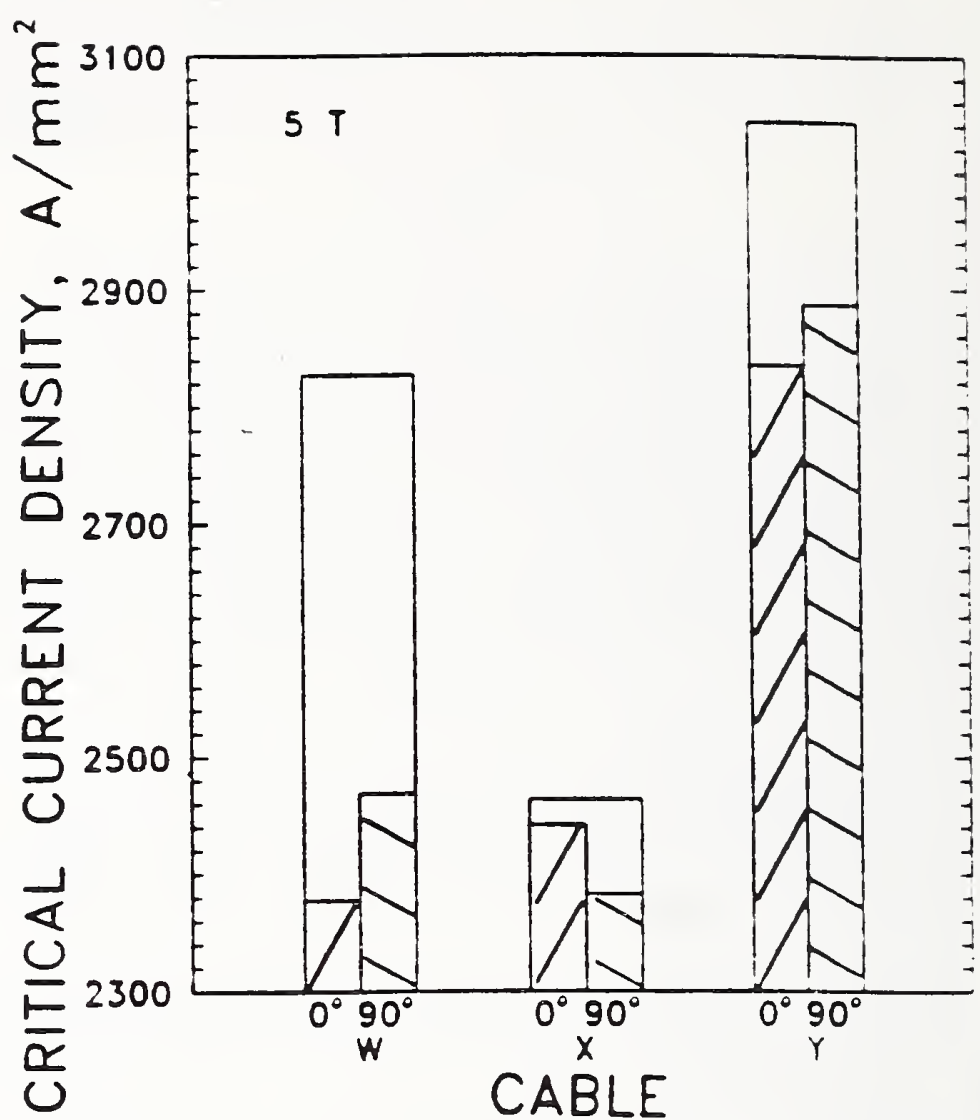

Figure 1. Critical current density of cable strancs and their respective virgin wires for 0 and $90^{\circ} a=\vdots$ The virgin wire $J_{c}$ is represented by the continuous line segmen $=$ spanning 0 co $90^{\circ}$ for each cabie. The strand $J_{c}$ values at 0 and $90^{\circ}$ are represented by the shaded bars for each cable.

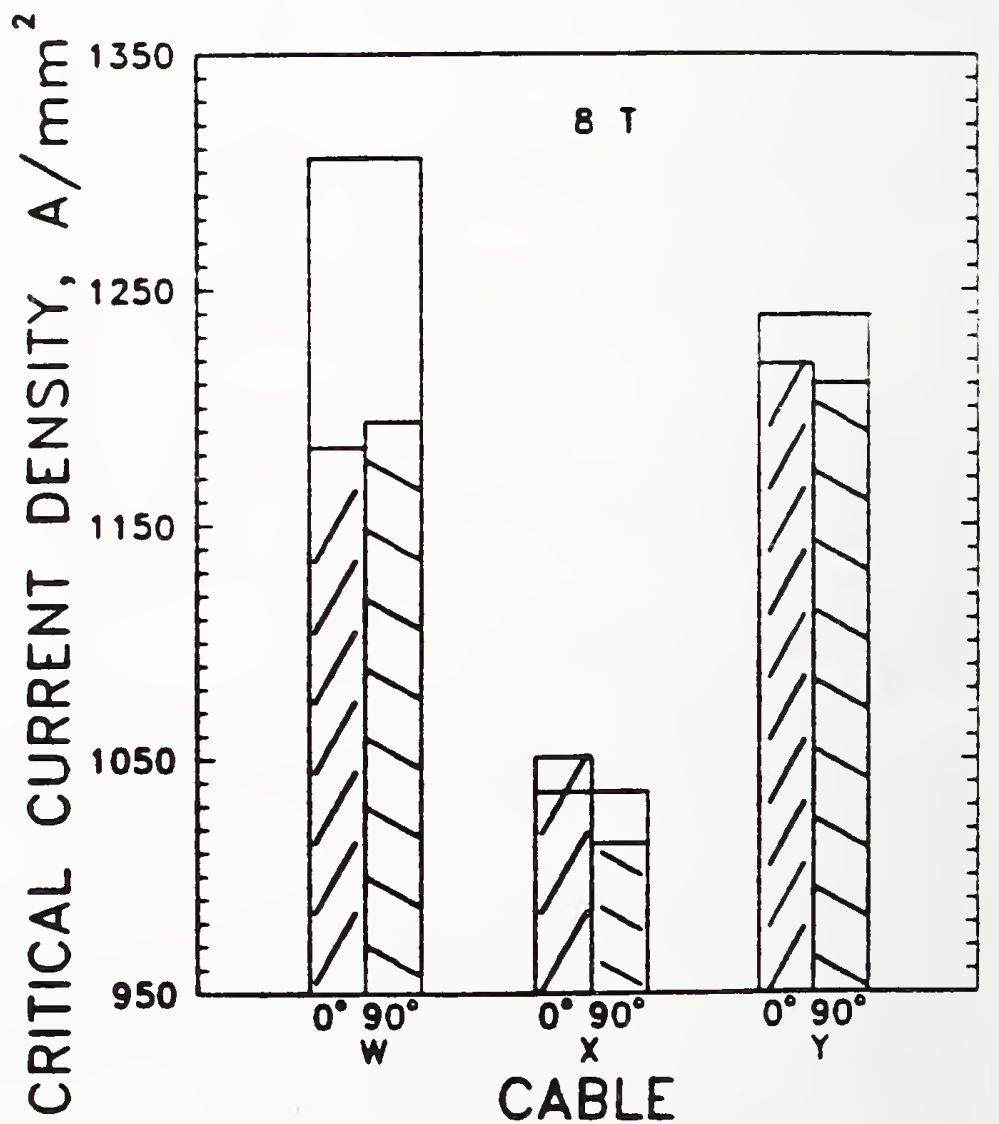

Figure 2. Critical current density of cable strands and their respective virgin wires for 0 and $90^{\circ}$ at $8 \mathrm{I}$ The virgin wire $J_{c}$ is represented by the continuous Iine segment spanning 0 to $90^{\circ}$ for each cable. The strand $J_{c}$ values at 0 and $90^{\circ}$ are represented by the shaded bars for each cable. 


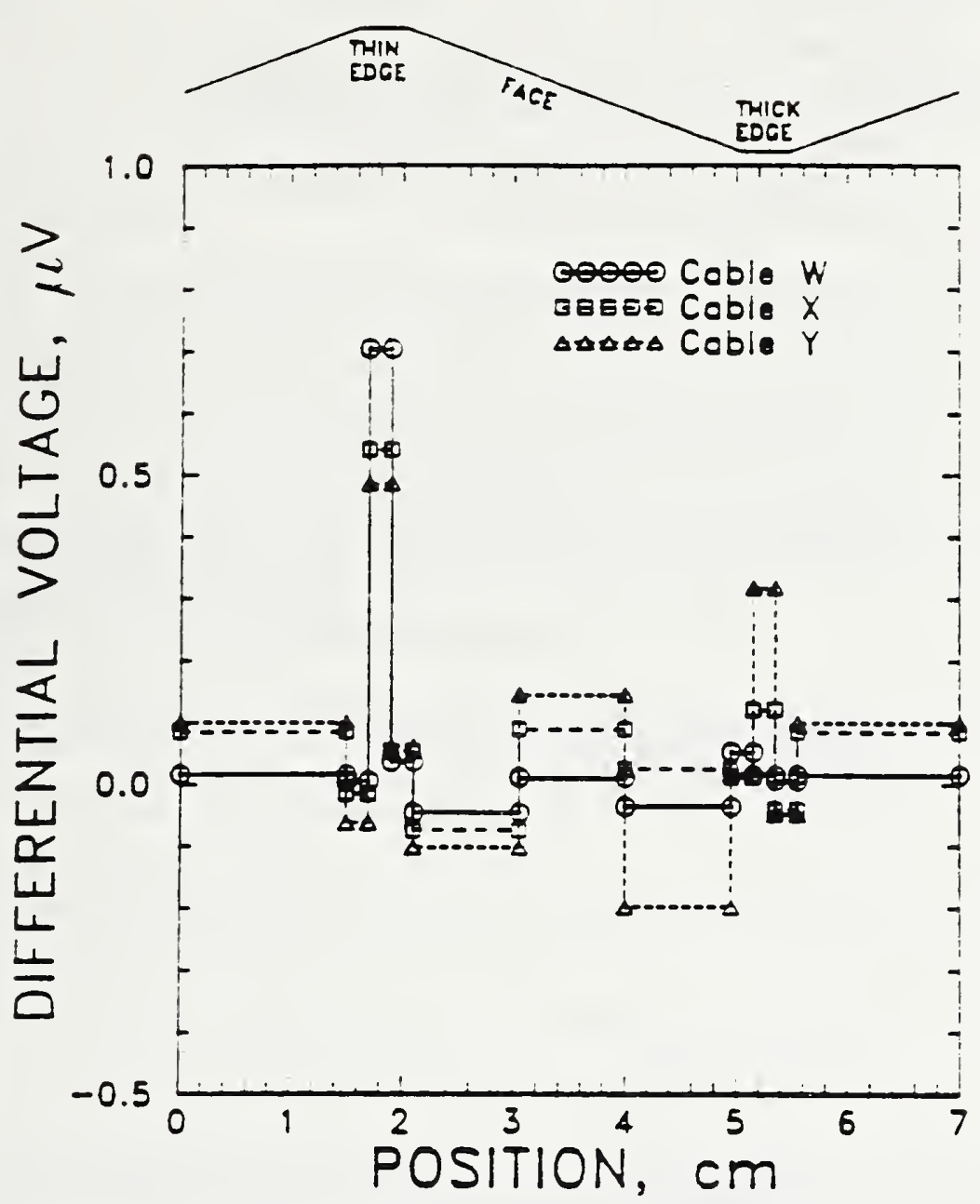

Figure 3. Differential voltage profiles at $5 \mathrm{I}$ and an appiied magneric field angie of $0^{\circ}$ for caoles $\mathrm{h}, \mathrm{X}$, anc $\because$ at currents of $285 \mathrm{~A}, 307 \mathrm{~A}$, and $339 \mathrm{~A}$ respectively.

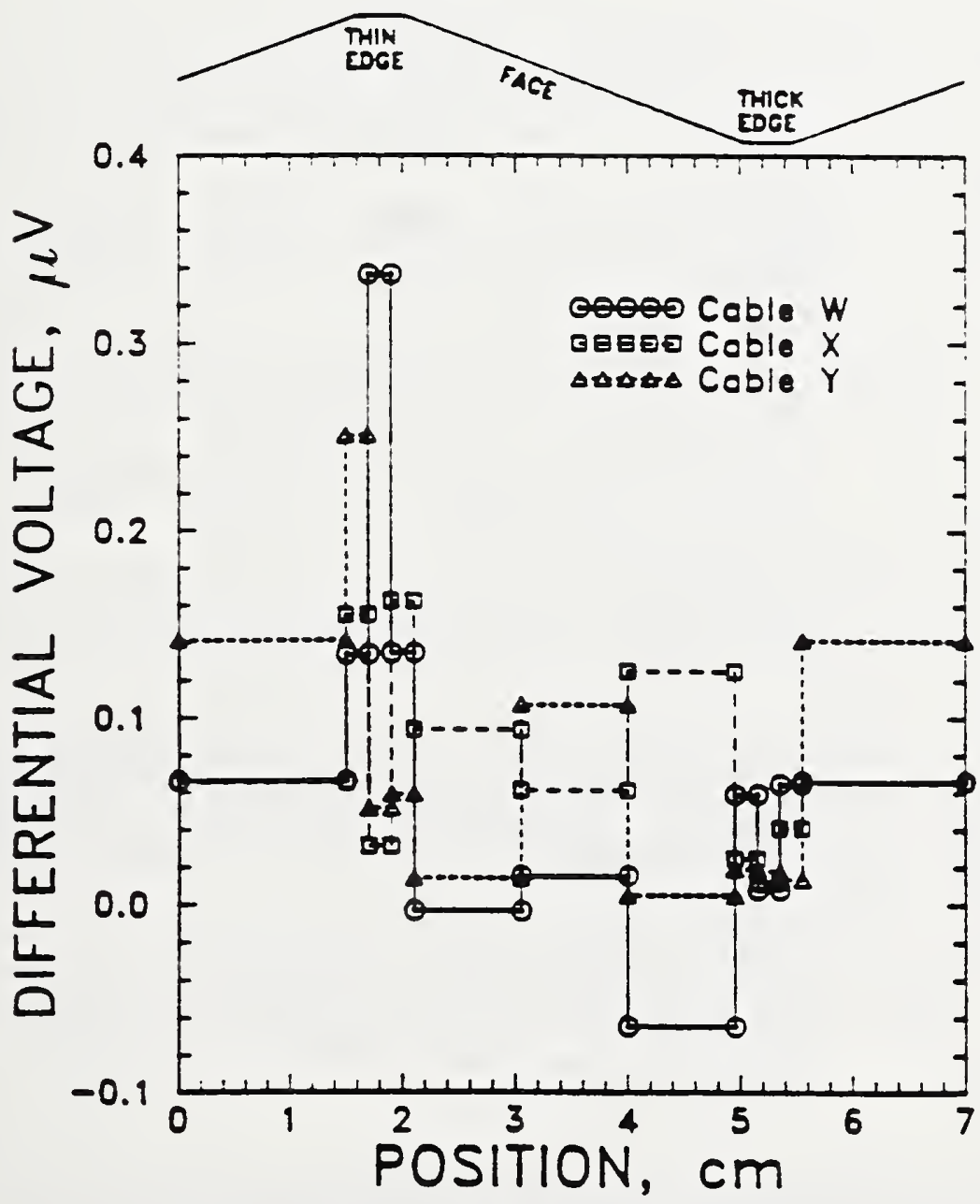

Figure 4. Differential voltage profiles at $5 \mathrm{I}$ and an applied magnetic field angle of $90^{\circ}$ for cables $W, X$, and $Y$ at currents of $296 \mathrm{~A}, 300 \mathrm{~A}$, and $345 \mathrm{~A}$ respectively. current capacily of the concuctor. This is evidenced by a ciose agreement between the measured stzanc critical currents and the taximum acrieved currencs (quench currents:. For a sampie that has poor longitudinal thermal conductivity, the short edge segments might act as weak links. Migiting tne curzen. capacicy to a value below that required to reach zie

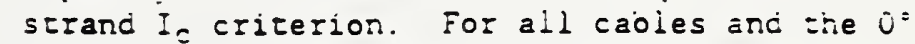
orientation. the majority of the voltage is concentrated at the edges of the caole with the centra: portions being dominant. At $90^{\circ}$. the voltage concentration increases at the corners of the edges :comparison with the centers.

The negative voltages shown in the plors are projection voltages 6,7 associated with current redistribution among the filaments. The strongest evidence of intrinsic (not associated with the locarion - of the current contact) transverse currents within the strand is a region of nega:: $\because e$ volcage bounded by regions of large positive volrages. The curve for cable $Y$ is the best example of this structure. This eype of structure is present in the center of these plots. This indicates that the current redistribution is caused by the longitudinal variation in the reiative current carrying capacity of the filaments zacher thas being caused by current injection at the current

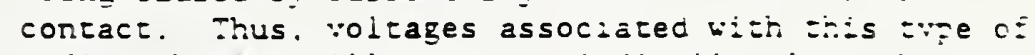
redistribution will occur periodicaily aiong tie en:iz length of the cable strand.

Although the negative voltages are the most obvious indication of current redistribution. there are othe: indicators. These indicators have the same generai character as the negative voltages with the exception of polarity. The positive current transfer voltages are evident when observing a series of differencia: voltage plots in which the sample current is increasing. There are portions of the differential voltage profile that rise abrupty. like a flux fio: volcage, and then level off with increasing current until the actual flux flow region is reached. These transicory posicive voltages, like the negative voltages, are indicative of intrinsic current redistribution within the cable strand.

\section{Discussion}

The main objective of this work is to determine the current capacity of severai different caole sirancs with the ulcimate goal being an increased understanc:-. of the sources and degree of current capacizy degradation in these conductors. Iypically, the $I_{c}$ of a conductor is an accepted practical measure of its current capacity. However, for these particular conductors, there are some difficulties in relating $I_{C}$ to the actual current capacity of the cable strands. owing to the electrical inhonogeneity of the strands caused by the cabling operation, there is a large variation in the $I_{c}$ along the strand's length. The problen is determining what current level in this fairly broad range of critical currents best reflects the sirand's practical current capaciey.

One approach is to assume a weak link situation where the strand segment that has the lowest $I_{c}$ determines the overall current capacity of the strand. A comparison between the actual quench currents (the maximum observed current prior to thermal runaway) and the weak link $I_{c}$ shows that the current capacity of the strand is significantly higher than the weak link $I_{c}$ This enhanced current capacity, above the weak link $I_{c}$, is due to the strand's relatively good stability.

At the other extreme, the current capacity of the strands could be assumed to be equal to the strand $I_{c}$. For the conductors rested here, this would not be a bad 
assumb:ion. as evidenced by the close agreement between tie strand $I_{c}$ anc the quench currents. however. Ghere are two problems associated with simply measuring zae strand $I_{c}$ and assuming this to be the strand's practical limit. First, the strand $I_{C}$ gives no information about the voltage distribution along the strand's lerger. and. consequently, it is not useful in understanairg the sources of current degradation in the caole. $\therefore$ so. For conductors that are less stable than trose tested here. the actual current limit might be ciose to the weak link $I_{c}$ and, in this case, the strand $I_{c}$ level could not be acnieved.

Another factor associated with the $I_{c}$ measurements For these caole strands is the presence of zatrinsic current-rransier voltages that are caused by periodic current redistribution along the strand's length. This current eransier is apparenty caused by the periodic mechanical deformation of the strand and, thus, it is not limited to the current contact area. Due to its intrinsic nature, these current transfer voltages play a roie in determining the current capacity of the cable. not only in testing but in application as well. It is clear that $I_{c}$ data alone are insufficient for characterizirg these conductors. For this reason the cifferential vollage dara were aliso presented.

\section{Conclusions}

Based on these measurements, some generai conclusions can be stated regarcing the eiectromagnetic character oI these cables and its effect on their current capacities. Also. the measurements have implications regarding short sample testing of these caoles.

The mechanical deformation of the cable strands associated with the cabling process can lead to very localized reductions in their current capacity. The widest spread in local current capacity occurs with the applied magnetic field parallel to the cable's width. Despice large local variations in the cable strand's current capacizy, the quench current and the strand $I_{c}$ do not vary much with the angle of the applied magnetic field. The deformation geometry of the cable is such that the interaction between the applied magnetic field and a strand segment's aspect ratio or its pitch angle have the same cendency. In other words, a field angle that is detrimental (beneficial) to a strand segment's current capacity due to its aspect ratio is also detrimental (benericial) due to its pitch angie. However. the various strand segments have different critical orientations such that the detrimental and beneficial effects of the field angle on the various segments rend to cancel one another over the rotal length of the strand. For these particular conductors. the relevant $I_{c}$ criteria may be a spatial average (the strand $I_{c}$ ) because the degradation in current capacity is concentraced over short regions of the cable strand and local remperature rises are limiced by strong end cooling. Any compromise in sample stability may lower the $I_{c}$ to that of the weak link segment of the cable serand.

These results have two implications for short-sample $I_{c}$ testing of cables. First, the data indicate that both magnetic field orientations, parallel to the cable's width and perpendicular to lts width, need to be rested to determine the limiting orientation for the $I_{c}$. The limiting magnetic-field orientation can be parallel or perpendicular to the cable's width and the limiting orientarion is not known beforehand. Second, a large difference in current capacity degradation can exist between the thick and thin cable edges; thus, changing the direction of the test current (for each field orientation) can affect the measured $I_{c}$. This is due to a self fleld effect where the location of the peaik magnetic field depends on the current direction. Thus, the peak field location should be part of the data recoraed for snort sample measurements of these conductors. Consequenty, these more detailed cable measurements should be made periodicaliy as part of the cable development process.

The wire from which these cables are made has evolved to the point where they have a high virgin current capacity and a relatively nigh tolerance to mechanical deformation. Considering the amount of mechanical deformation of the strands caused by the cabling process. the resulting degradation in current capaciey is surprisingly low. In the case of the latest outer winding cable, sampie $Y$, the maximum observed degradation in its strand $I_{c}$ was only 6.88

\section{Acknowledgements}

The authors extend their thanks to $I$. C. Stauffer for sample preparation, to A. N. Srivastava for daca plotting; and to R. M. Scanlan and J. M. Royet (Lawrence Berkeley Laboracory) for samples and discussions.

This work was supported by the Department of Energ: Division of High Energy Physics.

An effort was made to avoid the identification of commercial products by the manufacturer's name or label, but in some cases these products mignt be indirectly identified by their particular properties. In no instance does this identification imply endorsement by the National Bureau of Standards, nor does it imply that the particuiar products are necessarily the best available for that purpose.

\section{References}

(1) L. F. Goodrich, E. S. Pittman, J.W. EkIn, and R. M. Scanlan, "Studies of NbTi Strands Extracted from Coreless Rutherford Cables," IEEE Irans, on Marnerics, MAG 23, 1642, 1987.

(2) J. W. Ekin, L. F. Goodrich, and S. L. Bray, NBSIR, National Bureau of Standards, Boulder Colorado (to be published).

3) I. F. Goodrich, W. P. Dube, E. S. Piteman, anc A. F. Clark, "The Effect of Aspect Ratio on Critical Current in Multifilamentary Superconductors," Adv, Cryog, Eng.-Macerials, Vol. 32, 833, Plenum Press, New York (1986)

[4] J. Royet and R. M. Scanlan, "Manufacture of Keystoned Flat Superconducting Cables for Use in SSC dipoles," IEEE Trans on Manneries, MAG 23 , $480,1987$.

(5) D. C. Larbalestier et a 1., "High Critical Current Densities in Industrial Scale Composites Made From High Homogeneity Nb $46.5 \mathrm{TI}$. IFEE Trans, on Marnecics, MAG 21, 269, 1985.

[6] L. F. Goodrich, J. W. Ekin, F. R. Fickett. "Effect of Twist Pitch on Shore-Sample V-I Characteristics of Multifllamentary Superconductors," Adv Croog. Eng. Macerials, Vol. 28, Plenum Press, New York (1981), P. $571-580$

(7) L. F. Goodrich, "The Effect of Fleld Orientation on Current Transfer in Multifilamentary Superconductors," IEEE Trans. Mag. MAG-19, 244. 247 (1983). 


\section{BIBLIOGRAPHIC DATA SHEET}

1. PUBUCATION OR REPORT NUMBER

NISTIR 89-3912

2. PERFORMING ORGAMIZATION REPORT NUMBEF

3. PUBLCATION DATE

November 1989

4. TITLE AND SUBTITLE

ELECTROMECHANICAL PROPERTIES OF SUPERCONDUCTORS FOR HIGH ENERGY PHYSICS APPLICATIONS

PART II

5. AUTHOR(S)

J. W. Ekin, L. F. Goodrich, S. L. Bray, N. F. Bergren, and R. B. Goldfarb

6. PERFORMING ORGANIZATION (IF JOINT OR OTHER THAN NIST, SEE INSTRUCTIONS)

U.S. DEPAATMENT OF COMMERCE

NATIONAL INSTITUTE OF STANDARDS AND TECHNOLOGY

GAITHERSBURG, MD 20899

7. CONTRACT/GRANT NUMBER

8. TYPE OF REPORT AND PERIOD COVERED

9. SPONSORING ORGAMIZATION NAME AND COMPLETE ADDRESS (STREET, CITY, STATE, ZIP)

Division of High-Energy Physics

U.S. Department of Energy

Washington D.C. 20545

(DOE Interagency Agreement 非DE-Al05-85ER40240)

10. SUPPLEMENTARY NOTES

See NBSIR 86-3061 dated December 1986, title as above.

DOCUMENT DESCRIBES A COMPUTER PROGRAM; SF-185, FIPS SOFTWARE SUMMARY, IS ATTACHED.

11. ABSTRACT (A 200-WORD OR LESS FACTUAL SUMMARY OF MOST SIGNIFICANT INFORMATION. IF DOCUMENT INCLUDES A SIGNIFICANT BIBLIOGRAPHY OF UTERATURE SURVEY, MENTION IT HERE.)

This report presents data on superconductor performance under mechanical load. The data are needed for setting mechanical design constraints and measuring the electromechanical performance of NbTi superconductors for DOE high-energy physics magnet applications. The effect of axial tensile stress, applied at room temperature, on the critical current of NbTi superconciu tor strands has been measured. The data show a simple result that the effect on the critica. current is independent of the temperature at which the stress is applied; this allows the exi ting $4 \mathrm{~K}$ data base to be used to determine critical current degradation from room temperature fabrication stress, from cool-down stress introduced by differential contraction, and from 4 stress generated by the Lorentz force when the magnet is energized. A study of the critical current variations along NbTi strands extracted from a Rutherford cable has been made also. The results show that the principal mechanical degradation is extremely localized at the regions where the NbTi strand is bent around the edge of the cable. For example, only $3 \%$ of the total strand length can contribute $92 \%$ of the total strand voltage. A further study has been made of the effects of bending strain on the critical current of NbTi conductors. The degradation of the critical current from bending strain is much greater at low values of electrical field than at high, suggesting that irregularity of the filament cross-sectional area introduced by bending may be the source of the $I_{C}$ degradation. The bend tolerance of a NbTi condu tor can be enhanced by increasing the local copper-to-superconductor area ratio. Measurement of the permeability, saturation magnetization, and intrinsic coercivity of several high-perme ability steel alloys were made. The overall differences of saturation magnetization and intrinsic coercivity between cold-rolled steel samples were not significant.

12. KEY WORDS (6 TO 12 ENTRIES; ALPHABETICAL ORDER; CAPITALIZE ONLY PROPER NAMES; AND SEPARATE KEY WORDS BY SEMICOLONS)

bending strain; cable; coercivity; critical current; electromechanical; magnetic properties; mechanical properties; NbTi; permeability; Rutherford cable; saturation magnetization; SSC; stress effect; Superconducting Super Collider

\section{AVAILABIUTY}

$\mathrm{X}$

\section{UNLIMITED}

FOR OFFICIAL DISTRIBUTION. DO NOT RELEASE TO NATIONAL TECHNICAL INFORMATION SERVICE (NTIS).

ORDER FROM SUPERINTENDENT OF DOCUMENTS, U.S. GOVERNMENT PRINTING OFFICE, WASHINOTON, DC 20402.

ORDER FROM NATIONAL TECHNICAL INFORMATION SERVICE (NTIS), SPAINGFIELD, VA 22161.

14. NUMBER OF PRINTED PAGES

154

15. PRICE 

